

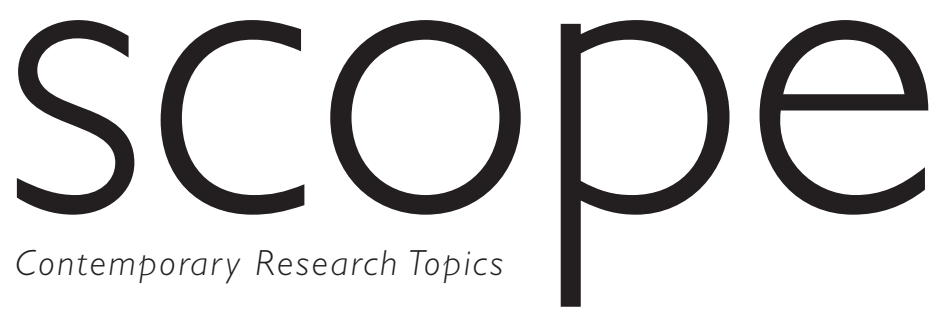

art \& design 17:

Fashion

November 2019 
Scope: Contemporary Research Topics (Art \& Design) is peer-reviewed and published annually in November by Otago Polytechnic/Te Kura Matatini ki Otago, Dunedin, New Zealand. Within this series, this issue is devoted to issues of contemporary fashion and the future of the fashion system. Simon Swale is the editor of this issue.

The series Scope (Art \& Design) aims to engage discussion on contemporary research in the visual arts and design. It is concerned with views and critical debates surrounding issues of practice, theory, history and their relationships as manifested through the visual and related arts and activities, such as sound, performance, curation, tactile and immersive environments, digital scapes and methodological considerations. With New Zealand and its Pacific neighbours as a backdrop, but not its only stage, Scope (Art \& Design) seeks to address the matters which concern contemporary artists and arts enquirers in their environments of practice.

EBSCO Database: Scope: Contemporary Research Topics (Art \& Design) is catalogued on the EBSCO Database in recognition of academic quality and alignment with international peer review processes.

An online version of the journal is available free at www.thescopes.org; ISSN (for hardcopy version): I 177-5653; ISSN (for online version): | |77-566।.

(C) 2019 the authors; ( ) illustrations, the artists or other copyright owners.

Submissions for Scope (Art \& Design) are invited from artists, designers, curators, writers, theorists and historians. Submissions should be sent in hardcopy and electronic format by 30 April for review and potential inclusion in the annual issue to Leoni Schmidt (Chief Editor) at Otago Polytechnic/Te Kura Matatini Ki Otago, Private Bag 1910, Dunedin, New Zealand and leoni@op.ac.nz with a copy to scope.editorial@op.ac.nz. Please consult the information for contributors below and hardcopy or online versions for examples. Peer review forms will be sent to all submitters in due course, with details concerning the possible reworking of documents where relevant. All submitters will be allowed up to two subsequent resubmissions of documents for peer approval. All final decisions concerning publication of submissions will reside with the Editors. Opinions published are those of the authors and not necessarily subscribed to by the Editors or Otago Polytechnic.

Formats include: editorials; articles; perspectives; essays; artist and designer pages; logs and travel reports; reports on and reviews of exhibitions, projects, residencies and publications; and moving, interactive works (to be negotiated with the editors for the online version, with stills to appear in the hardcopy version). Other suggested formats will also be considered; and special topics comprising submissions by various contributors may be tendered to the editors. All material will be published both in hardcopy and online. Submissions should engage with contemporary arts practices in ways which may contribute to critical debate and new understandings. High standards of writing, proofreading and adherence to consistency through the Chicago referencing style are expected. For more information, please refer to the Chicago Manual of Style; and consult prior issues for examples. A short biography of no more than 50 words; as well as title; details concerning institutional position and affiliation (where relevant); and contact information (postal, email and telephone number) should be provided on a cover sheet, with all such information withheld from the body of the submission. Low resolution images with full captions should be inserted into texts to indicate where they would be preferred; while high resolution images should be sent separately. Enquiries about future submission can be directed to scope.editorial@op.ac.nz. 
Copy Editing: Paul Sorrell.

Design \&Typesetting: Joanna Wernham.

Printing: Dunedin Print Ltd.

Cover: Photographer, Angela Lyon; Designer,Tsega Gebremedihm; Model, Charlotte Goodyear.

Editorial Team for this Special Issue - Fashion: Simon Swale (Issue Editor), and Pam McKinlay (Editorial Liaison); School of Design, Otago Polytechnic / Te Kura Matatini ki Otago, Dunedin, Aotearoa/ New Zealand

For peer review and editorial advice and comment, the editors rely on a range of appropriate reviewers, but in the first instance on members of the Editorial Board:

\section{Editorial Board for this Special Issue - Fashion:}

- Sue Prescott, College of Creative Arts, Massey University, Wellington, New Zealand

- Vanbana Bhandari, National Institute of Fashion Technology, New Delhi, India

- Anne Normoyle, TAFE NSW, Sydney, Australia

- Robert Ott, Faculty of Communication and Design, Ryerson University, Toronto, Canada

\section{Editorial Board (series)}

- Associate Professor David Bell, Dunedin College of Education, University of Otago, New Zealand

- Dr Kevin Fisher, Film \& Media Studies and Visual Culture, University of Otago, New Zealand

- Mahomed lqbal Dawood Jhazbhay, Arabic and Islamic Studies, University of South Africa, Pretoria, South Africa

- Dr Jane Venis, Otago Polytechnic / Te Kura Matatini ki Otago, Dunedin, Aotearoa/New Zealand

- Dr George Petelin, Queensland College of Art, Griffith University, Brisbane, Australia

- Dr Khyla Russell, Emeritus Professor (Retired)

- Prof Elizabeth Rankin, Art History Department, University of Auckland, New Zealand

- Henry Symonds, Whitecliffe College of Art \& Design, Auckland, New Zealand

- Peter Stupples, Dunedin School of Art, Otago Polytechnic / Te Kura Matatini ki Otago, Dunedin, Aotearoa/ New Zealand

- Grant Thompson, Manukau School of Visual Arts, Manukau Institute of Technology, New Zealand

- Associate Professor Linda Tyler, Centre for New Zealand Art Research and Discovery, National Institute of Creative Arts and Industries, University of Auckland, New Zealand

- Associate Professor Soumitri Varadarajan, RMIT University, Melbourne, Australia

- Dr Maragaret Roberts, The National Art School, Sydney, Australia 


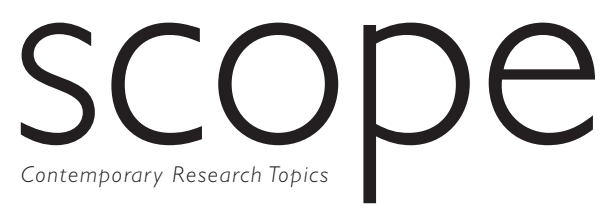

\section{CONTENTS}

6

8

17

Tyla Stevenson

23

Jane Malthus and

Moira White

32 Stella Lange

4I Rekha Shailaj

56 Pam McKinlay

66 Angela Lyon

88

Kirsten Koch

$\mathbf{0 0}$ Katie Mangai
Scope Special Issue - Fashion

From Formality to Fluidity: Fraser Crowe, "Art as Fashion,

Fashion as Art,"Twenty Years on

The Kardashian complex: Performing Sexuality and Femininity through Image and Screens

The Business of Staying Dry: Designing Waterproof Textiles and Garments in Nineteenth-century New Zealand

Craft as a Fashion Activist Practice

Different Shades of Life: A Pedogogy of Lived Experiences

Scorchers and Shoppers: Women, Early Automobilists' Clothing and Fashions for "Milady of the Electric"

International Emerging Fashion: A Photography Project by

Communication Design Students

Report on a Clothing Upcycling Seminar, Dunedin:

Researching Clothing Upcycling in Otago

Ethical Fashion: Scaling for Social Impact - A Presentation by Samantha Jones of Little Yellow Bird, Thursday 9 May 2019 
art \& design 17

November 2019

103

Simon Swale , in discussion with Bernadette Casey, Donna Dinsdale, Emily Miller-Sharma, Murray Bevan and Sue Prescott.

I I I Katie Day

II7 Ruby van der Zanden

I26 Maia Holder-Monk

136

I Can Breathe Here: An Exploration of Auto-ethnography, Intuition and Embodiment in Design Process

Soft Universe

Downhill/Ascent: An Exploration of Conceptual Fashion in Ski Apparel

Ordinary 


\section{SCOPE SPECIAL ISSUE - FASHION}

\section{Simon Swale}

Kia ora koutou and welcome to this, the second special fashion issue of Scope Art and Design. This follows the initial issue published in 2017, and like it, builds upon a successful fashion symposium organised by fashion staff at Otago Polytechnic's School of Design to coincide with Dunedin's iD Fashion Week.

As with the symposium, the theme of this special issue is 'Fashion Fluid', and like the 2017 theme 'Metamorphosis' is dedicated to tracking, reflecting and critiquing the ever-changing local and international fashion system. Once again this issue places sustainability as a central concern. This reflects not just the industry's continued and increasing need for systematic changes, but also the place sustainability holds within Otago Polytechnic's strategic framework. This issue considers a range of fashion and design contexts, featuring for instance technological developments both historical and contemporary, and traditional practices of making alongside the avant garde.

Historically focused articles encompass both the local and the global. Jane Malthus and Moira White focus on the emergent technologies of waterproofing fabric in the nineteenth century, a necessary functional, if not fashionable innovation that addressed the often inclement conditions faced by New Zealand's settler poulation. Such functionality would be further required with the proliferation of motor vehicles worldwide from the turn of the century, and Pam McKinlay's article considers a specifically gendered development of clothing in response to this phenomenon. McKinlay reminds us that the electric car is no recent innovation and that women were at the forefront of engaging with this technology in the early twentieth century, and demonstrates that functional dress could indeed be married with fashionable taste.

Bringing the traditional very much into the contemporary realm, Stella Lange articulates the potential of craft to operate as an alternative fashion practice resistant to the traditions and proliferations of mainstream fashion. For Lange, craft provides activist opportunities and for alternative systems of making and consumption, ones with their own highly engaged communities of practice.

One such community is discussed by Kirsten Koch in her account of the clothing upcycling seminar which she organised early in 2019 . Koch discusses a range of local practitioners who work with upcycled resources and who have established a supportive and significant community here in Dunedin.

The potential for strategic innovations to be both sustainable and profitable is demonstrated in Katie Mangai's report on a presentation by Little Yellow Bird founder Samantha Jones. Jones has built a hugely successful business that draws significantly on her logistical background to create a unique business model, and her presentation "Scaling for Social Impact' demonstrated that off shore manufacturing could be both ethical and socially engaged, with Jones working closely with her off shore supply chain to ensure Fairtrade standards.

Exploring notions of place, ethnicity and identity are cornerstones to the work of Rekha Rana Shailaj. with a life lived across the globe, Rana Shailaj draws upon her own experiences and articulates these richly, in both her writing and her design work. responding to an increasingly globalised social order, Rana Shailaj unites cultural perspectives to form new hybridities, which simultaneously address her desire for socially responsible design. 
The iD Fashion Week Emerging Designer Award competition is unique in Australasia for the global scope of its participants, and this year the contenders were all able to experience Dunedin city's unique sites through a location based photoshoot initiated by Prof Margo Barton of Otago Polytechnic. This project was facilitated and documented here by Design Lecturer Angela Lyon, who worked with a group of Communication Design students to capture the vibrancy and innovations of the international designers. This project demonstrates also the power project based, real world learning for design students.

A range of other highly innovative fashion design work is also featured within. Katie Day, Ruby van der Zanden, Maia Holder-Monk and Grainne O'Connell collectively demonstrate the great diversity of approaches and outcomes of contemporary fashion design. All four articulate their practice through their unique writing voice and all demonstrate the depth of intelligent and critical thinking that informs their own innovative design work.

Natalie Smith's focus on the art-fashion nexus provides context for understand and discuss the more avant garde creations of contemporary fashion. Smith's article provides a timely consideration on the work of New Zealand designers Deborah Crowe and Kim Fraser, specifically their award winning outfit from 1997 Dual Outlook. With Dual Outlook, Crowe and Fraser created fashion both conceptual and prophetic in a manner analogous to art. Utilising unique and typically un-fashion materials, Crowe and Fraser displayed a prescient concern for the "onslaught of digital communication" which today seems so endemic.

This onslaught has generated unlikely results that would have been hard to predict twenty-five years ago and the impact of social media upon the fashion system and beyond has been immeasurable and contentious. Representations of women on social media provides the focus of Tyla Stevenson's article, who argues for the agency displayed by woman such as Kim Kardashian. Kardashian, Stevenson argues, is a woman in control of both her body and its representation through social media, and that whatever we may make of Kardashian's use of this power, it is the shift of power from the media platform to the subject that must remain the focus.

This issue concludes with an account of a panel discussion between leading fashion professionals that occurred as part of iD Fashion Week. Comprising designer Emily Miller-Sharma, sustainability entrepreneur Bernadette Casey, PR specialist Murray Bevan and educators Sue Prescott and Donna Dinsdale, discussion focused on the extent of change faced by the fashion industry in the last decade- and thought on the continued changes likely in the future...

Our thanks go to all involved in making this special issue of Scope possible. Firstly to all the authors whose work here contributes to new knowledge and understandings for what fashion is, can, and will be become in the future.

Thanks also to all the reviewers, including those members of the editorial board, who so generously give their time and expertise to ensure Scope offers the highest quality of academic credibility.

To Paul Sorrel and Joanna Wernham, whose work as copy editor and designer respectively adds greatly to your reading pleasure and helps make this journal such a visually rewarding experience. Thank you both- it was a pleasure to work with you once again.

This publication would not be possible without the funding from the Otago Polytechnic Research Office so thanks go also to their staff and for Otago Polytechnic's dedication to promoting research excellence.

Final thanks go to Pam McKinlay and Jenny Aimers for their support and organisation and for keeping us all on track! 


\section{FROM FORMALITY TO FLUIDITY: FRASER CROWE, “ART AS FASHION, FASHION AS ART," TWENTYYEARS ON}

Natalie Smith

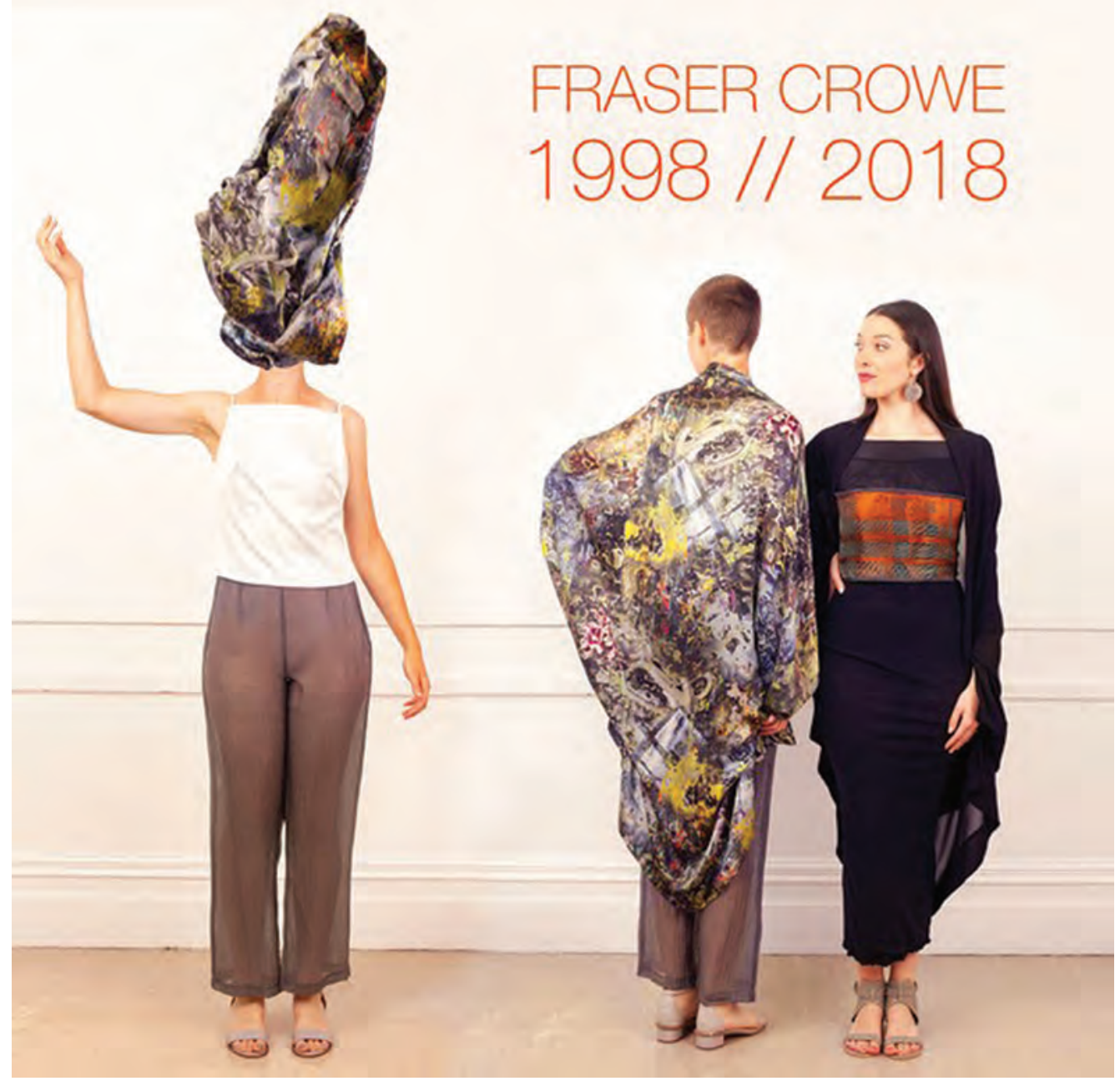

Figure I. Image courtesy of Fraser Crowe. Photography: Caryline Boreham. Models: Daphne Simons and Awhimai Fraser. Post production: Deborah Crowe. 
In 1998 an article on the fashion label Fraser Crowe appeared in Art New Zealand. The title of the article, "Art as Fashion, Fashion as Art: Deborah Crowe and Kim Fraser," spoke to the interchangeability, or fluidity, of the borders and boundaries between the two worlds.

The author, Mark Kirby, noted that Crowe and Fraser's collaborative designs were considered unusual because they were conceptually based and did not fit "any of the customary fixed fashion categories." The designs reflected the duo's backgrounds: Fraser has a background in fashion design, while Crowe has a background in fibre and sculpture. In 1997 Fraser Crowe won the Supreme Award at the Benson \& Hedges Smokefree Fashion Design Awards (BHSFDA) for Dual Outlook, a garment made from a copper sheath with a woven visor. The design prophetically conceptualised the future - a future where we would need to cocoon ourselves from the onslaught of digital communication. Using Fraser Crowe as a case study, this paper explores how, 20 years on, the relationship between art and fashion is now more fluid than ever.

Twenty years ago, at the height of the international debate on the relationship between art and fashion, Mark Kirby published an article in Art New Zealand on Fraser Crowe, the Auckland-based fashion label of artist Deborah Crowe and fashion designer Kim Fraser. "Art as Fashion, Fashion as Art" was written shortly after Fraser Crowe had won the Avant-Garde Section and Supreme Award at the 1997 Smokefree Fashion Design Awards. The winning entry, Dual Outlook (Fig. I), signalled a new creative direction for New Zealand fashion. A sculptural garment made from copper sheeting and with a woven visor, it conceptualised what life might be like in 2005.'

This paper revisits Kirby's article and the creative practice of Crowe and Fraser, who relaunched their label in 2018 after an eight-year hiatus. In the 1990s, breaking boundaries, border crossing and reducing fashion to art or craft categories was a significant part of the art-fashion debate. Two decades on, the boundaries are more fluid, the border easier to cross, and categorisation is less rigid. Today there is greater recognition within the fashion and art worlds of the potential for fashion design to be an expressive visual medium in its own right.

Kirby's article must be read within the broader context of debates on the interrelationship between art and fashion, which reached a crescendo in the late 1990s and early 2000s. Central to these discussions was the idea that fashion could be seen as closer to art when it formally looked like art. In their book Fashion and Art, Adam Gezcy and Vicki Karaminas describe the classic art-fashion nexus object as "sculptural": "Couture, which began in [the] 1850s with Charles Frederick Worth is a key place to start speculating on the art-fashion nexus. It is when garments start to assume the status of substantive, sculptural objects, which just happen to have the human support to activate them."'

Fashion writer Susannah Frankel used this formula to describe Japanese designer Rei Kawakubo's "Dress Becomes Body Becomes Dress" (spring-summer 1997) collection as being "just like art." Describing a white-padded dress with rear protrusions, Frankel states:

Viewed from the front, the model's slender, ankle-length dress - in pure white stretch organdy with fragile cape shoulders - looked like nothing so very out of the ordinary. From behind, however, two small kidneyshaped protuberances, positioned at the shoulder-blades, like angel's wings, suggested more radical things to come. Sure enough, as the show progressed, one model after another came out with increasingly stranger and larger swellings, all under long skinny, semi-sheer dresses - either red, white or blue, or in winsome ginghams and gentle, fondant-coloured prints.

There were lopsided bustles, misshapen padded hips and collar bones, fat snakes coiling round waists and rib cages, and even - there is no other word for them - humps. ${ }^{3}$

The 'weirdness' of the collection prompted Frankel to write: "those that did understand, however, were in raptures this was art, living sculpture, Kawakubo's most powerful collection for years." In emphasising the formal properties of Kawakubo's design, Frankel overlooks deeper narratives on the relationship between the body and the fashion garment, and the representation of the body in the fashion image. 


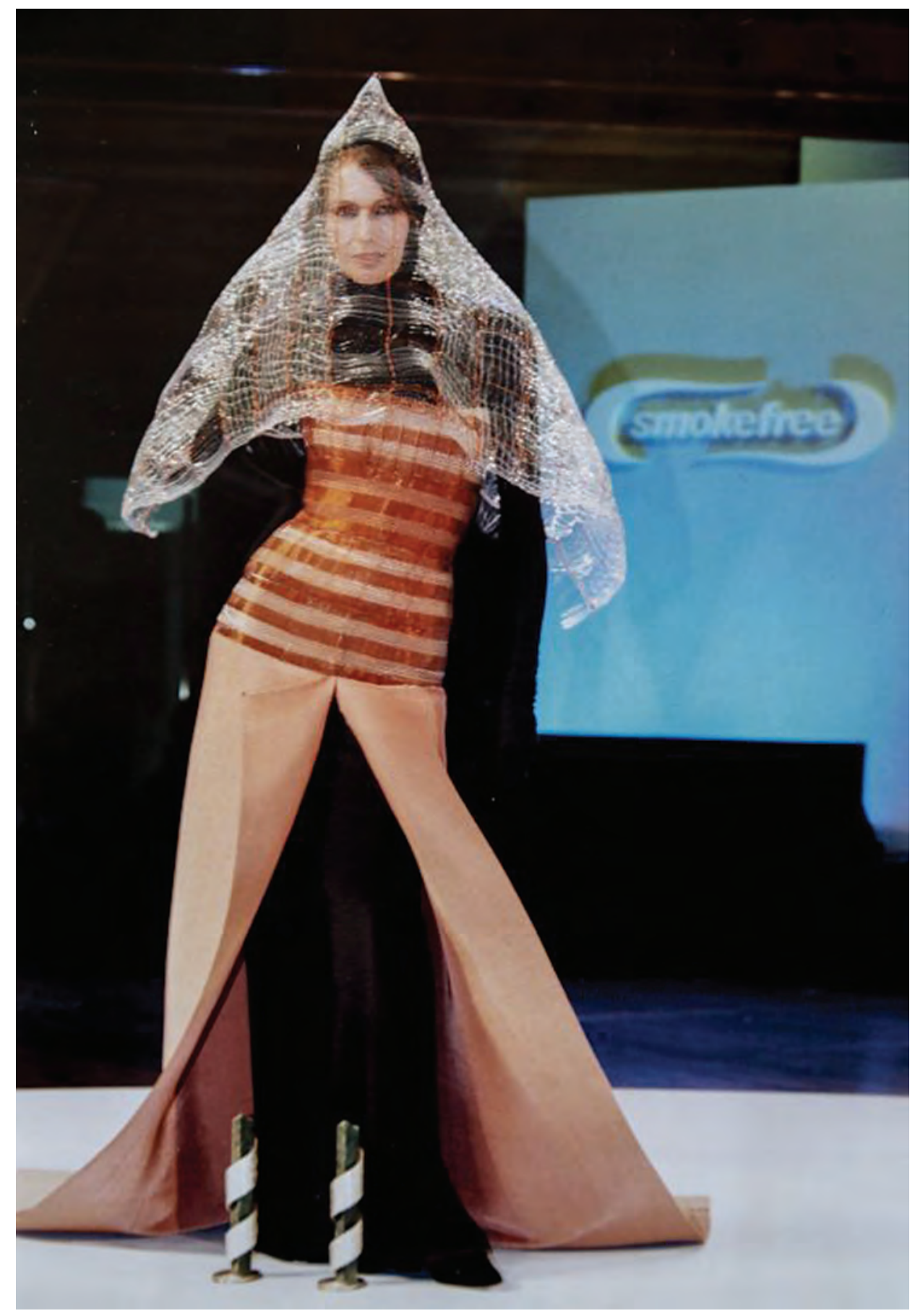

Figure 2. Image courtesy of Smokefree Fashion Awards. Photography: Lance Lawson. Model:Amanda Dorcil. 
The debates of the late 1990s and early 2000s also pointed to the rise of fashion exhibitions, and the use of the runway show for performance, as indicators of a growing closeness between the fields. ${ }^{5}$ Nathalie Khan coined the phrase "radical catwalk" to refer to runway shows that presented narratives and concepts, thus subverting the traditional trade show function of the catwalk as a viewing platform for buyers. ${ }^{6}$ Ginger Gregg Duggan extended Khan's analysis to develop a typology categorising the runway show into five areas of performance: the "spectacle;" the "substance" show; the "scientific"-orientated performance; the show in which "structure" is foregrounded; and the "statement" event.?

Fiona Anderson's seminal essay "Museums as Fashion Media" (2000) explored the art-fashion debate through the rise of fashion exhibitions in museums and galleries. These exhibitions had attracted criticism for privileging entertainment over education. Anderson argued that the rise of fashion exhibitions could be traced to changes in museum funding in the 1980s and 1990s which required cultural institutions to develop new marketing strategies and public programmes to bring in a more diverse audience. She surmised that fashion exhibitions can fulfil the dual role of bringing in new audiences and being educative, especially when fashion is framed and contextualised within audiences' own experiences of it. ${ }^{8}$

Formally and conceptually, Dual Outlook fulfilled the criteria for exploring the art-fashion nexus, enabling the debate to reach the pages of Art New Zealand. Introducing Fraser Crowe, Kirby stated:

Their success is unusual because their designs are conceptually based and, as such, do not fit within any of the customary fixed fashion categories. They are clearly unsuited to the usual forms of commercial mainstreaming of fashion design, and are almost too utilitarian to be considered Wearable Art. This positioning between the useful and the expressive represents a philosophical attitude that argues for dress as an expressive visual media in its ownright, in addition to its usual function as a social and personal signifier.

The garment was designed to a brief to "imagine what life would be like in the year 2005."'10 Fraser Crowe prophetically imagined a world in which we would be struggling to juggle new technologies. At the time, both designers were working at MIT (Manukau Institute of Technology) and felt pressured to check the answerphone and intranet before getting to lectures:

We anticipated that by the year 2005, the complexity of advancements and demands on our time would be phenomenal. Our 'take' was from the viewpoint, or outlook, whereby technology was playing a dual role; that of implying simplicity and apparently creating ease; yet simultaneously creating complexity. This inspired our notion to create a holistic garment form that provided a sculptural 'safe space' away from the demanding needs of technology."

Dual Outlook is simultaneously a cocoon to shield the wearer from external threats and a space or perspective from which to observe rapid changes in technology and their impact on our lives. ${ }^{12}$ The garment can also be viewed as an early example of upcycling - a process that gives value to old or used products - as opposed to recycling, which often reduces the value of a product. ${ }^{13}$ The skirt of the garment is made from a polyester fabric coated with copper, used as electrical shielding tape in the computer industry, while the visor draws on Crowe's skills as an art weaver and is handmade from unusual items including fine elastic and copper wire. Fraser, of Ngati Hako descent, and Crowe, of Scottish descent, describe Dual Outlook as reflecting their Celtic/Māori heritages. ${ }^{14}$

Then, as now, Fraser Crowe dismissed categorisation. In 1998 they stated:

... we feel that our work is as valuable as any other art form. We are very cautious as to how we argue for it in terms of the clichéd art-versus-craft debate - we see ourselves more as visual artists, than fine, applied or craft artists. In a sense we don't give a hoot how we are categorised, we have no control over this anyway, and tend to consider such pigeonholing as hopelessly redundant. ${ }^{15}$ 
For Fraser Crowe, it is the ideas embedded in their work, and the potential of fashion to comment on the contemporary moment, that is important. Dual Outlook not only conceptualised the future, but it addressed broader themes of identity and the relationship between the wearer, the garment and the space they occupy. This potential to use fashion to comment on the contemporary moment versus yet the devaluing of the conceptual vision of fashion design, due to its location within popular culture, is a tension British designer Vivienne Westwood has struggled with. In her book Vivienne Westwood: An Unfashionable Life (1999), Jane Mulvagh notes Westwood's frustration with the lack of recognition of the ideas invested in her work, and how these ideas have effected social and cultural change. Westwood believed that she failed to receive early recognition for her work because fashion is perceived as popular culture. ${ }^{16}$ Yet for Westwood, fashion is her chosen artistic medium: "I use fashion as an excuse to talk about things in broader cultural terms, because that's where my interests lie."'17

Beyond formalities, Dual Outlook represented the potential for fluid collaboration between the worlds of art and fashion. Crowe studied in the Embroidered and Woven Textiles Department at the Glasgow School of Art and creates woven textile objects. Fraser is a self-taught fashion designer who started creating leather clothing in Queenstown in the 1980s. In the mid-1980s she returned to Auckland and launched her label KimSkins. The pair met when they shared an office at MIT. ${ }^{18}$ Dual Outlook marked the beginning of Fraser Crowe, a creative partnership making high-fashion womenswear which ran from 1997 to 2000. Fraser Crowe was sold in WORLD, Plume in Dunedin and also in Sydney, and is now represented in public collections including Te Papa Tongarewa The Museum of New Zealand and the Dowse Art Museum. ${ }^{19}$ In 2018 the pair relaunched their label as an online brand.

Kirby's article provided a national angle on the international artworld debate on "art as fashion, fashion as art." Within the New Zealand fashion world, Dual Outlook played a seminal role in changing perceptions of what fashion could be and look like. Nationally, Fraser Crowe's win signalled the social, political and economic changes occurring in New Zealand fashion.

The Benson \& Hedges/Smokefree Fashion Design Awards (1964-1998) were New Zealand's premiere fashion event, televised nationally; they were a launchpad for up-and-coming designers. Until 1995 the awards were underwritten by tobacco sponsorship. In 1996 the Health Sponsorship Council entered into an agreement with event organiser Maysie Bestall-Cohen Promotions to ensure the continuation of the event until another sponsor was found. The awards folded in 1998 due to an inability to secure ongoing sponsorship.

Under the umbrella of Benson \& Hedges, the awards deferred to French discourses of fashion as a fine art; this approach replicated the social and cultural tastes of Bestall-Cohen, who took over the running of the awards in 1982. ${ }^{20}$ Over time, Bestall-Cohen was forced to make the awards relevant to New Zealand's image - an image perceived to be more in tune with the often elusive concept of 'No. 8 wire' inventiveness and also with youth. There was also a strong desire to see the awards acknowledge our location in the Pacific. In 1993 the Avant Garde Section was launched in response to the creative success of the New Zealand Wearable Art Awards - which had a stronger sense of national identity. In 1995 an Oceania Section was launched, in response to the rise of Style Pasifika.

The Health Sponsorship Council (HSC) recognised that the New Zealand fashion industry was changing. The demise of tobacco sponsorship collided with trade liberalisation, which flooded the market with cheap apparel imports, forcing designers to innovate in order to survive. Creative agency Colenso was engaged to assist with the development of a new vision.

Focus groups were held with New Zealand women to discuss their perceptions of New Zealand fashion, and the emotive connections they held with Benson \& Hedges. Participants associated Benson \& Hedges with perceptions that included: "moneyed," "'good taste, leaning towards the classical and prestigious," "Narcississm," "Exclusivity and Privileged" - ideas linked with European high style and conspicuous consumption. ${ }^{21}$ They also thought that the New Zealand fashion scene was behind the times and were excited by the influence of urban Pacifika themes emerging in the work of young designers, and what they saw as the "confluence of 'designer' and 'street' fashions." 22 


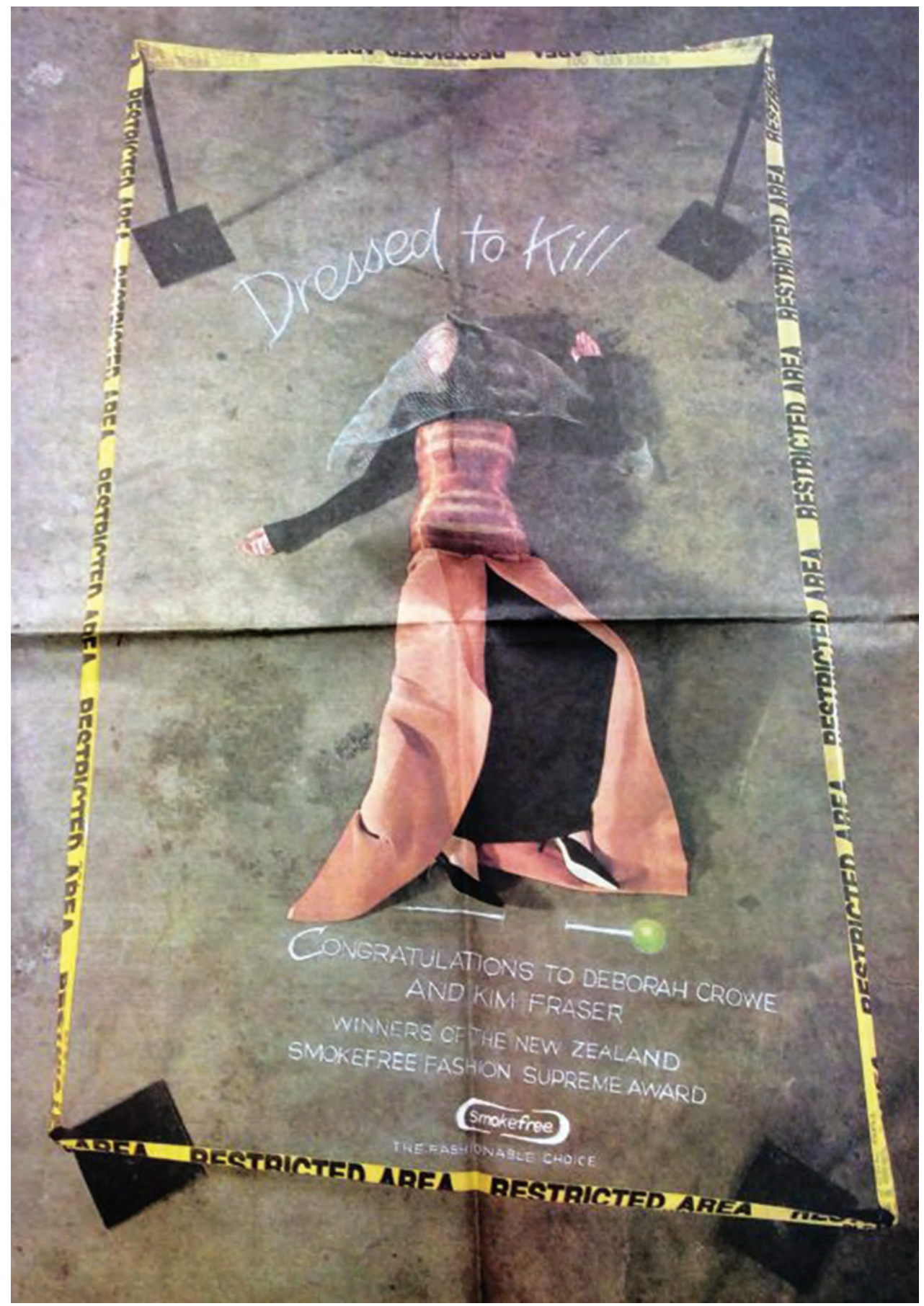

Figure 3. Image Deborah Crowe and Kim Fraser's 1997 award-winning garment and the award's new symbol, a pounamu pinhead. Photograph: courtesy of Natalie Smith. 
Pacific Island fashion activism was driven by Rosanna Raymond who in 1993 started the first Pasifika festival, lobbying for a change in the Pacific Island urban look. ${ }^{23}$ Some focus group participants felt the change of sponsorship was an opportunity to harness what was happening at grassroots level in New Zealand fashion. They also felt that a change in sponsor was a chance to foster an image more in tune with New Zealand culture. ${ }^{24}$

"Taking the Ash out of Fashion" became the HSC motto, implying an industry that had burnt itself out and was in need of rejuvenation. ${ }^{25} \mathrm{An}$ advertisement featuring a model wearing Dual Outlook lying on concrete, surrounded by hazard tape and accompanied by the text "Dressed to Kill" implied the changing direction of New Zealand fashion (Fig. 2). In this moment, Dual Outlook came to represent not only the idea that fashion could be art, but the idea that New Zealand fashion moved fluidly between the two worlds. The piece was described by Smokefree as having a "strong art beat" and by judge Konstantina Moutos as "international" in standard. ${ }^{26}$

Last year I interviewed Crowe and Fraser, revisiting key themes from the Kirby interview. Dual Outlook remains central to their design philosophy, premised as it was in what the future would be like; it represents their position that it is the "job of the artist to question what is going on around us." ${ }^{27}$ In Kirby's interview, they referred to Dual Outlook as being "emblematic of [their] concerns as designers and artists." These same concerns prevail in their practice today. ${ }^{28}$

In the intervening years, we have seen the rise of McFashion. As journalist Michele Lee argues, "In our "I want it now' world, fashion has begun to resemble fast food: fast, disposable, easy, unintimidating, entertaining, and largely homogenous." Fashion brands like Gap are as ubiquitous as McDonalds. ${ }^{29}$ In this climate, Fraser Crowe believe it is not only the designer who is critiquing fashion, but also the consumer who is seeking out responsible, lasting design imbued with a sustainable message, as well as designs that allow them some agency. Crowe recalled one woman who purchased a Fraser Crowe dress with a tie. This consumer took the tie attached to the dress and pulled it between her legs to create pantaloons, thus re-writing the idea that as consumers we purchase a look dictated to us by the fashion industry or social media influencer. In creating garments with multiple uses, Fraser Crowe state that they are giving "power, agency, authorship and curatorship to the wearer." "We don't dictate a look; the look comes from the wearer. The body builds a relationship." ${ }^{0}$

Growing options for fashion education in New Zealand have also helped change the image of fashion. Fraser, who now teaches at Auckland University of Technology, where she researches sustainable fashion, notes that today's students are more interested in aesthetics and sustainability. The development of community workshops to encourage the sharing of sewing skills is further empowering consumers to invest in fashion through mending and repairing. "Embellishing the Flaw," a recent workshop run by the duo, sought to pass on skills to a new generation. ${ }^{31}$ Westwood's statement, "Buy Less. Choose Well. Make it Last,"32 has become somewhat of a company mantra. Surface design, or elements in fashion which have a handcrafted element, are viewed as promoting sustainability and encouraging a "care of use" and "beauty in use" ethic and fostering an "emotional" relationship with the garment, resulting in a longer life span. ${ }^{33}$ For Fraser Crowe, their hope is that their garments will become cherished heirloom items passed down from mother to daughter.

A publicity photograph printed with the text "Fraser Crowe 1998//2008," created for the re-launch of the brand, marks the shifts which have occurred in the art-fashion debate over the past 20 years (Fig. 3). On the left, a model stands gesturing upward, her face obscured by the sculptural solid-rock-like formation of Featherweight Kimono (20 I 8), created from the "\#lesslandfill" textile collection, printed on 100 percent silk satin georgette. Printed with references to the natural world, the sculptural styling of "\#lesslandfill" belies its lightness and alludes to the earlier debates which had privileged formal looks over the recognition that, to paraphrase Westwood, "fashion is the medium of choice for some visual artists and a platform to effect change." To the right, a model wears an earlier iteration of Fraser Crowe, a woven bustier from 1998 with an ironically titled It's All Academic top from 2018 perhaps a reference to the early academicising of fashion as art. The woven bustier provides a link between the past and the present; "\#lesslandfill," like the bustier, is a weaving - a weaving of images. 
Although the borders and boundaries have shifted, this publicity image states that the creative drivers that were at the core of Fraser Crowe's early practice remain the same. The duo continue to use fashion to express ideas on social issues, sustainability and the body's relationship with textiles.

The "\#lesslandfill" textile series weaves together images of everyday urban detritus with Auckland's verdant natural landscape. This weaving of imagery draws attention to the layers of rubbish we find in the natural environment, as well as global concerns about the sustainability of textiles and a reminder that items discarded in household rubbish eventually end up in landfill. ${ }^{34}$

The wearer of this Fraser Crowe garment distances themselves to some extent from the urban jungle and consumerism, and cocoons themselves in a garment that drapes and occupies space in interesting ways, and which is ethically and sustainably made. Like the wearer of Dual Outlook, the body in this space is both cocooned by it and able to look out from it. Featherweight Kimono and the "\#lesslandfill" series represent both deference to Dual Outlook, but also an evolution - a reminder of how far the art-fashion debate has come. Using Fraser Crowe as a case study, we can map how the art-fashion debate has unfolded, and the role that socially engaged practitioners have played in bringing these two worlds closer together.

Dr. Natalie Smith is a teaching fellow in the Department of Sociology, Gender and Social Work and a lecturer in Art History and Visual Culture at the University of Otago. Her research interests lie in the art - fashion nexus. 
I Mark Kirby, "Art as Fashion, Fashion as Art: Deborah Crowe and Kim Fraser," Art New Zealand, 87 (winter 1998), 34-6.

2 Fashion and Art, eds Adam Geczy and Vicki Karaminas (New York and London: Berg, 20 I2), 7.

3 Susannah Frankel, "Spring Fashion Special," The Guardian, I March 1997,T034.

4 Frankel, Spring Fashion Special."

5 Geczy and Karaminas, Fashion and Art, 9.

6 Nathalie Khan, "Catwalk Politics," in Fashion Cultures: Theories, Explorations and Analysis, eds Stella Bruzzi and Pamela Church Gibson (London and New York: Routledge, 2000), I I4-27, at 117.

7 Ginger Gregg Duggan, "The Greatest Show on Earth: A Look at Contemporary Fashion Shows and Their Relationship to Performance Art," Fashion Theory, 5:3 (200 I), 243-70. Her article drew on the exhibition, "Fashion: The Greatest Show on Earth" (Museum of Art, Fort Lauderdale, Florida, November 200I-2002).

8 Fiona Anderson, "Museums as Fashion Media," in Bruzzi and Gibson, Fashion Cultures, 37I-89.

9 Kirby, "Art as Fashion, Fashion as Art," 34.

I0 Kim Fraser and Deborah Crowe, "A Retrospective Response: Then and Now from a Collaborative Team," Context: dress/ fashion/textiles, 30 (winter 2015), 15-29.

II Ibid., 17.

12 ibid.

I3 Thilak Vadicherla, D Saravanan, M Muthu Ram and K Suganya, "Fashion Renovation via Upcycling," in Textiles and Clothing Sustainability: Recycled and Upcycled Textiles and Fashion, ed. Subramanian Senthilkannan Muthu (Singapore: Springer, 2017 ), 4.

14 Lucy Hammonds and Natalie Smith, When Dreams Turn to Gold:The Benson \& Hedges and Fashion Design Awards 1964 - 1998 exhibition catalogue. The Dunedin Public Art Gallery, Dunedin, 18 March - 25 June 2017.

15 Kirby, "Art as Fashion, Fashion as Art," 34.

16 Jane Mulvagh, Vivienne Westwood: An Unfashionable Life (London: Harper Collins, 1999), 30I-3.

17 Ibid., 227.

18 Katherine Findlay, "Fraser Crowe," New Zealand Fashion Museum, 2018/2019, http://nzfashionmuseum.org.nz/fraser-crowe/.

19 Their work has also been exhibited in galleries in New Zealand and in "Fashioning Textiles," a touring exhibition in Canada.

20 Natalie Smith, "When Dreams Turn to Gold:The Benson \& Hedges and Smokefree Fashion Design Awards 1964-1998" in Lucy Hammonds and Natalie Smith, When Dreams Turn to Gold:The Benson \& Hedges and Fashion Design Awards $1964-1998$ exhibition catalogue. The Dunedin Public Art Gallery, Dunedin, 18 March - 25 June 2017

21 "Creative and Strategic Recommendations: The NZ Smokefree Fashion Awards, Colenso Wellington," MS-Papers-7026-34. Maysie Bestall-Cohen Papers, National Library of New Zealand, Wellington.

22 Ibid

23 Rosanna Raymond, "Getting Specific: Fashion Activism in Auckland During the 1990s: A Visual Essay," in Clothing the Pacific, ed. C Colchester (Oxford and New York: Berg, 2003).

24 "Creative and Strategic Recommendations."

25 Natalie Smith "Gold, Ash and Greenstone:The Smokefree Environments Act and the Rebirth of New Zealand Fashion", End of Fashion International Conference presentation, Massey University 8-9 December 2016.

26 The New Zealand Smokefree Fashion Awards, press release, 30 April 1997. MS-Papers-7026-38. Maysie Bestall-Cohen Papers, National Library of New Zealand, Wellington.

27 Telephone conversation with Deborah Crowe and Kim Fraser, 19 June 2018.

28 Kirby, op.cit., p. 34.

29 Michele Lee, Fashion Victim: Our Love-Hate Relationship with Dressing, Shopping and the Cost of Style, Broadway: New York, 2003, p. 63

30 Telephone conversation with Deborah Crowe and Kim Fraser, 19 June 2018

31 "Workshop Embellishing the Flaw with Fraser Crowe," https://www.eventfinda.co.nz/2018/workshop-embellishing-the-flawwith-fraser-crowe/auckland.

32 'Vivienne Westwood on Capitalism and Clothing: 'Buy Less, Choose Well, Make it Last',' The Guardian, 29 October 2014, https://www.theguardian.com/membership/video/20I4/oct/29/vivienne-westwood-capitalism-clothing-video.

33 Eunsuk Hur and Katharine Beverley, "The Role of Craft in a Co-design System for Sustainable Fashion," Making Futures, 2 (2013), 40-55.

34 Telephone conversation with Deborah Crowe and Kim Fraser, 19 June 2018 


\section{THE KARDASHIAN COMPLEX: PERFORMING SEXUALITY AND FEMININITY THROUGH IMAGE AND SCREENS}

Tyla Stevenson

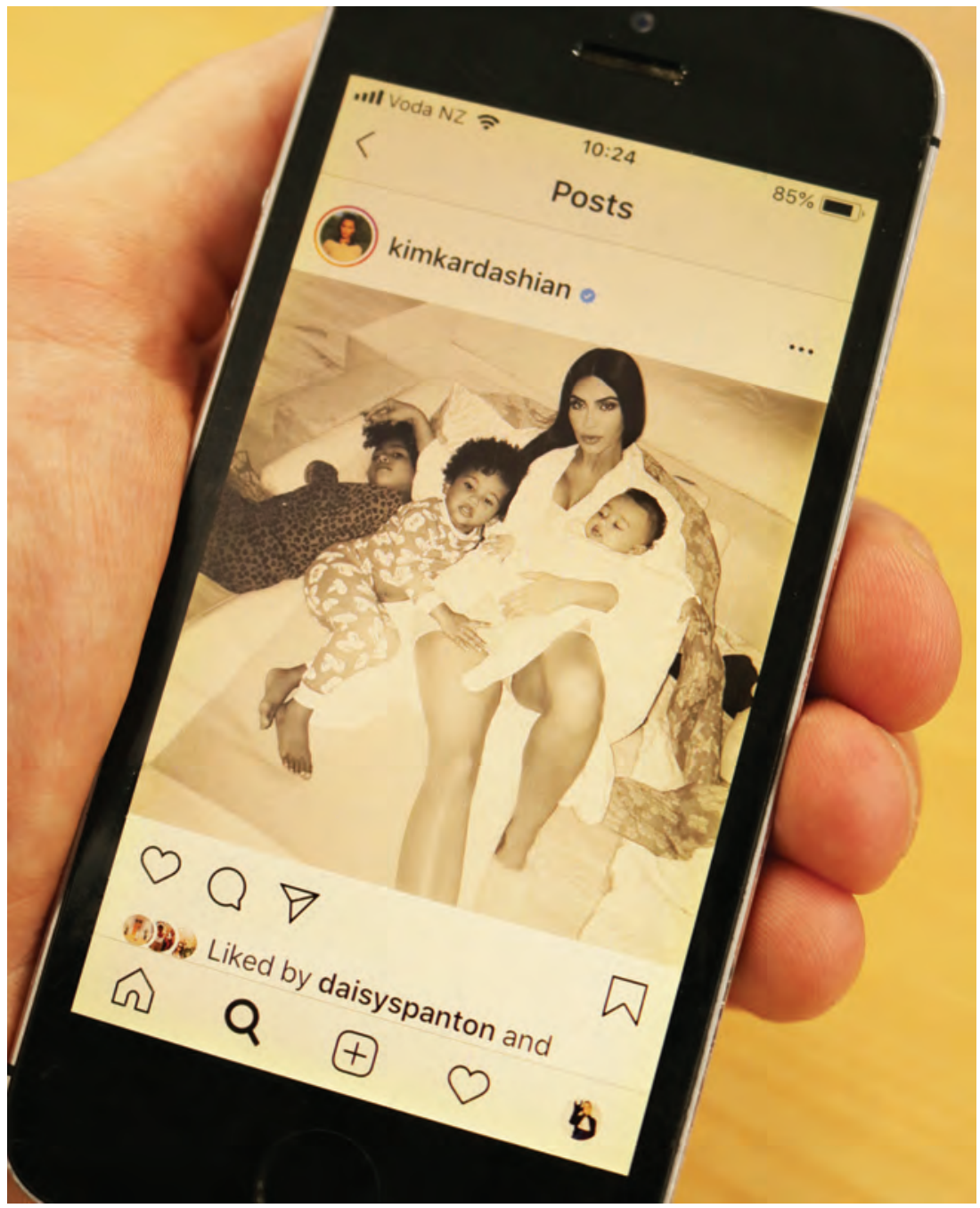

Figure I. technology such as smartphones have increasingly enabled the performativity of a diverse range of femininities, as well as affording control of their representation and dissemination by their subjects. 
Fashion as we understand it, is an umbrella term which envelops the in numerous ideas and domains within the broader industry. Within the present technological and political climate, the way clothing, garments and fashion are primarily consumed and disseminated, is through second hand and first hand interactions-with an abundance of different communicative technologies, including of course, online media. This paper focuses on the contemporary fashion image specifically that of viral online content attached to Kim Kardashian's Instagram account. With the number of those who have regular access to the internet and mobile devices continuing to rise, the production of the 'fashion image', and its reterritorialization back into the world is easier and faster than ever before. Because of the rise and accessibility of fashion image making, it is crucial we analyse it's production-specifically in the way that women's bodies are appropriated and beauty ideals are portrayed. Laura Mulvey, throughout multiple scholarly texts, suggests that women are often positioned to be considered as objects to be consumed, desired or looked at.' However, I would suggest that there are limitations to this analysis being applied to a 2 Ist century fashion image making model, in a culture of complex feminist performativity.

Emphasis can be made on the materiality of the fashion garment, but the physical fashion garment and its virtual image coexist and cooperate in a synonymous way. As an example,Vogue have been producing fashion images since their conception in 1892, through illustration, photography and film. The ever-changing technological environment, has always entangled itself with and informed the way fashion and its image is disseminated and experienced. No longer does the industry rely on the fashion magazine and its tangible media to disperse and regulate industry content. Producing digital fashion photography and film online is not only an effective way of capturing a collection or the essence of a design, but also a productive and effective advertising tool. The way we interpret audience engagement with the product has shifted since the accessibility to online content. As Karaminas explains,

"Computer based imagery and mobile media have brought another dimension to the circulation and understanding of meaning and its impact on audience reception... where once fashion photography relied, or two dimensional print media, relied on the image to seduce the audience into purchasing a garment by constructing a narrative of desire digital media immerses the audience into the desired world of the luxury brand by evoking visual and olfactory pleasure."'

Although Karaminas has opened a critical field of enquiry into the investigation and analysis of the digitisation of the fashion image online, what remains mostly unexplored in the conversation is that digital media and the advancement of technology has offered a new understanding of the role of image, moving or still and its relationship to the active participant and spectator, now that its common and popular for the subject of an image to also be its creator.

There are multiple facets to online image sharing. One of the most prominent platforms for sharing images is the social media network Instagram. Instagram is a network that is embedded into your smartphone, enabling users to post their own content any time. Users follow each other, providing 'likes' for favourable content. Instagram as a social media site has doubled its user accounts in the past two years, with 800 million active users.

A popular form of content posted on Instagram is the 'selfie'; a form of self-portraiture taken with the users smartphone camera. With the rising accessibility to the internet, use of smartphones and social media, more people have the opportunity to circulate their image and it is important to analyse the content of these images. How are these images produced, and by who? Who or what is assigned the most autonomy and validation within communicative media? Usually when discussing ideas surrounding the way women are portrayed through image and media, blame is often directed at content creators for fashion media such as photographers, magazines and advertisements for promoting homoginist, stereotypical and unrealistic beauty standards. But when it is the public that are producing the images, who are also the subjects of the image, can we apply a similar critique?

Mulvey's famous academic text Visual Pleasure and Narrative Cinema was published in 1973. Her analysis of Hollywood cinema during the 70's doesn't consider the types of technological changes we have today, but the way 
Hollywood cinema is consumed and enjoyed within the 2 I st century doesn't veer far from its earliest conception. Regardless a summary of Mulveys analysis of classical cinema is needed as it is still being used to critique and analyse the role women play in contemporary still and moving image.

Men are empowered as the subject of the male gaze, while the female, as object, exists in order to be viewed. ${ }^{3}$ Mulvey argues men can identify with the active role of the subjective protagonist that thereby generates a sense of agency, which women don't achieve as the objectified other. Instead, it is implied, women are positioned in an exhibition to be looked at, with their appearance associated with coded erotic visuals. This split between the active protagonist male, and the sexually coded, passive female determines the male gaze, a projection of fantasy onto the female figure. Camera shots and editing features are styled accordingly, objectifying the female character, panning up and down her female figure and dissecting the body into fragmented pieces when moving in for close-ups. ${ }^{4}$

The male gaze concept has been used as a way to critique the way social media is being used to hypersexualise young women and their bodies, and notes, that new technologies and digital reproduction have made the consumption of women's bodies even more accessible than ever before. ${ }^{5}$ Maintaining that the proliferation of images of people (including celebrities) mean they are more widely available for public consumption. Authors such as Kelly Oliver argues that social media outlets such as Instagram were invented within a culture of the male gaze, formulated to reinforce it. ${ }^{6}$ Suggesting that the images women produce of themselves in various seductive poses, which they then post onto their social media accounts such as Instagram and Facebook, re-create the male gaze objectification onto themselves.

There is however little indication throughout Oliver's or Muveys texts that women can be in control of their own image production when operating webcams, camera phones and other online internet based technologies. This is an important reconceptualisation of the male gaze critique in the age of social media and image sharing, and one presented by Michele White. ${ }^{7}$ White suggests that we can use feminist analysis that doesn't simply imply that visual media is always taking part in a process that assumes viewers look upon and possess women's bodies in a relationship of the subject objectifying the object. ${ }^{8}$ White presents the webcam operator as an example of women using computer technologies and the virtual image to make themselves and their bodies visible in a controlled way. While webcams have the potential to reinforce gender norms regarding performing eroticism for the voyeur, women have heightened control over their image making and the manner of its representation. ${ }^{9}$

The webcam user and the use of a front facing camera is synonymous with online media and the exchange and production of moving and still images. While it provides a site to begin theorising a different set of concepts around spectatorship and the gaze, specifically the ways in which webcam operators have the subjectivity to gaze back. Within the world of webcam operating, the operators and their spectators can resist the binary logic of man/active, women/passive of classical cinema and the image produced by the webcam operator is often too fragmented, skewed often due to the closeness of the body to the cam, for voyeurism to enact properly. White suggests that "...the promised reality of webcams is also distributed by the overt camera processes, varied website elements, blurred, or static infused views, and webcam operators who refuse to meet the spectators demand". ${ }^{10}$ I suggest that there are positive political aspects of women's webcams which include the operator's defiant modes of address and resistance to fully producing images for the male gaze. It is useful to consider how the gaze is sometimes disrupted in an internet setting, even if all not all spectators notice this. The idea that this medium or Instagram is manufactured by and for men prevents an extensive understanding of women's active role in using online media and producing images of female representation.

The Kardashian's, a multibillion dollar matriarchy of socialites, is an example of a business selling both their bodies and sexualities to their fans and followers. Kim Kardashian, the face of the family brand was reportedly as the most Google searched person of 20 I5. Kim has III million Instagram followers, and with the other family members not far behind it is easy to understand the scale of their fame. 
Since the launch of their reality show, Keeping Up with the Kardashian's in 2007 the Kardashians have been commodifying the idea of the unconventional modern family. Their loyalty, love-lives, wealth, consumption, fame, bodies and sexuality are exploited for profit and played out on the national and international stage. While it would be easy to argue that the overt hyper sexuality of the Kardashian brand is another example of the media presenting women as dependant ornaments to be looked at and sexually desired, the Kardashian's can in fact be considered a group of women utilizing their bodies and sexualities to achieve their career and financial goals. Kim Kardashian in particular, has used Instagram and other social media as a smart marketing strategy. Through control of her image making, Kim performs an erotic hyper sexuality, simultaneously establishing conservative family values, thereby constructing an image of herself as both "the Madonna and the whore."'

American women in the public eye haven't always had the agency to control their image and content like the Kardashians have. While Kim, for example, is able to choose how she wants to portray herself from day to day, be it an erotic, bedazzled bikini, bathroom selfie or a family picture on vacation. This amount of control over the dissemination of the personal imagery of star-like celebrities would have been unheard of throughout the developing Hollywood star system of the 1930's and 40's. Performers before this time were somewhat anonymous, and as audiences showed interest in knowing the people behind the characters, studios realised that the star's identities were now marketable. By this stage film studios had arranged limiting contracts with their talent that put their publicity departments in authority over their image construction and dissemination. Giving the star no option to terminate or any legal right to break their contract often reflected a one sided operation in favour of the studios. ${ }^{12}$ Due to the development of the smartphone Kim Kardashian and contemporary stars alike are able to take on a more DIY approach to their image dissemination, often opting to use the selfie that shows, both figuratively and literally, full autonomy over their image making. It would be naive to say that the contemporary Hollywood star system is now a democratised organization with stars in complete power over their image and opportunities, as well as it is ingenuous to assume that a celebrity like Kim Kardashian doesn't have authority of her body, image and its intended use.

The Kardashian clan use a variety of styling, lighting, photography, video, written word and careful content management to present themselves and their brand to their fans and millions of followers. They epitomize contemporary ideas of the American dream through their diligent entrepreneurial spirit, cultivating their image through social media and the idea of the celebrity, which they maintain through their online presence with their fans. Kim Kardashian has successfully appealed to a variety of markets, all genders, age groups, economic class both liberal and conservative. McClain maintains "Their branding and celebrity empire would not exist without the smart use of social media. Their usage is an exemplar of how to buttress popularity, extend celebrity, and associate image and products. The Kardashian's are a prototype of how social media usage can be used to attain the American Dream of success" (I32). ${ }^{13}$

Kim and the Kardashian family overtly benefit from their own exploitation. To take a surface-level reading we could come to the conclusion that the commodification of their hyper sexuality implies that to attain similar success, the consumption of specific fashion and beauty products is needed. Kim and the Kardashian family solidify their own beauty and fashion brands (Dash Boutique, KKW Beauty and Fragrance, Kylie Cosmetics) by living in them, therefore associating their lifestyle with their product. In Kardashian Komplicity: Performing Post Feminist Beauty, Giulinana Monteverde explains how the Kardashian's are often criticised by feminists of projecting complicit behaviours favouring oppressive body and beauty standards. ${ }^{14}$ Rather than the author simply regarding the Kardashian's involvement within the fashion and beauty industry as oppressive or superficial however, Monteverde instead suggests that they are reinforcing a neo-liberal logic. Montevede explains how "interactions with beauty are not necessarily evidence of patriarchal victimhood". ${ }^{5}$ It is important to avoid generating assumptions that women who engage with beauty standards are complicit in their own oppression. There are various feminist critique of beauty culture that are valid, but there are also examples of beauty practices being useful for the subversion of gender performance and sexuality. There are numerous reasons why people engage with beauty practices, and one cannot assume it is in favour of essentialist heteronormative gendered system. 
In many ways Kim Kardashian reflects a type of raunch culture and "do-me" that can be considered as a combination of somewhat conflicting feminist ideologies. Those that engage with this culture use provocative appearance and behaviour as acts of female liberation and empowerment, often through overtly sex positive attitudes. ${ }^{16}$ It is undermining those that engage in beauty practices to assume they undertake this appearance to please or attract men. Taking control of their femininity and sexuality complicates the idea of the male gaze, and is then aligned with ideas of "female emancipation and self-determination rather than its previous connotations of patriarchal oppression and subjugation." ${ }^{\prime 7}$ To align sex positivity and active hyper sexuality with anti-feminist ideology is regressive, when in reality these ideas are related to feminist core issues such as the right to choose what individuals can do with their own bodies. But when it comes to a celebrity mother like Kim Kardashian, posting images of her own body to her Instagram, account the media is quick to obsess with her feminist intentions.

To progress from the black and white binaristic thinking of previous feminist waves, critics need to open themselves up to other modes of thinking and to re-evaluate what would previously be labelled as anti-feminist; we need to adapt our modes of thinking alongside technological changes. To apply a critique of classical cinema to, say, an Instagram selfie, is ignoring its critical potential, and reveals its irrelevance. Instead, promotion of a politics of ambiguity is necessary to articulate the complex negotiations between sexual objectification and liberation. ${ }^{18}$ While it would be easy and convenient to assume that sexual subjectification is an oppressive media ploy adopted by virtual women, we need to also acknowledge the opportunity to renegotiate notions of feminine sexuality. It might be useful to consider adopting traditionally contradictory modes of feminism to understand and produce more nuanced reading of $2 \mathrm{Ist}$ century expressions of sexual and feminine identities.

The analysis of the fashion image isn't as simple as blaming the hyper sexualisation of women on fashion industry media. Women are subject to their own image making, and it's not helpful to project historical feminist ideals onto these women, as modern feminism is a fluid and intersectional apparatus, that deserves the time and acknowledgement of how complex these ideas and identities can be. I want to acknowledge the meaninglessness of labelling Kim, the Kardashian clan or other celebrities alike as 'feminist' or 'anti-feminist'. To do so is to ignore the nuances of feminine performativity. Feminine identities of the new millennium are always in a constant in-between space or flux between the bound and unbound.

Tyla Stevenson is a Wellington based fashion design graduate with a research interest in the implications of new technologies, the internet and online media on the fashion system, identity and the body. The basis of this paper was presented at the 2018 Costume and Textile Association of New Zealand (CTANZ) symposium Unbound: Liberating Women. 
I Mulvey, Laura. “Visual pleasure and narrative cinema." In Visual and other pleasures, pp. 14-26. Palgrave Macmillan, London, 1989.

2 Karaminas, Vicki. "Image: Fashionscapes- Notes Toward an Understanding of Media Technologies and Their Impact on Contemporary Fashion Imagery." In Geczy, Adam, and Vicki Karaminas, (eds.) Fashion and Art (Bloomsbury: London and New York, 2013) 180.

3 White, Michele. The Body and the Screen:Theories of Internet Spectatorship. (MIT Press: Cambridge, MA, 2006). 70.

4 Oliver, Kelly. "The Male Gaze Is More Relevant, and More Dangerous, than Ever." New Review of Film and Television Studies, vol. I5, no. 4, (Feb. 2017), 452.

5 Oliver. "The Male Gaze Is More Relevant, and More Dangerous, than Ever." 452.

6 Oliver. "The Male Gaze Is More Relevant, and More Dangerous, than Ever." 453-4.

7 White, Michele. The Body and the Screen:Theories of Internet Spectatorship. (MIT Press: Cambridge, MA, 2006).

8 White. The Body and the Screen. 59.

9 White. The Body and the Screen. 59.

10 White. The Body and the Screen. 58

II McClain, Amanda Scheiner. Keeping up the Kardashian Brand: Celebrity, Materialism, and Sexuality. (Lexington Books: Plymouth, UK, 2015) 58.

12 McDonald, Paul. The Star System: Hollywood's production of popular identities. (London: Wallflower, 20I I).

13 McClain. Keeping up the Kardashian Brand, 132.

I4 Monteverde, Giuliana. "Kardashian Komplicity: Performing Post-Feminist Beauty." Critical Studies in Fashion \& Beauty, vol. 7, no. 2, Jan. 2016, pp. I53-172.

15 Monteverde. "Kardashian Komplicity: Performing Post-Feminist Beauty." I 56.

16 Genz Stéphanie, and Benjamin A. Brabon. Postfeminism: Cultural Texts and Theories. (Edinburgh University Press: Edinburgh, 2018) 91.

17 Genz and Brabon. Postfeminism. 93.

18 Genz and Brabon. Postfeminism. 97. 
THE BUSINESS OF STAYING DRY: DESIGNING WATERPROOF TEXTILES AND GARMENTS IN NINETEENTH-CENTURY NEW ZEALAND

Jane Malthus and Moira White

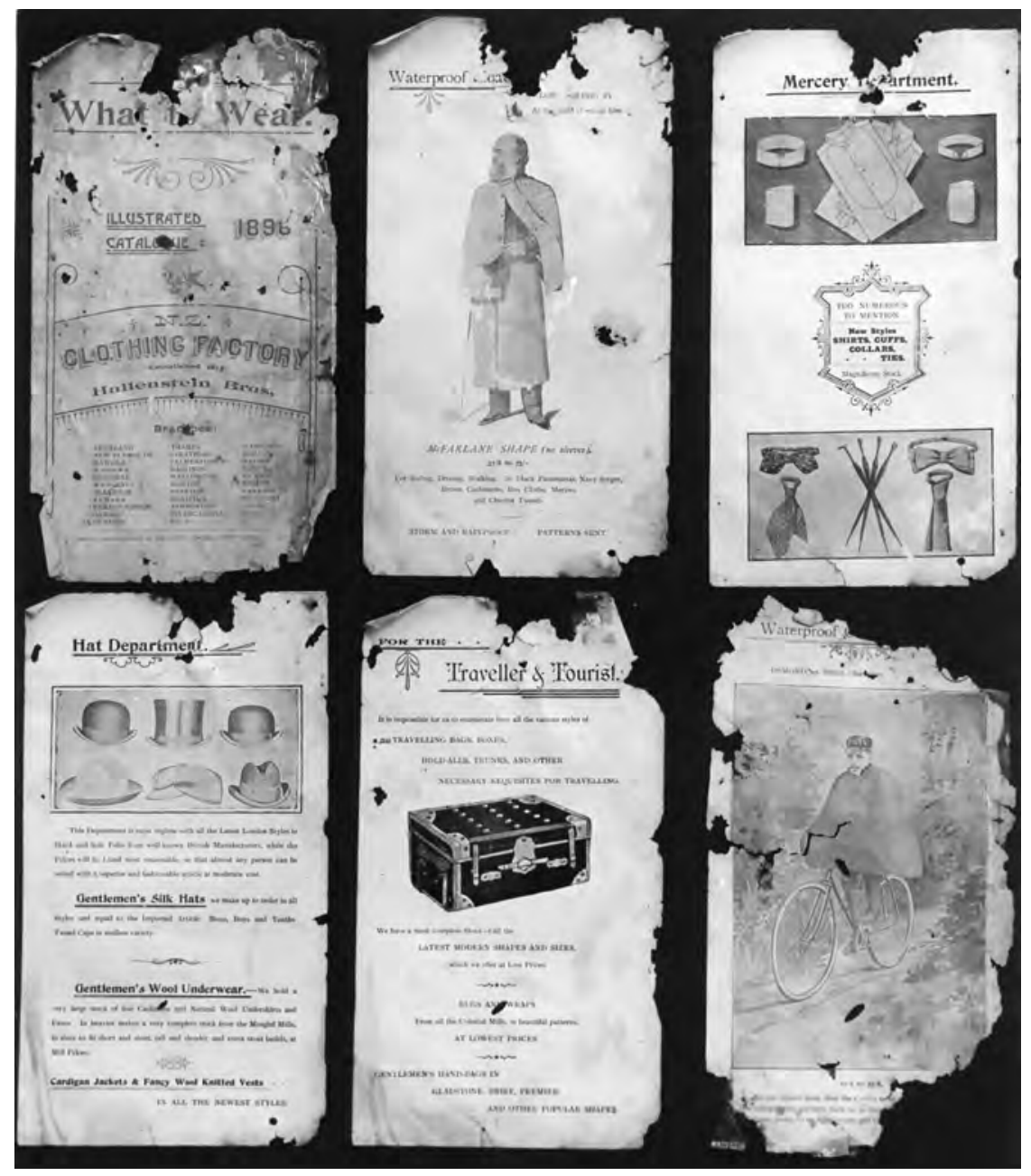

Figure I: Hallenstein Bros., image of 1896 Waterproof garments catalogue pages. Collection of Toitū Otago Settlers Museum, 1989 28.5- I. 
In New Zealand, waterproof and weatherproof clothing is often designed and marketed by romanticising rural activities, out-of-town travel and sporting pursuits in picturesque but rugged landscapes. Farmers mustering sheep or herding cattle, people getting out into the hills, or skiers and snowboarders posing in the mountains are familiar tropes in the advertising of such clothing. New Zealand's position as a group of islands in the southern hemisphere, exposed to weather coming from all directions, has meant that its human settlers needed garments for protection from rain, snow and wind. Maori used harakeke (Phormium tenax) and other plant materials such as kiekie for raincapes for centuries before Europeans arrived.' Unsurprisingly perhaps, British settlers, in conjunction with manufacturers in England, briefly investigated using the plentiful local flax plant to create covers and bags that would keep out the rain. Experiments with creating waterproof cloths from Phormium tenax, carried out in England it seems, were reported in the New Zealand Gazette and Wellington Spectator as early as August I843: "Mr. Donlan, the patentee of the waterproof cloth, delivered to Mr. Ball in 1837 a sufficient quantity of the waterproof fabric for a waggon [sic] cover; this cloth was put into use, and every stratagem was used to test its strength, soundness and durability, for a period of five years ..."'

It is not known if the waterproofing of the New Zealand flax cloth relied on properties of the fibres and weave or on some chemical additive, and while colonial experiments with making use of Phormium tenax continued throughout the nineteenth century, keeping people dry with waterproofed textiles followed a different path.

Chemical additives were first patented by Charles Macintosh in the United Kingdom in 1823. He developed a method of sandwiching rubber, softened by naphtha, between layers of cloth. By 1824 this cotton and rubber material began to be manufactured in Manchester. ${ }^{3}$ Naphtha is a flammable oil obtained by dry distillation of coal tar, shale or petroleum. Macintosh dissolved rubber in naphtha to produce a liquid, which was then brushed onto fabric, wool cloths initially.To make it really waterproof, he created a sandwich of two layers of this naphtha-treated fabric with moulded rubber between them. There were problems, however. Seaming the cloth caused holes where rain could penetrate; the natural oils in woollen cloth caused the rubber to deteriorate, and the fabric became stiff in cold and sticky in hot weather. ${ }^{4}$ According to the 1829 Gentleman's Magazine of Fashion, two further problems were the unpleasant smell and the shrinkage caused when one stood close to a fire. ${ }^{5}$

Multiple attempts to improve waterproof fabrics were made over the nineteenth century. After the textile-finishing calender process was developed in 1849 using heated rollers to create a smoother, shiny-surfaced fabric, American textile manufacturers experimented with calendering Macintosh's fabric, finding that it improved pliability and waterproofness. Thomas Hancock patented the vulcanisation or hardening process in 1843, which made rubber less sensitive to changes in temperature, so it was possible to then use a single coated fabric for waterproofed garments. ${ }^{6}$ Charles Goodyear refined that process, patenting his version in 1884. By late 1877 a Cravenette waterproofing process that could be applied to any textile without apparently changing its texture or weight was patented in Bradford, England," and "the new Cravenette waterproofs" arrived at Ballantyne and Co. in Christchurch, New Zealand, the same year. ${ }^{8}$ Experiments were made with substances other than rubber, too. Gutta percha (another latex), oils, fats, varnishes, waxes, acids and oxides were all used to waterproof fabrics. ${ }^{9}$ Oilskin, for instance, was a fabric such as cotton canvas with a skin of oil applied as waterproofing, used especially by sailors and miners, ${ }^{10}$ but it had the disadvantage of being very flammable.

Even with all these improvements and refinements waterproof fabrics were very heavy and hot and smelt bad, so garment designs had slits and vents to allow for air circulation." Pretty and fashionable they were not. In his A History of Men's Fashion, Farid Chenoune commented: "As to rubber raincoats, such as the Macintosh that appeared around 1840, they were hardly deemed stylish. Abel Léger nevertheless pointed out in his 1912 L'Elegance Masculine that "it is so practical that it can be excused for being ugly, for generally being smelly and for having all the unhealthy drawbacks of rubber which prevents evaporation of perspiration."'।2 
Ladies' waterproofs were just as bad: the only choice for many years, according to the Ladies' page of the Otago Witness in 1884, was "the sack-like waterproof cloth coat with sleeves fastening round the wrist with elastic" or "the hideous sticking plaster-like black mackintosh ... . It is only quite lately that the manufacturers of India-rubber waterproof clothing have seemed to think it desirable to rescue the fair sex from assuming the outward and visible guise of a refined kind of cabman or messenger."13

Macintoshes, rainproof and waterproof coats and mantles were being mentioned and advertised for sale in New Zealand to town and country dwellers from the very early days of print media: two Auckland suppliers advertised such stock "at reduced prices" in $1843 . .^{14}$ So-called "oiled waterproof" coats, leggings, jackets, sou'westers and pilot coats were being imported and sold by $1852 .{ }^{15}$ Thomson, Strang and Co. of Dunedin offered ladies' rainproof Oxford and Cambridge mantles in 1874. That same year, men's and boys' clothing from the New Zealand Clothing Factory (established the year before by the Hallenstein family), including waterproof coats, was being supplied to I. Hallenstein and Company's Lawrence shop. ${ }^{16}$ E. C. Brown and Company's Fashion House in Christchurch supplied their "distant customers" in the countryside with goods on a parcel system, such as a mourning parcel for $€ 2$ IOs that included "2 $y$ ds $4-4$ celebrated rainproof crape."'7

Other newspaper references to waterproofs include this item from 1868 in Napier:Thomas Hitchings had his new black waterproof Inverness Cape with a black velvet collar stolen from a cloak room at a dinner for the Governor, and had to advertise for its return. ${ }^{18}$ In 1882 a waterproof coat worth 2 pounds was a prize for the best Clydesdale bred by the exhibitor at the Clutha Agricultural and Pastoral Society's annual show. The coat was donated by Brown, Ewing, and Co., Dunedin. ${ }^{19}$ They also gave a waterproof coat as first prize for a brood mare in foal or "with foal at foot" at the Waitahuna Farmer's Club show in $1888 .{ }^{20}$

From these and other references, it seems that the term 'waterproof' was used for oilskins, fabrics made using the Macintosh process, heavily fulled woollen fabric garments and rubberised cloth, and that such garments were in demand as useful, and even prized, possessions.

The claims of waterproofness that these advertisements made mostly went unchallenged in nineteenth-century New Zealand. There were no standards or consumer organisations to verify the truthfulness of manufacturers' or retailers' claims. It seems that waterproofs did not keep one completely dry. In October I 874 the Otago Daily Times reprinted an article from the Timaru Herald:

We seem to be getting in spring all the wet, violent, unpleasant, uncertain weather which should, if the usual climatic programme had been adhered to, have varied the monotonous sunshine of last winter. It is, however, a consolation to know that the rain, vexatious as it is to dwellers in towns, and travellers by land or sea, is doing no end of real good to everybody. As the lambing season is just commencing continued drought would now be fatal. ... When, therefore, the sodden citizen wearily pulls off his third pair of dirty boots, and hangs up his dripping, leaky, meretricious macintosh, before he changes his sopping clothes, let him lay the flattering unction to his soul, that meat will be "down" before long, though wool is "up"..."

Recipes for do-it-yourself waterproofing abounded in newspapers. Both the Bay of Plenty Times and the Taranaki Herald suggested that travellers should wear good Scottish tweed rather than waterproof cloth. The tweed coat could be made waterproof by soaking for 24 hours in a solution of "sugar of lead" (lead acetate) and alum in "soft water," then drip-drying it. "The rain does not penetrate the treated cloth."'22

An early-twentieth-century Cutter's Practical Guide gave its tailors a recipe for waterproofing that involved soaking and boiling woollen cloth first in a solution of water, soap and glue, then after it was almost dry, soaking it in a bath of water, alum and salt. This would, the authors said, make the cloth rainproof while still being supple and comfortable to wear, but they did caution that it would not "turn ordinary cloth into Macintosh material."23 


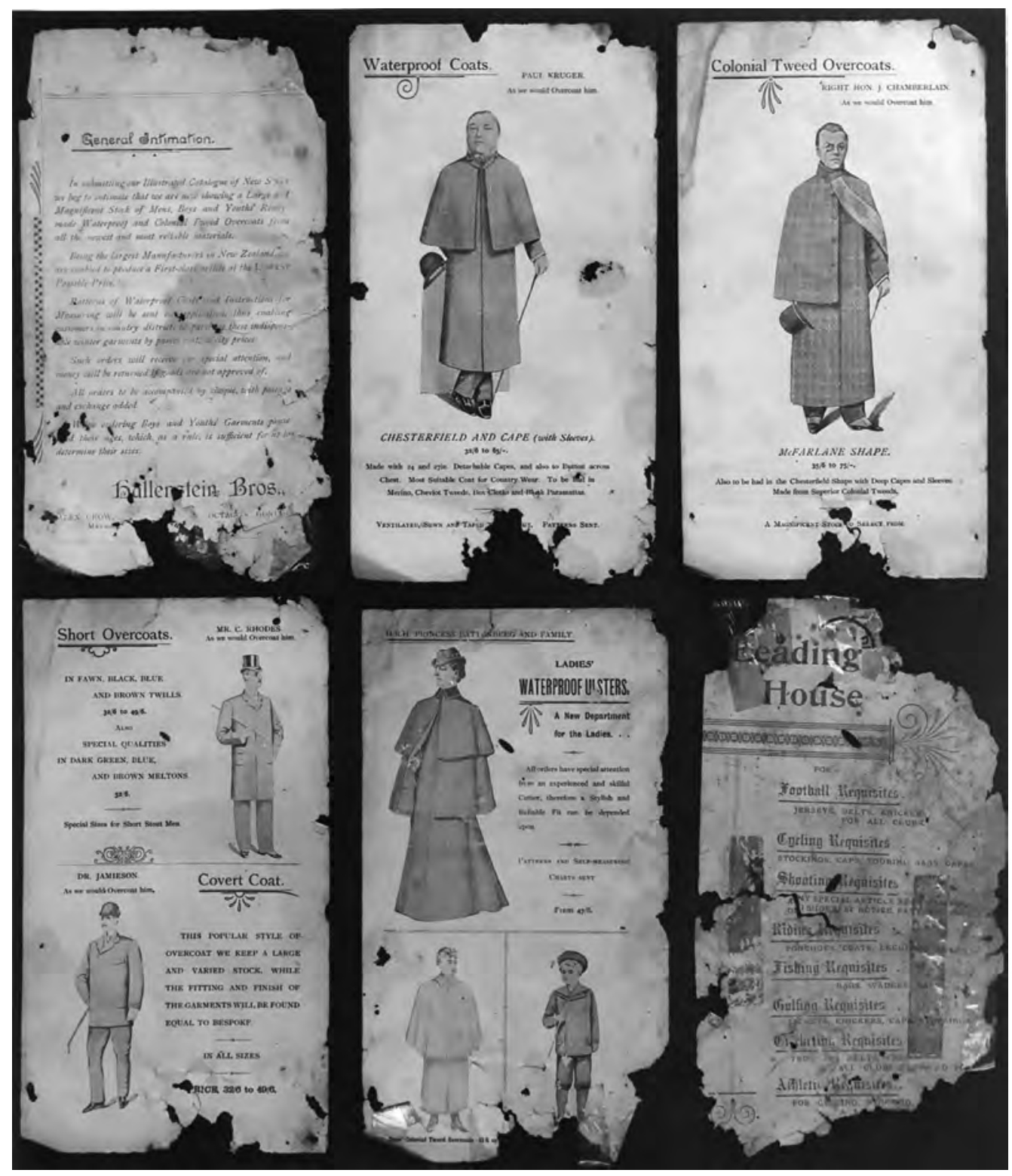

Figure 2. Image of Hallenstein Bros., I 896 waterproof garments catalogue pages. Collection of Toitū Otago Settlers Museum, 1989 28.5-2. 
With the New Zealand market for waterproofed clothing reportedly worth $£ 30,000$ per year, ${ }^{24}$ Hallenstein Brothers set up a separate waterproof factory in Dunedin in the late 1880s. This was announced in the Otago Daily Times of 22 October 1889 thus:

Some four months ago Messrs Hallenstein Bros, and Co. added the manufacture of ladies and gentlemen's waterproof clothing to their productions, and thus established an important industry. The manufacture is carried on in a building adjoining the New Zealand Clothing Factory. As the manufacture of waterproof clothing is a new one in New Zealand, the manager (Mr Allured) and an experienced staff had to be procured from the Home country. They have been busy since their arrival making up for the winter season a variety of goods, including men's Inverness capes, Chesterfields, ulsters, ladies' capes and cloaks, military regulation cloaks, waterproof buggy rugs, gaiters, leggings, cushions, sponge bags, \&c. The firm aim at manufacturing goods superior to those imported, and has procured several patent rights, including one for ventilation. The public will have an opportunity of inspecting these goods at the forthcoming exhibition, a bay having been procured in which to make an extensive show. ${ }^{25}$

Was this move taken because of increasing demand for such clothing on the part of rural and urban consumers, or were Hallensteins carried away with the possibilities offered by new technological processes, the challenges of meeting and exceeding the achievements of competitors, the opportunities for marketing, and the appeal of new products? Hallensteins were certainly aware of many British manufacturers or suppliers of waterproof clothing, listing some 37 different producers as potential suppliers in correspondence, but perhaps it was a combination of economics and experimentation that spurred them to try local production. ${ }^{26}$

New technological processes were certainly attempted. From Bendix Hallenstein's correspondence about supplies it is clear that the company was intending to produce a form of waterproofed cloth very similar to Charles Macintosh's. Hallenstein mentions the arrival of India rubber and naphtha (which continued to be mentioned in their annual accounts for some years), but also that a patent application had been unsuccessful, and that "Fairfax had copied the machinery and swindled us." There is mention, too, of an "explosion of the wonderful invention" - but it is unclear if that was just a colourful expression relating to the failure to get a patent, rather than an actual blow-up. ${ }^{27}$

While it is uncertain who is meant by the swindling claim, there had been an article in the Otago Daily Times, 20 days prior to the Hallensteins' announcement, that Messes Levy, Guthrie and Co. of Rattray Street were getting into the manufacture of waterproofs. ${ }^{28}$ Because piece goods could be imported duty-free - but coats and other waterproof ready-made garments attracted duty of 25 percent - it made commercial sense to import fabric (or buy it locally if one could) and make up ladies' and gents' waterproof coats, leggings, hats and stockings, combined boots and trousers for fishermen and boatmen, and possibly air and water beds. ${ }^{29}$

Other competitors in the waterproof garment business in the 1890s included more Dunedin firms: Lorie and Co., and the Zealandia Waterproofing Company. Zealandia, a company owned by the Taylor family, had brought a Mr Tennant out from Glasgow in 1889 to run their waterproof manufactory in High Street, Dunedin. They produced a very practical riding and driving coat, sleeveless, with a 24 -inch-deep cape, complete with "slings inside to act as rests for the arms when travelling" and tabs so that the cape could be formed into sleeves when driving a team of horses. Tabs also meant that the lower section of the coat could wrap around the legs when riding. This garment also came with a detachable hood. ${ }^{30}$

At the New Zealand and South Seas Exhibition of $1889-90$ in Dunedin, locally made and imported waterproof garments were displayed. Hallensteins won first prizes for "Ladies' colonial made waterproof mantles" and waterproof carriage rugs, air cushions and leggings. The Zealandia Waterproof Company won first prizes for their men's garments, with special mention made of the "Onslow" riding and driving coat, while Hallensteins came second in this category. English firms also took out prizes. Zealandia showed buggy rugs, waders and various styles of waterproof coats at the I89| Otago Agricultural and Pastoral Society show, ${ }^{31}$ and that same year won the letter carriers' tender for supply of waterproof overcoats with capes at 39 s each. ${ }^{32}$ 
By 1900, Lorie's, who were near neighbours and staunch competitors of Hallenstein's NZ Clothing Factory "Lorie's stores lead for boys' and men's clothing," they claimed - had well-established men's and women's Macintosh departments, making their own designs from cloth imported "from the best Glasgow and Manchester makers." "With the exception of the very cheapest ones, every coat is double sewn and finished with glaze to prevent the water from soaking up the inside or sleeves" - and they offered their designs with or without sleeves. The cloths were wool as far as it is possible to tell. ${ }^{33}$

It seems that firms in competition with Hallensteins were importing their waterproofed cloth from companies such as David Moseley and Sons, of Manchester, ${ }^{34}$ and making it up into garments in New Zealand. Thomson and Beattie of Invercargill were open about their practice in 1892, stating that they held a large stock of waterproof materials in the piece, ready to make up into "Golden Wheel Waterproof garments" that were double-sewn throughout, but still cheaper than imported garments because the imported ones paid 25 percent duty. ${ }^{35}$

Country and small-town retailers also imported garments themselves. Draper E. Dimant of Lawrence predicted: "A rush will in all probability be made for the parcel of Ladies'Waterproof Cloaks just landed. These goods are ... stylish - Waterproof, neat, serviceable, and wonderfully cheap, even from IIs 6d each. Electric lining, freely selling and much to be desired." ${ }^{36}$ And Penrose's Drapery of Timaru stated: "Grumbling "bout the weather is simply empty bosh; wiser far a hundredfold to don a Macintosh. We have 'em, prices 35s, 37s 6d, 45s, 55s for gents' macintoshes, ladies' macintoshes from 12s 6d to 60s." ${ }^{137}$

One advantage of New Zealand-made waterproof garments was that they were not perished by the voyage through the tropics. ${ }^{38}$ The Marlborough Express in 189 | claimed: "Not any fear of getting old stock, or a coat 'perished' by being imported, as they make up all their waterproofs and can safely recommend them. There is no danger of the garment coming to pieces as the coats are sewn throughout. Try the N.Z. Clothing Factory."39

Hallensteins advertised waterproof clothing made to order or off the rack at the DIC in Dunedin (their outlet for the upwardly mobile middle classes). ${ }^{40}$ In their illustrated catalogue of 1896, Hallensteins offered a range of new styles of ready-made men's, boys' and youths' waterproof and colonial tweed overcoats made "from all the newest and most reliable materials.' They also supplied patterns of waterproof coats and instructions for measuring to their country customers, so that they, too, could purchase "these indispensable winter garments by parcel post at city prices." ${ }^{\prime \prime}$ The catalogue showed the range as drawings on famous people of the day. A waterproof coat on Lord Salisbury, then British Prime Minister, was their McFarlane shape with a cape but no sleeves, suggested for riding, driving and walking, and available in a range of cloths and colours. Paul Kruger, State President of the South African republic, and the face of Boer resistance against the British during the Boer War of I899-1902, is shown wearing the Chesterfield and cape with sleeves, described as the most suitable coat for country wear. A new department offered waterproof ulsters to ladies, ${ }^{42}$ with patterns and self-measuring charts sent. Here the illustration featured $\mathrm{HRH}$ Princess Battenberg (Princess Beatrice, fifth daughter and youngest child of Queen Victoria) and two of her three sons (Alexander, Leopold and Maurice). ${ }^{43}$ Ulsters, with capes, had been available for women since the late 1870s. While the models had clear overseas pedigrees, the woollen and worsted fabrics were often from local mills such as Mosgiel, Kaiapoi and Roslyn.

New products, or at least new designs in existing materials, were developed, but it is hard to ascertain who thought of them first. Some coat designs were clearly so well known that the name alone told consumers what the garment looked like. Sargood Son and Ewen, established in Dunedin from 1869, ${ }^{44}$ offered their range of waterproof coats in 1898 in a charming catalogue.

The Paddock coat, a clever crossover of town and country, male and female, was a newish design in the late nineteenth century, although it is hard to determine where and when it was first created. It was a loose-fitting double-breasted coat with $2 \times 4$ buttons, flapped chest pocket on left front, flapped hip pockets, side back seams with pleats or vents. It had no side seams - just a vertical dart for shaping at each side, and no waist seam. Its sleeves were 

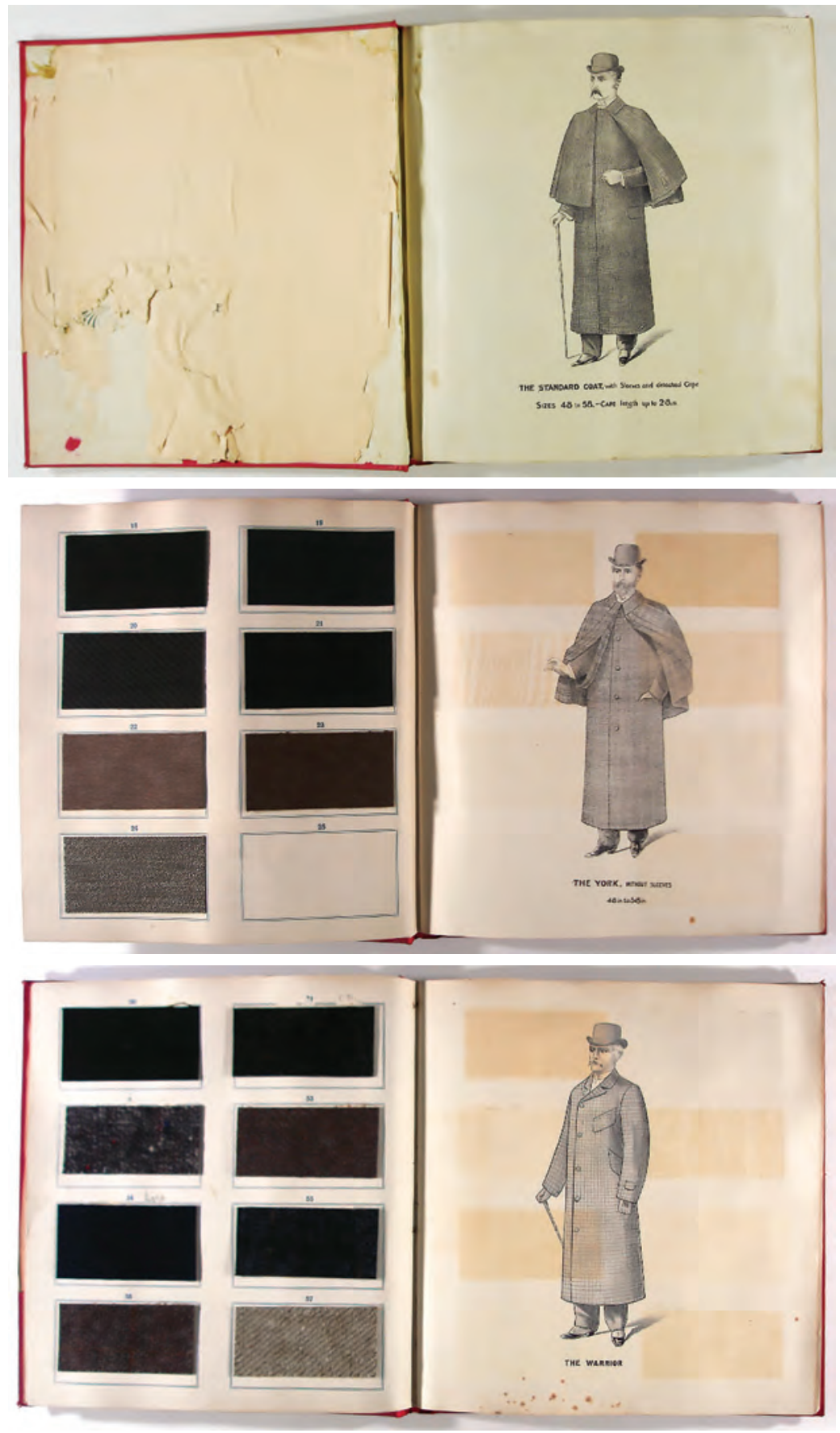

Figure 3a, 3b 3c. Selected pages from Samples of Waterproof Coats,

Sargood, Son and Ewen, Ltd, 1898.

Collection of Toitū Otago Settlers Museum, 1957//49/I. 
set in and loose fitting. ${ }^{45}$ Paddock coats were designed for sports and outdoor activities for both men and women, and usually advertised with macintoshes, oilskins and other "waterproof" items. The D.S.C. in Auckland had Paddock macintoshes, among other items, "selected by our London Buyer" " in 1898;46 George and Kersley of Wanganui had "Paddock Macintoshes" for sale in 1899;47 and James Smith, in Wellington, stated that they were in such demand that they had had been "compelled to supplement our first order."18

By the late nineteenth century, then, there was a flurry of activity surrounding waterproofing techniques, the supply of fabrics, the design of garments and the desire to protect customers from the elements. Despite early assessment and experimentation with plants endemic to New Zealand, European settler importers and manufacturers had supplied their fellow settlers from the northern hemisphere with less-than-stylish macintoshes, oiled waterproofs or thick heavy woollen overcoats. That these became prized garments was in part due to the variability of New Zealand's climate, as well as people's many outdoor activities. While some people did try home waterproofing, it seems, Hallenstein Brothers and others certainly attempted to develop techniques to waterproof quantities of fabric, and designed garments specifically for local conditions, albeit closely following European traditions. Competition among businesses drove improvements, fueled in part by the exhibitions that showcased business entrepreneurship. The most important thing was that increased availability of waterproof fabric, however and wherever it was made, meant that garment manufacturers could offer their town and country clients greater physical comfort and more protection in difficult environments. Perhaps they were also able to look more fashionable outdoors, either working or travelling. Entrepreneurship, business and marketing competition, technical and design innovation all combined to benefit both town and country consumers.

Jane Malthus is a dress historian and Honorary Curator for Dress at Otago Museum.

Moira White is Curator, Humanities at the Otago Museum, Dunedin. Her principal research areas involve the material culture collections of museums.

I Awhina Tamarapa, Whatu Kakahu/Maori Cloaks (Wellington:Te Papa Press, 20I I), 54, 55. "Flax - its Varieties," Daily Southern Cross, 16 June 1869, 5.

2 "New Zealand Flax," New Zealand Gazette and Wellington Spectator, 23 August I843, 3.

3 Penelope Byrde, Nineteenth Century Fashion (London: BT Batsford, 1993), 135.

4 www.britannica.com/EBchecked/topic/354755/Charles-Macintosh.

5 Valerie Cumming, CW Cunnington and PE Cunnington, The Dictionary of Fashion History (Oxford: Berg, 20 I 0), 277.

6 Byrde, Nineteenth Century Fashion, 135.

7 Phyllis G Tortora and Robert S Merkel, Fairchild's Dictionary of Textiles, 7th ed. (New York: Fairchild Publications, 1996), 623. The description provided to the USPTO for "Cravenette" was "Chemical Compositions for Processing Fabrics and Garments Made of Wool, Cotton, and Synthetic Fibers and Blends Thereof to Make Them Water Repellent," www.trademarkia.com/ cravenette-71690067.html.

8 Star, 18 November 1887, 2.

9 Mary Brookes Picken, The Fashion Dictionary, rev. ed. (New York: Funk and Wagnalls, 1973), 407. Gutta percha is a latex substance obtained from trees grown mostly in the Malay Peninsula. 
I I "Raincoat," How Products are Made, Vol. 6, http://www.madehow.com/Volume-6/Raincoat.html\#b\#ixzz I ut I sjpOa.

12 Farid Chenoune, History of Men's Fashion (Paris: Flammarion, 1993), 124.

13 Otago Witness, 25 October 1884, 27.

14 Daily Southern Cross, 29 April I843, 2.

15 Thomas Weston and Co. advt. in New Zealander, 17 July 1852, I.

16 TuapekaTimes, 20 May 1874, I.

17 Akaroa Mail and Banks Peninsula Advertiser, I5 June 1883, 2. The parcel also included black cashmere, black alpaca, black hose, black gloves and $1 / 2$ dozen cambric handkerchiefs.

I8 Hawkes Bay Herald, 16 June 1868, 2.

19 Otago Daily Times, 29 November 1882, 3.

20 Otago Witness, 6 January $1888,16$.

21 Otago Daily Times, 19 October 1874, 2.

22 Bay of Plenty Times, 19 September 1894, 4; Taranaki Herald, 24 August 1870, 3.

23 The Cutter's Practical Guide: Ladies' Garments (London:The John Williamson Company Ltd., n.d. [prob. I906], 23.

24 Otago Daily Times, 2 October 1889,6.

25 Otago Daily Times, 22 October 1889, 2.

26 Hallenstein Records, Hocken Collection Archives ARC-004I, AG 295-039/025.

27 Bendix Hallenstein correspondence, 8, 9 August 1889. Hocken Collection Archives ARC-004I, AG296. No mention of the explosion seems to have been made in the local press.

28 Otago Witness, 3 I March 1898, 33, reported that Messrs Levy, Guthrie and Co. had begun to produce waterproof materials on 14 September 1889.

29 "A New Industry," Otago Daily Times, 2 October 1889, 6.

30 Otago Daily Times, 4 February I890, 3. (Both Taylor and Tennant had links with Sargood Son and Ewen, another firm prominent in nineteenth-century Dunedin.)

31 Otago Daily Times, 28 November I89I, Supplement, I.

32 Otago Daily Times, 18 August 189I, 4. By 1900 Zealandia may have changed or morphed into the British and Colonial Waterproof Company, which, under the management of Mr John Tennant, provided waterproof sheeting for Boer War contingents (Otago Daily Times, 23 February 1900, 5).

33 Otago Witness, 3 May 1900, 21 -2.

34 Otago Daily Times, 9 March 1889, 5.

35 Southland Times, 8 October 1892, 2. According to an advertisement in the Southland Times, I | August | 89|, 3, "Golden Wheel Clothing" was the new brand for garments made in Thomson and Beattie's workroom.

36 TuapekaTimes, 6 April 1892, 3.

37 Timaru Herald, 26 May 1898, 2.

38 Marlborough Express, 5 June 1895, I.

39 Marlborough Express, II May |891, 2.

40 Bruce Herald, 7 December 1894, 3.

41 Hallenstein Bros., 1896 catalogue.

42 For example, in the Marlborough Express, 17 March 1894, 2, Hallenstein Bros. and Co. included ladies' macintoshes in the eight different shapes it offered at its NZCF Blenheim branch.

43 http://en.wikipedia.org/wiki/Princess_Beatrice_of_the_United_Kingdom.

44 Otago Daily Times, 9 February 1869, I.

45 http://en.wikipedia.org/wiki/File:Paddockcoatd_jan 1904.jpg and Norah Waugh, The Cut of Men's Clothes (New York: Routledge, 1964), 148.

46 Auckland Star, 24 September 1898, 7.

47 Wanganui Chronicle, 4 April 1899, 2.

48 Manawatu Standard, 17 April 1899, 2. 


\section{CRAFT AS A FASHION ACTIVIST PRACTICE}

\section{Stella Lange}

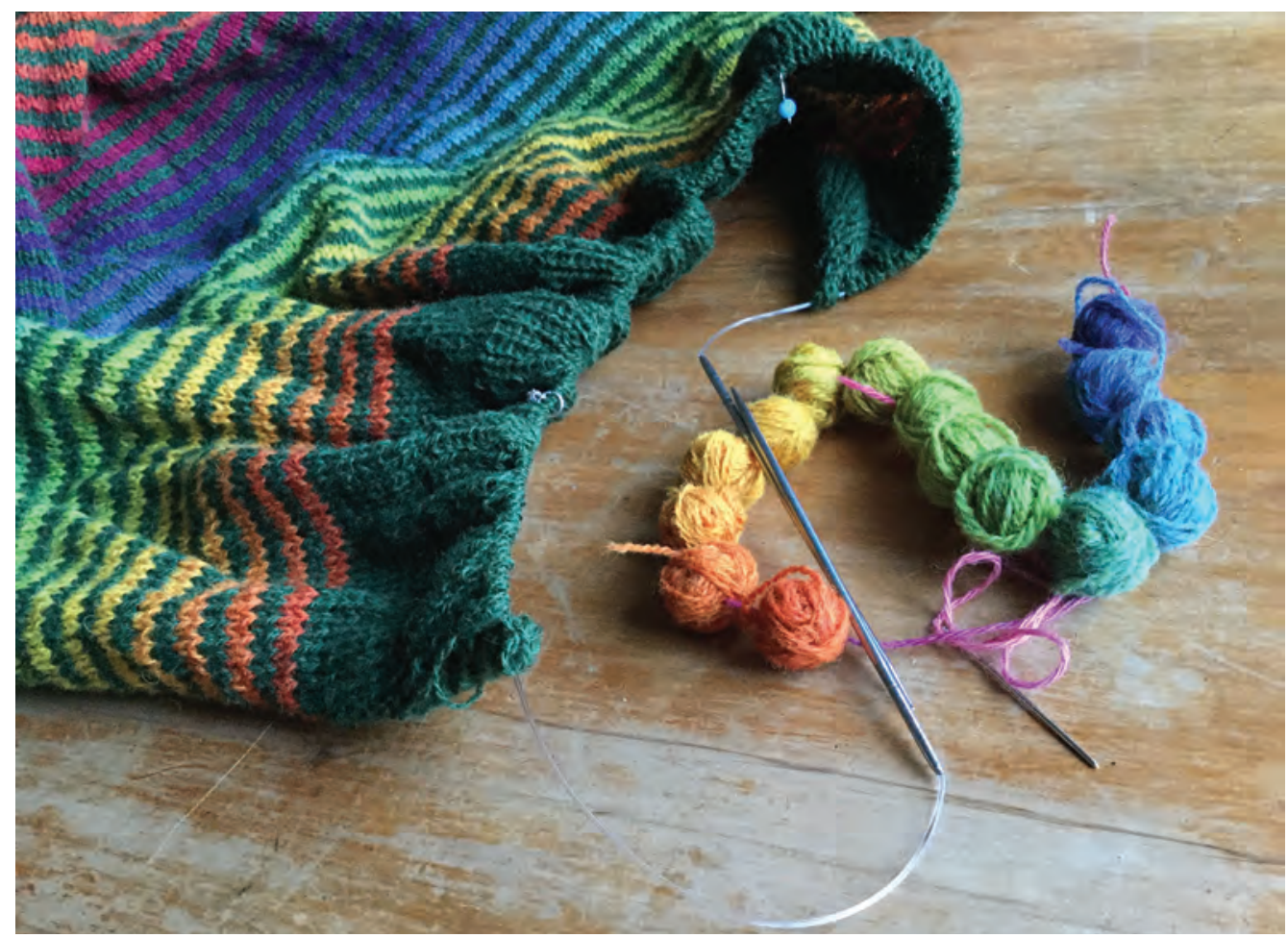

Figure I. Handknit in progress - customising colours to make a garment unique. Photo credit: Stella Lange, 2016.

Fashion is more than a commercial activity, more than a process of inspiration, design, production and distribution directed at consumers. Those called consumers have roles beyond consumption. Fashion is a dialogue between designers/producers and those who choose how to dress. Of the multiple viewpoints which can be used to examine "fashion practice," theories of "quiet activism" and craftivism have been little discussed. Fashion by its very nature illustrates and provides agency for wearers, a display of independent and free choice. Contemporary fashion is predicated on fashion designs being developed and then produced, marketed and distributed to the fashion public. The role of craft makers as fashion practitioners is little discussed beyond the role of the craft designer or craftsperson making for sale. One overlooked fashion practice is that of the craftsperson wearer. Positioning craft as part of a wearer's fashion practice, as craftivism, a deliberate activism, be it "loud" or "quiet," enables a consideration of alternative fashion practices. Those wearing fashion choose how they wear and maintain commercial fashion designs - and yet they are often categorised as mere consumers. My work has begun to tease 
out a form of fashion activism, undertaken by those who choose to work with fashion that sits outside of the design-production-distribution-consumption model. This is a practice of fashion where production is decentralised and more connected to the wearer and wearing. A fashion practice that signals a resistance to consumerism, in an authentic, and visible way - raising questions about how things are made and how we as people (not consumers) can create and maintain our fashion.

Fashion is defined by the Oxford English Dictionary as "a popular or the latest style of clothing, hair, decoration or behaviour," or alternatively as "a manner of doing something."The first definition seems far too narrow, too tight, too reliant on having just the right shoes or the right brand. The second definition - a manner of doing something - has more potential to describe the myriad of practices that constitute what fashion is. If fashion is a practice rather than specific items, a verb rather than a noun, then there is potential to discuss more nuanced kinds of fashion practice. When fashion is accepted as meaning more than having the 'right' bag, shoe or coat, then the potential to discuss practices that are used to create a fashionable identity is opened up beyond discussing the silhouette or colour of a particular item.

The traditional 'model' of fashion assumes that garments are designed and distributed within a system that is geared towards the commercial,' involving creation, production, promotion and selling. The thing 'sold' can be a garment, an image or aspirational fantasy. This model originated in the Industrial Revolution, when centralised production of textiles become the norm. Fashion became something offered to the buying public, something to be consumed. While this is still true for many fashion practices, there are legitimate fashion practices that lie outside or alongside these commercial systems.

Fashion, as a practice, provides agency, ownership of dressing and facilitates choices about the selection of garments, how they are worn and, beyond that, how things are maintained and cared for. Agency indicates an ability to act independently, to make choices without restriction. Fashion provides agency to both individuals and communities what is worn and how it is worn communicates a chosen identity. Amy Twigger Holroyd identified a type of fashion, "folk fashion," where wearers don't look to the high street for their wardrobe, but instead turn to craft in order to construct the kind of fashion they want to wear.?

As identified by Holroyd, folk fashion is a form that is not practiced professionally - rather, pieces are designed and made outside of the professional and industrialised system of fashion production and distribution. Craft occupies a significant space in Holroyd's folk fashion - knowledge and mastery of material selection, cutting, shaping, forming and finishing are all craft skills. Craftspeople differ from designers and artists in the fundamental principle that skilled individuals are at the heart of craft production. ${ }^{3}$ There is craft in conventional fashion - much fashion design utilises craft in the creation of new designs which are then outsourced for industrial production, while some niche products are designed and made by skilled craftspeople to be sold to a fashion public. The difference with folk fashion is that pieces are crafted by the 'folk' who wear them - not by industrial means or by craftspeople producing items for sale. Craft in this context refers to the practices used to make items individually, as opposed to the mass manufacturing processes employed to create huge numbers of identical products for commercial sale.

Craft has been discussed in various contexts - in terms of the mastery of form and process, ${ }^{4}$ its relationship to art, ${ }^{5}$ and in relation to history and theory. ${ }^{6}$ In my work, craft is seen as both a fashion practice and as activism. (A fuller discussion, debating nuanced definitions of craft, is thus outside the scope of this piece.)

Twigger Holroyd discusses the various reasons why wearers choose folk fashion. For some, it is about the act of making; for others, it reflects a desire to have something that fits their unique body or style; and for many it is a rejection of the limited offerings in style, colour and fit offered by the dominant fashion supply chains. When craft is used to create individual fashion, there is visible evidence that the crafter has autonomy over what they make and what they make visible to the world. Where these practices, fashion and craft, come together in craft fashion, each wearer displays their autonomy in their fashion choices. 


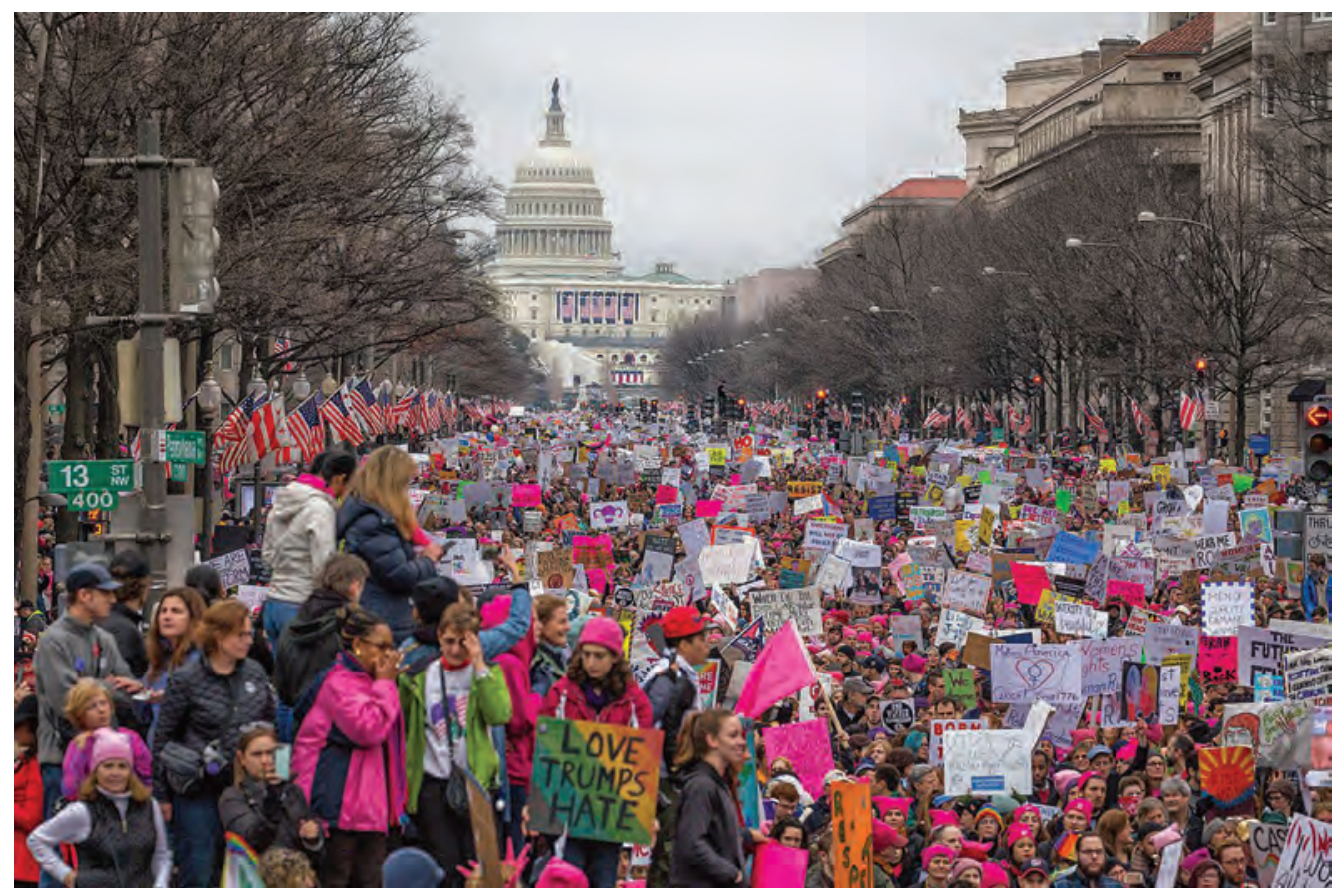

Figure 2. The Women's March on Washington (2I January 20 I7), discussed by Black (20 I7), an example of "loud activism," required the commitment to protest publicly, and required time, transport and a willingness to be identified in person and potentially in wider media coverage. Photo credit: Mobilus In Mobili - Women's March on Washington,

CC BY-SA 2.0, https://commons.wikimedia.org/w/index.php?curid=55796823.

Like fashion, activist practices undeniably provide agency to both individuals and communities. Activism is typically presented as visible protest. Activism seems most recognisable when it is loud, involving public demonstrations by individuals and communities in protest. However, activism, in many forms, can also be found operating at much quieter volumes, and these quieter voices deserve recognition as activist practices. Betsy Greer describes quiet activism and observes that "assertive" acts of activism are less attractive to many people.?

Shannon Black takes this a step further and discusses the gendered and social bias present in more visible and louder acts of activism. "Black theorises the "costs" of visibly "assertive" acts of activism, which she calls "loud activism" - for example, the Women's March on Washington held on 21 January 2017 (Figure 2). Taking part in visible displays of activism requires not only a desire to become involved, but also temporal, economic and societal considerations. For some, the time, cost and notoriety that accompany visible activism is beyond their personal agency.

Laura Pottinger discusses how activism is embedded in seed saving and sharing by gardeners, calling for "embodied activism at varying volumes" to be recognised, explaining that the power of these tiny and almost hidden acts of making and doing is that they "critique, subvert, and rework dominant modes of production and consumption."'10 Deliberate choices to construct and wear fashion that has not been mass-manufactured, distributed and sold to be consumed can be considered an activist practice.

To understand how craft fashion practices can be a form of activism requires understanding the theory behind "design activism." Design activism considers the way things are conceived, made and used. Alastair Fuad-Luke outlines three ways that activism is visible in design - anti-activism, slow activism and green activism." In anti-activism designers reject dominant or imposed practices, while slow activists seek to negate the expectations around rapid 
change that accompany contemporary life. Green activists prioritise ecological choices. Each of these pathways describes a way to understand and analyse activist practices - but, importantly, they can also be used to identify and describe quiet activist craft fashion practices.

When used as a fashion practice, as an activist practice, craft allows for a gentle engagement that is no less authentic than the more visible and louder activist approach. Unlike these more visible forms of social activism, craft, in the form of quiet activism, has the potential to resonate with a wider range of people than noisier disruptive action.

Craft fits comfortably alongside theories of leisure and fashion. Acts of craft and acts of fashion both require what are often considered luxuries - of time, space, and materials or money. Craft, and fashion, seen as a leisure activity, is something done to 'relax' and is very much considered part of the practitioner's identity.

Like fashion practitioners, many craft practitioners have a growing awareness of how their practices can be positioned as a response to consumerism. This is driven in part by increased awareness among consumers of the environmental and social damage of the increased consumption of what are called consumer goods, material possessions. Fast fashion has been identified as one site of visible over-consumption; ${ }^{12}$ what is unclear is the extent to which fashion consumers can recognise the difference between fast fashion and post-industrial commercial fashion production in general. While academics discuss and debate alternatives to fast fashion, ${ }^{13}$ how widespread this distinction is among ordinary fashion practitioners is not known.

It is important to recognise craft as an activist act and at times as an activist fashion act. By its very nature craft activism, like design activism and fashion activism, contests the conventions that determine how things are made. Craft fashion throws the spotlight on working conditions and highlights the disruption between the mechanised and the humanised worlds of production (Figure I). Craft hints at a viable alternative to global supply chains. Craft positions some of its labour in a domestic space and in so doing cast a shadow over the way that industrial products are made. Lisa Lou has articulated this point: "The story and the way things are made is very important, it is part of the meaning ... I don't think you can separate the meaning from how things are made. ... if we do that, then what we do is negate labor, and the people that are part of a process."'14

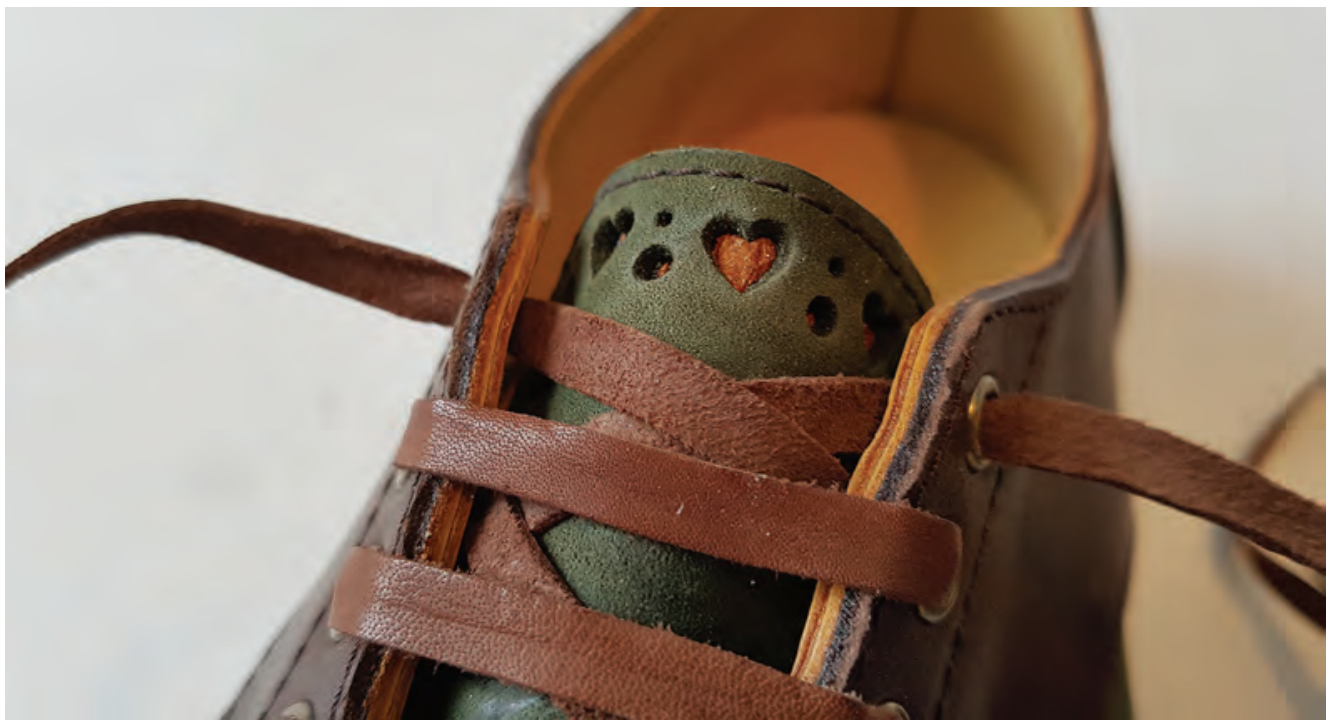

Figure 3. Hand-crafted shoe. I crafted this as a participant at Shoe School (http://www.shoe-school.com),

a workshop for handmaking shoes. Participants are guided through the process of designing and crafting a pair of handmade shoes - a very deliberate commitment of time and money. Photo credit: Stella Lange, August 2016. 
Craft fashion can be positioned in the space that Fuad-Luke calls "half-way products," items partially made and intended to be finished by the consumer. In disrupting the conventional manufacture process where objects are provided to consumers in a competed state, craft materials can clearly become activist products. This finishing by the consumer, the crafter of the intentionally half-made product, allows the labour to be partly supplied by the consumer - and in this way all craft can be positioned as an activist practice. ${ }^{15}$

Beyond simple labour, craftivism also signals a resistance to how things are made and, beyond this, how things are maintained. Bratich and Brush explain that watching someone knit garments, fashion garments, reveals alternatives to mass production. ${ }^{16}$ Garber describes craft as "a human microphone of makers and viewers." ${ }^{17}$ The simple act of crafting - by its very difference from the alternatives - is a deliberate choice (Figure 3). If the craft itself is the microphone, then the article works as the sound - amplified by the act of being made outside of a factory. The internet provides examples of crafted fashion as an alternative to mass-produced offerings, and the potential to be an example itself.

Activist practice focuses on the way that the craft space presents an alternative to the factory sweatshop for producing domestic textiles. Black cautions against the blank acceptance of craft being used in activist efforts ${ }^{18}$ - and this is right, but there is always a sub-element in craft where someone is rejecting a dominant consumer approach to life. Fuad-Luke ${ }^{19}$ describes activism as "thinking, imagination, and practice applied knowingly or unknowingly to create a counter-narrative aimed at generating and balancing positive social, institutional, environmental and/or economic change."

Fuad-Luke discusses the role of the artefact in activism, highlighting how "demonstration artefacts" reveal alternatives. Craft or folk fashion provides evidence that mass-manufactured and commercial fashion is not the only option. As a time-consuming act, crafting highlights the deliberation, the planned decision to create or modify fashion artefacts instead of purchasing readymade.

Importantly, according to Fuad-Luke, activism can be an unconscious act; individuals may feel a need, or a sense of unease to which they are responding, without being able to fully and clearly articulate their reasons and underlying concerns. Even when fashion crafters do not recognise or name their crafted work as activism - by its very rejection of a dominant mass-production mode - craft fashion is still activism.

Industrialised and globalised production of much of the 'stuff' we use, and the branding myths associated with it, are often at odds with individual experiences and ideas. In New Zealand we are told that our merino comes from our beautiful high country, yet we find labels indicating that the garments were not produced here. New products are marketed as slow fashion - thus solving the problem of rampant consumerism - and yet require us to purchase and consume them. According to Fletcher and Grose, up to 80 percent of the environmental cost of a garment occurs during the ownership period, not during production, so careful shopping alone won't provide the solution. ${ }^{20}$ As consumers, we are urged to be conscious shoppers, to be informed about our choices. Retail activism is distinctly at odds with anti-consumerism, and so creates a dilemma. How can individuals align with anti-consumerism and yet own industrialised and mass-produced products?

Craftivism answers the question, what does anti-consumerism look like?

In the Western world, consumerism is a dominant theme of the twentieth and twenty-first centuries. Many historians trace this back to Bernard London's influential 1932 essay which sought to resolve the economic slump of the 1930s. ${ }^{21}$ While many other factors have contributed to the growth of widespread consumerism, London's concept of planned obsolescence influenced developments in industrial production and product life. The central idea of London's plan was to stop making items that were durable, and instead design and produce items that had a limited life. This approach was key to long-term employment in both retail and industry. We no longer live and dress in a world where buying fashion products provides much-needed employment - instead, we are now facing the consequences of overproduction, and buying less is the new goal - an approach promoted as part of slower fashion. ${ }^{22}$ 


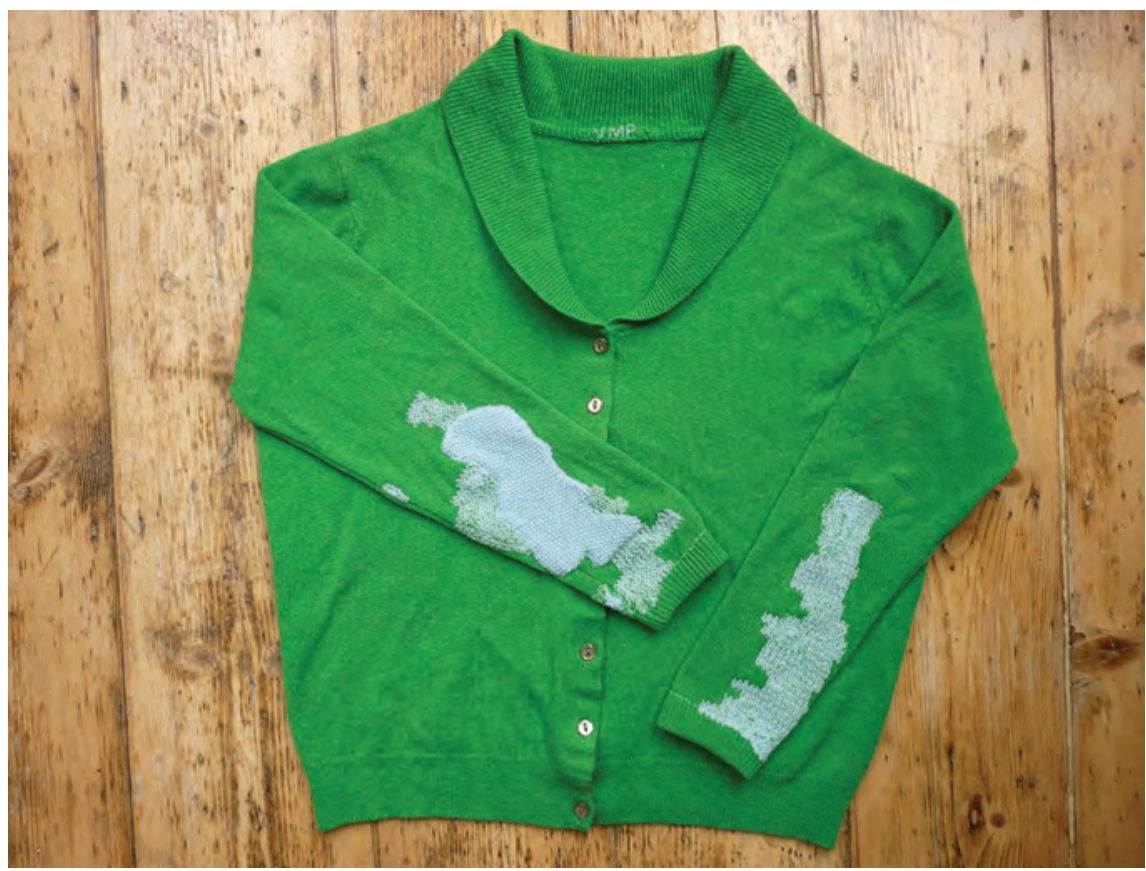

Figure 4. "The Visible Mending Programme \# I I,THAT Green Cardigan,"

27 January 2012,TOMOFHOLLAND, https://tomofholland.com/20 I2/0 I/27/the-visible-mending-programmeI I-that-green-cardigan/ (before and after). Reproduced with permission from https://tomofholland.com.

Perhaps the term 'consumer' itself needs to be questioned - consuming implies acts of using, of finishing and, implicitly, of needing replacements. Many forms of design activism reject the idea that people are consumers; instead, the goal becomes not to consume, but to reduce the act of consumption. This style of activism takes many forms - Reduce, Reuse, Recycle, Repurpose and, what is often the missing R - Repair. Crafting and craftivism offer partial solutions that fit with contemporary lifestyles.

Garber points out that for many in craftivism, the act itself is more important than the thing being produced. ${ }^{23}$ Repair can be seen as both a personal act of activism and as a more publicly recognisable act of anti-consumerism. Repairs say clearly:"I didn't go shopping" and "This is my slow fashion."

Buying second-hand is also an alternative to consumerism - but can be far less visible. Where fashion is curated in consignment shops - specialist boutiques which broker the selling of privately owned fashion garments - there is nothing to communicate that the item was not bought new. Because older or vintage second-hand garments can look different to current fashion offerings (in style or fabrication), wearing such garments can be examples of activism. Mending and repair - both in the act of practice and in the act of display - are more likely to communicate activist choices and values to others.

In our incredibly connected world, and via the social media mechanisms that allow individuals to find and connect to others with whom they share ideas, in presenting their acts of repair and of crafting, individuals - beyond being actors - can provide tangible, visible evidence that they 'did something.' In his Visible Mending Program (VMP), Tom of Holland does just that. Tom van Deijnen (his real name) is an influential textile repairer, regularly interviewed in the Guardian and invited by Burberry and Selfridges to work with their brands to highlight the craft of repairing. Tom's online presence highlights both making and mending - his VMP project showcases a craftivist approach to owning garments. (Figure 4). 
Mending and its twin, repair, has a long social history. The meaning of repair has shifted significantly over the later twentieth century. As crafivist acts, repair and mending have shifted from the secret and private domestic sphere into a more visible, public space. Even when an item is one that would not usually be visible when worn - like the socks in Figure 5 - the evidence of acts of repair can be very public.

In addition, details of how the repair was made are often spelled out, as in the blog post series by Hunter of Pantsville Press about "that cardigan." 24 Figure 8 represents one of thousands of images online which present what appears to be a how-tomend tutorial, but which can also be read as a demonstration, a permanent and public capture of an act of quiet, authentic craftivism, of repair.

These acts are authentic as they result in change but, unlike other activists strategies like protests, they do not demand that others change what they do. The Pantsville Press blog also presents other visible acts of repair, where garments are stitched and either the process or the result is presented publicly (Figure 6). In New Zealand, at Sew Love, Sarah Lancaster and her a vintage camper van, Cecil, kitted out with solar-powered sewing machines, tours the country offering equipment, lessons and clothing repairs on the spot (Figure 7). For Sarah, "teaching people how to mend their own clothes is a form of empowerment for the consumer, rather than buying more."

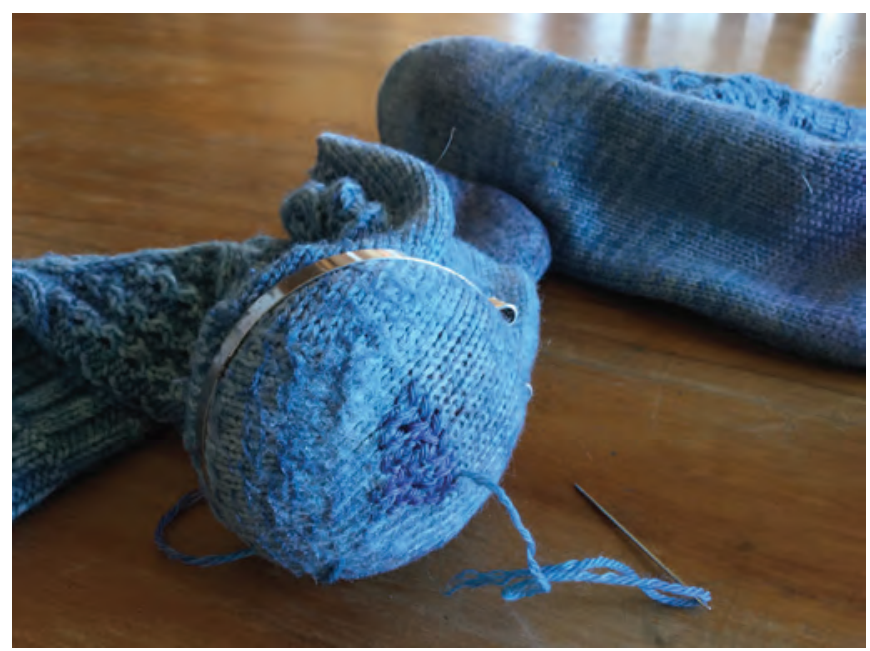

Figure 5. The author's visible mending in action. Photo credit: Stella Lange.

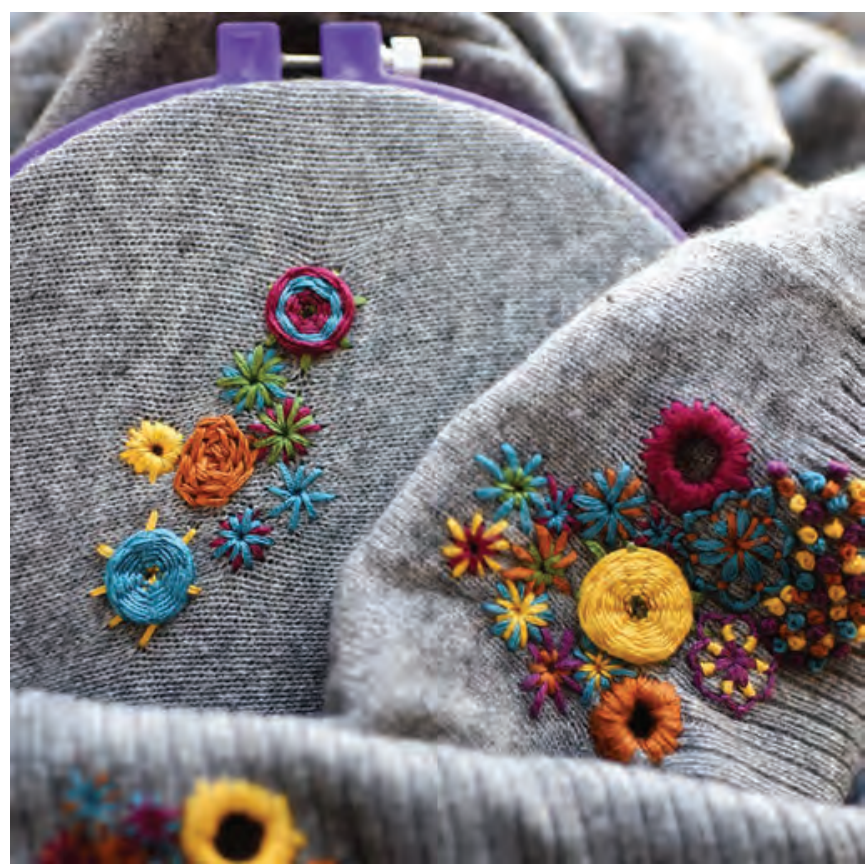

Figure 6. One example from Pantsville Press of a visible act of mending, a decorative and communicated act of craftivism.

Reproduced with permission from https://pantsvillepress.com (retrieved 12 August 2019) 


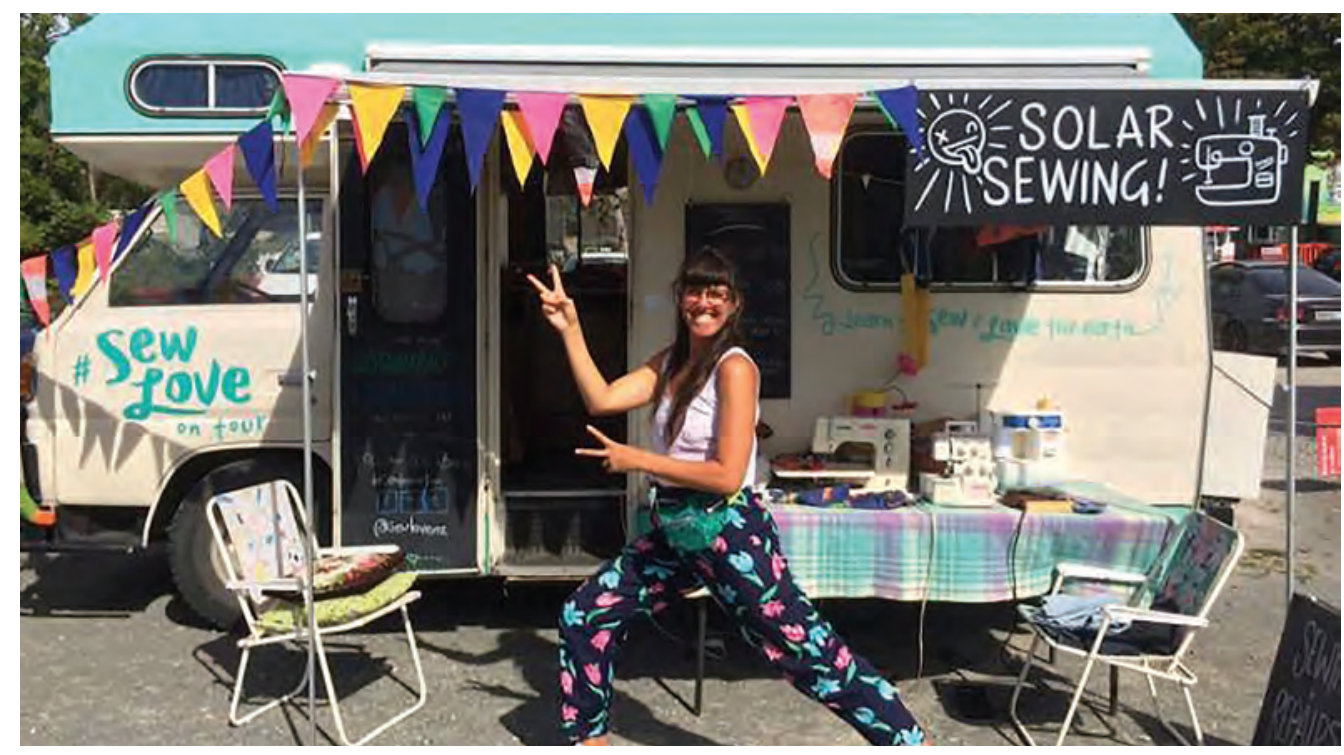

Figure 7. Sarah Lancaster actively promotes and educates others in repair and making to empower consumers around New Zealand using Cecil, her solar-powered mobile home fitted out with multiple sewing machines.

Reproduced with permission from image owner (retrieved 12 August 2019).

Locally, in Dunedin, New Zealand, Fiona Clements, of Señorita AweSUMO, runs make-and-mend sessions every month from her workshop, Just Atelier. These practioners are not alone - many others promote and showcase craft-based approaches to modifying fashion, as demonstrated in person and online.

Within craft there are hierarchies, separations by skill, by material, by approach. Some repairs are informed by the repair practices of others, and draw on history. Mending work in the style of boro and kintsugi are sympathetic to a quiet activist approach in that they are highly decorative. Boro is a form of visible repair once employed in Japan by the very poor - it is often grouped with sashiko. Both are a type of embroidery that uses running stitches and are now popular as a decorative method of stitching and mending. Katrina Rodabaugh's Mending Matters is one of many books, print and online articles that provide "a slow fashion guide for a well-loved wardrobe."'25 In these publications, the primary focus is on the act - the act of repair overshadows any story about the garment or other benefits of mending. The garment becomes a site of activism, of craftivism, of quiet craftivism.

These examples are not isolated, but are drawn from a wider pool of authentic craft activism, of visible activism - craftivist actions recorded online that provide evidence of a rejection of consumerism. Contemporary repair practices signal a resistance to consumerism in an authentic and visible way - raising questions about how things are made, and how we as people (not consumers) can create and maintain our fashion.

Stella Lange (10000-0002-3676-433I) is a Principal Lecturer at the School of Design, Otago Polytechnic, working with undergraduate and post graduate students. Stella'a research looks at the care and repair of domestic textiles, and social expectations of textile repair in 20th Century New Zealand. Her practice is primarily textile based, primarily hand knitting, extending to spinning, stitching and weaving but includes drawing and writing. 
I Nicola White and lan Griffiths, eds, The Fashion Business: Theory, Practice, Image (Oxford: Berg, 2000).

2 Amy Twigger Holroyd, Folk Fashion: Understanding Homemade Clothes (London and New York: IB Tauris, 20 I 7).

3 Colin Gale and Jasbir Kaur, “The Craftsperson," in their The Textile Book (Oxford: Berg, 2002), 63-75.

4 David Pye, The Nature and Art of Workmanship (London:The Herbert Press, 1968).

5 Peter Dormer, The Culture of Craft (Manchester: Manchester University Press, 1997).

6 Richard Sennett, The Craftsman (New Haven, CT:Yale University Press, 2008); Howard Risatti, A Theory of Craft: Function and Aesthetic Expression (Chapel Hill, NC: University of North Carolina Press, 2007).

7 Betsy Greer, Craftivism: The Art of Craft and Activism (Vancouver, BC: Arsenal Pulp Press, 20I4).

8 Shannon Black, "KNIT + RESIST: Placing the Pussyhat Project in the Context of Craft Activism," Gender, Place \& Culture, 24:5 (2017), 696-710, https://doi.org/l0.1080/0966369X.2017.1335292.

9 Laura Pottinger, "Planting the Seeds of a Quiet Activism," Area, 49:2 (20 I7), 215-22, https://doi.org/ I0.1 I I I/area. I 23 I 8.

10 Ibid., 215.

I I Alastair Fuad-Luke, "Key Design Movements," in his Design Activism: Beautiful Strangeness for a Sustainable World (New York: Earthscan for Routledge, 2009), 203-13.

I2 Kate Fletcher and Lynda Grose, Fashion and Sustainability: Design for Change (London: Laurence King Publishing, 20 I2); Alison Gwilt and Timo Rissanen, eds., Shaping Sustainable Fashion: Changing the Way We Make and Use Clothes (London: Routledge, 20 I I), http://www.amazon.com/dp/I 8497I24I7; Safia Minney, Slow Fashion:Aesthetics Meets Ethics (Oxford: New Internationalist, 2016).

13 Kate Fletcher, "Slow Fashion: An Invitation for Systems Change," Fashion Practice, 2:2 (20 I0), 259-65, https://doi.org/ I0.2752/I 756938 I OXI 2774625387594.

14 Liza Lou, cited in Jessica Hemmings, "Liza Lou: Shifts in Aspiration,” Surface Design (spring 2017), 32-7.

15 Ibid.

I6 Jack Z Bratich and Heidi M Brush, "Fabricating Activism: Craft-work, Popular Culture, Gender," Utopian Studies, 22:2 (201 I), 233-60; Hemmings, "Liza Lou."

17 E Garber, "Craft as Activism," The Journal of Social Theory in Art Education, 33 (2013), 53-66.

18 Black, "KNIT + RESIST."

19 Fuad-Luke, "Key Design Movements."

20 Fletcher and Grose, Fashion and Sustainability.

21 Bernard London, Ending the Depression through Planned Obsolescence, 1932, http://upload.wikimedia.org/wikipedia/ commons/2/27/London_\%281932\%29_Ending_the_depression_through_planned_obsolescence.pdf.

22 Michael Clarke, "Exhibition Review - Madeleine Vionnet: I 5 Dresses from the Collection of Martin Kamer," Fashion Theory, the Journal of Dress, Body, and Culture, 6:3 (2002), 323-6; Fletcher, "Slow Fashion."

23 Garber, "Craft as Acivism."

24 "Done! Er...for Now... | Pantsville Press," https://pantsvillepress.com/2018/I0/I8/done-er-for-now/ (accessed I3 August 2019).

25 Katrina Rodabaugh, Mending Matters: Stitch, Patch, and Repair Your Favorite Denim \& More (New York: Harry N. Abrams, 20 8 8). 


\section{DIFFERENT SHADES OF LIFE: A PEDOGOGY OF LIVED EXPERIENCES}

Rekha Shailaj

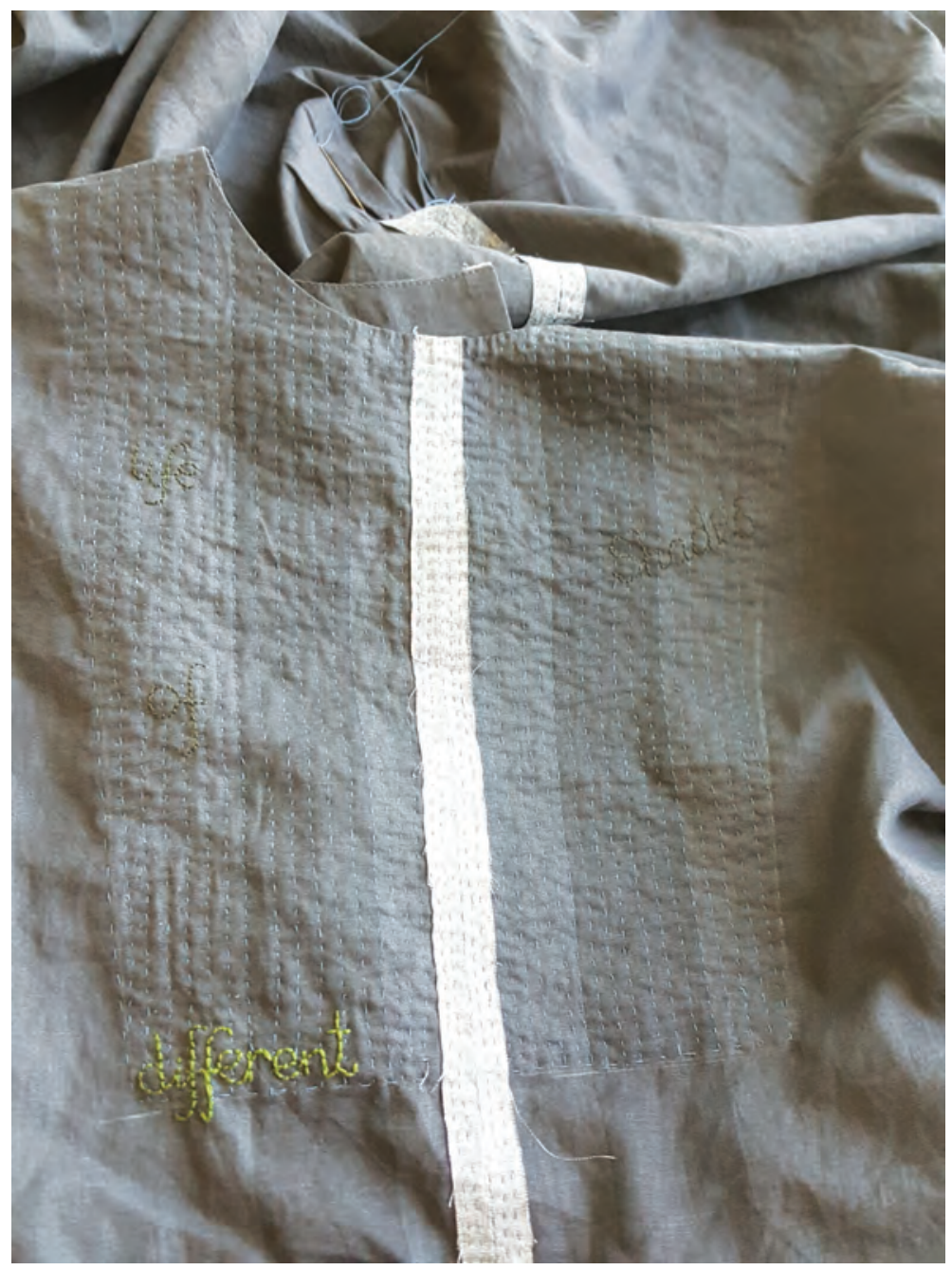

Figure I. Different shade of life dress, with embroidery and running hand stitches; a near zero-waste design. 


\section{INTRODUCTION}

There is a sense of unsettledness that some people feel as an emotion which brings them face to face with a strange method of working with their creative impulses. The research process itself becomes complex, vast and muddled. Having lived in countries other than my birthplace for the past 23 years, I have assessed my life experiences as an immigrant, traveller, nomad and a restless global citizen. I was born in India and immigrated to New Zealand in 1996. Since then, I have travelled to the Middle East twice to live with my husband and returned back to New Zealand, my adopted homeland. My research is grounded in personal experiences of living as a migrant, traveller and a nomad. In this body of work, The Different Shades of Life, I aim to unfold my life within my spatial existence constituted by the "Third" space: "The notion 'Third' refers to the constructing and re-constructing of identity, to the fluidity of spaces, to the space where identity is not fixed and as such is a feature of any kind of spatial existence."' Homeland, lived experiences, movement across spatial boundaries are some of the key ideas that embody the dichotomy of placement/displacement that I have used to conceptualise my design practice. I am aware that I exist and live my life in the "Third" space, where I feel unsettled and settled at the same time.

As a researcher, I want to make sense of the world I live in, the knowledge I gain from my experiences, and the social reality I face. These perceptions are changing as I travel the globe and seek to be settled in a place, whether it is my birthplace or somewhere other. The phenomenological human science methodology articulated and developed by Max van Manen in his book Researching Lived Experience underpins my research. I reflect phenomenologically on my lived experiences in order to grasp the pedagogical essence of meaningful experiences. The work of German-Jewish philosopher Vilém Flusser, specifically his books The Freedom of the Migrant and A Philosophy of Design, underpins my research rooted in lived experience. Flusser was a German-Jewish philosopher from Prague who fled in 1940 to Brazil where he was a professor of the philosophy of communication and wrote a daily newspaper column. In 1972, he moved to France and wrote books in both German and Portuguese.

In what follows, indented text by Vilém Flusser is followed by my interpretation and synthesis of Flusser's text into my creative work. I have contextualised my work, which lives on the cusp of differences, within Flusser's philosophy of being a migrant.

As we occupy and travel through spatial dimensions, such as our motherland, adopted homeland, faraway lands or travel routes, our experiences within each one and their phenomenological mix mark our journeys through these spaces. We become permanent travellers gathering temporal, transient experiences that come to life through the touch of a stimulus. The connectivity between these different experiences and their associated stimuli results in infinite patterns that are reflected in our lived bodies, time, space and our relationships with others. These reflections on my lived body, lived time, lived space and lived relationships underpin my research process as design practitioner.

Van Manen regards these four existential elements (lived body, lived time, lived space and lived relationships) as helpful guides for reflection on the research process. "These four existentials of lived body, lived space, lived time and lived relation to the other can be differentiated but not separated. They all form an intricate unity which we call the lifeworld - our lived world."2

As a lived body, we experience clothing through the feel of fabric on the skin, the feel of space between the garment and the body, and through the physical changes in the body. Natural materials echo the natural skin, and the lived body embraces them unconsciously. My understanding of lived time is built on my reflections on the past, present and future dimensions of my life. My lived experiences of the past surface in my present as memories and shape my future as their signification affects the choices I make in my present.

For van Manen, "the house is the location of our shared lived space, the home."' As an immigrant, I experience my lived space to extend beyond the home and homeland to connect with Flusser's concept of Heimat. For him, "the English home does not fully encompass the German Heimat, which allows for connotations such as home, homeland, and region 
(of one's origins), often accompanied by notions of nostalgia, even myths." ${ }^{4}$ Flusser believes that there is a need for us to reconfigure our houses, as they are becoming sites where the "noise" that characterises them is not translated into experience. "Experience is noise that gains meaning only in the habitual, that is, is therein transformed into information."

A house should be conceived of no longer as an artificial cave but rather as a bending in the field of interpersonal relations ... to which relationships are attracted as to a magnet. An attractive house of this sort would gather relationships, process them into information, store the information, and then forward or redirect it to others. A creative house would be a node in the network of interpersonal relations. ${ }^{6}$

The attempt to blend my Indian culture with my adopted Western culture is disrupted by my experiences of travel between the motherland, my adopted homeland and potential nomadic lands where I have lived intermittently. As a result, it is hard to mark my Heimat as a singular place. My lived relations with others form the foundation of my Heimat. This conceptual Heimat - without land, roof, floor, doors and windows - is shaped by interpersonal relationships across the globe.

"If he is not to perish, the expellee must be creative."

As a migrant it is hard to define my homeland, where I can say I have been habituated to normal surroundings or, in Flusser's words, where the blanket of habit covers and protects me. I am forced to choose the country I should live in and make my home. The motherland feels distant and alien, but so does my adopted homeland. It is hard to settle down in one place. This feeling of unsettledness has led me to retreat into my creative space, the "Third" space where my craft exists and I feel most settled and happy.

\section{EXILE AND CREATIVITY}

Here is the hypothesis I propose. The expellee has been torn out of his accustomed surroundings or has torn himself out of them. Custom and habit are a blanket that covers over reality as it exists. In our accustomed surroundings we notice only change, not what remains constant. Only change conveys information to a person who inhabits a dwelling; the permanent fixtures of his life are redundant. But in exile everything is unusual. Exile is an ocean of chaotic information. The lack of redundancy does not allow the exile to receive this information blizzard as meaningful messages. Because exile is extraordinary, it is uninhabitable. To be able to live there, the expellee must first transform the information swirling about him into meaningul messages; that is, he must process the data.This is a matter of life and death. If he is not able to process the data, he will be swamped and consumed by the waves of exile breaking over him. Data processing is synonymous with creation. If he is not to perish, the expellee must be creative?

After many years of living as a migrant my lived experiences, accumulated in my motherland, have surfaced and increasingly so as I have removed myself from that habitat. It is an extraordinary situation, where the experiences of the past are felt and relived with various extensions to the real, and hence have transformed into new entities. This directs our attention to Flusser's idea that the expellee must be creative and he must process the data. These taken-for-granted experiences surface from the past, and one feels them being lived again in new settings. According to van Manen, we appropriate the meaning of lived experiences from the past, and it is difficult to understand the depth of these experiences as they implicate the totality of life.

I regularly explore the depth of my sartorial experiences of the past specific to my Indian culture and recreate them in the present. Van Manen suggests that "lived experiences gather hermeneutic significance as we (reflectively) gather them by giving memory to them. Through meditations, conversations, day dreams, inspirations and other interpretive acts we assign meaning to the phenomena of lived life."' 
My qualitative research methodology underpins the pragmatic approach, whereby humans are capable of shaping their experiences. Their reality resides in the process that evolves and undergoes change as life unfolds itself. As a researcher, I an aware that my focus is not so much on the methods I use, but rather on the transformative nature of my design process which is informed by social reality. Hence, I find that I often need to work with a variety of research methods including reflexive, reflective, narrative/storytelling, interpretive/contextual, and iterative action approaches.

\section{EXPERIENCE}

Flusser explicates the notion of experience in relation to our passage through life. He questions whether our movements as we step out of the door and return back home through the same door constitute an experience. "We go out into the world to experience, and we lose ourselves in the process; we then return to find ourselves again, and we lose the world that we experienced."' He prods us to conceive the process of experience, not as moving from the present into the future, but instead as the future coming to meet us in our present. "We experience the world not because we move out into it but because it approaches us."10

Nevertheless, it is not simply the case that what we experience always streams in on us. In fact, we often go out and gather in what there is to experience - go looking for it. Everything that surrounds us - and we ourselves - is bathed in an unfathomable mystery, and we are able to experience only those aspects of the mystery that approach us, concern us. Ever since we have learned to think phenomenologically instead of historically, experience has become something that approaches and concerns us."

What is a lived experience? How can we understand and attach pedagogic value to a lived experience? Van Manen states that "phenomenological human science begins in lived experience and eventually turns back to it."'2 Wilhelm Dilthey explains that "the reality of lived experience is there-for-me because I have reflexive awareness of it, because I possess it immediately as belonging to me in some sense. Only in thought does it become objective."'13

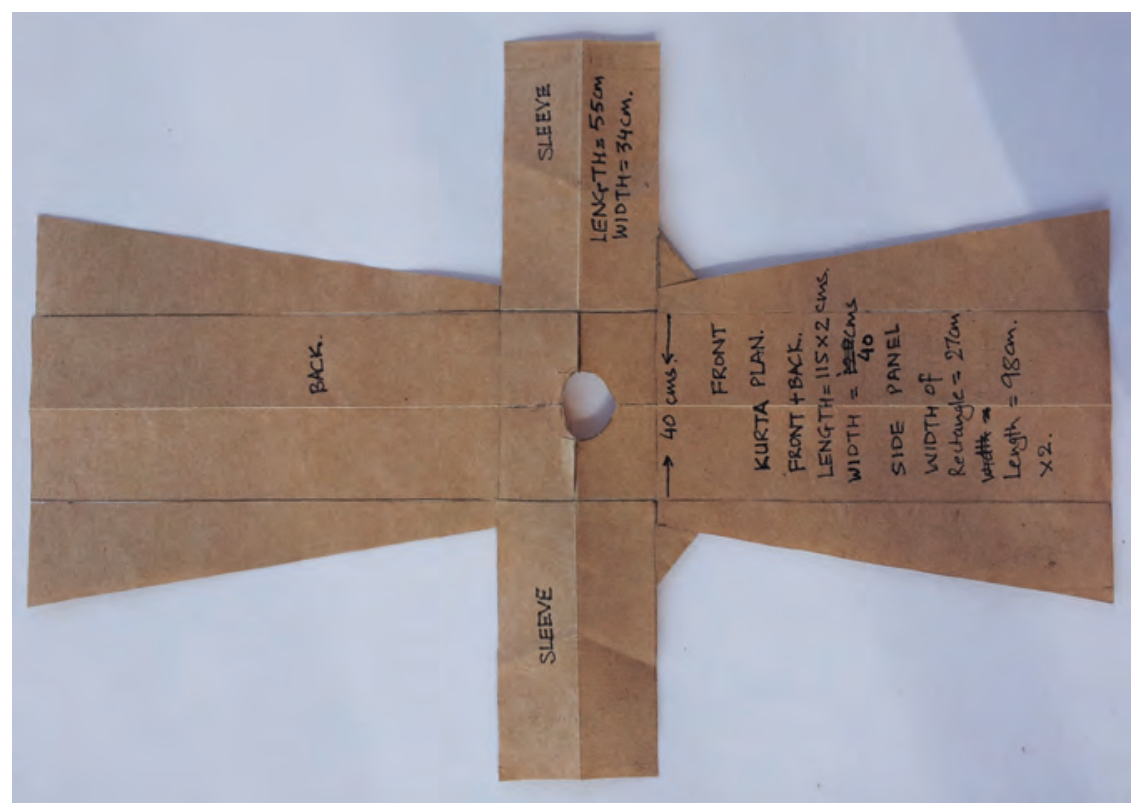

Figure 2. Top view of paper pattern for a kurta, showing panel lines and neck opening. 
Lived experiences come to life in our present when we assign them memory, reflection and meaning. Assessing and analysing my sartorial experiences requires a textual practice and a pedagogic orientation to the lived experience. Clearly, I am emotionally invested and interested in these experiences.

One such experience is that of my mother making clothes for us to wear. On reflecting back, I realise that at the time she did not use paper patterns. She calculated the measurements in her head and drew the pattern directly onto the fabric. Indian tailors and designers call this localised technique table-cutting. At the time, I could not understand her method of working. However, today I have connected with this experience and drawn from it to create fashion designs. The use of numbers and geometry is essential to this method of designing. The technique heavily relies on the use of panels. A basic rectangular shape is cut into two panels, using diagonal lines. These new shapes are trapezoids that can be rotated and swapped to join the rectangular shapes. A trapezoid is a four-sided enclosed shape with a pair of parallel sides. In Figure 2 these trapezoids are attached to the central rectangular piece and constitute the front and the back of the traditional dress or kurta. The sleeves are made up of rectangular shapes, and triangular gussets provide ease around the armhole.

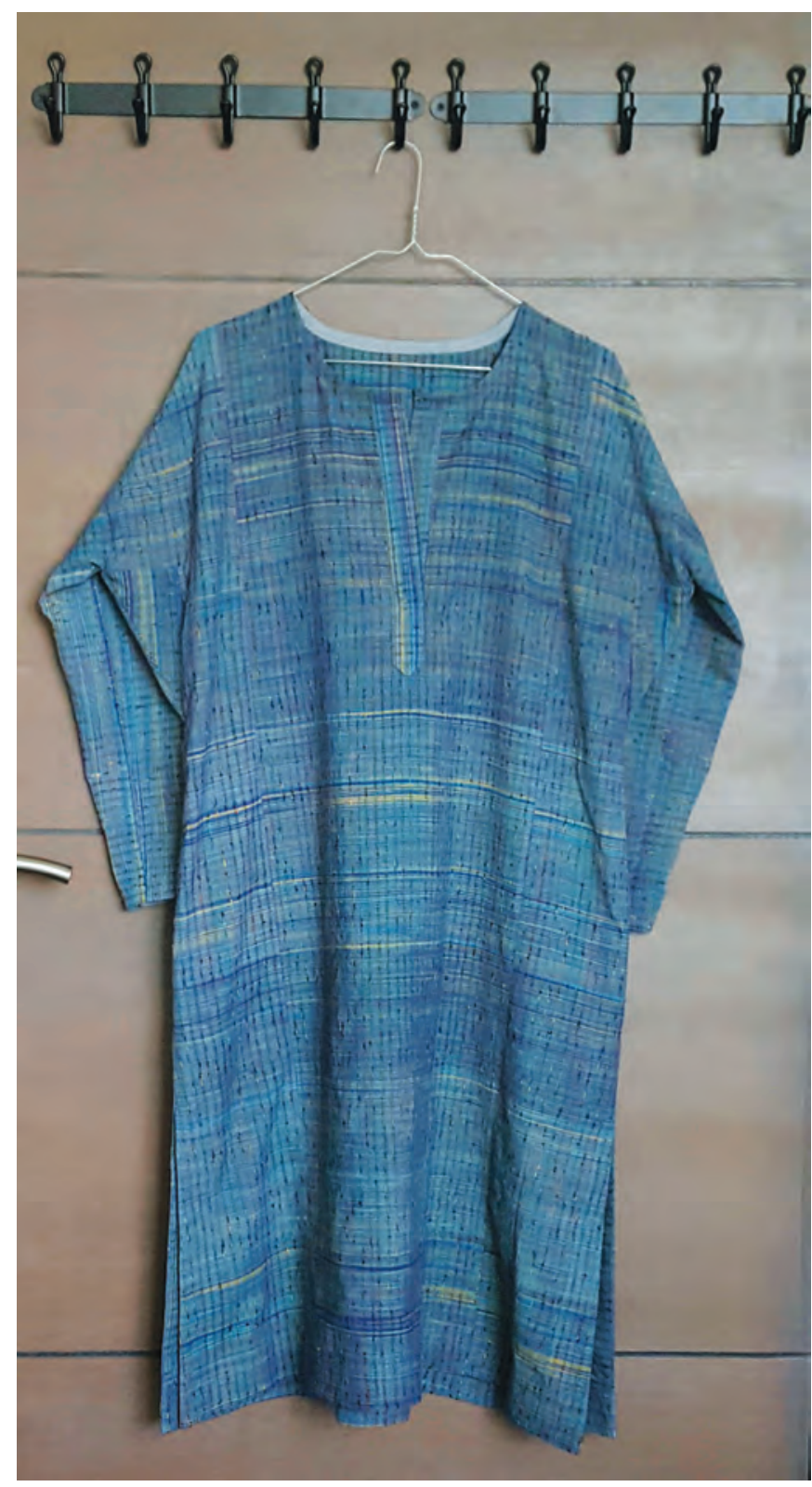

Figure 3. Kurta design with shoulder slope.

A near zero-waste design from 2019 (Figure 3) utilises a clever arrangement of different geometric shapes. The design is embedded in and inspired by past memories of wearing khadi kurtas and making an activist statement through sartorial choices. The fabric (khadi) is woven on a handloom, complete with imperfections, giving it textural value. Living away from my homeland for the past 23 years, I feel starved of these traditional Indian textiles; however, 


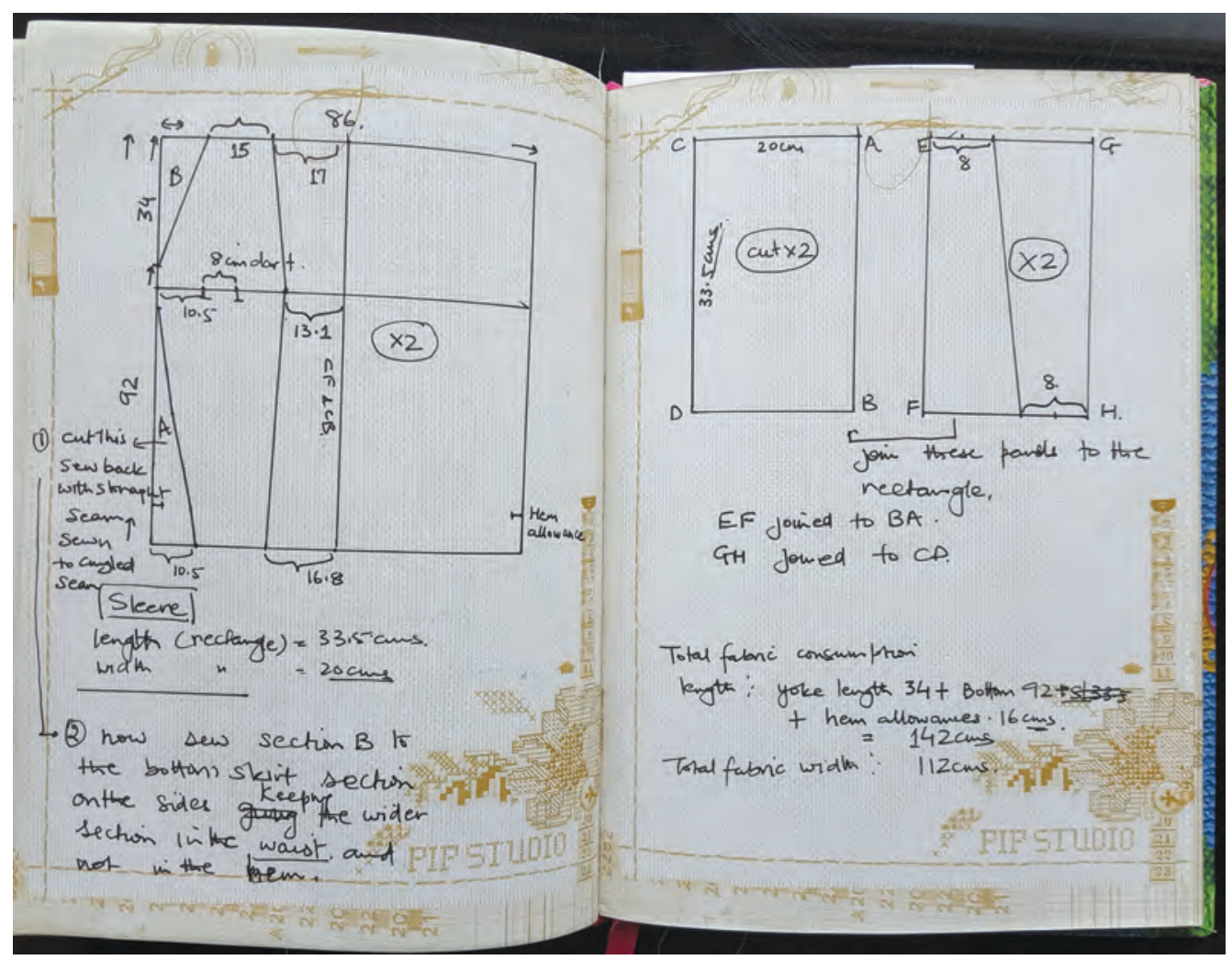

Figure 4. Detailed design notes from my design diary.

I cannot easily source these specialist fabrics today. My husband's niece gave me this fabric as a gift, several years ago. When I received it, it became one of my treasures and it took several years to incorporate it in my designs. I could have made something contemporary with it; however, I chose to use the traditional kurta design in a quest to connect to my past identity, which is still alive somewhere in the crevices of my eclectic identity. Its making was contextualised as I moved to Bahrain for a year to live with my husband. I came closer to my birthplace and visited my family in India for a period longer than usual.

Today, I have recreated the traditional look of the kurta using design methods that achieve minimum fabric wastage using techniques that are familiar to me from the days when I experienced my mother's table-cutting methods. I have now added to her techniques and transformed them, giving them a special character. Citing Dilthey, van Manen states: "Lived experiences are related to each other like motifs in the andante of a symphony. Dilthey talked about 'structure' or 'structural nexus' as something that belongs to a particular lived experience (something like a pattern or unit of meaning), which becomes part of a system of contextually related experiences, explicated from it through a process of reflection on its meaning." 14

The only limitation of the kurta design is the lack of shoulder slope. As soon as the shoulder slope is built into the design using traditional patternmaking techniques, it creates wastage of fabric. However, the use of clever geometry allows for a shoulder slope and neck opening without fabric wastage (Figure 5). I have developed many designs using this technique, involving playing with the diagonal cut line that echoes the shoulder slope by rotating and swapping the left/right and front/back panels (Figures I, 5, 6 and 8). 
The designs become more complex as the panel lines increase in number and as the sleeves, pocket bags and facings are cut using the panelling technique. This method of designing is process-driven and relies heavily on a robust system of making notes, drawing scaled-down versions of design drafts, and toiling on a small scale before the design is tested full scale. Any alterations to the design drafts will produce different silhouettes. The patternmaking process depends on cutting out templates for neck and armhole openings, and draping procedures.

This design system forced me to find meaning in the method and the process. While the method and process is partly rooted in traditional ethnographic techniques, it is also dependent on innovative and scientific ways of calculating, recording, making, altering and experimenting. The iterative actions used in designing are based on both definitive figures and imaginative, unpredictable silhouettes. This underlines the need to engage in many design iterations to find different solutions.

\section{WE NEED A PHILOSOPHY OF EMIGRATION}

Humans are contingent beings because their movements are directed along certain pathways by natural and cultural things in their surroundings. To be contingent means being surrounded by things that steer the movement of the contingent being along certain pathways. There is in their surroundings one place without things. This place that is free of things may be called the ironic. When we take an ironic stance, we are afforded a clearer view of our contingence. The movement into irony is an act of outrage. And with this motion a person rises above contingence. Movement away from irony is a form of engagement. With this motion the person returns to his state of contingence to change it. These two movements taken together are called freedom. I could also call this outrage in irony "emigration" and the reverse movement out of irony (engagement) "immigration." ... in my outrage I emigrate out of one contingence to immigrate into another, but my emigration is not only a matter of outrage; it is also a form of flight. Is a person free simply because he is able to flee? ${ }^{15}$

As an emigrant and immigrant, the pathways I left and chose 23 years ago are still partially contingent. The circumstances of that contingence are always in flux, seeming to transform with the passage of time. The feeling of normalcy that comes with permanence is missing. The roots that ground you in a place are weak. It is the irony of being faced with the possibility of another round of movement that causes one to vacillate from an emigrant to an immigrant position, that makes a contingent being more of a nomad. To choose another homeland is possible only under certain circumstances, and to return to the existing one is dependent on how well one can adapt to changed circumstances. Both options are fraught with contingencies. This practical stage of taking flight from and landing in multiple homelands (all different in some respects) creates a sense of unsettledness. Do I have the potential to make something out of this unsettledness? While the "natural things" that Flusser identifies keep me grounded in any chosen homeland, the different "cultural things" push me into the in-between spaces, the interstices where I find comfort in unsettledness. Following an ideology that explains the expelled, unsettled being, I work with contradictions and conflicts, such as traditional/unconventional, original/borrowed, clarity/ambiguity, high/low. Flusser point out that "we are all expellees to the extent that we unsettle ourselves, when our seatedness in habit is continually exorcised." 16

When I engage in fashion design, my work is generally informed by nostalgia for my motherland and its traditional clothing, textiles and techniques. These original design references transform into unconventional outcomes as I start applying borrowed ideas from different lived cultures. Consequently, the design process becomes complex and ambiguous. Unless I stop and articulate it, the sense of vagueness intensifies.

The design process transcends the non-availability of traditional tools. It adapts to unconventional materials and processes such as paper in place of fabric, hand-sewing in place of machine-sewing and draft notes in place of paper patterns. The complexity of visualising different shapes and forms according to geometry informs the design process. Practical movements, such as displacing, swapping, rotating the different components of a design ensemble, are used 
as a technique to alter the form and shape of clothing design. As a result, the designs are different and strange to the wearer.Wearers react with confusion - this is not normal experientially. These designs are not rooted in convention, tradition and sartorial norms. It is almost as if they are seeking references to and appropriation of elements from different cultures and echoing the unsettledness that I experience as a global dweller.

My garment designs resemble the silhouettes of objects such as sacks, tents, barrels and bubbles. They allow for the body, space and the garment to be experienced by the wearer in their phenomenological existence. I wear my 'tents' when I want to be comfortably moved between spaces, distance, time, 'sacks' when I want to hide from the external gaze, and 'bubbles' when I am experiencing temporality.

The design process for my dresses (Figures 5-8) started with sourcing fabrics. I discovered the fabrics in a huge pile of discounted cotton bedsheets in a supermarket. I started to deconstruct these fitted sheets by unpicking the seams and the elastic sewn into the seams. The focus moved to repurposing these nearly thrown-away bedsheets. The organic move of unpicking lent itself to hand-sewing stitches, raw unfinished edges, the repurposing of the discoloured edges as trims and hand embroidery as key elements that became integral to the designs.

As my research progressed towards the concept of preservation, restoration and upcycling, my designing followed the path of emotional engagement with my experiences and memories of making ethnographic clothing and craft. The reconditioned textiles were transformed into panelled dresses with different silhouettes including tents, bubbles and cocoons. My aim was to use the material with near-zero wastage. As designing progressed, new techniques involving the use of geometric shapes and angled lines developed to conserve the fabrics.

As I move further into the realms of unsettledness, it is the act of self-preservation that most clearly articulates the narrative of sustainability.

\section{CONCLUSION}

Do I seek to be bound by the Heimat and a concomitant sense of rootedness, or liberated from my Heimat into unsettledness? My design methodology thrives on the creativity that comes with the freedom of an immigrant who weaves her connections with others, occupies her "Third" space and surrounds herself with conscious temporal experiences. It is the dichotomy of settled and unsettled state that is important for my creative work. While creativity resides in the "Third" space of the Heimat, and it is very settling to be creative, this creativity is born of the unsettled state. This creativity is alive, transforming and never settled. As I keep travelling in an unsettled state seeking the Heimat, I will only be settled through my creativity. As Flusser states, the expellee should have the potential for making something out of their unsettledness. As a creative designer, I seek the habitual associations of the known home so that I can receive "noise" as "information," and so that I can produce information even though my Heimat has become conceptual and formless. 


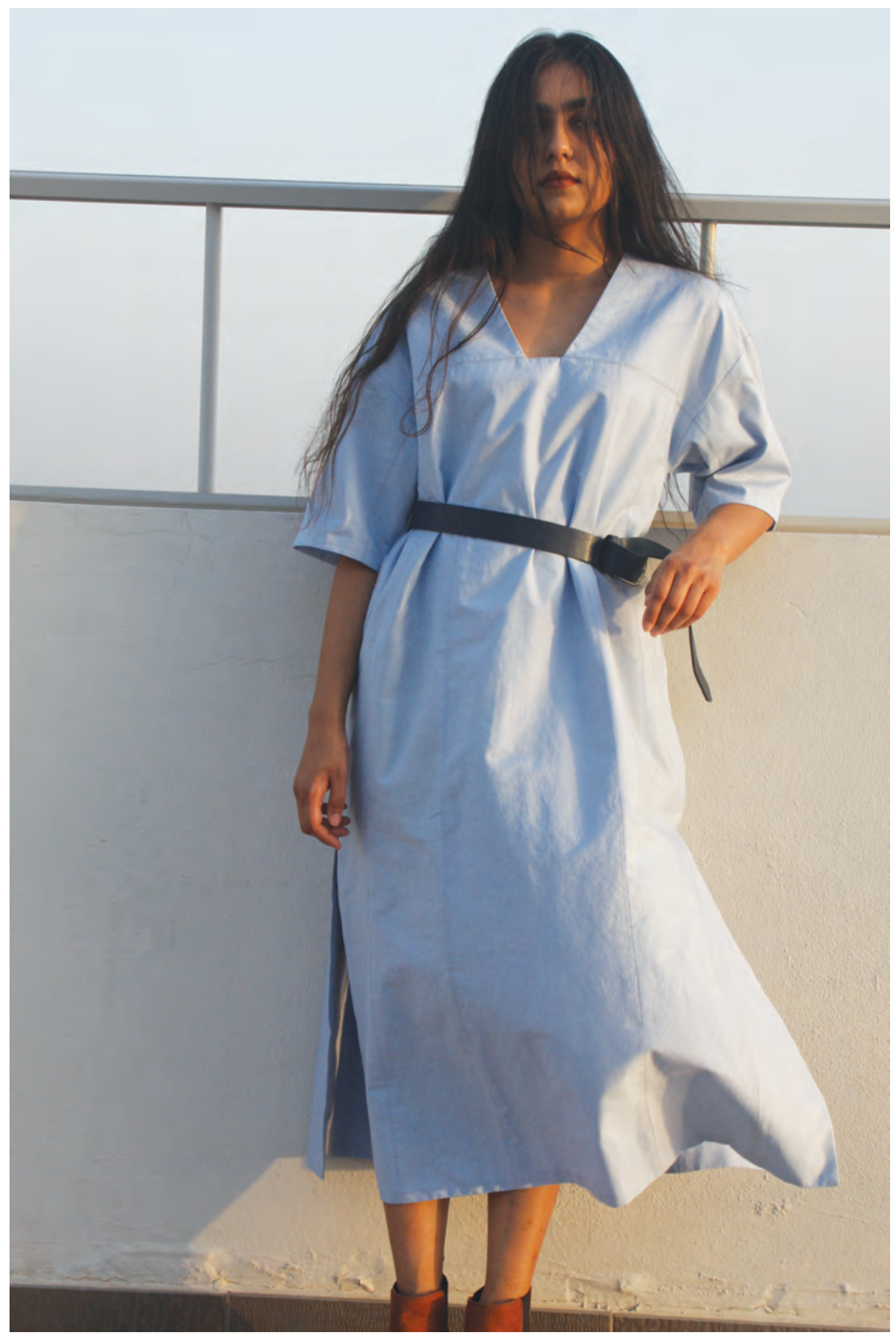

Figure 5. Long kurta dress with near-zero fabric wastage;

what wastage there is derives from the marginal sleeve-head shaping. 


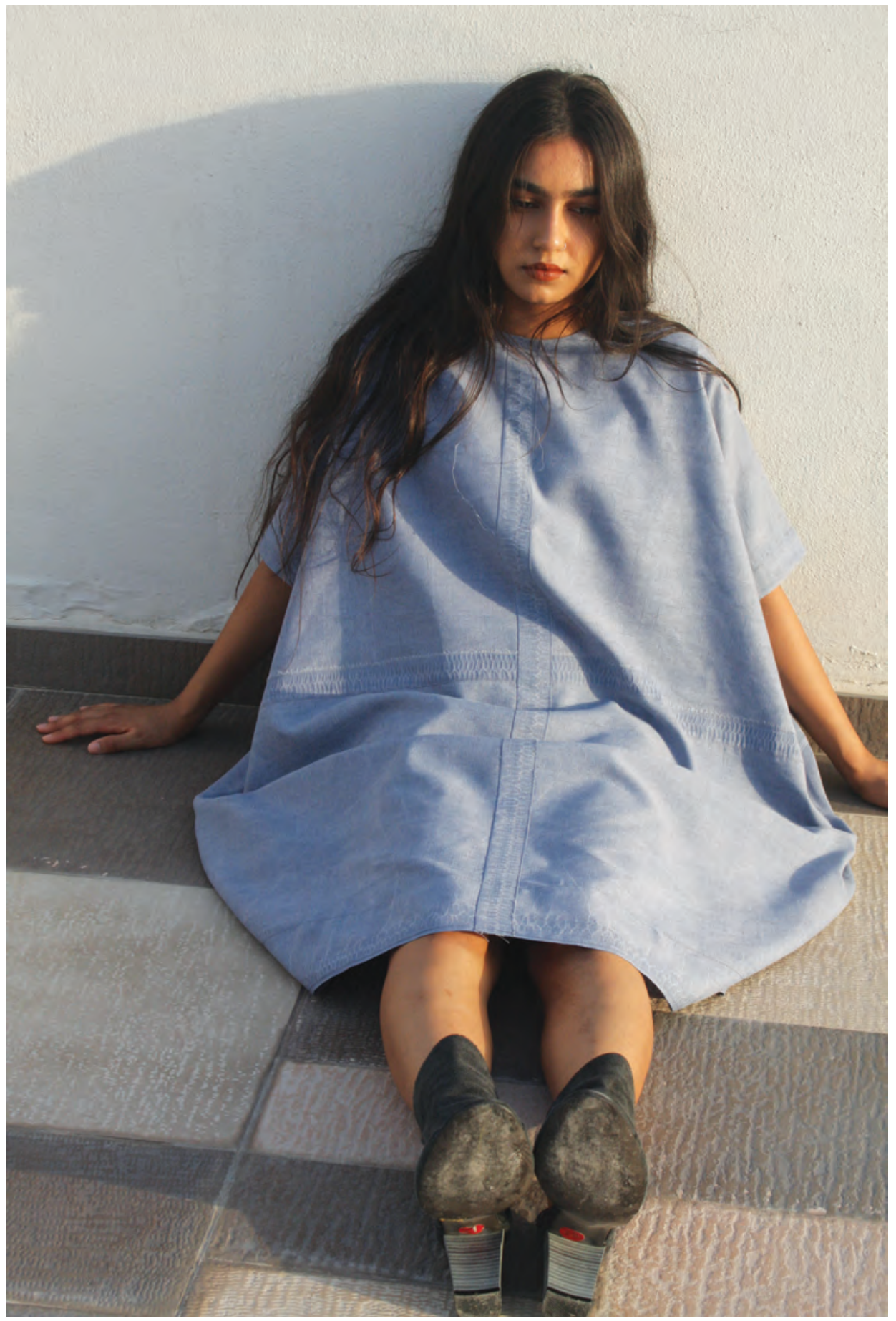

Figure 6a.The Cocoon dress (front and back views), a near zero-waste design; any waste occurs at the neck opening. 


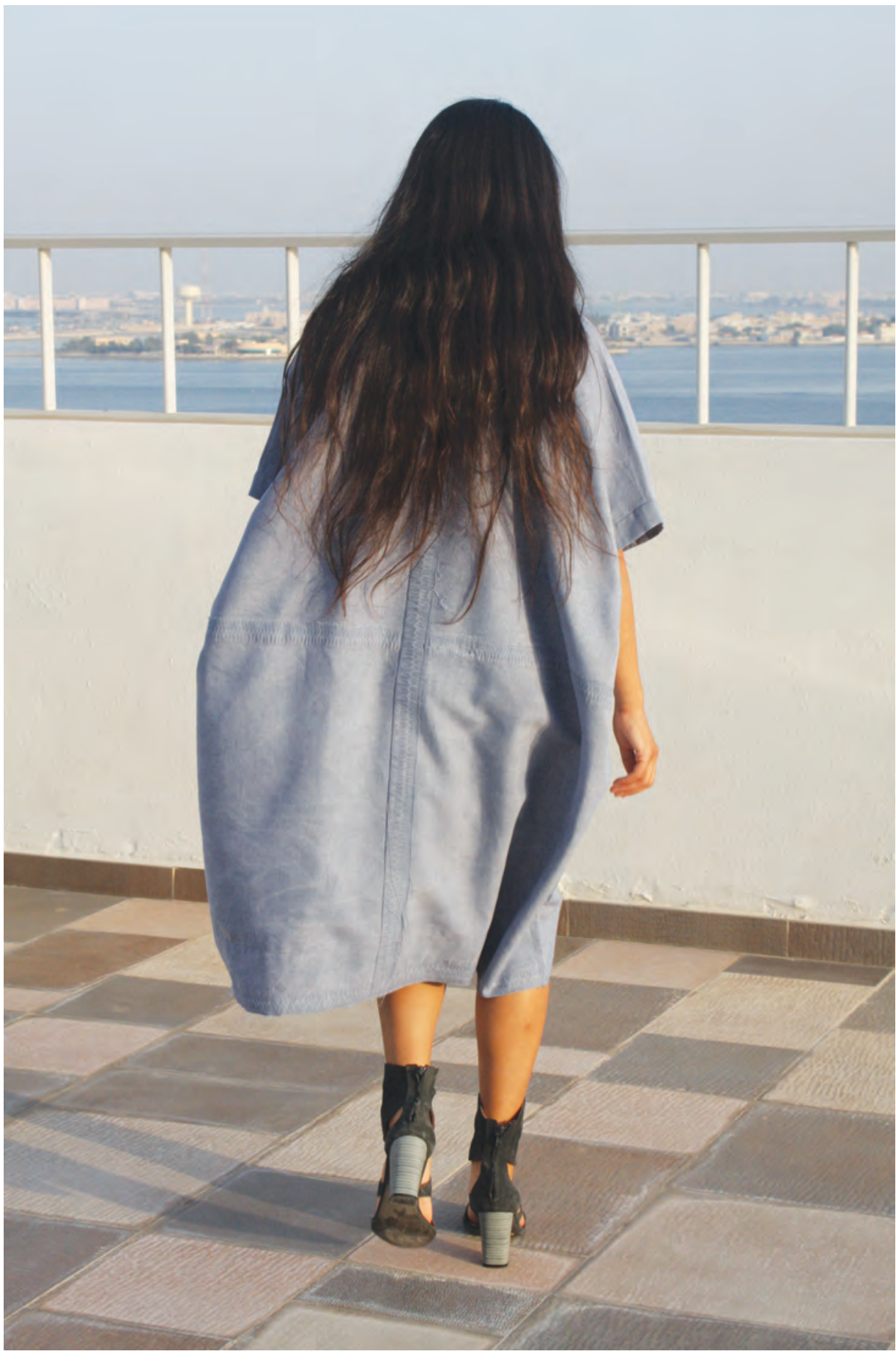

Figure 6b.The Cocoon dress (front and back views), a near zero-waste design; any waste occurs at the neck opening. 


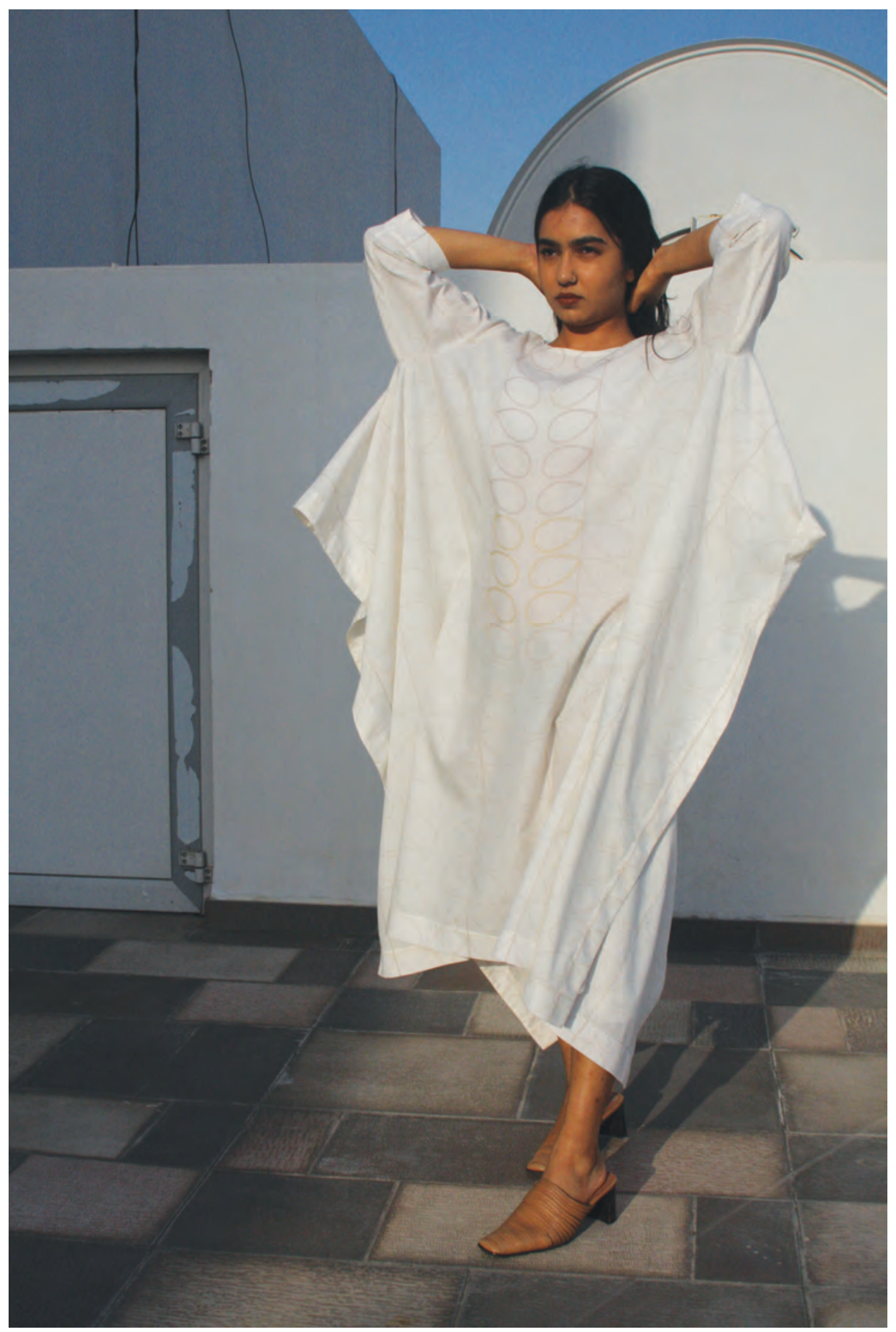

Figure 7a. The Tent dress, with embroidered front panel and open side seams. Near zero-waste design. 


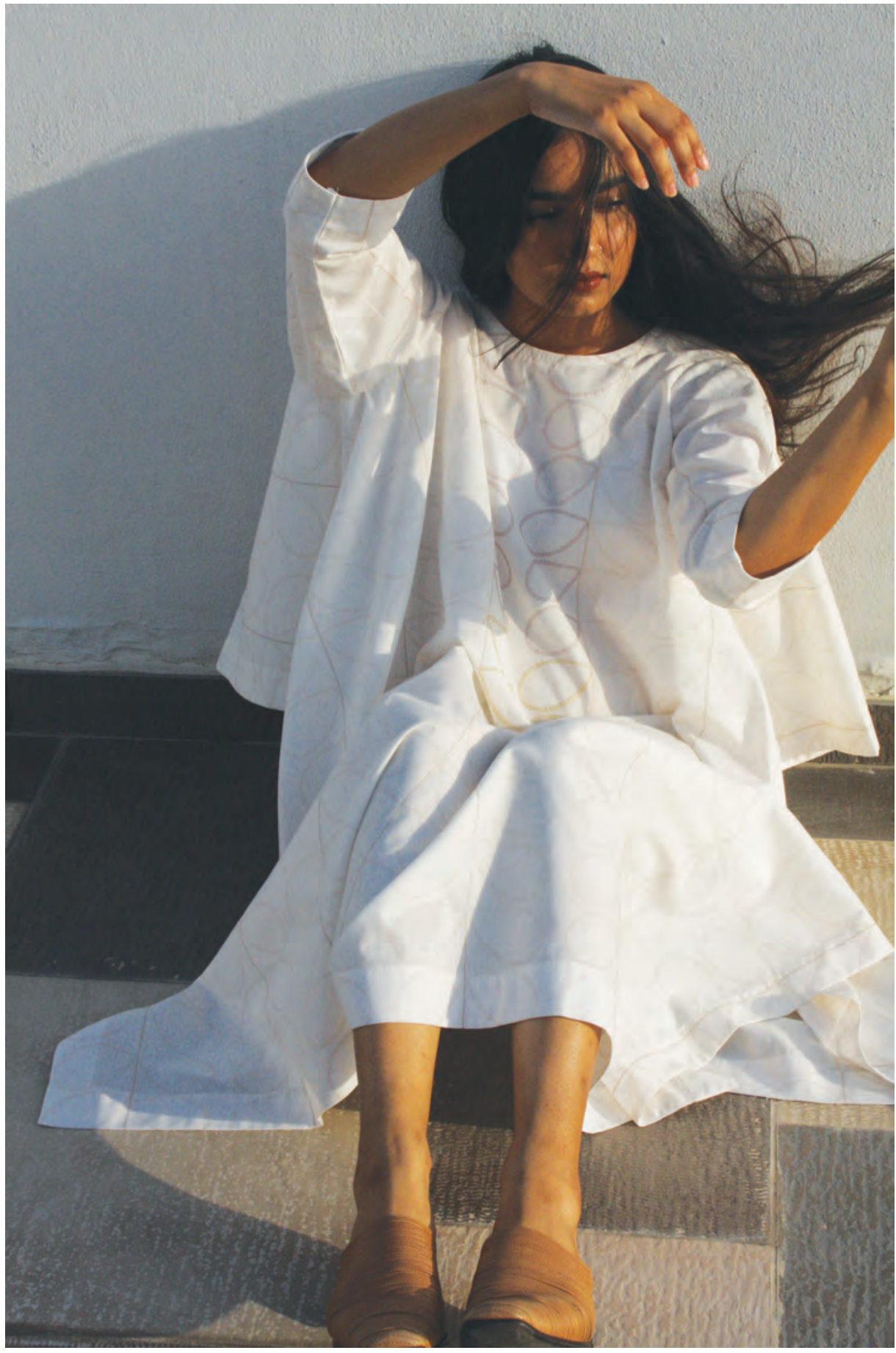

Figure 7b. The Tent dress, with embroidered front panel and open side seams. Near zero-waste design. 


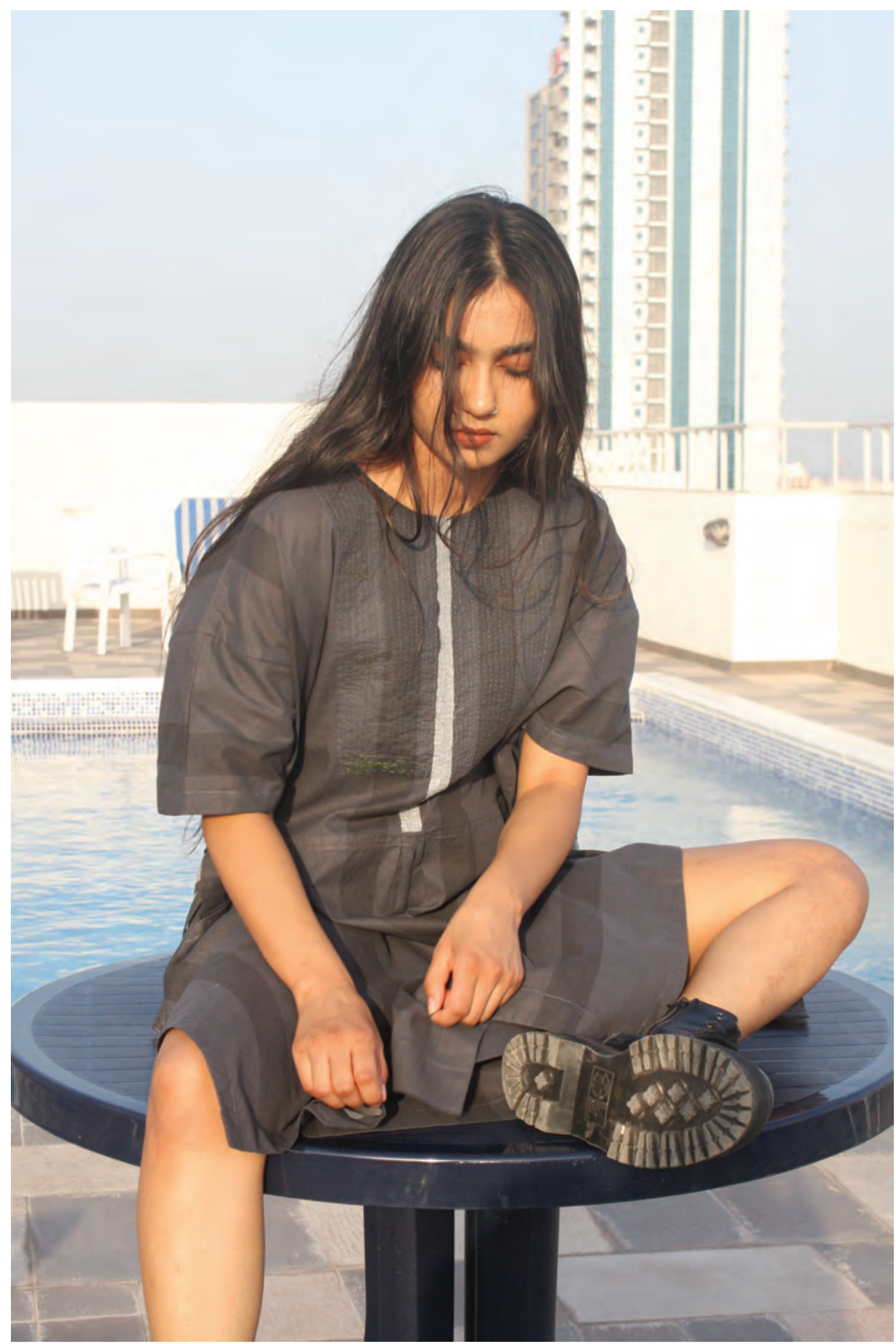

Figure 8. The Different shade of life dress, showing the long side slits. 
Rekha Rana Shailaj is a Senior Lecturer at School of Design, Otago Polytechnic teaching on the Fashion programme. Rekha graduated with a Diploma in Design (Fashion) from Otago Polytechnic in 1997 and completed a Master of Fine Arts (Design) with distinction in 20II from the Dunedin School of Art, Otago Polytechnic. As a conceptual designer, Rekha practices design in a multicultural environment, working with subjectivities and identities created through different fashion systems, drawing on both Eastern and Western sensibilities. Ethnographic clothing is an area of special interest, especially from India where she was born and raised. Her current research focus is on working with traditional clothing from India and extending the construction methods to create near zero waste fashion outcomes.

I Edward W Soja, Thirdspace: Journeys to Los Angeles and Other Real-and-imagined Places (Cambridge, MA and Oxford, UK: Blackwell, 1996).

2 Max van Manen, Researching Lived Experience: Human Science for Action Sensitive Pedagogy (London and New York: Routledge, 20I5), 105.

3 Ibid., 106.

4 Vilém Flusser, The Freedom of The Migrant (Chicago, ILL: University of Illinois Press, 2003), I.

5 Ibid., 55.

6 bid., 55-6.

7 |bid., 81.

8 van Manen, Researching Lived Experience, 37.

9 Flusser, The Freedom of the Migrant, 65.

10 Ibid., 66.

II Ibid., 69-70.

12 van Manen, Researching Lived Experience, 35.

13 Wilhelm Dilthey, Selected Works, Vol. 5: Poetry and Experience (Princeton, NJ: Princeton University Press, 1985), 223, quoted in van Manen, Researching Lived Experience, 35.

14 Dilthey, Poetry and Experience, 227-8, quoted in ibid., 37.

15 Flusser, The Freedom of The Migrant, 21 -3.

16 Ibid., 27. 


\section{SCORCHERS AND SHOPPERS: WOMEN, EARLY AUTOMOBILISTS' CLOTHING AND FASHIONS FOR “MILADY OF THE ELECTRIC"}

Pam McKinlay

Fashions for Milady of the Electric

New Fall Garments to Be Seen in Electrics on the Boulevards and Roads
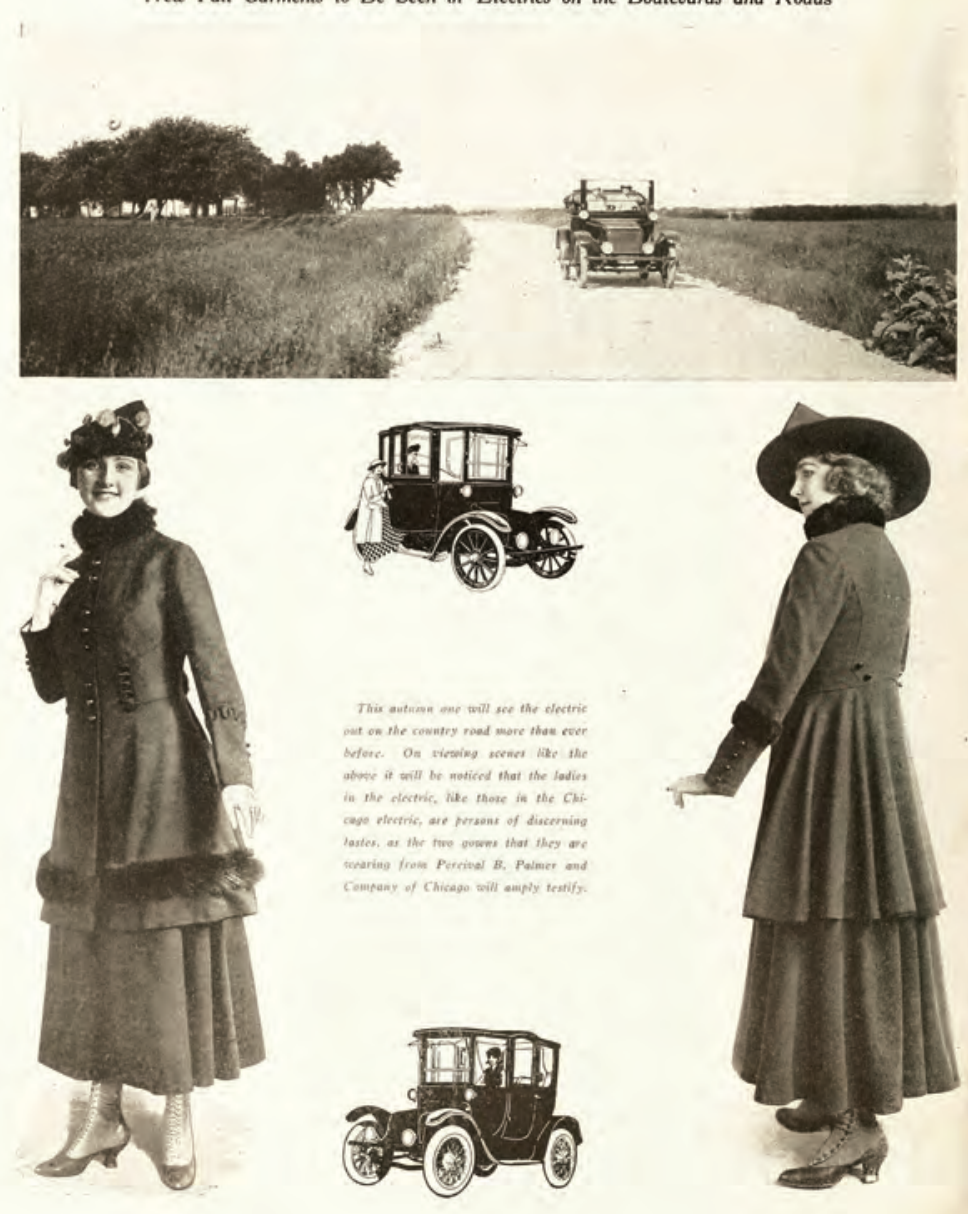

Figure I. Fashion plate for "Milady of the Electric," c. 1916. Creative Commons License.' 
The popularity of automobiles exploded shortly after the turn of the twentieth century, creating a lucrative new market for lines of specially designed recreational clothing. A pastime of the affluent and adventurous, early motoring had its own special couture; the centrepiece was the motoring or automobile coat, a shapeless yet functional piece of attire for both men and women. As more women got behind the wheel, tensions between female independence and perceptions of women's proper place in the world became more apparent. Electric vehicles were touted as the lesser of two evils for forward-thinking women with a bent for driving. The fashion market flourished, with designs appealing to "Milady of the Electric" marketed as a way of maintaining both femininity and independence (but not too much).

\section{HAY, STEAM, ELECTRONS AND GAS}

We think of electric vehicles as a futuristic, twenty-first-century technology. However, in the early 1900s, there were 300 companies making electric vehicles. At the turn of the twentieth century, 40 percent of automobiles in America were powered by steam, 38 percent by electricity, and 22 percent by gasoline. ${ }^{2}$ Gas and steam cars required strength and time to start, with steam vehicles requiring up to 45 minutes' start-up time. Steam-powered cars died out with hay (horses), leaving the other two contenders for domination of the roads. There were more than 30,000 electric vehicles on the roads in the United States in 1900 and they looked like they were here to stay. The hiatus between then and now, when electrics are once more on the ascendant, was filled by a story of energy and the politics of big oil - a story which has been told elsewhere. ${ }^{3}$

Early gasoline- (petrol-) powered cars required manual strength and technical know-how to drive. Physical effort was required to start the car by cranking and, when driving, with changing gears. Kickbacks from cranking caused bruising and broken thumbs, and roadside injuries abounded as a result of the need to restart stalled engines in congested traffic. Early automobiles were open, cold and dusty. Petrol cars were also noisy (unmuffled), smelly, were subject to excessive vibration and occasionally blew up - Clara Ford (wife of automobile magnate Henry Ford) referred to them as "explosion cars."

At the turn of the twentieth century, the lack of infrastructure was a barrier to longer journeys for both gas and electric motorised transport, both in terms of roading and refuelling. Roading was poor - marginal at best outside of urban centres. The earliest filling stations were pharmacies selling ligroin (petroleum ether). ${ }^{5}$ The increase in the popularity of electric cars was linked to the advent of domestic lighting, with light bulbs driving demand for infrastructure that could reach every home and be available to the general public. ${ }^{6}$

\section{DRESSING FOR ADVENTURE - AUTOMOBILE COATS}

Most early automobiles required wardrobe preparations for travel. Early gasoline combustion-powered cars were open, draughty, noisy, shaky, unreliable and smelly contraptions. Early cars had no roofs or doors and were driven mostly on dirt roads. New lines of sporting or leisure clothing were created alongside the new automobile technologies. The "car coat" (first called automobile or motoring coats), ${ }^{7}$ hats, specialty driving gloves and goggles (offering protection from dust and the occasional pebble) were necessities for men, matched by car coat, gloves, hats and veils and/or goggles for women (Figures 2, 3 and 5). In the early days of motoring, cars were the province of the very rich. Motoring clothes became a statement of status, class and luxury, with people arriving at functions in motoring attire to appear as if they had arrived by automobile.

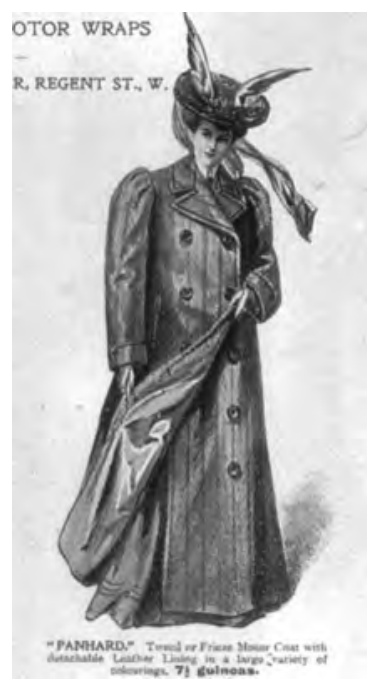

Figure 2. Automobilists' motoring coat for women.

Image: Wikimedia commons: Public Domain. 
The car coat was first designed as a functional, fulllength over-garment to provide maximum warmth and coverage in order to protect the driver and passengers from the elements: wind, wet, cold and dust and, in the case of petrol cars, from oil and exhaust fumes - as well as staying warm during frequent roadside repairs and breakdowns (Figure 2). Car coats came in fur, leather and heavy wool, ${ }^{8}$ with a move to lighter fabrics ('duster coats') in linen or alpaca wool ${ }^{9}$ for the warmer seasons when the enemy was dust rather than mud. Car coats have survived in the clothing realm as a shorter variant of the early garment and - in a design closer to the original car coat lineage - in the greatcoat.

Virginia Scharff described the new sportswear as dressing for duress, not style:

Girded in corsets and petticoats and forty pounds of underskirts and overskirts, cloak and formidable hat, she is clad for immobility... First, the duster, or motoring coat. It might be made of leather or rubber or fur; in all cases it was hot and heavy, adding yet more poundage to her already heavily freighted body. Then there were a host of devices to protect face, eyes, hair and hat. These ranged from simple, if cumbersome, goggles and heavy veils to more

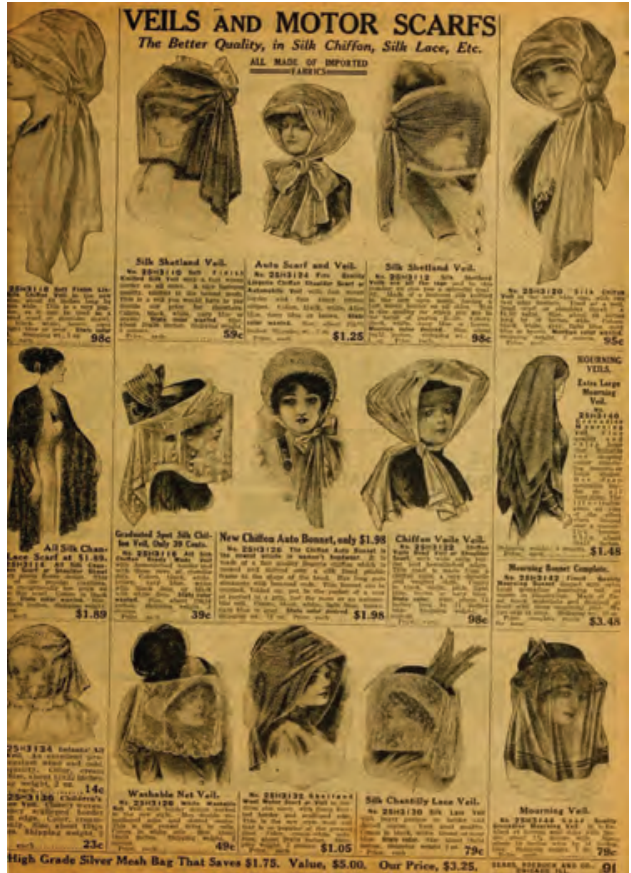

Figure 3.Women's hats also included removable veils as dust shields to protect the wearer's face as in this catalogue from Sears.' elaborate contraptions. On rainy days, the motoring woman might choose a waterproof rubber hood and shoulder cape, looking rather like someone who planned to take a shower with all her clothes on. An all-weather motoring mask for women approximated a large bucket inverted over her head. Made of mica with a translucent linen veil, it closely resembled the protective head covering worn by modern workers who handle plutonium. ${ }^{10}$

\section{ENTER THE ELECTRIC CAR}

Electric vehicles were different. They were free from the noise and smell of gasoline-powered cars and offered a gentle, smooth ride compared with the vibration of the latter vehicles. ${ }^{12}$ They were more reliable than their gas cousins and were equipped with an electric starter, ${ }^{13}$ later widely adopted in all motor vehicles as a concession to female frailty. ${ }^{14}$ They required no cranking and were easy to operate $-a$ child could drive them (even a woman):

A car charged with electricity can be driven by a child. There is practically nothing to go out of order or to go wrong. A hard-working goblin has been imprisoned in the accumulators, and for the number of miles which he is condemned to serve the car is bound to run. Nothing is easier than to drive a properly-made electric motor car. (Otago Daily Times, 25 June 1900) ${ }^{15}$

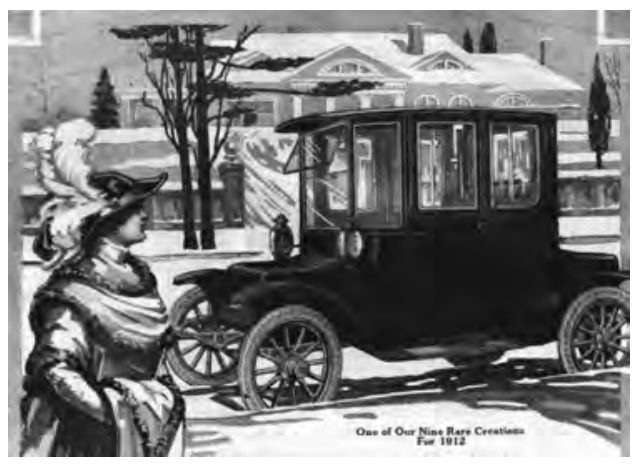

Figure 4. Detroit Electric Vehicle Advertisement. Image credit: Wikimedia Commons, Public Domain. 


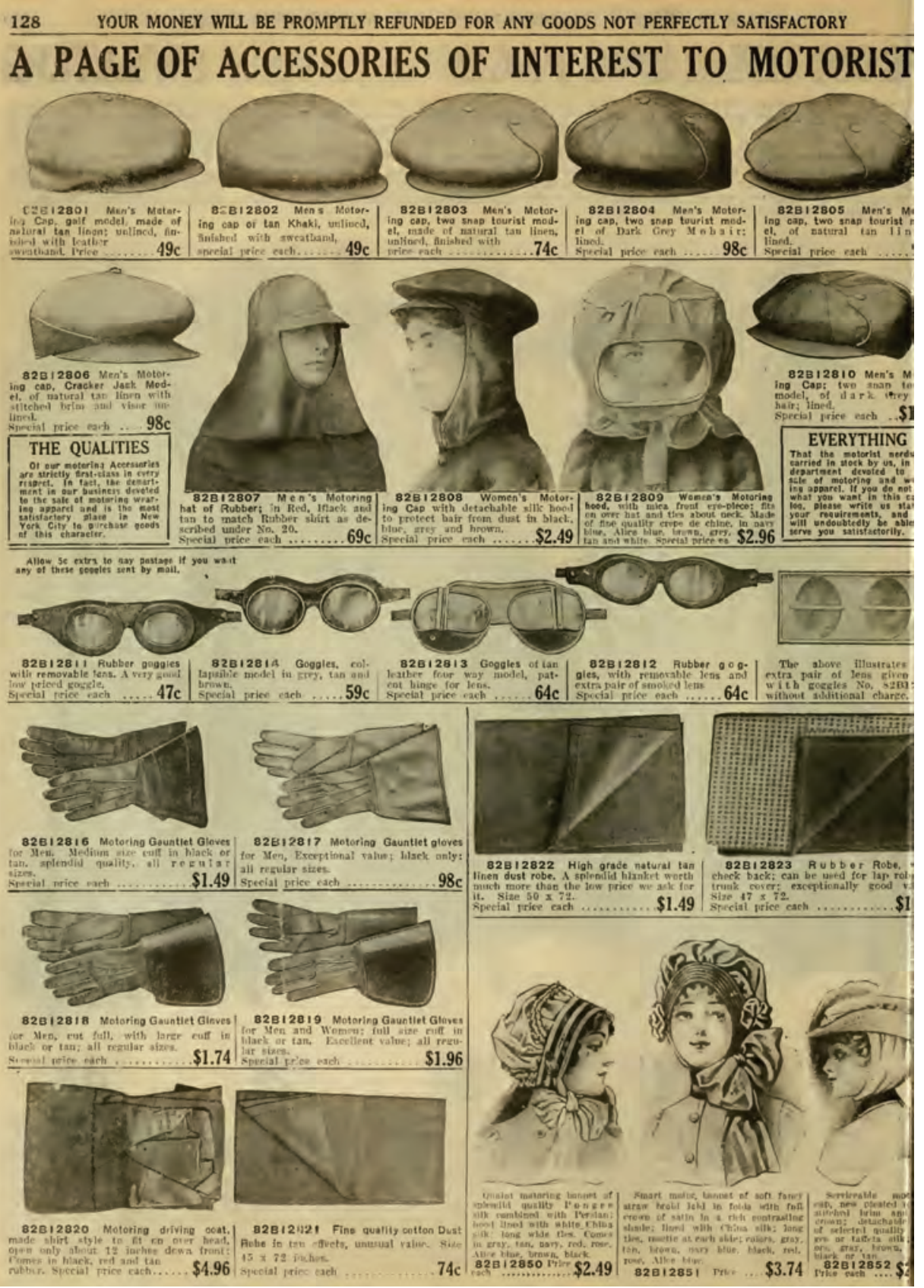

Figure 5. Women's hats also included removable veils as dust shields to protect the wearer's face as in these catalogues from Macy's."

Image Credits - Sears Catalogue - Veils and Motor scarves, http://www.archive.org/stream/catalogno I2400sear\#page/9I/ mode/ I up and Macey's Catalogue, A Page of Accessories of Interest to Motorists https://archive.org/stream

catalogueno 16 spro0macy\#page// 30/mode/2up. 
Many early models were custom-built, their design based on enclosed carriages (aka horseless carriages) to insulate the occupants from the noise and smell of other traffic. In addition, an enclosed vehicle freed a woman from the necessity of a male companion as she made her way about public spaces in the city, and freed her from the privations of public transport. In 1907, the Society for the Protection of Passenger Rights in New York City noted that crowding had reached "the point of indecency" in public transport. At the end of the nineteenth century, a fleet of electric cabs was introduced to the streets of London. They were nicknamed Hummingbirds, due to the humming noise they made. Women without their own wheels would happily wait for an electric taxi to enjoy the perceived benefits of a clean, smooth ride - Hummingbirds were preferred over "explosion cars" any day. By I899, 90 percent of New York City's taxi cabs were electric vehicles. The Electric Vehicle Company operated 2000 electric vehicles, along with the attendant charging infrastructure needed to support this new enterprise. ${ }^{16}$

\section{GAS IS FROM MARS, ELECTRICITY IS FROMVENUS ${ }^{17}$}

As we have seen, only the affluent could afford to drive in the early days of automobiles. The Electric Vehicle Assocation's (EVA) marketing messages appealed to luxury, convenience and those aspiring to both. ${ }^{18}$ Luxury firm, the Baker Motor Vehicle Company, marketed themselves as the "aristocrats of motordom," providing reliable vehicles for businessmen for whom time was money. Although primarily targeted at women, electrics were seen as having sartorial benefits for doctors, bankers and other professionals who required similar protection for their clothing when out and about in town. Driving an electric had many practical bonuses. Time and energy were saved, with no tiresome (sweat-inducing) cranking and stalling; drivers' suits would not get crumpled, rumpled, windblown and spattered, and one could arrive in style sans shapeless carcoat.

These vehicles were first advertised as "Electric Sensations for Men." However, as the electric car became increasingly associated with women they were eschewed by men, despite their reliability and cleanliness. They were classy, but not masculine enough. To counter this perception, fake parts such as false radiators were put on 'men's electrics' and men's vehicles were designed as 'sporty, more macho options, with features such as lowered suspension.

\section{OUT OF BOUNDS:THE LADIES' AUTOMOBILE CLUB, SCORCHERS AND SPEED QUEENS}

Driving gave women freedom and independence as early as 1898. Cars provided mobility and independence without the ridicule attracted by other forms of personal transport such as the bicycle and the "reform dress" and bifurcated dresses associated with it. ${ }^{19}$ As more forward-thinking women got behind the wheel, tensions arose between conventional perceptions of a woman's place and their desire for independence and personal mobility. As Matthew Lasar says, "Clearly a society that had yet to decide whether women could vote, enter professions, or even use the phone to invite friends to dinner parties was experiencing just a little bit of anxiety about females driving cars." 20

Nowhere was this tension more evident than in the early days of motor sport. The Ladies' Automobile Club was Great Britain's first dedicated motor club for women. The club was mostly social, although some women were involved in early racing driving. ${ }^{21}$ Pioneering racing driver Dorothy Levitt was a "scorcher." Dubbed the fastest woman in the world, she wore an extravagant green dress (often dressing to match the colour of her car) to the track at Herkomer in 1907, but was barred from racing at the newly opened Brooklands, the first purpose-built racetrack in the world, in 1908.2 The rules were relaxed for a ladies' handicap in 1908, at which the ladies wore colour-coordinated outfits and gloves with their skirts tied securely with pieces of cord to stop them riding up over their knees. Women were banned again following this race until ladies-only handicaps were once more allowed in 1928.

As well as a racing driver, Dorothy Levitt was a motoring journalist and wrote a book for women drivers. In The Woman and the Car (1909), ${ }^{23}$ her aim was to dispel the myth that women were not strong enough to get behind 
the wheel and to show that they were technologically competent, as a counter to prevailing sentiment as illustrated by the following quotation: "A woman's brain evolves emotion rather than intellect; and whilst this feature fits her admirably as a creature burdened with the preservation and happiness of the human species, it painfully disqualifies her for the sterner duties to be performed by the intellectual faculties." ${ }^{24}$ She provided advice on what to wear behind the wheel, with practicality as well as femininity in mind. "Under no circumstance wear lace or fluffy adjuncts to your toilet. There is nothing like a thick frieze, homespun or tweed coat lined with fur. Do not heed the cry,'nothing like leather.' Leather coats do not wear gracefully."

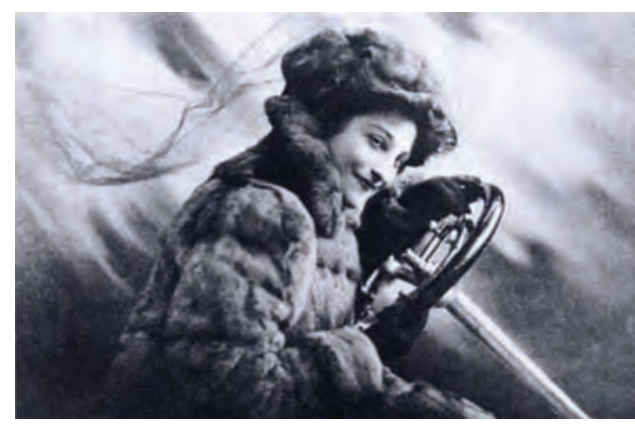

Figure 6. Pioneering racing driver Dorothy Levitt wearing a fur car coat and veil; from the frontispiece of her book The Woman and the Car, 1909.

Image credit: Wikimedia Commons, Public Domain.

In her book, Levitt shares advice on servicing one's car, with handy tips on how to clean a carburettor with a hat pin (as illustrated in hands-on photographs) and recommends keeping a hand mirror in the tool drawer under the driving seat to enable the motorist to see behind her when necessary. The idea caught on and it is to Levitt that we owe the invention of the rear-view mirror. ${ }^{25}$ Other innovative early women drivers were Mary Anderson, who invented the first windshield wiper, ${ }^{26}$ and Bertha Benz, who pioneered brake linings and the second gear. ${ }^{27}$

\section{SHOPPERS AND SOCIALITES - STAYING IN BOUNDS AND KEEPING UPWITHTHE ROCKEFELLERS}

In 1910, under the headline "MORE COMFORTS FOR WOMEN IN AUTOS: Manufacturers Have Studied the Many Details for Women's Demands in the 191 I Models," New York Times technical correspondent Charles Duryea stated that "it has simply been assumed that women would not drive, and so long as the tonneau was roomy, comfortable, and well inclosed her needs were supposed to be well met." 28

One of the more interesting arguments for women driving was the reconciliation of driving with modern motherhood and the fashionable belief that healthy young children needed fresh air: "in no way can a child get so much air in so little time as by the use of the automobile ... It is the light electric runabout which deserves the title of scientific perambulator."29

Eventually, the restrictive features of luxury urban electric cars (less power than gasoline-powered cars and limited range) were seen as being wholly advantageous for females and a practical compromise for women who would insist on driving. Electrics were seen as being best suited for running errands around town and thus a way of keeping women within the domestic sphere. An electric was a very suitable vehicle for driving to town, but not beyond! ${ }^{30}$

In America, many of the wives of nineteenth-century American innovators and movers and shakers drove electric vehicles, including the Rockefellers (founders of the Standard Oil Company). The Edison, Ford and Packard women all drove electric, and the first five presidents' wives followed the same path. ${ }^{31}$ Such was the demand that the superintendent of the Detroit Electric Car Co. employed his daughter, Lillian Reynolds, to sell to these upper-class women. ${ }^{32}$ In Europe, the trend-setters were the aristocracy including several kings and queens. At this stage, many electrics were more like mobile parlours on wheels, complete with monogramed interiors. "One does not so much enter the Baker as climb it. Once inside, it's apparent that the designers were less intent on building a vehicle than they were in creating an ornate mobile parlor ... much like the booth of a Victorian tea room." ${ }^{33}$ 


\section{PARLOUR AWAY FROM HOME}

Growing competition between auto manufacturers saw the increasing 'domestication' of the automobile to suit the market needs of upper-class women. Manufacturers sought to cater to female 'needs' by designing enclosed carriages with high ceilings intended to keep ladies' tall hats from being crushed and their hair from being mussed. ${ }^{34}$

These vehicles were designed from the inside out with extravagant interior styling, with a focus on upholstery and paintwork. Features included custom-

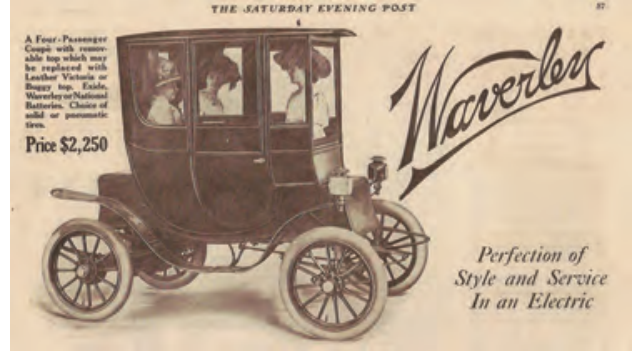

Figure 7. Waverley Electric Vehicle Advertisement. Image credit: $v$ Wikimedia Commons, Public Domain. monogramed interiors, velvet upholstery, sophisticated

lighting and heating, built-in vanity cases and vases for flowers. A rudder-like arrangement in place of a steering wheel meant that the car could be driven from the front or back seat, whichever was more convenient. ${ }^{35} \mathrm{~A}$ further nod to the increasing refinement of electric vehicle design was the first use of curved window glass in a production automobile, an expensive and complex feature to produce.

"These were women's shopping cars," says classic car collector Jay Leno. "There were thousands of these in New York, from about 1905 to 1915. There were charging stations all over town, so ladies could recharge their cars while they were in the stores." 36
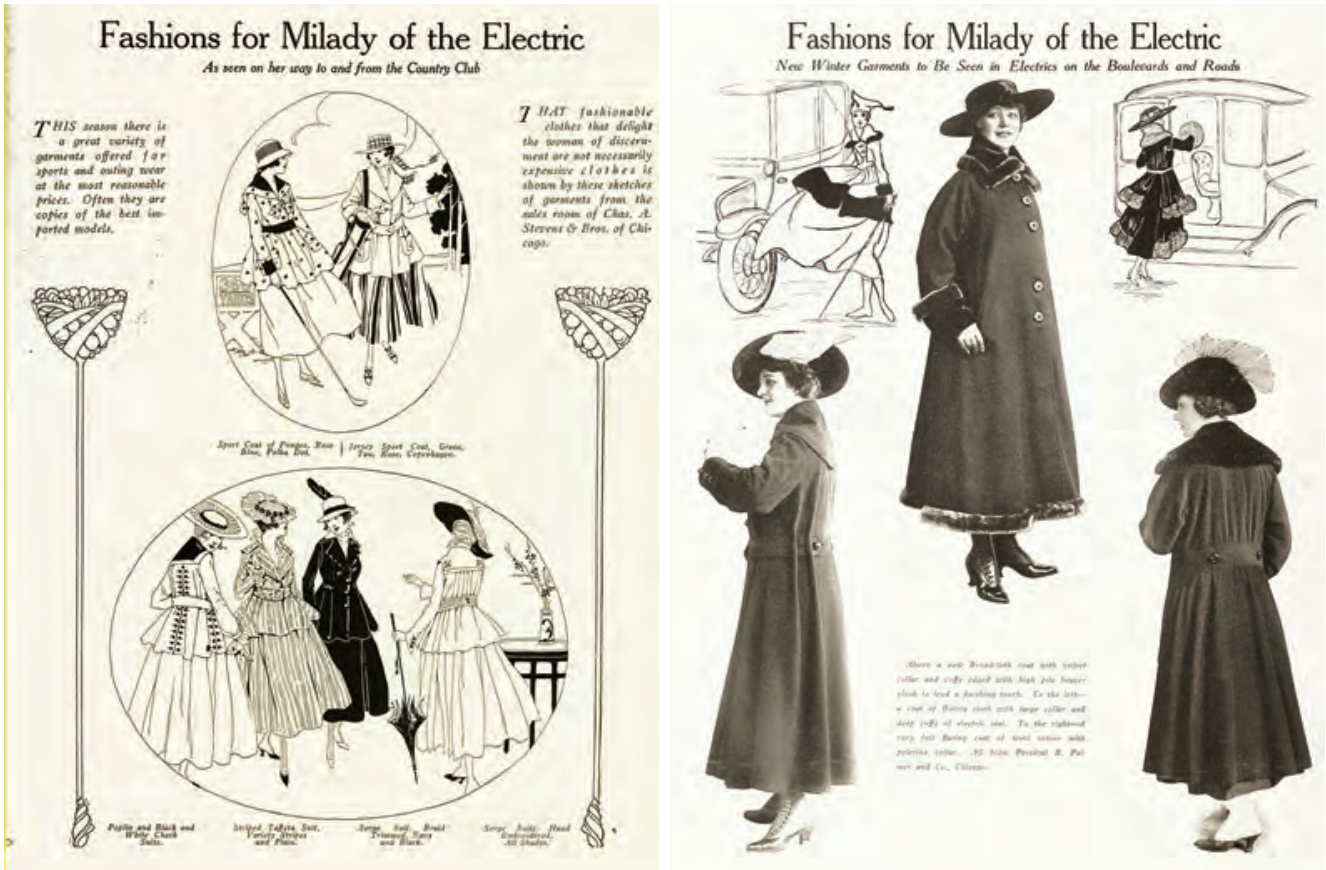

Figures 8 and 9. Fashion plates for "Milady of the Electric," c.1916.

Creative Commons License. ${ }^{37}$ 
There was no longer any need for the cumbersome car coat in such an elevated mode of transport, driven by the cream of female society. Marketers quickly changed tack to tout the virtues of electric vehicles and their fashion benefits for women. One could throw away shapeless and style-less autoist's slip-ons, coveralls and dust coats if one simply drove an electric. As more women got behind the wheel, new fashion lines appeared each season in women's journals and leading newspapers directed to fashionable female drivers, or "Milady of the Electric."

\section{CONCLUSION}

Only the affluent could afford the new automobile machines that appeared at the end of the 1890s. The early days of motoring were a time of outdoor adventure which was accompanied by new lines of sportswear, functional attire to wear over street or evening clothing. Early women drivers were forward-thinking and challenged notions of impropriety on the road and, more shockingly, on the race track. Of the two main forms of motorised vehicles (gas and electric), electrics were seen as the lesser of two evils and far more suitable for women to drive. Clothing design kept step with each stage of motoring evolution. At each stage, women who took the wheel were appropriately attired in the style attuned to the vehicle they were driving, whether they were scorchers or shoppers. The fashion advantages of driving electric were one of the marketing strategies targeting women, encouraging them to remain in the appropriate realm for femininity and domestic life.

Pam McKinlay (미 0000-0002-1731-6437) has a DipHSc in clothing/design and a BA in art history from the University of Otago. She works part-time at the Dunedin School of Art and the Research Office, Otago Polytechnic, and is a modern EV-eryday woman. 
I "Fashions for Electric Car Women - Ad circa 1916," 22 October 2013, http://ctgpublishing.com/fashions-for-electric-carwomen-ad-circa-1916/ (accessed 21 July 2019).

2 https://www.britannica.com/technology/automobile/History-of-the-automobile.

3 Peter B Doran, Breaking Rockefeller:The Incredible Story of the Ambitious Rivals who Toppled an Oil Empire, audiobook (London: Penguin Audio, 2006); Chris Paine, dir., Who Killed the Electric Car? (New York: Sony Pictures Classics, 2006).

4 Safety was a frequent theme in electric automobile advertising. Certainly, electric cars were safer to start than hand-cranked gasoline cars, but manufacturers also stressed that electrics were safe to charge. An illustration, from a 1917 Rauch and Lang Carriage Company catalogue, makes the point vividly with a child holding the plug while mother turns on the power. See www.thehenryford.org/collections-and-research/digital-collections/artifact/95366\#slide=gs-333917 2 (accessed 21 July 2019).

5 Sarah Crofts, "Women in Motorsport \& Social History: Berta Benz," Beaulieu, I February 20 I 6, https://www.beaulieu.co.uk/ news/women-in-motorsport-social-history-berta-benzl (accessed 21 July 2019).

6 '“'Do it electrically.'... Already that wonderful force, generated in the grey power-house on the banks of the Rakaia River is lighting our homes and city streets, turning the giant wheels of industry, cooking our food, and driving our vehicles... You know, too, that our city is fast becoming a clean, 'smokeless' city land and that we are saving from 60,000 to 70,000 tons of coal annually ... ." "Electric Power. In Home and Street," The Sun, 6 November 19 | 8, https://paperspast.natlib.govt.nz/newspapers/ SUNCHI9I8I 106.2.40 (accessed 21 July 2019)

7 Curt McConnell, "A Reliable Car and a Woman Who Knows It": The First Coast-to-Coast Auto Trips by Women, $1899-1916$ (Jefferson, NC: McFarland, 2000).

8 Valerie Cumming, CW Cunnington and P Cunnington, The Dictionary of Fashion History (Oxford: Berg, 2010 ), 135.

9 Ibid.

10 Virginia Scharff, Taking the Wheel: Women and the Coming of the Motor Age (Albuquerque, NM: UNM Press, 1992), I5- 16.

II Catalogues - Sears, Roebuck and Co., Catalog No. 124 (1912), "Veils and Motor Scarfs," https://mww.archive.org/stream/ catalognol2400sear\#page/91/mode/lup and and Macey's Catalogue, A Page of Accessories of Interest to Motorists, Catalogue no. 16, spring/summer / R. H. Macy \& Co., 128 https://archive.org/stream/cataloguenol 6spr00macy\#page/I30/ mode/2up (Retrieved 21 July 2019)

12 The Sun, 6 November 1918,https://paperspast.natlib.govt.nz/newspapers/SUNCHI9181 106.2.40 (accessed 21 July 2019).

13 EE Schwartzkopf, Automobile Topics, 22 (1911), 1204.

I4 Etta Place, "Crazy Woman Driver! Gender Divisions in the Early Days of the Automobile," The History Bandits, I June 20 I5, https://thehistorybandits.com/20 I 5/06/0 I/crazy-woman-drivers-gender-divisions-in-the-early-days-of-the-automobile/. Kettering himself was not intending to make a "gallant bow" to female drivers with his invention. He thought the self-starter, a so-called "feminine frill," would eventually become a standard feature of every automobile because of its universal utility (accessed 21 July 2019).

15 Otago Daily Times, 25 June 1900.

16 Scharff, Taking the Wheel, 49.

17 Lynne Mason, "Electric Car History," Electric Cars are for Girls, https://www.electric-cars-are-for-girls.com/history.html (accessed 21 July 2019).

I8 "Early Electric Cars," Chuck's Toyland:A Historical Preservation from Charles D. Test, 1912 Electric Vehicle Association Of America "We'll go right over to the Bank - my Electric is at the door" Electric Vehicle Association Of America Boston New York Chicago, Motor Age, July I I, 1912, 106 https://www.chuckstoyland.com/category/automotive/early-electric-cars/ (accessed 21 July 2019).

19 Julie Wosk, Women and the Machine: Representations from the Spinning Wheel to the Electronic Age (Baltimore, MD: John Hopkins University Press, 2003), I 16.

20 Matthew Lasar, "Electric Ladyland: When Battery-powered Cars were Built for Women," arstechnica, I8 April 20।2, https:// arstechnica.com/gadgets/2012/04/electric-ladyland-when-battery-powered-cars-were-built-for-women/ (accessed 21 July 2019).

21 Rachel H-G, "The Ladies' Automobile Club," Speedqueens: Women in Motorsport from 1897 to the Present Day, I4 October 2017, http://speedqueens.blogspot.com/search/label/Edwardian\%20and\%20Victorian\%20racers (accessed 21 July 2019).

22 Sarah Crofts, "Women in Motorsport \& Social History: Belles of Brooklands," Beaulieu, 3 August 20 I 6, https://www.beaulieu. co.uk/news/women-in-motorsport-social-history-the-belles-of-brooklands/ (accessed 21 July 2019).

23 Dorothy Levitt, The Woman and the Car: A Chatty Little Handbook for all Women who Motor or who Want to Motor (London: John Lane, 1909). 
24 E Frost-Knappman and K Cullen-DuPont, Women's Suffrage in America: An Eyewitness History (New York: Facts on File, 1992), 279.

25 Sarah Crofts, "Women In Motorsport \& Social History: Dorothy Levitt," Beaulieu, https://www.beaulieu.co.uk/news/womenin-motorsport-social-history-dorothy-levitt/ (accessed 21 July 2019).

26 HVA, "Women at the Wheel," Hagerty, 24 October 2012, https://www.hagerty.com/articles-videos/Articles/2012/I0/24/ Women-at-the-Wheel/ (accessed 21 July 2019).

27 Crofts, "Women in Motorsport \& Social History: Berta Benz."

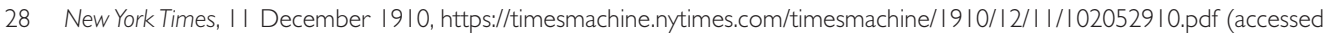
21 July 2019).

$29 \mathrm{CH}$ Claudy, Woman's Home Companion, 1907, cited in in Virginia Scharff, "Femininity and the Electric Car," Automobile in American Life and Society, http://www.autolife.umd.umich.edu/Gender/Scharff/G_casestudy.htm (accessed 21 July 20I9).

30 Lasar, "Electric Ladyland."

31 " "1912 Baker Electric Victoria, Used by Five First Ladies of the United States," The Henry Ford, https://wmw.thehenryford.org/ collections-and-research/digital-collections/artifact/195103 (accessed 21 July 2019).

32 The "first woman ever to sell a horseless carriage," Lillian learned to drive when she was I 5 and started in sales when she was 19."'Electric cars were for ladies,' she said ... 'It wasn't ladylike to drive a gasoline auto. With electric cars there was no oil or dirt to shoot up through floor boards, there was no dust, and they were almost automatic - you didn't have to know a thing about mechanics."' The Michigan Daily, I4 April 1946, https://digital.bentley.umich.edu/midaily/mdp.3901507|756/96/204/ (accessed 21 July 2019).

33 Dexter Ford, "Back to the Future in a 98-year-old Electric Car," New York Times, 5 August 2007, https://www.nytimes. com/2007/08/05/automobiles/05BAKER.html. (Interview with Jay Leno.)

34 Brendan McAleer, "Clean and Quiet:The I00-year-old Advantages of an Electric Vehicle," Hagerty, 22 September 20 I 7, https:// www.hagerty.com/articles-videos/articles/2017/09/22/detroit-electric.

35 The Michigan Daily, 14 April 1946.

36 Ford, "Back to the Future;"'The New York Edison Company's Automobile Bureau published a booklet for electric car owners. It included a map and address listings of charging stations in New York City. Stations outside the immediate area, as far as Boston and Philadelphia, were also listed. "'Electric Automobile Charging Stations in New York City and Vicinity', with Maps, Second Edition, August 1923," https://www.thehenryford.org/collections-and-research/digital-collections/artifact/17/903 (accessed 21 July 2019).

37 "Fashions for Electric Car Women - Ad circa 1916," 22 October 2013, http://ctgpublishing.com/fashions-for-electric-carwomen-ad-circa-1916/ (accessed 21 July 2019). 


\section{INTERNATIONAL EMERGING FASHION:A PHOTOGRAPHY PROJECT BY COMMUNICATION DESIGN STUDENTS}

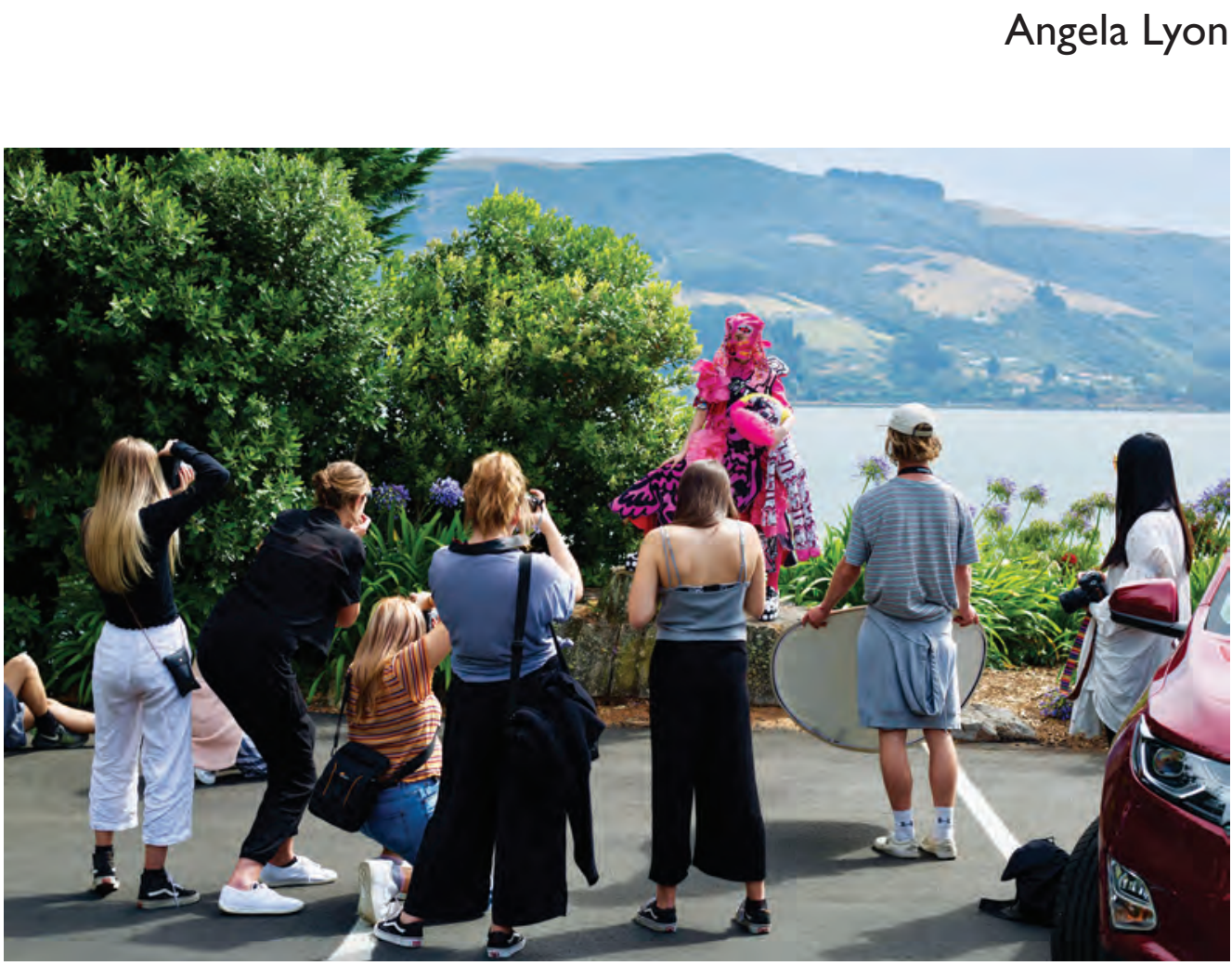

Figure I. students photographing model wearing Rebecca Carrington at Glenfalloch. Designer: Rebecca Carrington, Institution: Manchester Metropolitan University, UK.

Photographer: Christopher Hansen.

On 13th March 2019, Otago Polytechnic Communication Design students collaborated on a range of fashion photoshoots, capturing the designs of visiting international fashion design students in a range of iconic Dunedin locations. These visiting fashion designers were in the city competing in the prestigious International Emerging Designer award as part of the annual iD Fashion Week, coming from institutions in the United Kingdom, the Philippines, Australia, Japan, Argentina, China, the United States of America, Singapore and New Zealand.

The project was initiated by Professor Margo Barton, (Academic Leader of Fashion at the School of Design, Otago Polytechnic and iD Fashion Week Co-chair), who wanted to give the visiting emerging designers an opportunity to better experience Dunedin and the chance to have their garments photographed on models on location. The day was by organized by iD team members Ella Barton-Buchanan and Gauthier Dejace, who arranged models, (both international and local), hair and makeup from iD sponsor L'Oréal, buses and provided the travel itinerary as well 


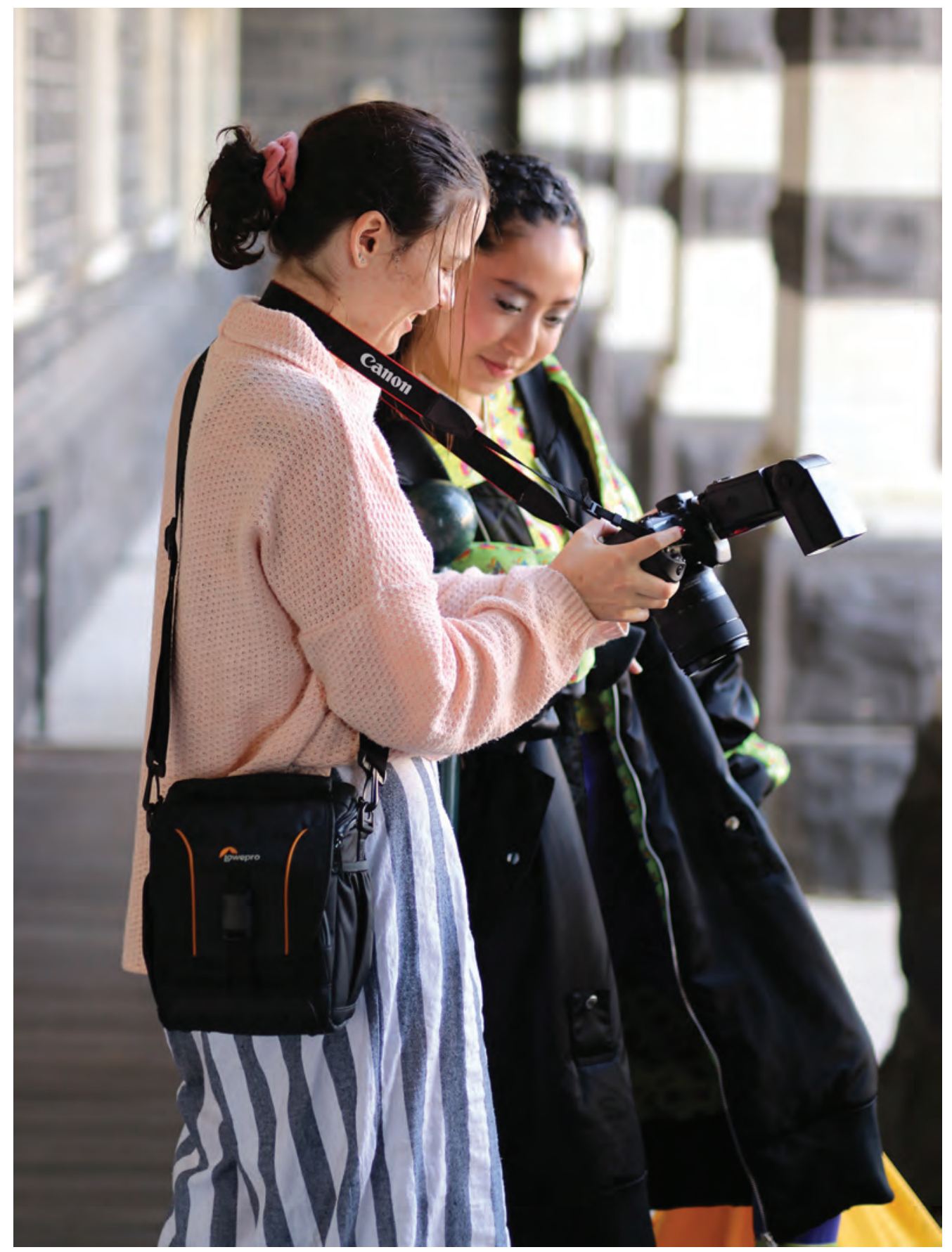

Figure 2. Laura showing Vivi her photographs of Vivi wearing Minori Yanagese. Designer: Minori Yanagese, Institution: Ozaka Bunka Institute of Fashion, Japan. Photographer: Angela Lyon. 
as additional planning details to the students. Ella and Gauthier continued to act as the project clients and liaised with students as the project developed. Each visiting fashion designer selected one outfit from their collection to be photographed on location.

At this time Communication Design students were undertaking a course in advanced techniques of Photography. Ordinarily I would assist students in generating their own brief and they would use advanced photography techniques to generate a photographic solution. However, the synchronized timing of iD Fashion Week provided a real-life brief and the opportunity for richer and unexpected experience in fashion photography and the opportunity for projectbased teamwork and learning.

Many of the students had limited camera skills and experience but showed themselves capable of working well in a team with a high level of problem-solving skills in the context of digital media design, as well as with a high level of self-management relating to the design process. Using these skills students developed a brief that would provide industry-ready images, suitable also for the designer's requirements, while at the same time creating outcomes required for assessment of their Advanced Design Techniques course.

With 27 garments to photograph in six locations, planning and preparation was key to ensuring the brief was fulfilled. As a group of competent researchers, students explored the conventions of fashion photography, identifying methods and techniques they could adopt to create images that were individual, contemporary and most importantly, presenting the international designs against the Dunedin backdrop. Class workshops saw us undertaking experiments in figure and viewfinder composition where we used each other as models, 'cutting shapes' and striking poses in a series of variable lighting situations anticipating the uncontrollable nature of the light and environments on the day.

Students planned and explored an individual area of expertise and presented these ideas to each other, together building a collective resource of skills and knowledge to pull from as required. Areas included portraiture, dynamic camera angles, figure poses, silhouettes and compositional shapes. This ensured the team would have a range of vibrant images to present. Students consulted with Ella and Gauthier who were very encouraging about the direction their planning had taken and confident in the skills, techniques and creative ideas students they saw presented, both collectively and individually.

\section{THE FASHION SHOOT DAY}

By the day of the shoot students were excited, with perhaps, over-planned anticipation. The day began with the emerging designers arriving by bus with garments in hand at the Dunedin Central Railway Station. By the time the models arrived from hair and makeup, a cruise ship had arrived and the station was abuzz with tourists. It was a beautiful crisp Dunedin morning with bright light and sharp dark shadows. Once dressed, the models moved to different areas of the railway station, with two or three photographers at a time, generally choosing to avoid the contrasting morning light conditions and opting for either bright or dark situations in order to get good exposure of the individual garment details, their models and the location. Unexpectedly a mass of tourist spectators, designers, train riders and photographers milling around the station made it difficult to get a background without people in it. We photographed a total of five different outfits at this location on five different models; Clementine, Charlotte and Cameron from Dunedin, and Emma and Vivi from Shanghai.

Everyone then boarded the bus to the next location, Glenfalloch, for photographs in the private, historic, harbor side gardens. After a generous lunch, we explored the gardens seeking suitable settings for the next set of outfits. The sun directly above brought challenges as the light reflected off the water and into the models eyes. Old and enormous macrocarpa provided an atmospheric and windswept backdrop which contrasted with the lush surrounds of native ferns, exotic flowers and other New Zealand trees that read of otherworldly garden parties and timeless picnics, all bathed in dappled light. 


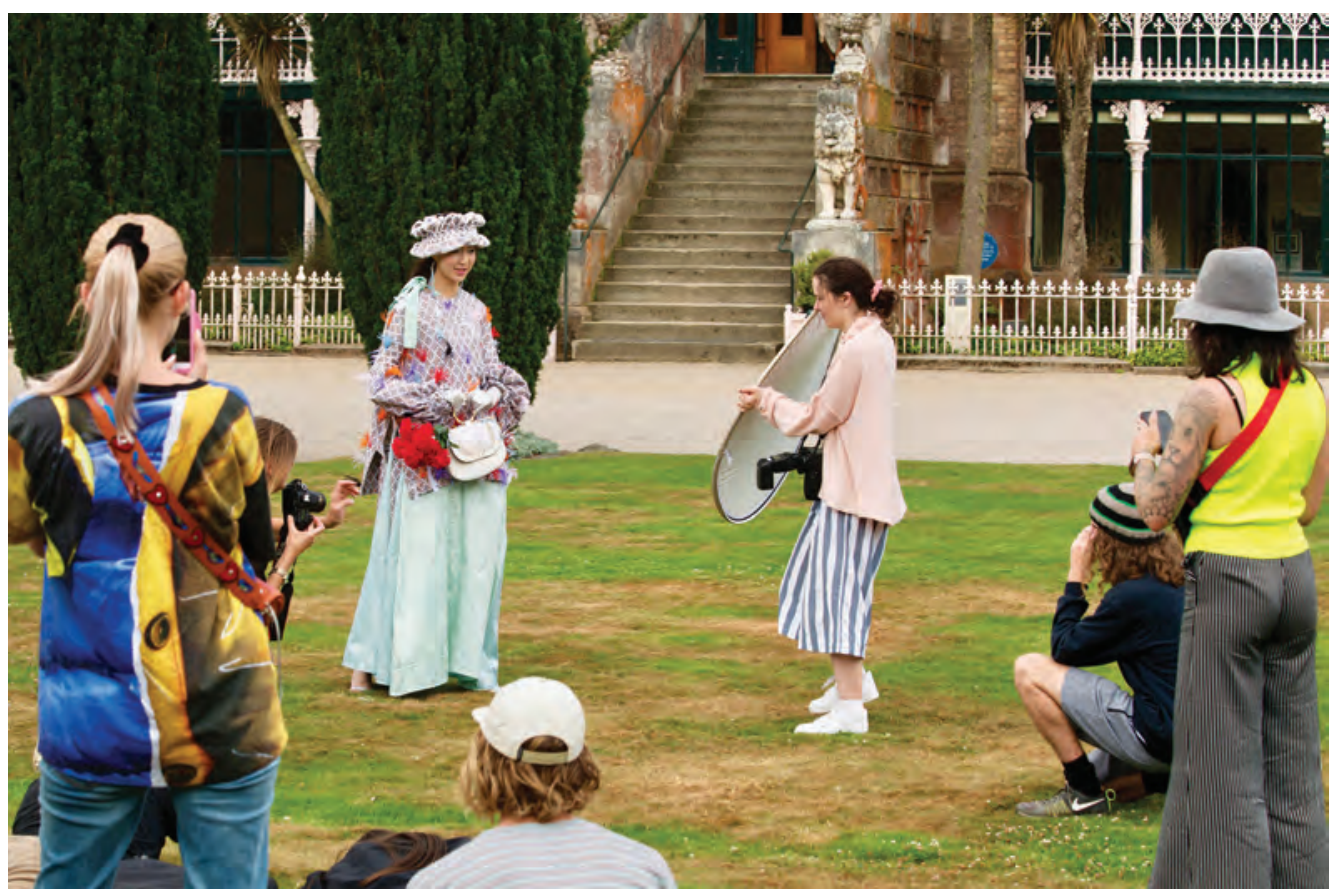

Figure 3. Students photographing Vivi wearing designer Amy Louise Redfords's garment in front of Larnach's Castle. Designer: Amy Lousie Redford, Institution: Manchester Fashion Institute, UK.

Photographer: Christopher Hansen.

The next location was Larnach's Castle and the bus climbed the winding road from the harbour's edge to the top of the hill. The castle provided a truly magical setting sitting atop the Otago Peninsula with its panoramic views from Taiaroa Heads to the city to Hooper's Inlet. In typical Dunedin style, we ran into many of the same tourists we saw visiting the Dunedin Railway Station that morning and they were eager to witness the next part of our day. It was amazing how the garments transformed, shape shifting into the Victorian / Edwardian environment as if stuck in a time sandwich.

A small team broke away from the group and took model Charlotte to the top of the castle. It seemed as soon as we hit the stone steps, the garments entered a portal, shifting instantly into golden medieval "castle-wear." We crept to up the turret, careful not to scratch the garment's satin fabric, arriving at the top with a backdrop that looked out over the craggy landscape of the peninsula past Hereweka - the Habour Cone. A storm was brewing. The light below the greying cloud was an electric golden colour, as if bouncing off the golden satin of the garment. We quickly took photos of Charlotte overlooking the edge, lording over the castle and Dunedin from a far.

Meanwhile other emerging designers and photographers explored and photographed in the nooks and crannies within the castle, as well as around the incredible ornamental gardens of the castle grounds. Castle hosts and tourists alike were enthusiastic to join in and support the spectacle. Time flew by very quickly and before we knew it everyone below was rushing onto the bus destined for the last two group sites, First Church and Emerson's Brewery. As we ran out of the castle, the moody sky burst and it began to pour: another Dunedin classic- the fourth season of the day! 
George, an emerging designer from London, together with his garment and model, Gauthier, Chris Hansen from the photography team and myself, were escorted to the airport for our last shoot of the day on the Dunedin Airport runway. Our new London friend could not believe that the airport would allow us access to do that. "Only in Dunedin" we laughed. We passed by the Maungatua ranges, all grey and blue, and even from the car the designer's garment popped all orange and reflector. It felt very 'international' passing through Customs to get our temporary passes. The stewards and security officers repeating proudly, "this would only ever happen in Dunedin", as they enjoyed the spectacle. Our shoot closed the runway for a full half an hour, as airport visitors watched on from the gallery's window. We raced to the 'piano keys' at the end of the runway escorted by Jim the fireman in a fire utility vehicle, offering his services as a model and joking all the way. The wet atmosphere and gustiness led to drops on the camera. Blur on the lens and longer exposures than we preferred were unavoidable. However the back drop was perfect for this garment in comparison to the earlier locations. I marvelled at the foresight and prior planning by the iD Fashion production team in anticipation of the final fashion shoot images!

The images produced at First Church and Emerson's too had their individual feeling of urban and industrial environment; stone, wood work and the greyness of the afternoon weather also popping out the colour of the garments and situation.

The students had a thoroughly enriching and invaluable experience and agreeing that they gained a lot by being thrown into the various situations and problem solving the issues that came with the day. One of the photographers, Laura Wellman, stated it was "quite nerve racking but good experience" while another, Chris Hansen said, "The experience gained from working alongside emerging and established professional artists with an international scope was priceless... and a lot of fun."

As everyone went their separate ways, the team of photographers were elated with the production of photoshoot. For us, Dunedin had turned up in style, providing a unique set of quintessential moments to record with our cameras. From the tour of young and old Dunedin, our four seasons in one day, the convenience of the localities and the familiarity and enthusiasm of the people involved; models, designers and spectators alike, the day provided a true Dunedin experience for all of us to take back to our respective worlds. On top of this was the experience of real-life project-based learning from which the students took away many new skills and knowledge beyond what could be delivered in a classroom-based environment.

A huge thank you to Ella Barton-Buchanan, Gauthier Dejace, Margo Barton and the iD Fashion Committee for organising the day. Also for models: Aart Model Management, Dunedin and Shanghai University of Engineering Science (SUES), Shanghai; Hair: Klone Dunedin; Makeup: Lisa Matson.

Photographed during the iD International Emerging Designer Awards, Dunedin, New Zealand, March 2019.

Angela Lyon is an artist and photographer based in Dunedin. She graduated with a Masters of Fine Art from Otago Polytechnic's School of Art in 2007. She currently is a lecturer of design and photography in Communication Design at Otago Polytechnic's College of Art, Design and Architecture. 


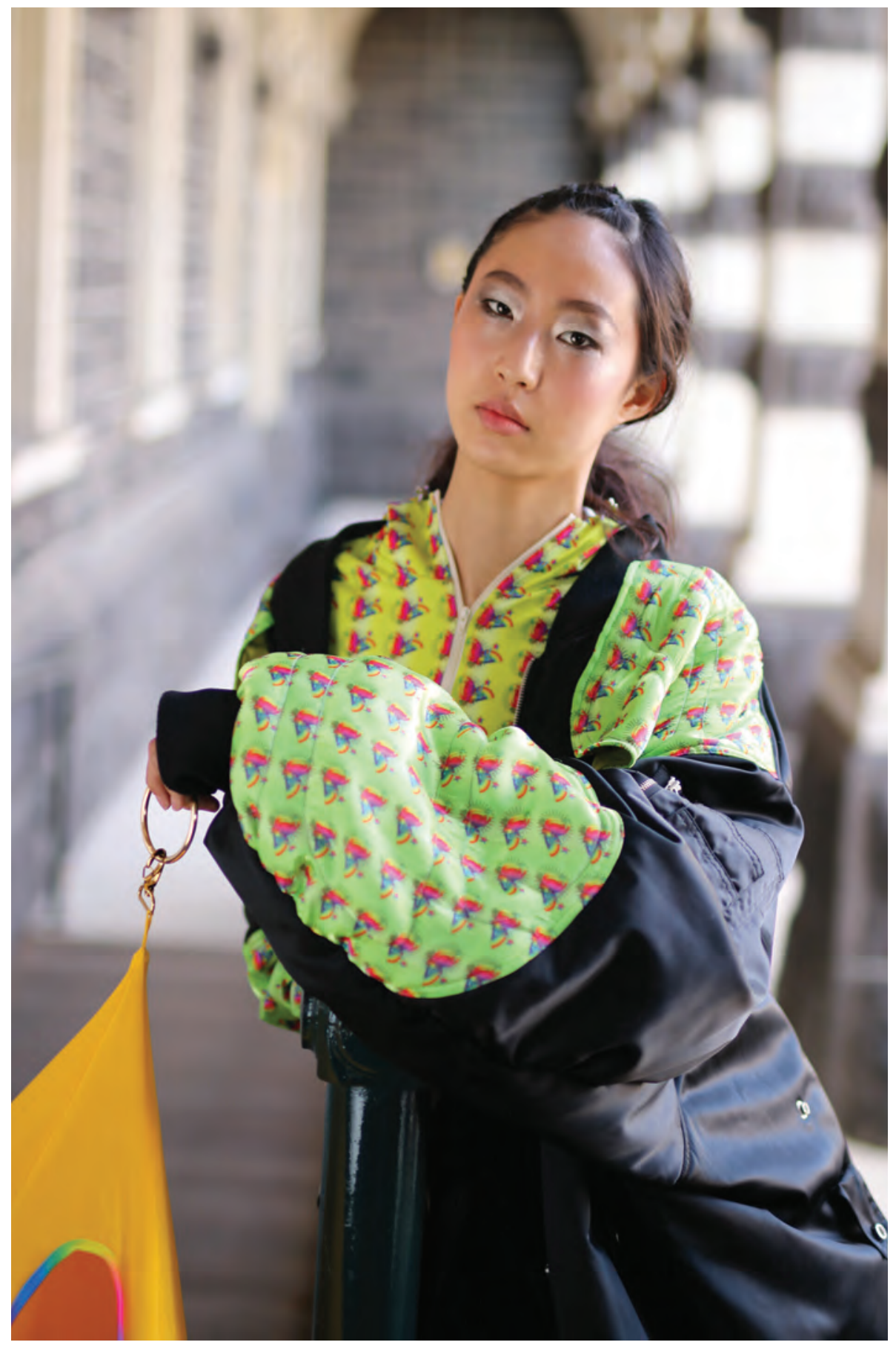

Figure 4. Designer: Minori Yanagese.

Institution: Ozaka Bunka Institute of Fashion, Japan. 


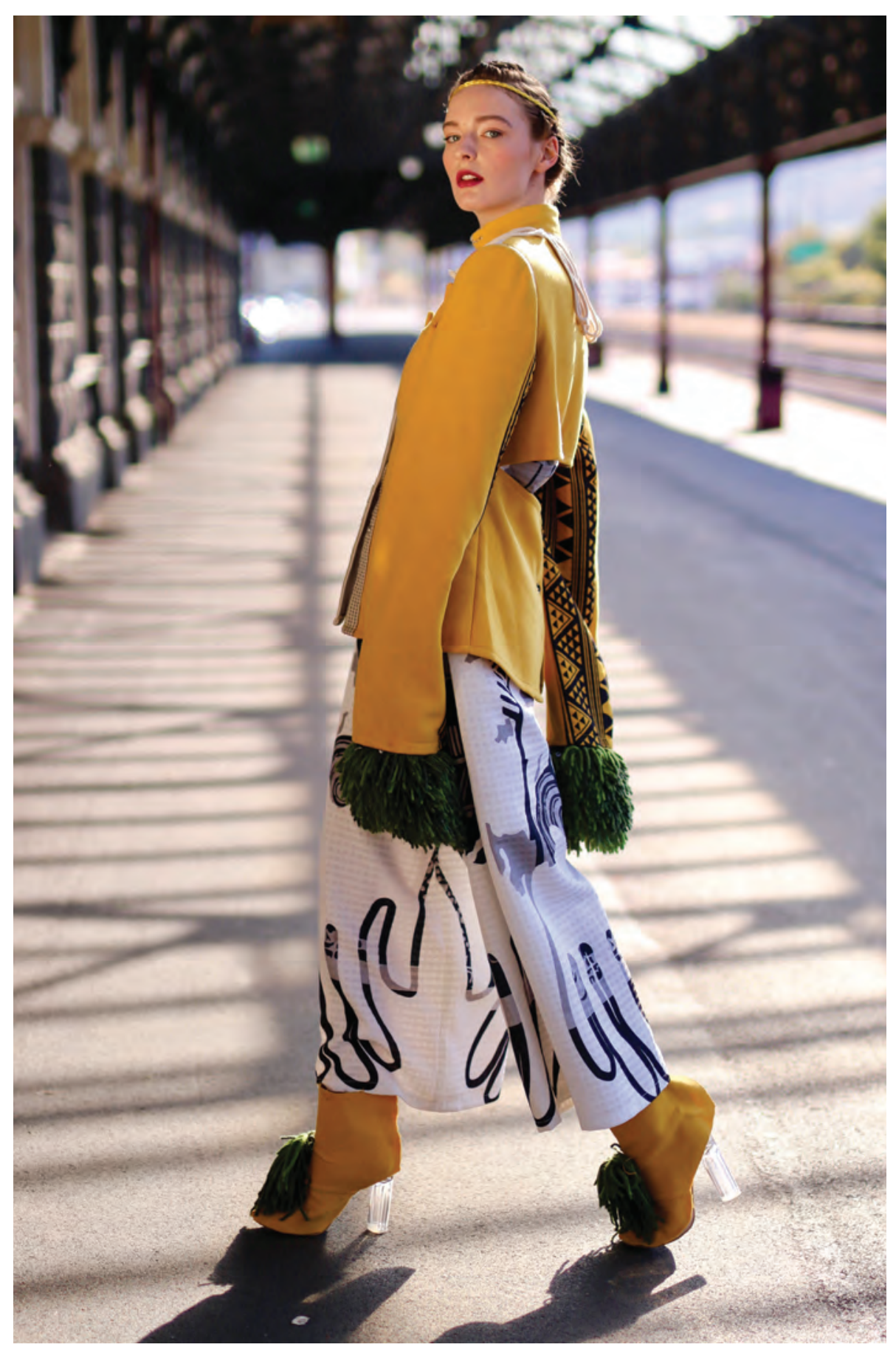

Figure 5. Designer: Xiuliam 'Lian' Zheng. Institution: IFA-SUES, China. Photographer: Jacob Koopman. 


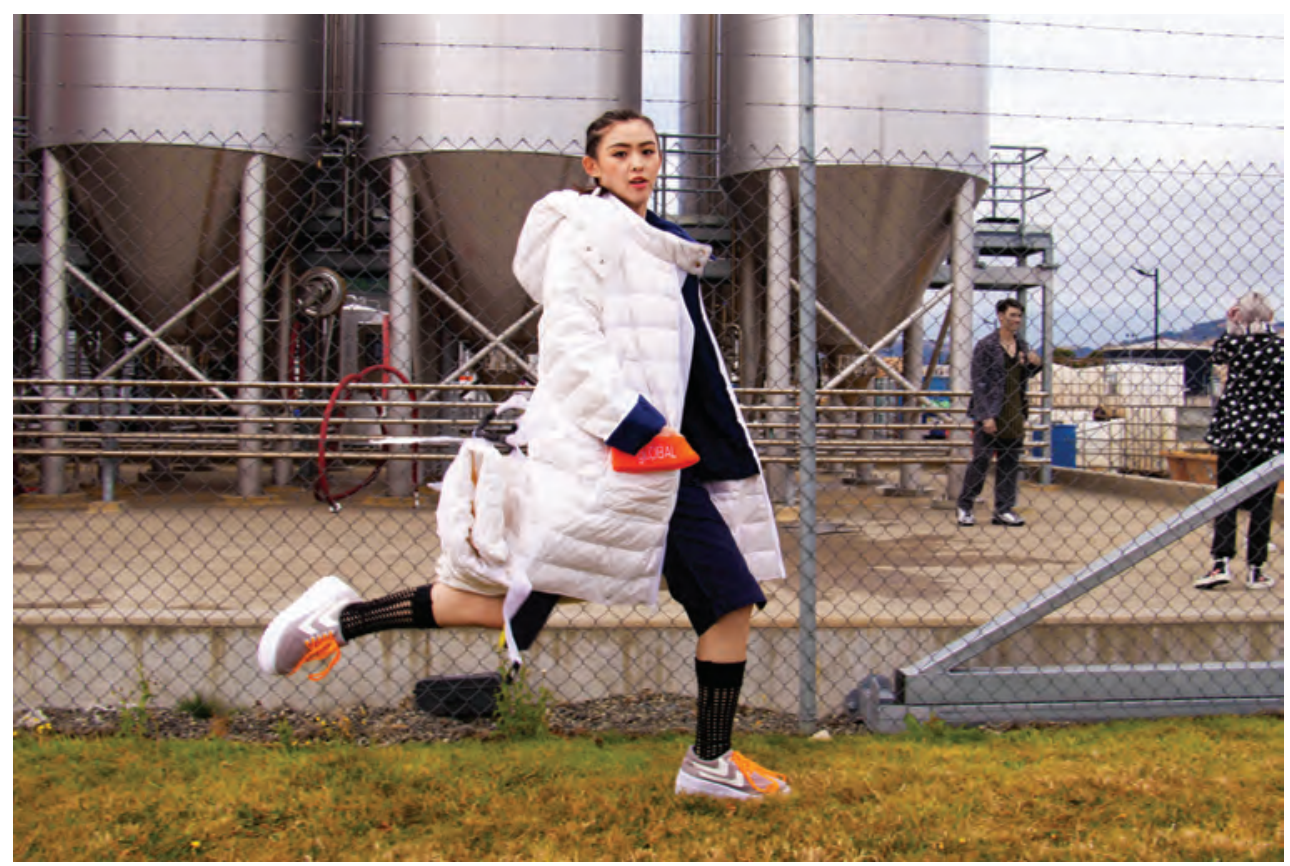

Figure 6. Designer: Cassandra Casas. Institution: Kent State University, USA. Photographer: Laura Wellman.

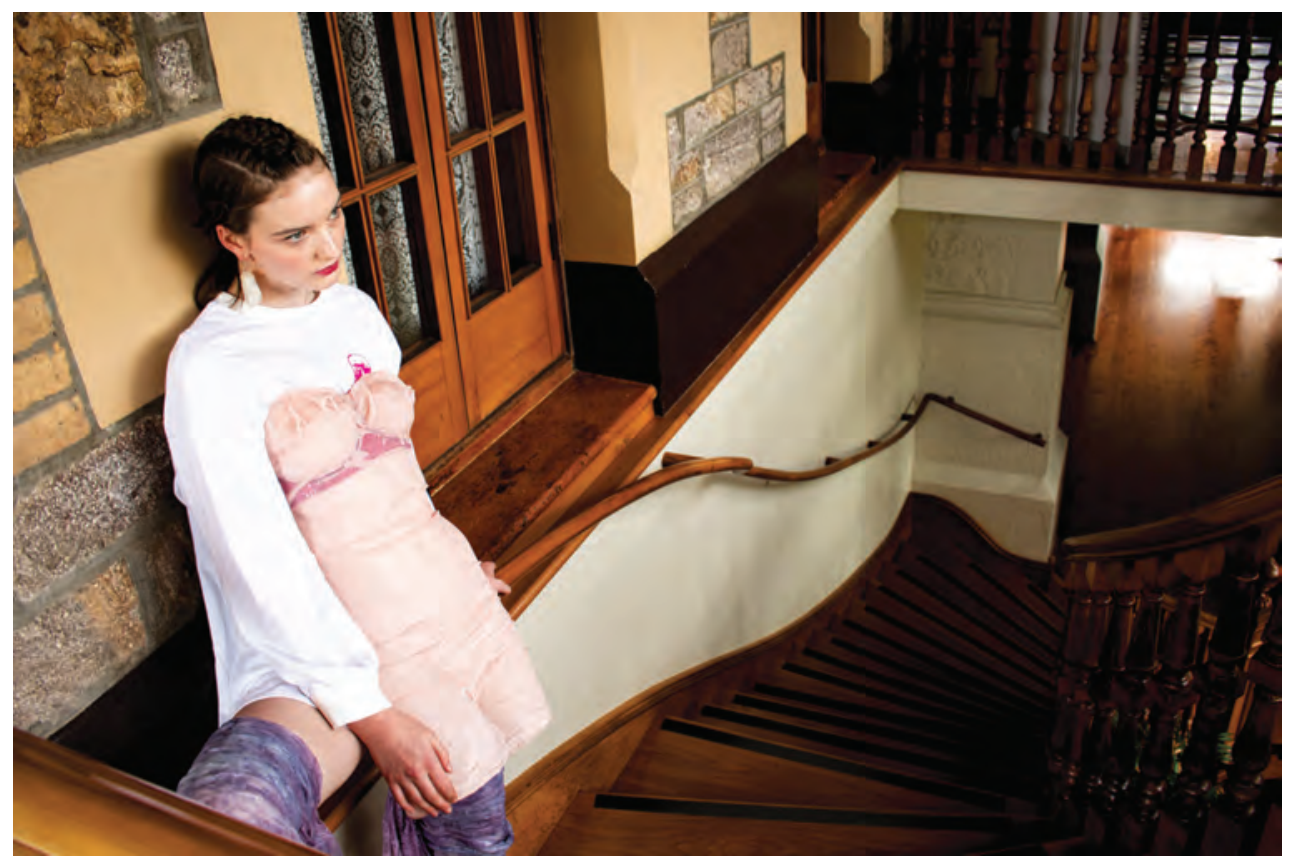

Figure 7. Designer: Olivia Goonatillake. Institution: RMIT, Australia. Photographer: Sam Doorey. 


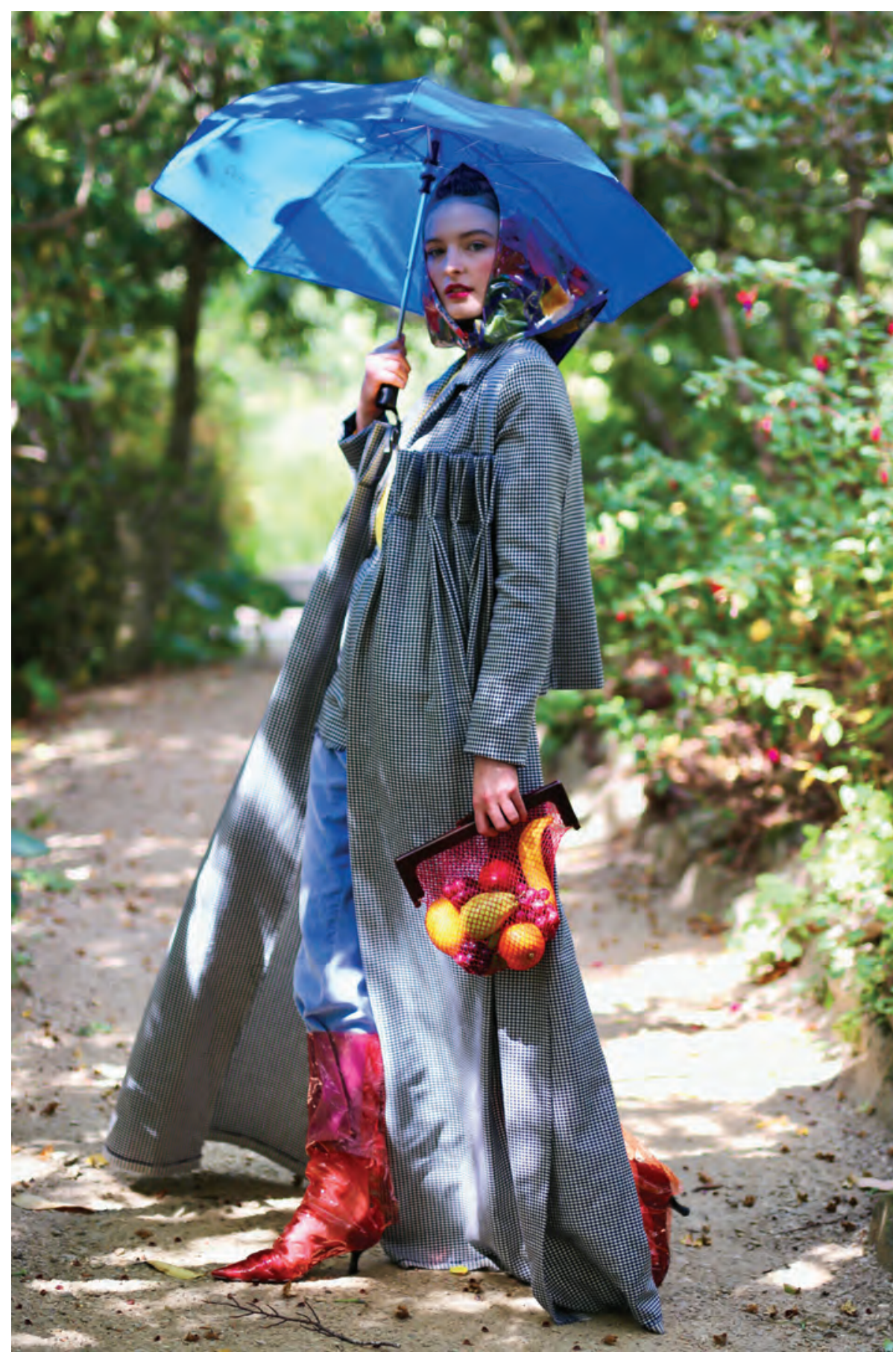

Figure 8. Designer: Anna Petry. Institution: RMIT, Australia. Photographer: Angela Lyon. 


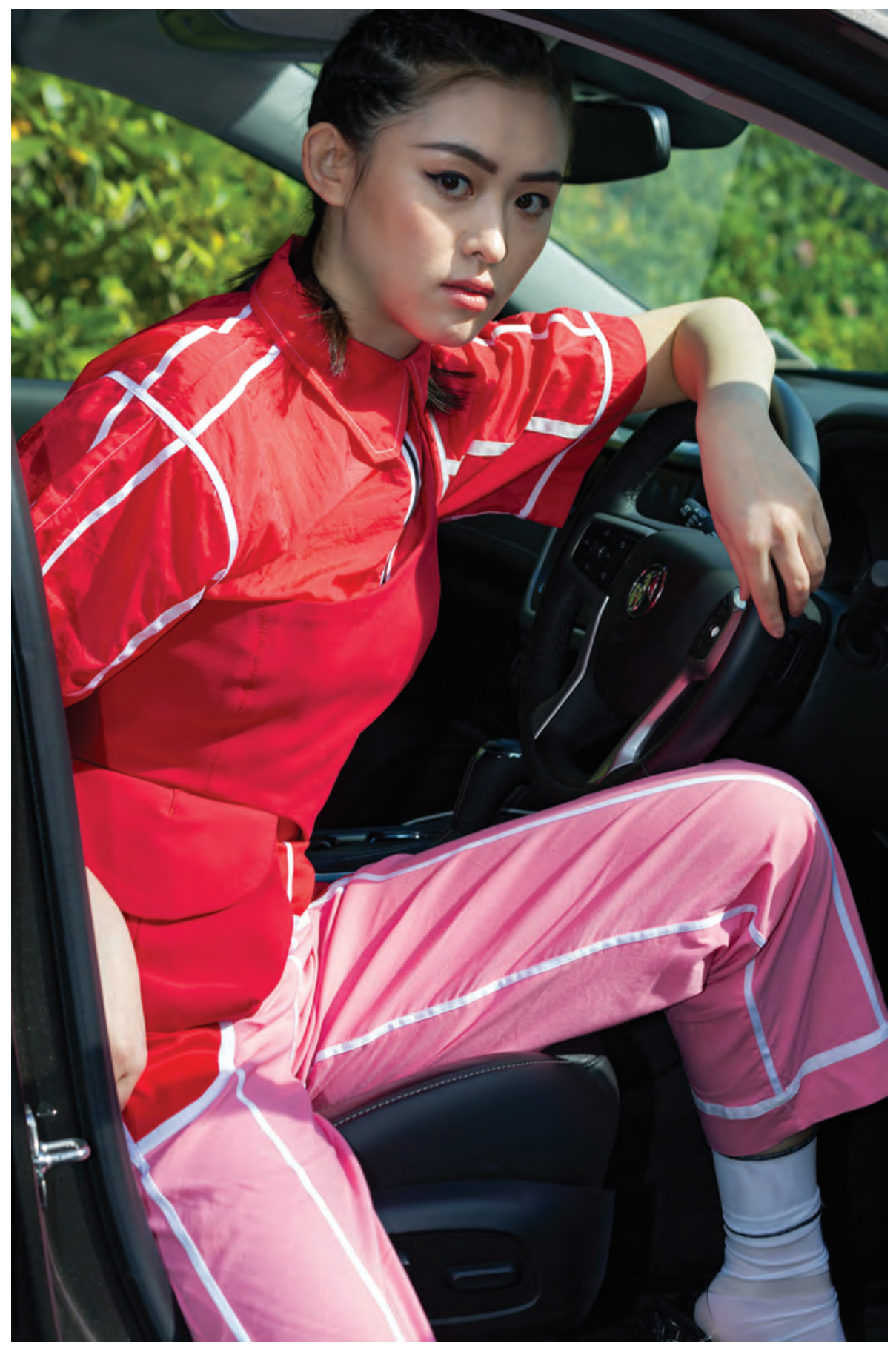

Figure 9. Designer: Lavinia Ilolahia. Institution: Auckland University of Technology, NZ. Photographer: Christopher Hansen. 


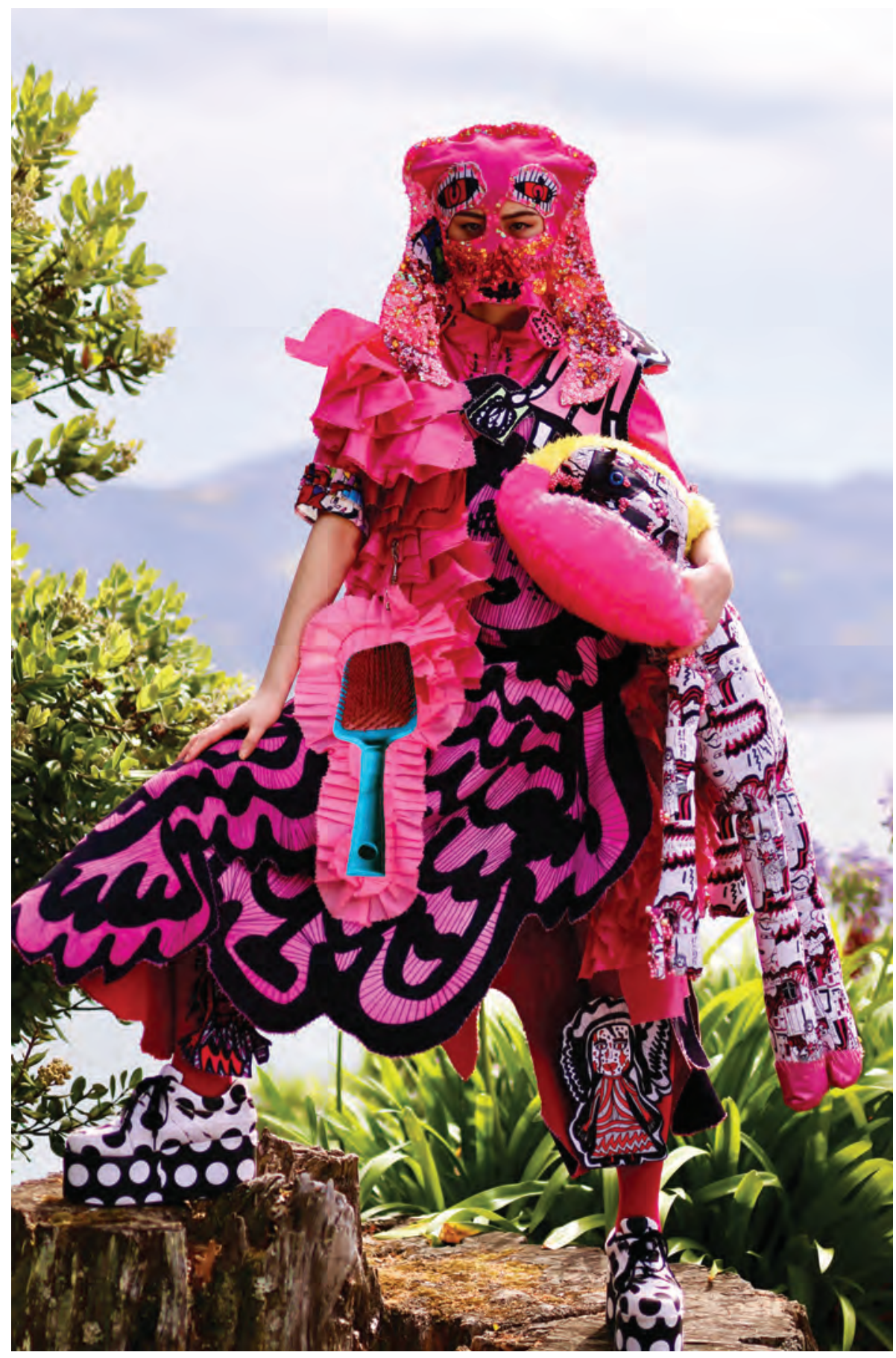

Figure 10. Designer: Rebecca Carrington. Institution: Manchester Metropolitan University, UK. Photographer: Madison Dollman-Low. 


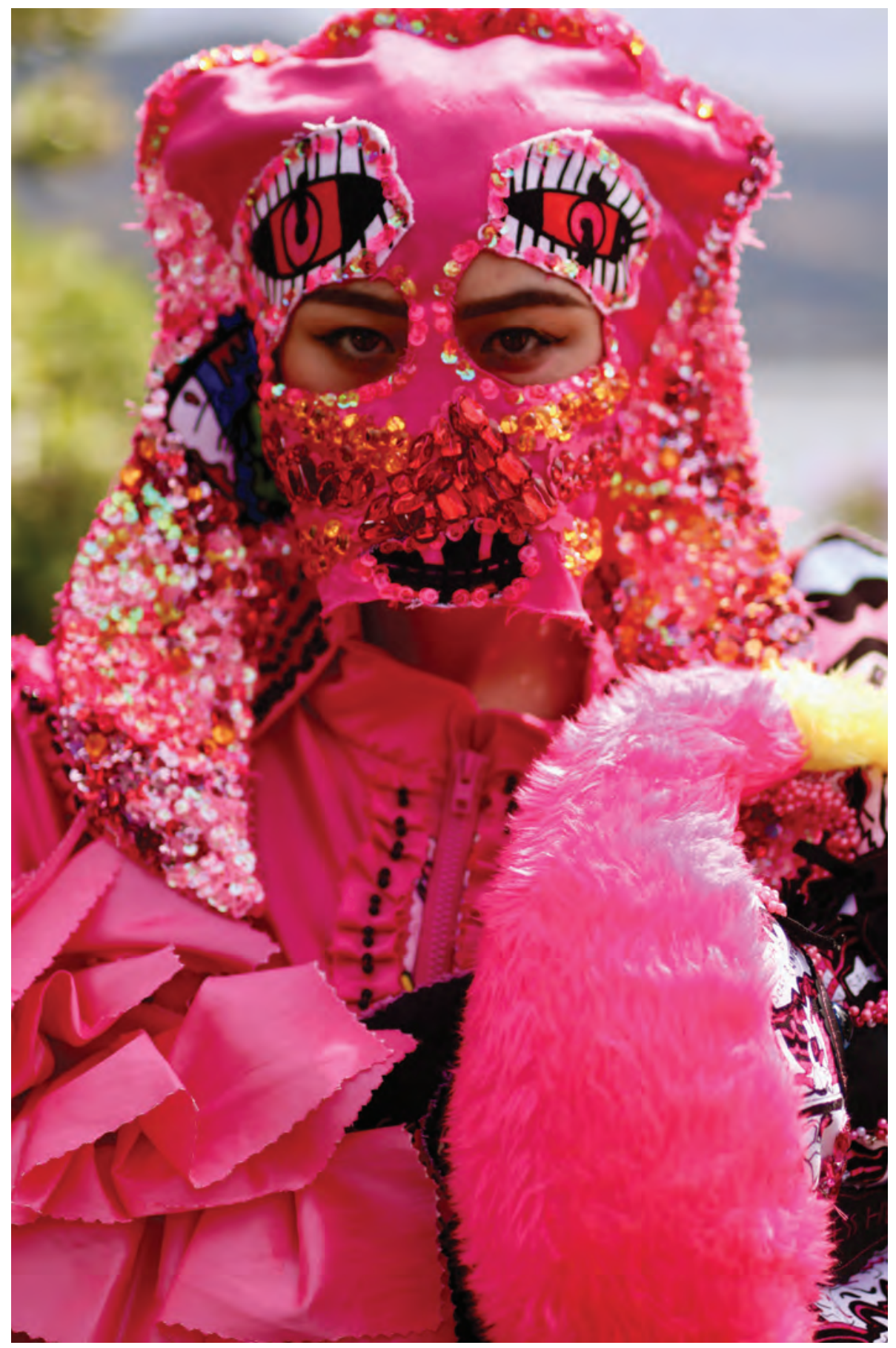

Figure I I. Designer: Rebecca Carrington. Institution: Manchester Metropolitan University, UK. Photographer Angela Lyon. 


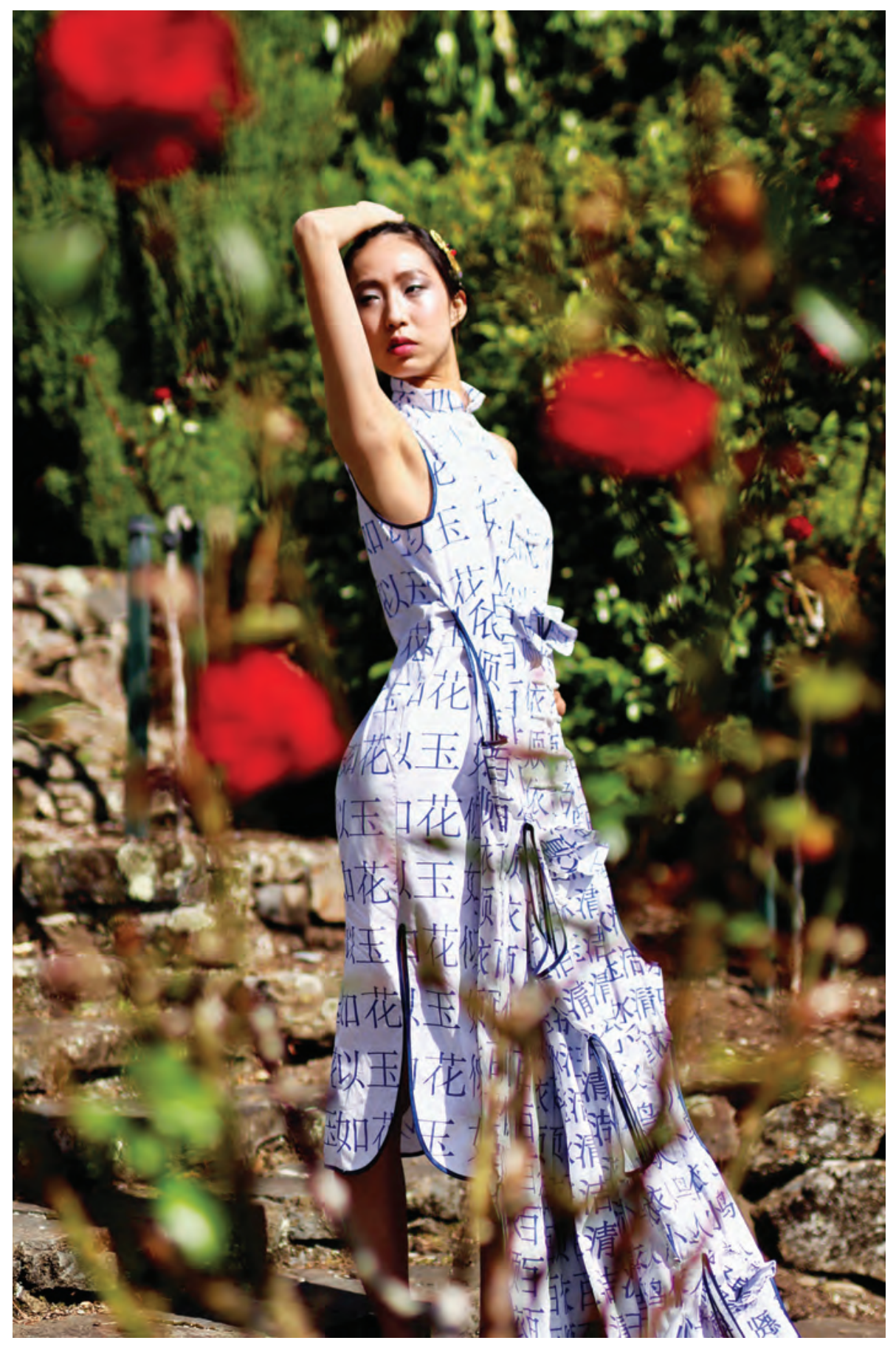

Figure 12. Designer: Betty Liu. Institution: RMIT, Australia. Photographer: Angela Lyon. 


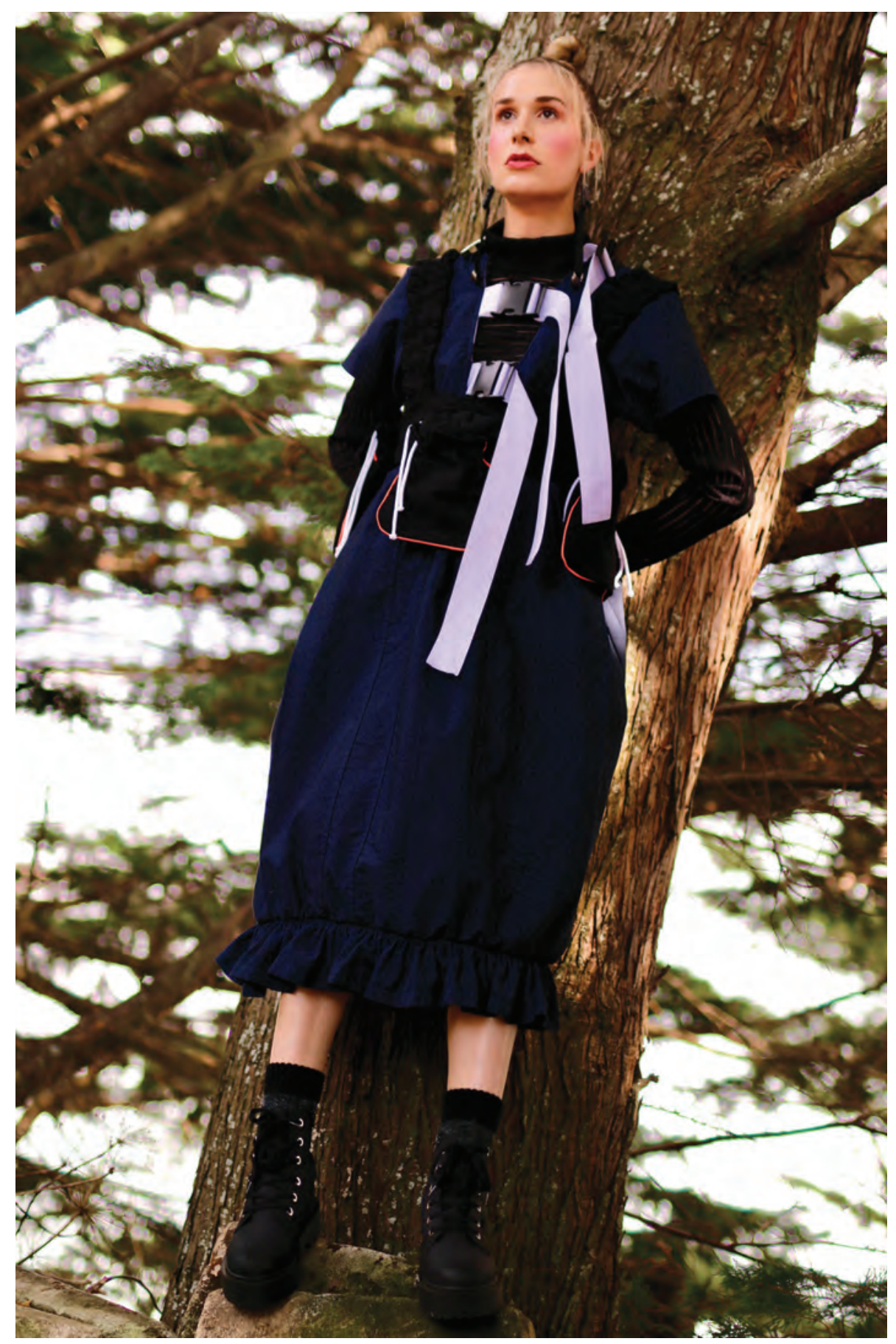

Figure 13. Designer: Kimberley Franklin. Institution: Massey University, New Zealand.

Photographer: Angela Lyon. 


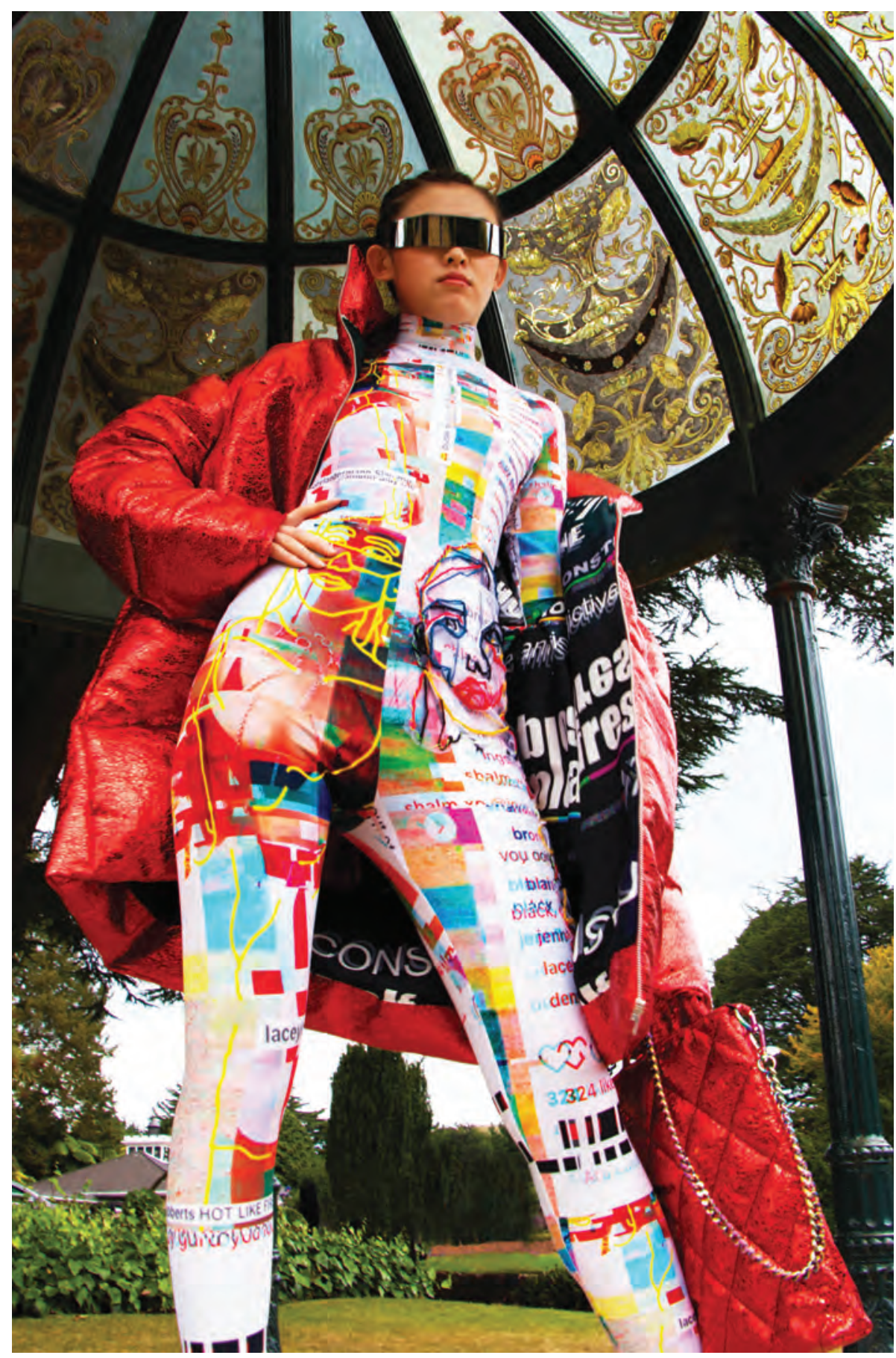

Figure I4. Designer: Eily Shaddock. Institution: QUT, Australia.

Photographer: Laura Wellman. 


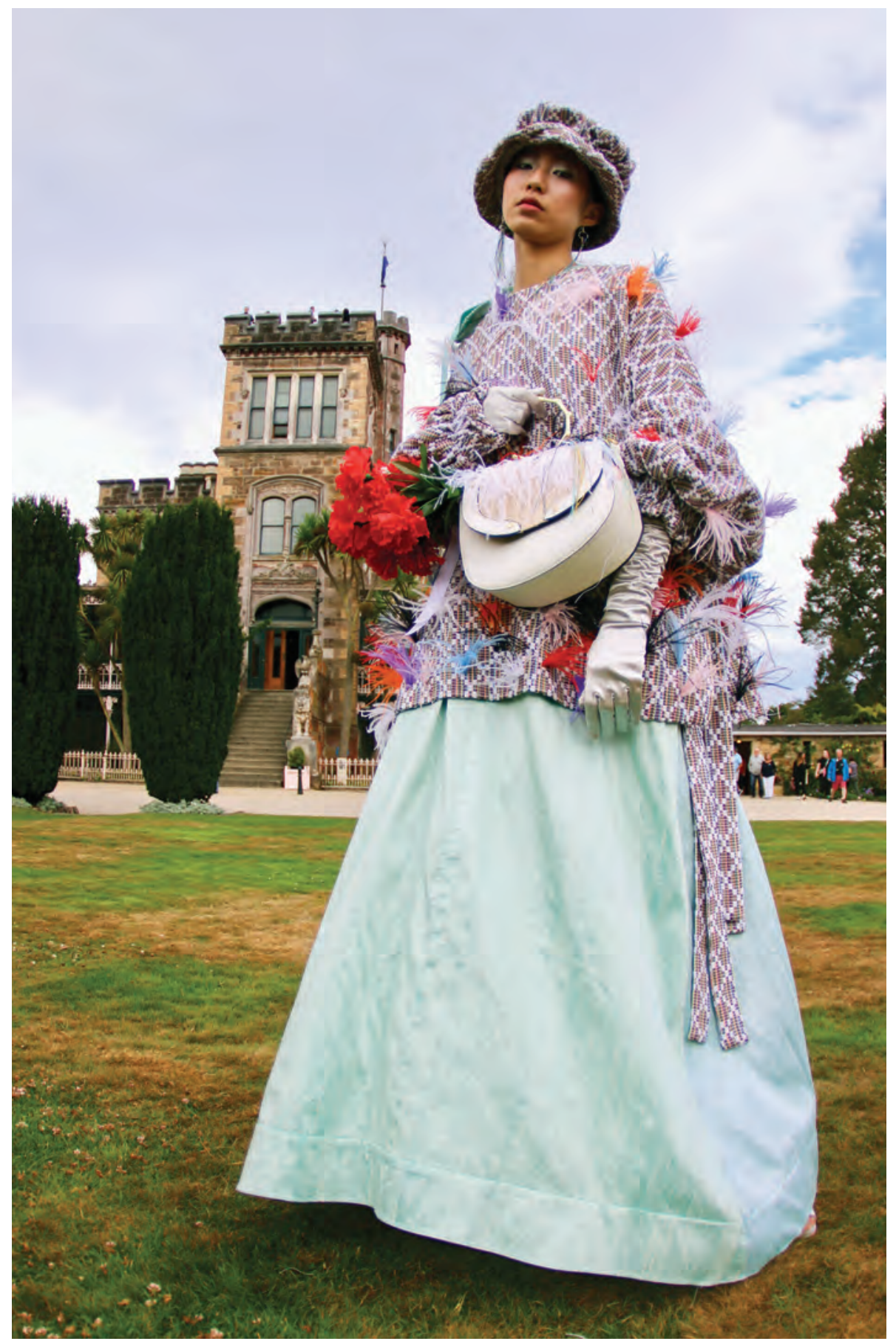

Figure 15. Designer: Amy Lousie Redford. Institution: Manchester Fashion Institute, UK. Photographer: Angela Lyon. 


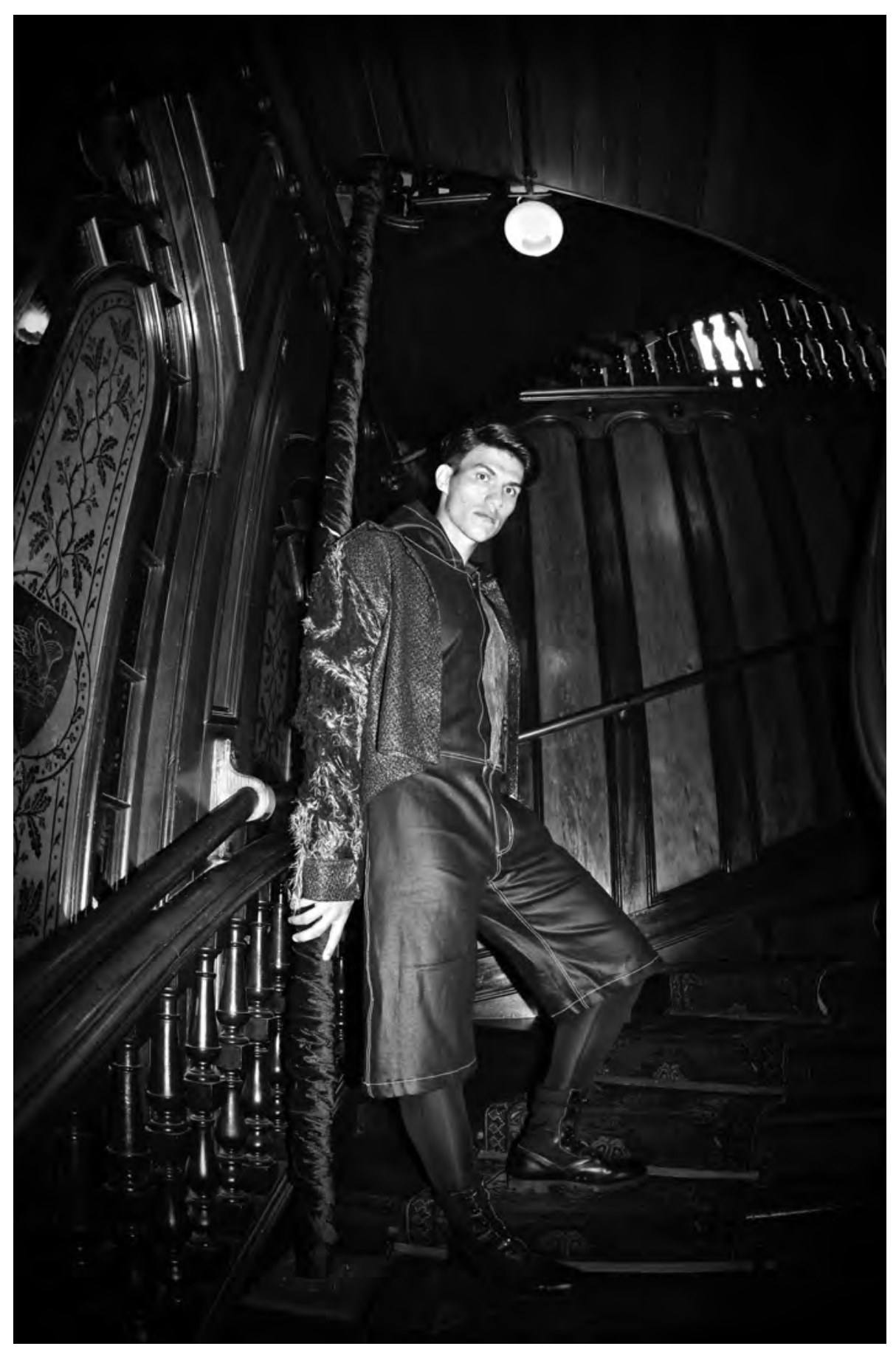

Figure 16. Designer: Erika Ryuu. Institution: Nanyang Academy of Fine Arts, Singapore. Photographer: Riley Coughlin. 


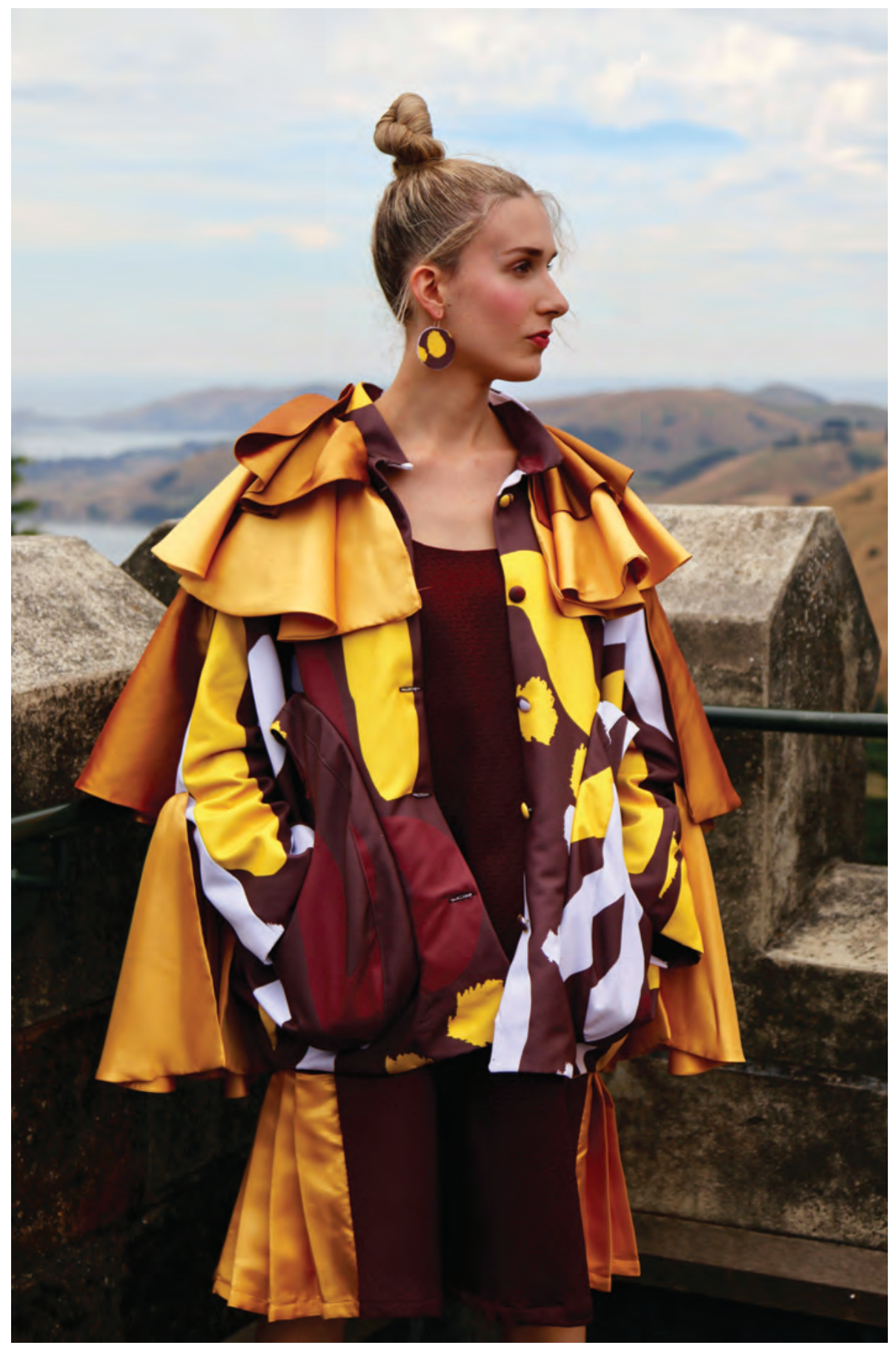

Figure 17. Designer:Tsega Gebremedihm. Institution: Massey University, New Zealand. Photographer: Angela Lyon. 


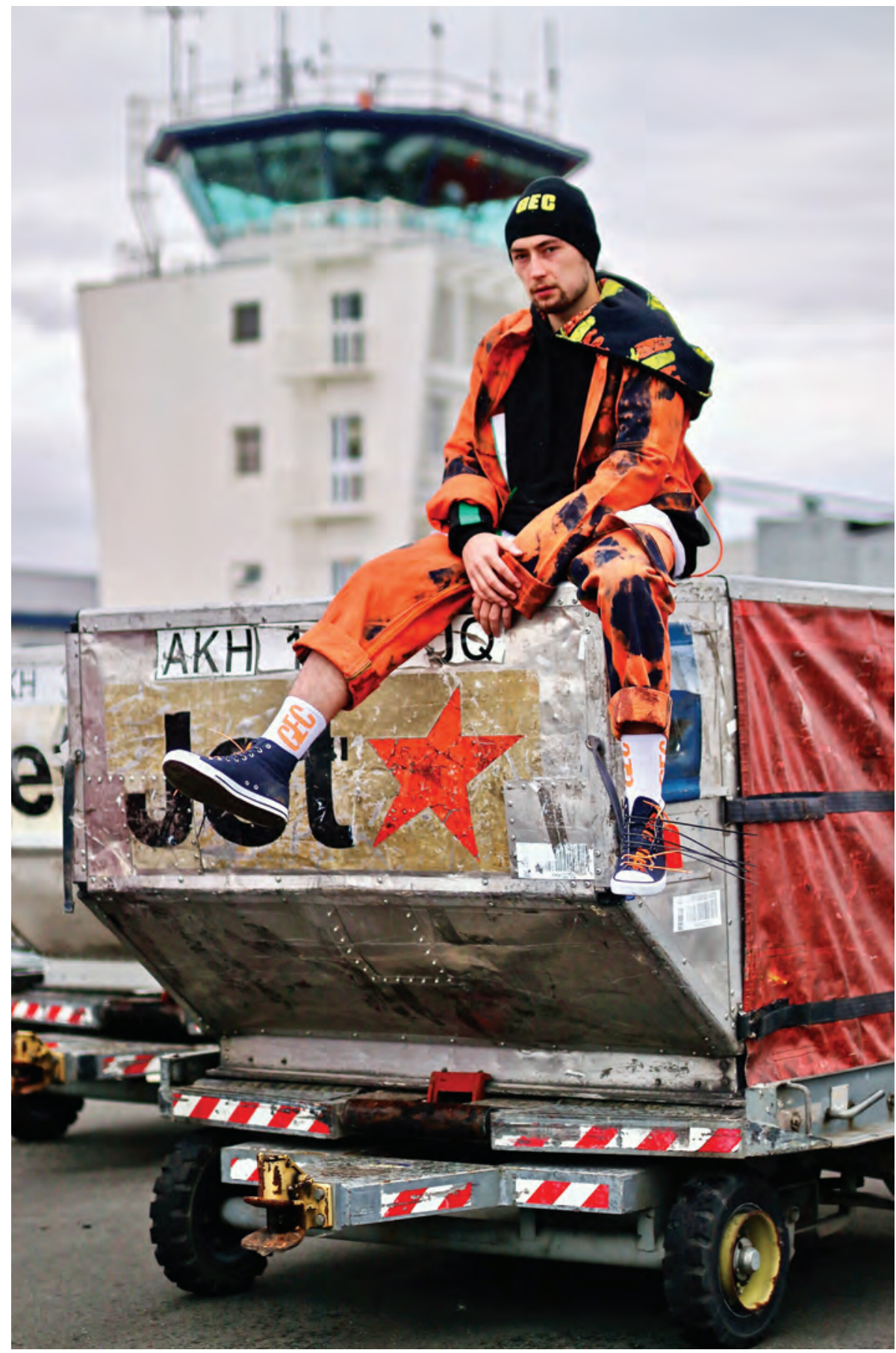

Figure 18. Designer: George Clarke. Institution: Bath Spa University, UK. Photographer: Angela Lyon. 


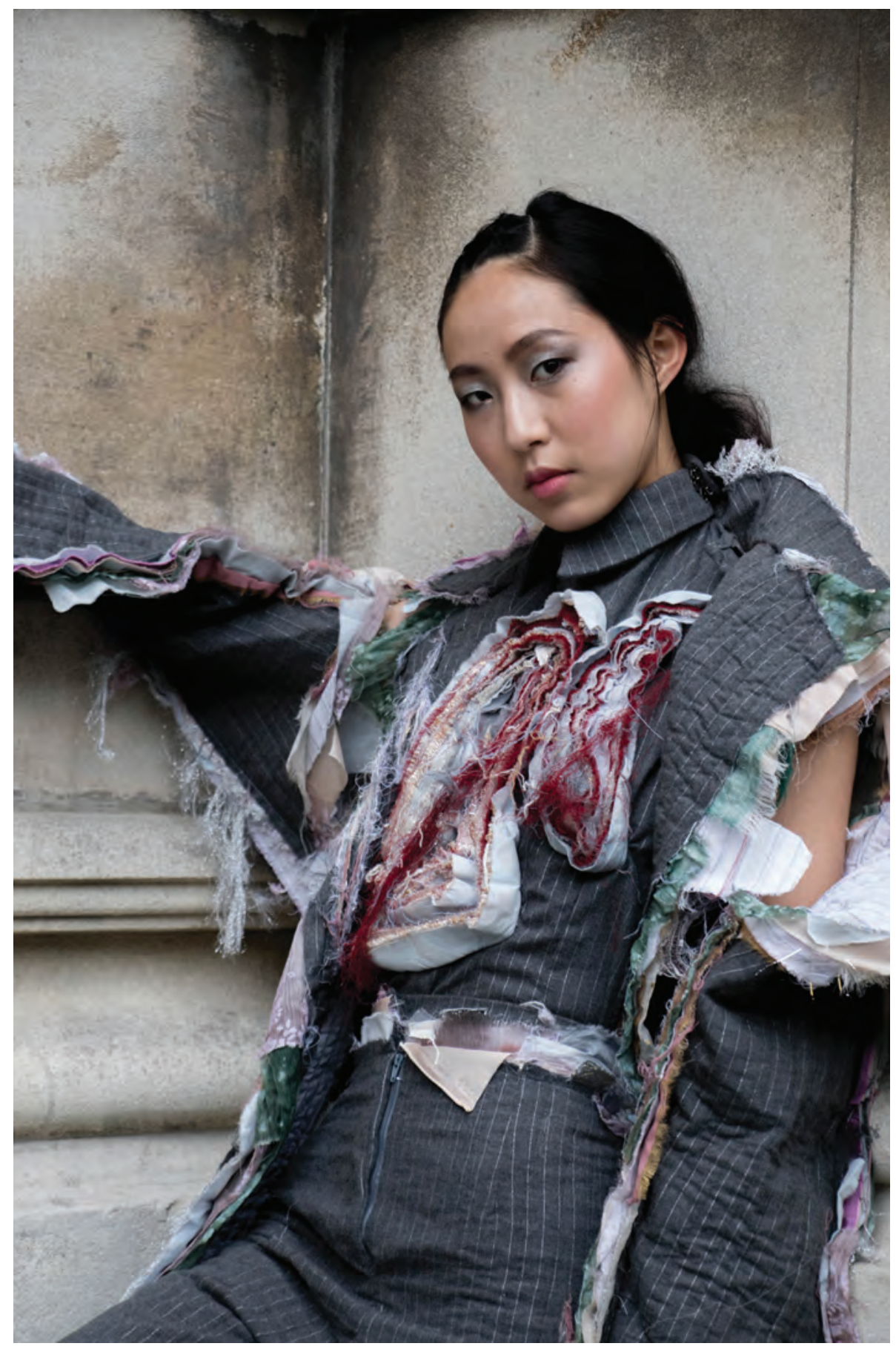

Figure 19. Designer: Ryoyu 'Yumi”'Wang. Institution: RMIT, Australia. 


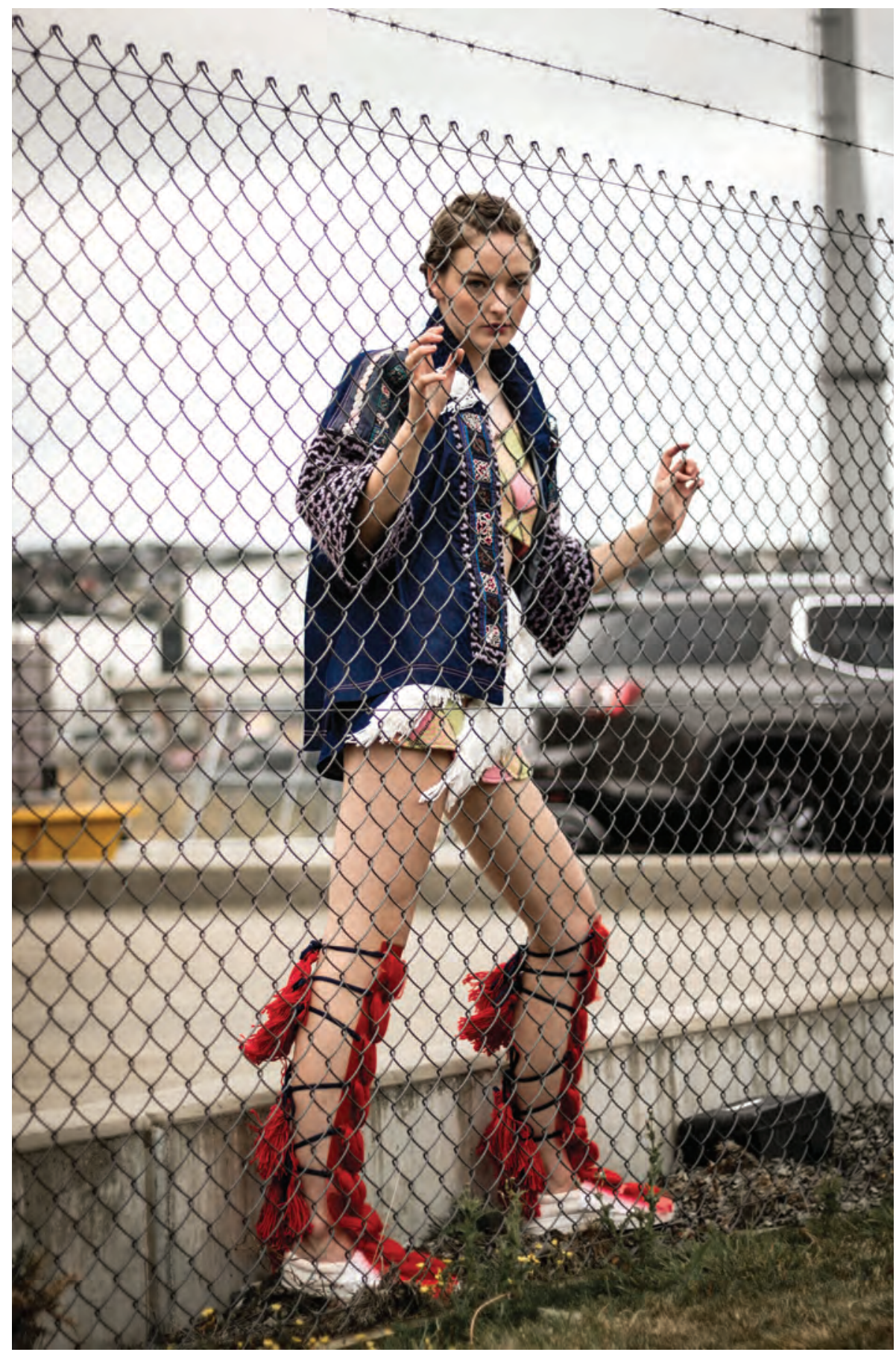

Figure 20. Designer: Xiaoping 'Fiona' Huang. Institution: University of Central Lancashire, UK. Photographer: Sam Doorey. 


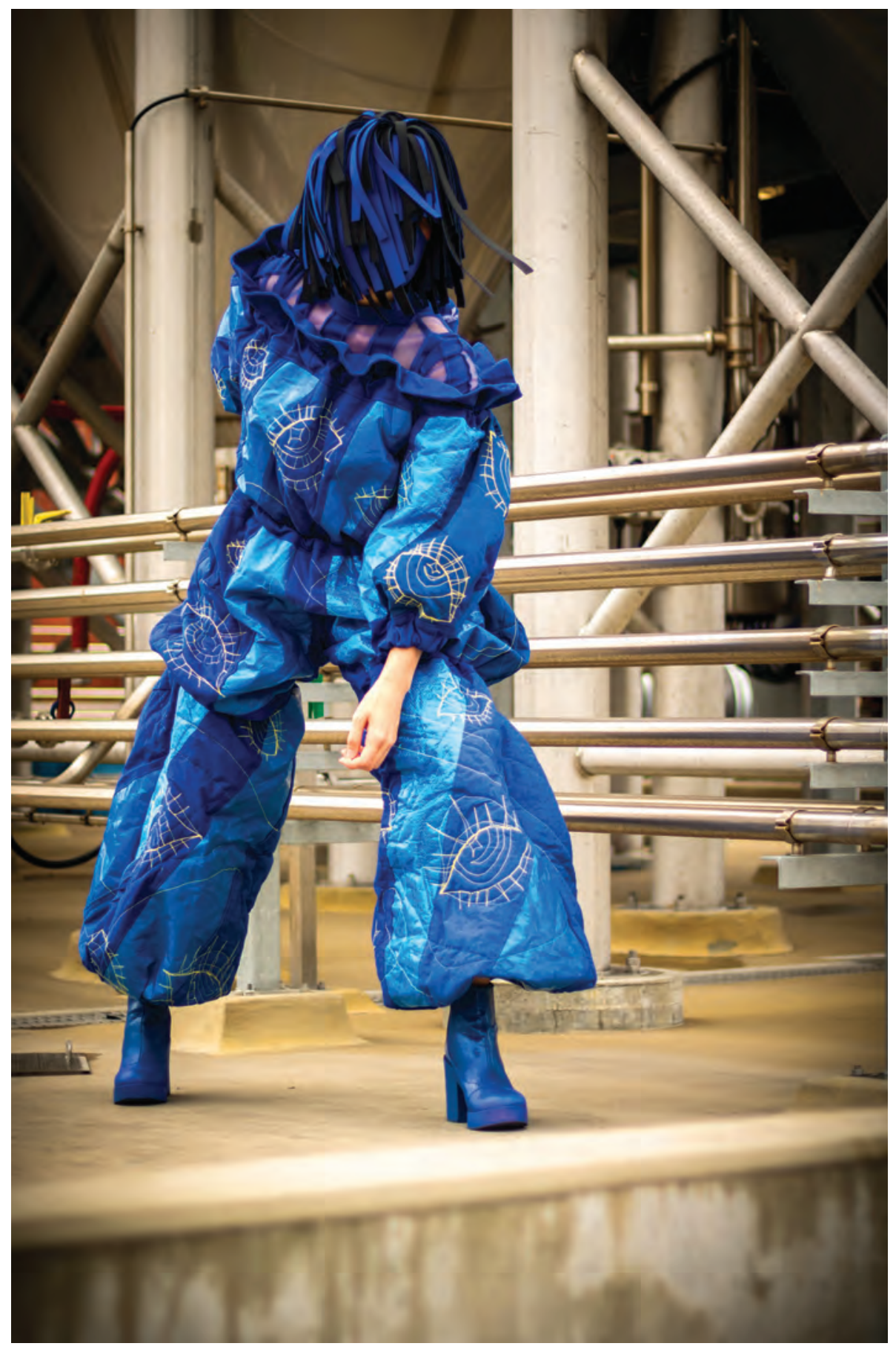

Figure 21. Designer: Bethany Cordwell. Institution: Queensland University of Technology, Australia. Photographer: Sam Doorey. 


\title{
REPORT ON A CLOTHING UPCYCLING SEMINAR, DUNEDIN: RESEARCHING CLOTHING UPCYCLING IN OTAGO
}

\author{
Kirsten Koch
}

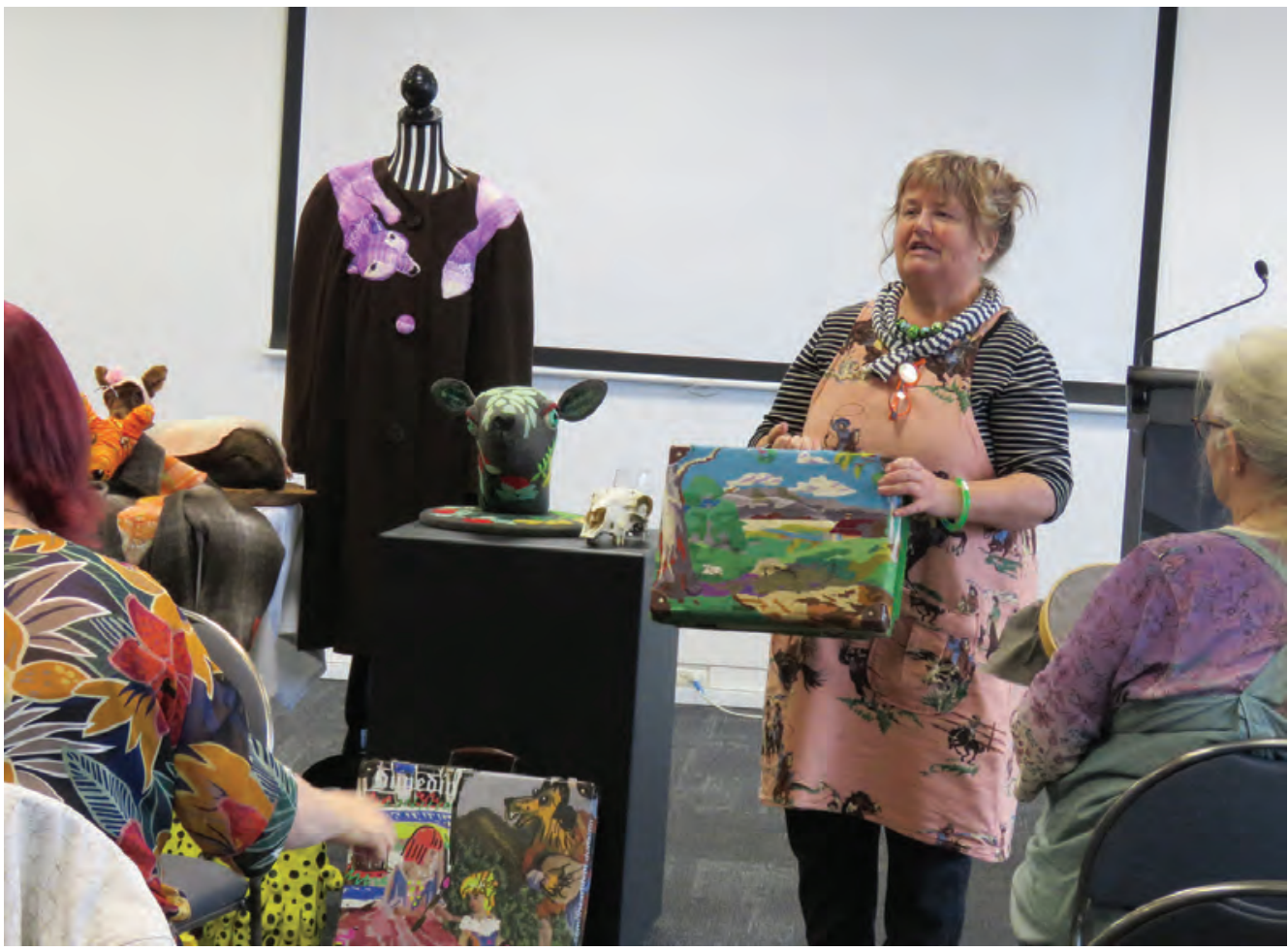

Figure I. Kerry Mackay showing her work at the Seminar. Kerry is holding her 'There's an Elephant buried in my Hometown' 201 I. Found cross-stitch, cardboard suitcase, foam board, artificial turf. Behind on mannequin 'Purple Fox Coat' 2014.

Retro woollen coat, vintage blanket, embroidery thread. (photo credit: Stitch Kitchen).

In this article I start by explaining the term 'clothing upcycling.' I then describe my research themes and I conclude with a summary of the eight presentations given at the Clothing Upcycling Seminar held in the Dunedin Public Art Gallery's conference room on Wednesday 24 April 2019. This seminar was designed as an interactive and public engagement component of my sociology Masters research project, Clothing Upcycling in Ōtākou (Otago). My research design has received approval from Otago University's Human Ethics Committee [reference number: | 8/I76]. All participants mentioned below have given their written informed consent to be part of the seminar, to be identified and to have their words and photographs used for associated media coverage. 
The Clothing Upcycling Seminar was held on 24 April, following iD Dunedin Fashion Week and the Dunedin Fringe Arts Festival - events that I felt 'clothing upcycling' sat somewhere between. The seminar was also intended to continue local action to commemorate Fashion Revolution Day. Fashion Revolution is a not-for-profit organisation that advocates for changes to the fashion industry to improve conditions for textile workers and help the environment. The organisation encourages thinking globally and acting locally in one's own community to celebrate local makers and to assess their working conditions and their connections to the global fashion industry. This ethos of both celebration and critique, and locating local practice within global industry and global practice, aligns with the way I had designed the research.

\section{RESEARCH ON CLOTHING UPCYCLING}

Upcycling is a fashion term used to describe the "technique of upgrading and adding value to a product or material that may otherwise be discarded."

For the broader research project, I interviewed around 13 local upcyclers. My research is designed to explore the under-researched area of local clothing upcycling practice. In addition to developing an overview of the field, I asked participants specific questions about how they situate their practice in relation to the global fashion industry and various fashion movements, and how they have set up their own practice and the conditions of their labour force.

The first interview focused on the participants' background in textiles and clothing upcycling and asked how they had organised their practice. The second interview was a studio visit where I asked participants about their processes and fashion alignment, taking photographs of their spaces, processes and completed designs.

Not all participants made solely wearable pieces; some used other 'slow fashion' techniques besides upcycling in their designs, and not all participants gave the name 'upcycling' to the techniques they used. I also intend to ask participants how they label their upcycling techniques, how they learnt and modified their techniques, and how they source and process upcycled materials. In this project, I do not anticipate surveying participants' entire practice, but rather seek to draw out relevant information about local upcycling, how upcycling fits within a participant's practice, seeking to represent each participant's voice in a personalised and narrative style.

As a clothing upcycler myself, the main aim of the research for me is to give participants the ability to respond academically and to directly engage with the public - a maker's perspective that honours the rich language of textiles, and the aesthetic, stylistic and pragmatic considerations that textile practitioners negotiate while creating their designs and structuring their practice or business.

For this research, I have concentrated on participants' wearable pieces with a view to discovering a clear correlation between these pieces and their making, on the one hand, and current fashion industry practice on the other. I will be asking participants to discuss their current practice, but will also focus on the upcycling processes within their practice and what they have to say about the dynamics of their practice including themes such as economics, health and well-being, precarious employment, passion work, career and life pathways, and female employment in the fashion and arts industries. These were all themes considered by Angela McRobbie in her book Be Creative: Making a Living in the New Culture Industries, ${ }^{2}$ which I had read while formulating the project.

Many of the participants' practices also echo social enterprise models for the creative arts industry discussed by McQuilten and White. ${ }^{3}$ The authors apply these models to the whole of the arts industry, arguing that no art piece or art-making can be unsullied or divorced from economics. So how does art happen in late-Fordism? They argue that a social enterprise model is becoming increasingly popular in terms of fitting the 'social good' that, artists in particular claim, creative industry provides. In her 2017 article "Political Possibilities of Art and Fashion Based Social Enterprise,"4 McQuilten researched the organisational structure and guiding principles of several 
Melbourne cultural textile groups. I created my interview themes in the light of the analysis provided in the three texts mentioned above.

\section{INFLUENCE OF FASHION MOVEMENTS}

In Dunedin, local upcycler designers are working in different ways that consciously or unconsciously employ eco fashion, ${ }^{5}$ anti-fashion, ${ }^{6}$ slow fashion ${ }^{7}$ and post-humanist approaches to fashion. ${ }^{8}$ Some of these themes were explored in the 2017 fashion number of the Otago Polytechnic journal Scope: Contemporary Research Topics (thescopes.org). Terms such as the death of fashion, post-fashion and fashion entropy reflect questions about how long the fashion industry can sustain itself at its current accelerated pace. ${ }^{9}$

With culturally exploitative practices and appropriation, and often limited representations of cultural 'difference,'10 these fashion issues and their associated theories prompt questions such as: Is the 'fashion' component about the article itself and how it was made? What of the maker and the craft? Where does the fashion design process sit and who benefits? Are textile materials simply materials? And how do you ethically source fabric and manufacture garments in an economically viable way? Are the structures of the fashion industry and late capitalism significantly shaping the way that fashion designers, artists and practitioners create and exist?

Fashion advertising has always utilised the idea of 'the look,' and the slow fashion movement," ' and subsequently upcycling, could perhaps be viewed, in part, as refocusing on the authenticity of 'the look.' Here the wearer owns the ethics behind the manufacture of their garment and the aesthetic decisions they employ when creating their 'look.' The slow fashion movement has reinstated the ready-to-wear ethos whereby wearers seek out vintage articles and meld them together with imagination and an artistic eye. Yet the movement is also an acknowledgement of the time it takes to design garments critically and to make them in a way that is responsive to materials, aesthetics and form. It has similarities with the haute couture ethos of valuing clothes, the craftmanship behind their design, and the material and environmental costs behind their manufacture. This sensitivity elevates the status of the wearer through their affiliation with the values embedded in their threads. This is a call made by Lidewij Edelkoort in her manifesto, Anti-Fashion: A Manifesto for the Next Decade ${ }^{12}$ - yet Edelkoort also calls for more everyday wear and the breakdown of upper-class, high fashion ideals in favour of a younger and more inclusive, democratised fashion face.

Two major public events organised for Fashion Revolution Week, which took place in the Octagon, Dunedin, in 2016 and 2017, are described in Fiona Clements' article "Unstitched: Local Fashion Revolution Dunedin."'13 Fiona Clements is the local Fashion Revolution representative in Dunedin. Stitch Kitchen is a trust set up under the name Just Atelier in 2015 by Fiona Clements and Fiona Jenkin. Desi Liversage has also played a key role in Stitch Kitchen and many other participants have been involved in its activities. Stitch Kitchen promotes public awareness of Fashion Revolution Day by promoting local designers, holding classes and engaging in community advocacy for the improvement of the social and environmental conditions found in the global fashion industry.

\section{CONDITIONS OF LOCAL AND GLOBAL TEXTILE WORK}

While textile workers around the world experience harsher labour conditions than are found in the New Zealand industry, the 2019 Tearfund report on ethical fashion ${ }^{14}$ and New Zealand designers' media responses to it indicate that the local industry is barely limping along. So what are the creative and employment possibilities in the local industry? And what is the structure of the global textile and fashion industry? Between maker and designer, and within the non-transparent manufacturing structures we support through our business practices as makers/ designers, and also in our fashion consumption, in the manufacturing models we support, there is room to ask: What can we do to subvert the industry through mending and self-ornament and by supporting ethical craftsmanship and buying quality, buying arty. 


\section{WHY PARTICIPANTS MAKE}

The participants in the study group are making for a variety of reasons. Many have their work for sale, some make for themselves, make for others, exchange pieces, make to show as wearable arts, as fine arts, or as sustainable fashion and a form of community political action. They are making, teaching others to make, working as part of a group, communicating and promoting work online, connecting with other global upcycling and slow fashion movements online, advocating for slow fashion and the arts, and capacity-building in the local community.

Some participants conceive of their practice in a spiritual or philosophical way, wanting to make and connect to nature, living a simple, more peaceful lifestyle, weaving from the llama's back, or simply being able to slip away into the meditative, calming and simultaneously exciting world of fabric, texture and form. Others conceive of their making as an overt political and economic activity, both at the macro level in their critique of the fashion industry, and also at the micro level in terms of the conditions of their employment, creating a sustainable ethos in their practice, and being aware of the supports and restraints they experience in sustaining their practice and their need to sustain themselves economically while practicing textile or clothing upcycling.

These two perspectives are not exclusive, however, and most participants identified spiritual, material and ideological drivers for their practice. The idea of sustaining one's business economically as a clothing designer in New Zealand, following a craft maker model, ${ }^{15}$ was discussed by Ariane Bray in the 2017 Scope fashion number. ${ }^{16}$

One aim of my research is to locate 'upcycler' designers in the history of New Zealand and Dunedin fashion and garment manufacturing. I also compare participants' thoughts on working conditions alongside other local slow fashion and craft-maker ideas. At this point in my research, I am bringing the literature reviews and the first interviews together, so my analysis is still some way from finding its final form.

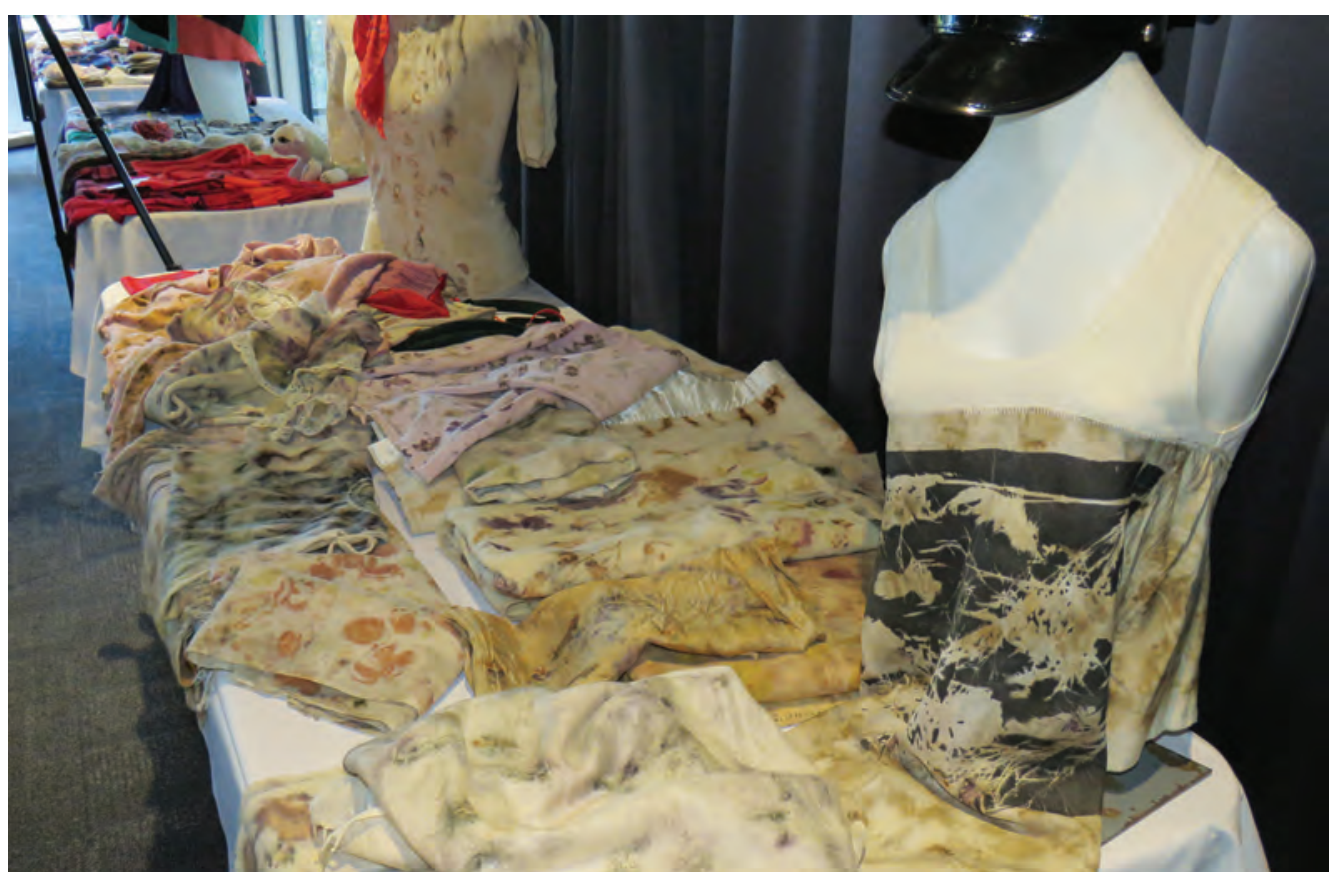

Figure 2. Kirsten Koch's Seminar display table. Eco dyed and printed work on table and eco-dyed and nature printed tank top (2017-2019). Upcycled merino singlet previously owned by designer's mother, dyed silk panel stitched with vintage silk embroidery thread with poly-cotton machine thread mend. Photo credit: Stitch Kitchen. 


\section{CLOTHING UPCYCLING SEMINAR, DUNEDIN, 24 APRIL 2019}

The seminar was a great success, with eight local Ōtākou textile practitioners, artists and designers discussing their practice and the garments they create using second-hand fabrics and clothing as a base material. Summaries of their contributions are given below.

\section{Kirsten Koch}

I showed PowerPoint images of my earlier textile artwork using upcycled materials and spoke about my connection to place, nature and family, all important features of my work. I mentioned my enjoyment of dress-ups, a practice I began early, making my own jewellery and adapting op-shop clothing as a young teen. My presentation moved on to showing images of my recent eco-dye, eco-print and nature prints on second-hand fabric and clothing. The eco-dye and eco-print works use a direct dye process using native and exotic flowers, leaves and plant material to create colours and outlines of the material forms. These are printed onto second-hand protein-based fabrics and clothes. My nature prints are created using raw plant and animal materials like kereru and seagull feathers, grass seeds and leaves, which are used as a resist under a silk screen ready to print onto fabric. I have been printing directly onto clothing, patching on prints and also nature-printing onto eco-dyed pieces. While I want to trial some more structural designs myself, I also like the idea of working with someone with more tailoring experience on joint projects. I have enjoyed taking eco-dye/eco-print workshops and have been working on a series of Love Blankets or Love Rugs, with the idea of working on commission for groups and families to make commemorative pieces for a birth, wedding/union or death, using the client's own flowers or foliage and fabric or blankets as materials.

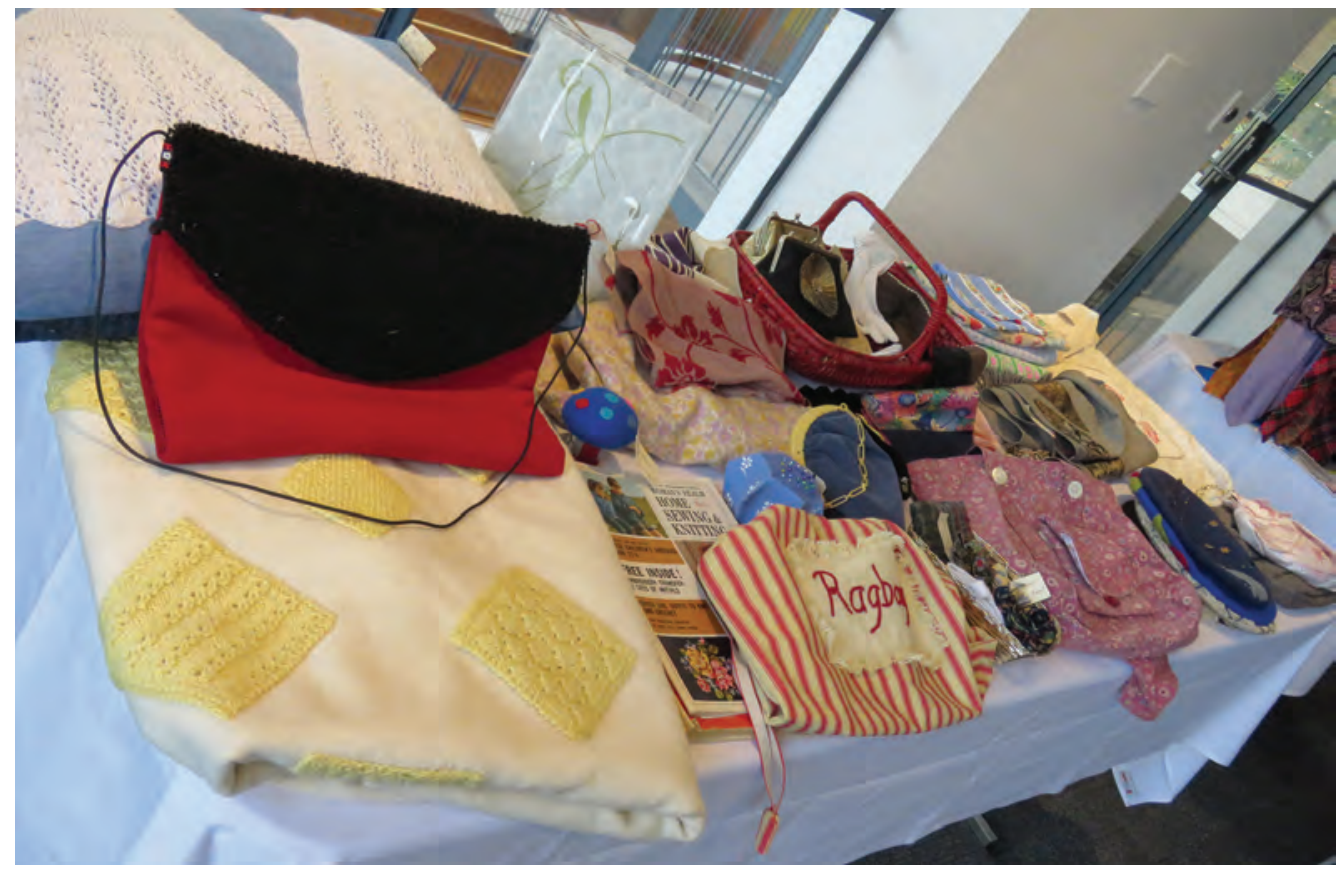

Figure 3. Elena Poletti's seminar display table. Examples of Elena's work reusing and repurposing fabric and clothing. Photo credit: Stitch Kitchen. 


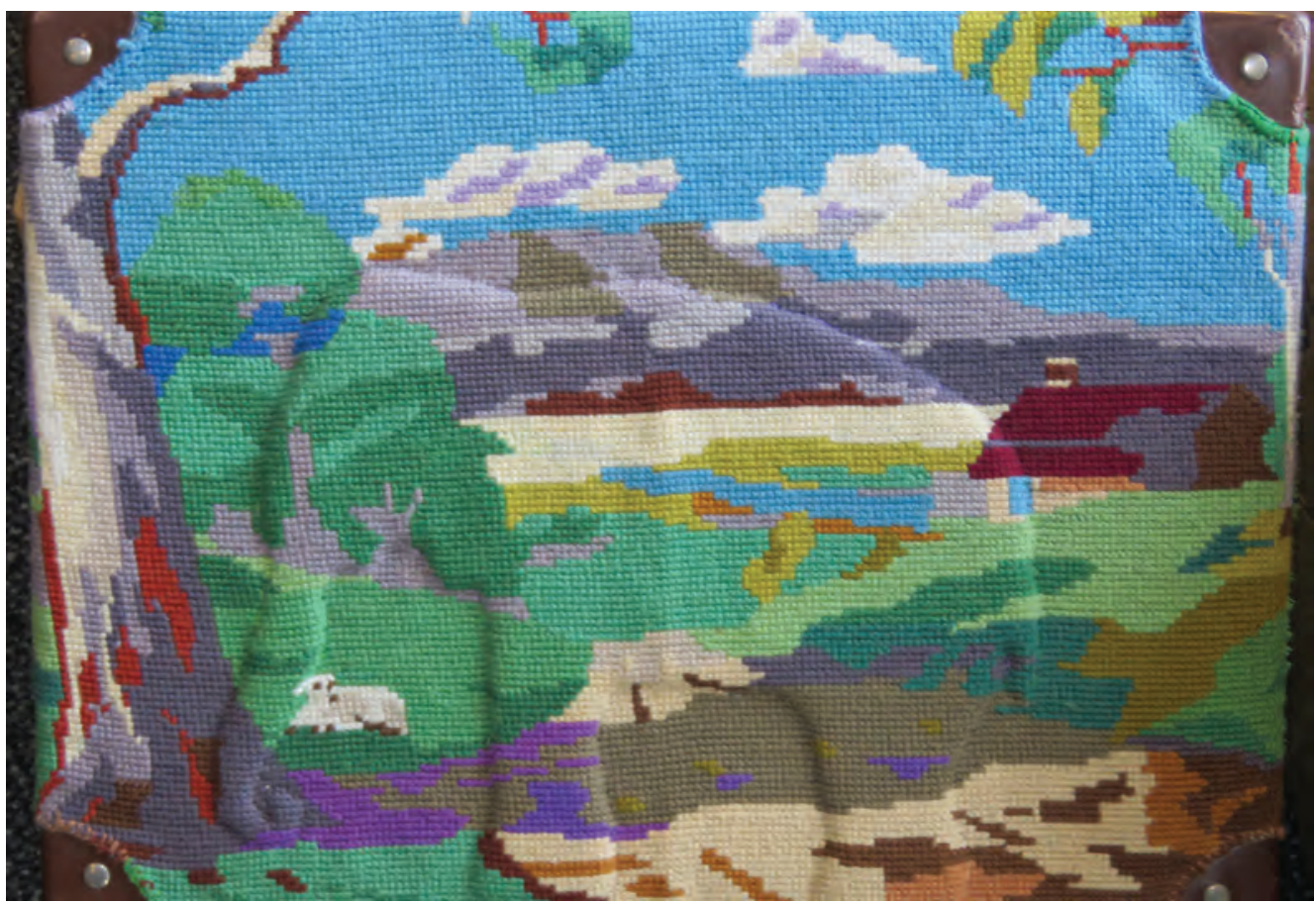

Figure 4. Close-up of Kerry Mackay's 'There's an Elephant buried in my Hometown' $201 \mathrm{I}$.

Found cross-stitch, cardboard suitcase, foam board, artificial turf.

\section{Elena Poletti}

Elena Poletti was second to speak. She shared the origins of her ideas and showed some of the eclectic vintage fabric finds which she has carefully brought together in order to preserve the glorious quality and previous life of the source pieces. Elena spoke about the 'play' and juxtaposition of materials and moods that inspire her making. With a career in European languages and a curiosity to try new techniques, Elena works with what she has at hand, re-injecting an edge of glamour to do her materials justice. She finds inspiration in being yet another person to hold the fabric and continue its story of care and human hands working with fine stitches.

Elena finished her talk by reading a poem about the power and the personally restorative qualities of working among her textiles late at night. I think I counted four changes in stole as Elena modelled her designs throughout her talk. Her studio, Atelier Jeux d'Esprit (second floor, Queens Building, 109 Princess Street), is like being inside the head of the owner. In a tightly packed room, small pathways emerge through the intriguing and ornate fabrics, clothing, homewares and vintage sewing equipment. Elena has collected vintage fabrics and items in her travels throughout the UK and Europe and her knowledge of their material history feeds into her artful pieces. This European quirkiness is continued through her interest in Klimt, Jugendstil, William Morris and the Arts and Crafts movement, helping her find ways to reconceptualise and reutilise objects and materials, making them into artful and often obscure new forms.

\section{Kerry Mackay}

Following Elena, we had Kerry Mackay from Dublin Bay. Kerry used her classroom 'show and tell' skills to give a personal and visually engaging presentation. Kerry has spent many years teaching and overseeing children's arts education and was one of the art teachers at Portobello School when I was at school there. Kerry presented a 
collection of her 'reskinned' bags, her coats with blanket fox-fur collars, her reskinned sheep skull trophy and her taxidermy lamb wearing a slinky skin and a little woollen bonnet. Kerry also showed one of her So obviously Rex reskinned handbags and some of her reskinned suitcases. Kerry talked about her work primarily as a teacher and an art teacher, but always as a maker; at this point in her life, she has the balance set towards more making and less teaching. She still enjoys the teaching, though, and has a business called theartdept which she runs with Pamela Brown. Kerry talked about her childhood memories growing up in Riversdale in rural Southland, showing her bag There's an Elephant Buried in my Hometown, referring to the time when a circus elephant had to be put down. Kerry talked about the influence of international female artists such as Yayoi Kusama and also about sourcing the cotton gloves she used for the yellow-and-black-spotted glove bag from her homage series I Applaud Myself. Kerry showed the audience items such as her purple fox coat and, with her theartdept suitcase titled Keeping the Wolf from the Door, she demonstrated how she reworks second-hand half-completed tapestries with the addition of a wolf motif and some colour and drama, and then reskins them onto vintage suitcases, handbags and trophies.

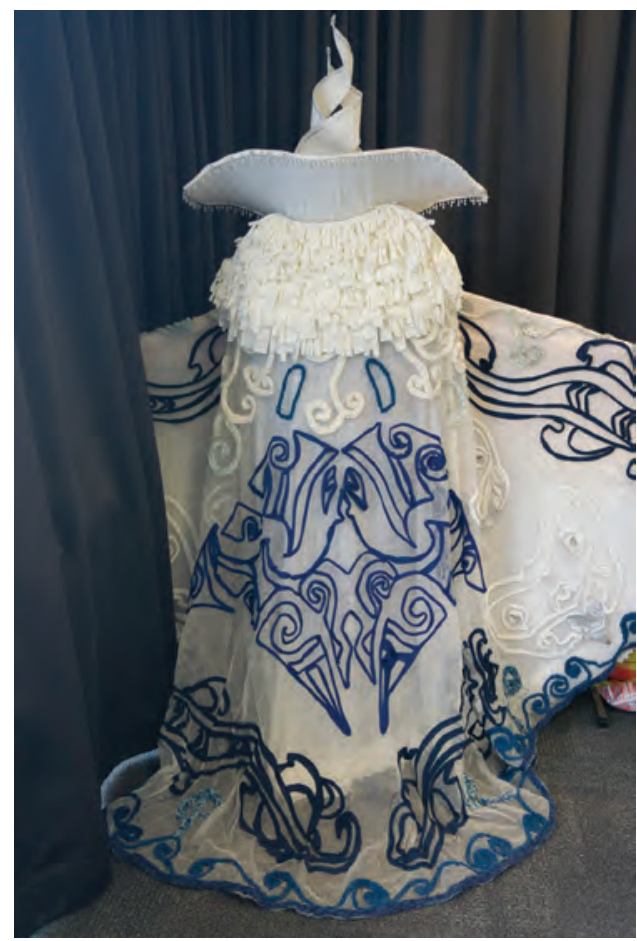

Figure 5. Simone Montgomery. Front view of Waipunarangi, 2018 Woolon Fashion Awards, wool, polyester and chicken wire.

Photo credit: Pam McKinlay.

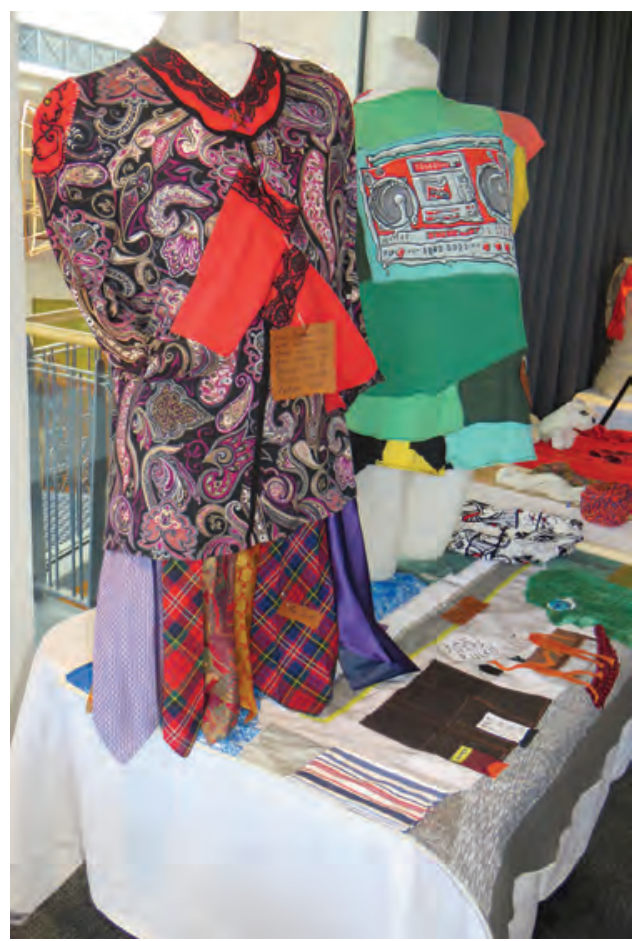

Figure 6. Kezka Bizarre's seminar display table, including The melted stereo T-shirt. (20|4).

T-shirt sleeves with reutilised t-shirt print.

\section{Simone Montgomery}

Simone Montgomery presented next. Simone acknowledged her Māori whakapapa of Kai Tahu, Kati Mamoe and Waitaha. Simone lives in Port Chalmers. She outlined her recent works and explored her love of clothing as 'costume' or 'role play.' She has distinct fashion interests including high fashion, as exemplified in her participating in race-day fashion, and steampunk. She draws on various aspects of her whakapapa and lived experience. Simone is excited about the ability of fabric and clothing to layer meaning and create juxtapositions. She uses upcycled fabrics extensively in her work. 
One of the images Simone showed was her work Waipunarangi, which she entered in the 2018 Woolon competition and which was displayed at the seminar. Simone shared stories of her entry into the world of textiles through making dolls' clothes and then through her experience of working in the rag trade in Dunedin in the 1980s, at the height of New Zealand's clothing production. She shared details about Dunedin's involvement in devising the early textile industry's 'sweating laws' and helping change the regulations under which the national textile industry operated.

Simone supported my introductory comments about the historical significance of Dunedin in any discussion of the ethics of the textile and fashion industries. The site of poor conditions for textile workers in the late 1800s, Dunedin became a pioneer in improving the New Zealand industry. Dunedin saw the birth of the first women's trade union, the Tailoresses Union, in 1889 and this union, along with the efforts of Reverend Rutherford Waddell, were instrumental in improving conditions through the Factories Act of $189 \mid .{ }^{17}$ These laws and conditions are once more in question with respect to today's textile industry practice.

\section{Kezka Zeitgeist Bizarre}

Kezka spoke about her early art practice as a street performer and musician making album covers and posters, writing lyrics and singing and making upcycled outfits for her stage performances. Kez has a large body of painting and drawing which may filter into her textile work even more, thanks to a new printer.

Kez moved on to talk about her past work in her 'real job,' cleaning. The heavy repetitive work involved has hit her body hard, leading her to a change of focus in both the artforms she works in and monitoring her health, working within her capacities on different days and different times of Day. Kez has started an online business, Of Cats and Unicorns, where she sells her upcycled garments and her hand-spun and hand-dyed alpaca and booties knitted with her spinning. Kez lives in Kaitangata, where she has been part of local textile groups and has given spinning demonstrations at the local hall. Kez has worked with a local second-hand shop making fabric bags from secondhand curtains for a 'plastic-free' initiative run by the shop.

Kezka spoke without her work or notes, using her experience in theatre to personally connect with the audience about her path through life and her passion for fabric and creating with upcycled fabrics. Kez talked about the connection between capitalism and industrialism and the disenchantment of the world - no such things as fairies, elves or even unicorns. The name of her business, Of Cats and Unicorns, reflects Kezka's reinvisioning of her life, taking pride in her work and creativity, and encouraging others to believe in themselves and their personal creativity. She does not want to live a repressed life as part of society's 'machine' - rather she wants to imbue life with a sense of personal magic.

\section{Desi Liversage}

Desi Liversage, owner of the label Altered Eco, was our next speaker, first in the busy afternoon shift. Desi lived in South Africa, then Rotorua, but has called Dunedin home for the last 20 years, where she has worked on her MFA, entering competitions, exhibiting and organising and running her business.

Desi displayed and spoke to her work while discussing her business approach, which involves three different lines of garment catering to various budgets. Items with a small addition of pockets and a knitted toy on, say, a child's garment, she is happy to sell for a low price. The next line in the range has a greater level of time invested in individual pieces and the prices are fair, but reflect the extra time and attention. Then with her top-of-the-line work, where Desi has designed the whole piece, or has spent considerable time embroidering the garment, the price reflects this increased attention to detail.

Desi talked about her move to designing clothes as a way of trying to make some income from her work as a textile artist. She talked about her ability to spot nice fabrics at a distance, on the basis that sourcing superior fabrics is the main advantage of second-hand purchasing - although the shelves are largely full of disposed fast fashion. 


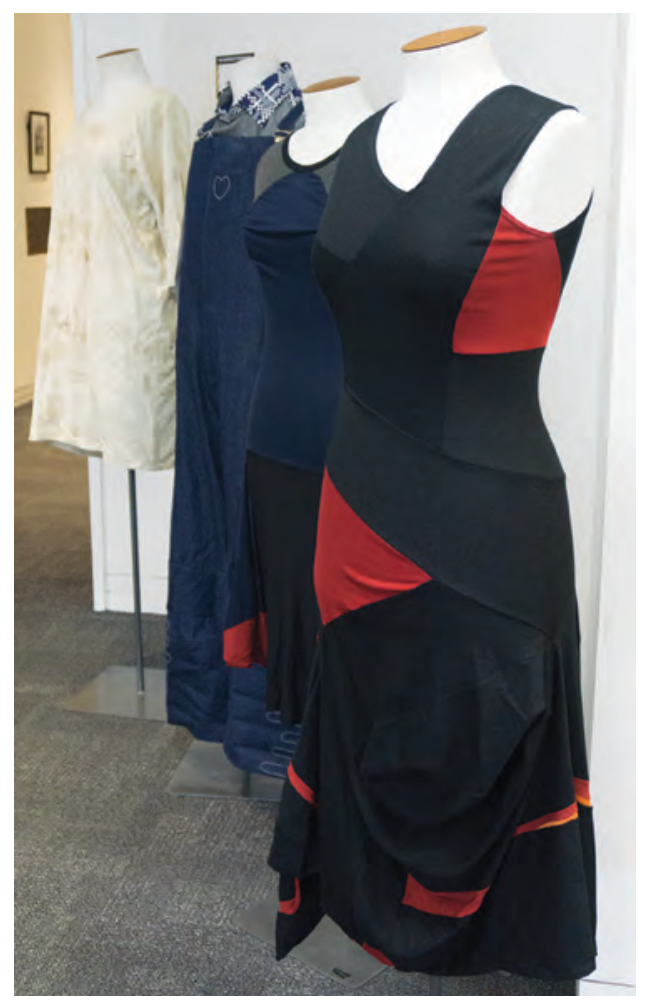

Figure 7. Desi Liversage Denim unicorn jacket. (2017). Second-hand denim jacket, embroidery threads, metallic fabrics and lei petals. Photo credit: Pam McKinlay.

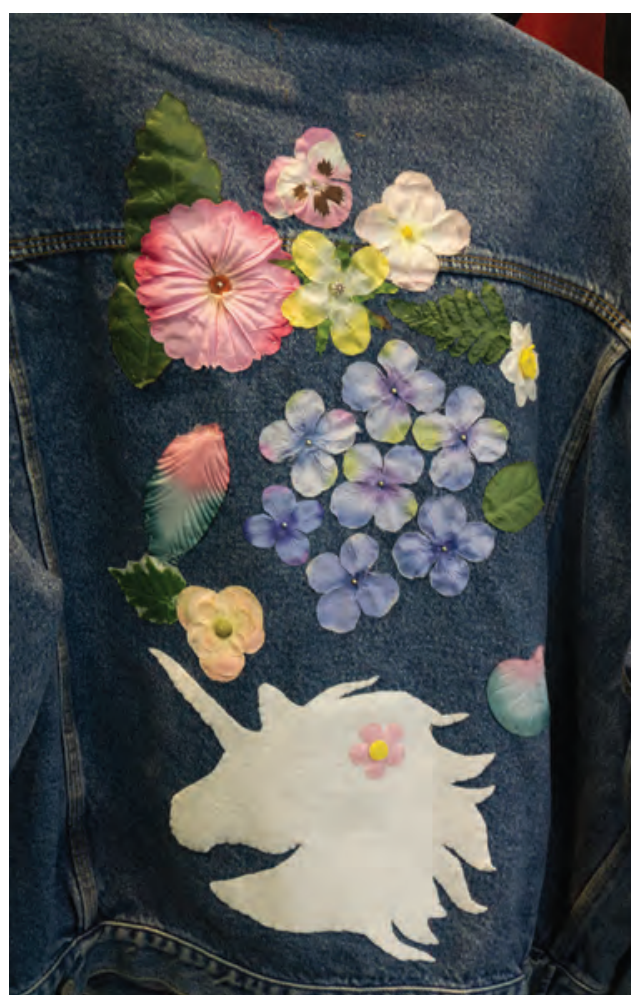

Figure 8. Fiona Clements' seminar display. Dress at the front from Waste What collection. Local manufacturer's Adventure Outfitter's merino and cotton off-cuts. Photo credit: Pam McKinlay.

Desi's rationale is that if she is going to put time and effort into working with these materials, she wants to start with quality base materials.

Desi showed her Divest Dress and told the story of its creation. She had had a slow day sitting on a clothing stall next to an Oil-free Otago stall at a local market and began embroidering the logo on their pamphlet - a tairoa (albatross) - on a black 1970s retro woollen dress from her stall. She then devised her own stitched representation of an oil slick in black and grey thread.

\section{Fiona Clements}

Next we had Fiona Clements, Pākehā, Kai Tahu, Clan Gordon, craftivist, zerowaste textile practitioner. Fiona, who grew up in Waitati, gave a PowerPoint presentation focusing on about her recent collections. She discussed her favourite jersey (which she was wearing), explaining how her grandmother dyed the wool and her mother knitted it for her and keeps patching both arms - and is even remaking one entirely reinforced arm for the coveted upcycled item. Fiona trained through Fashion Design at Otago Polytechnic and she has also recently completed the Graduate Diploma in Sustainable Practice. Her aim has always been to advocate for less waste in the fashion industry and to make zero-waste, ecologically sourced and upcycled designs under her label Senorita AweSUMO. Fiona Clements co-runs Stitch Kitchen with Fiona Jenkin where they run sewing classes, weekly community events and one-off or yearly events. 


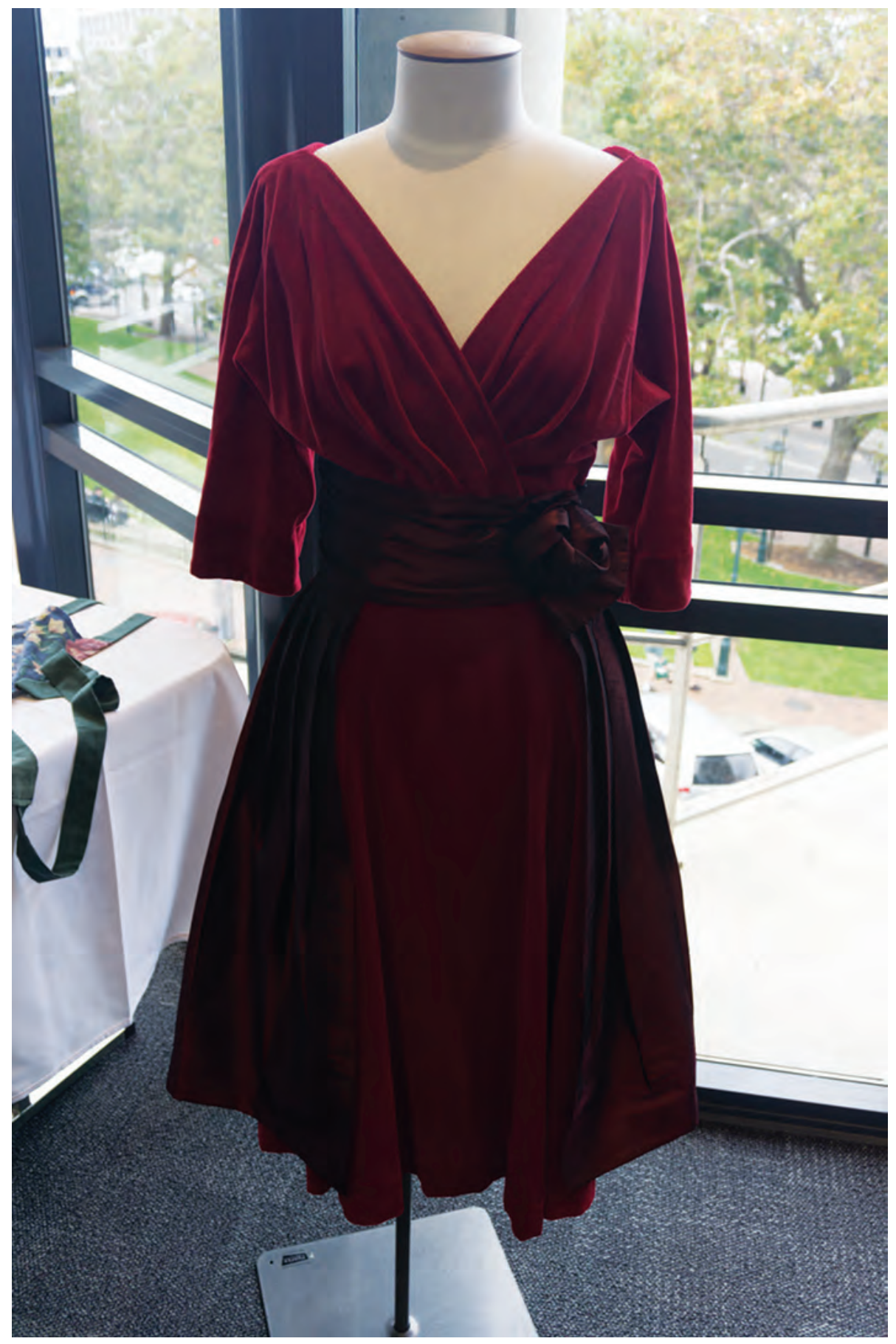

Figure 9. Fiona Jenkin. Red cotton vintage velvet dress. Upcycled damaged vintage dress. Photo credit: Pam McKinlay. 
Fiona's "Te Warewhare Whakapau - War on Want" collection, shown as a capsule at iD Dunedin Fashion Week 2014 , is made from manufacturers' off-cuts and items upcycled from local landfill. This collection spoke to clothing consumption habits and presented an alternative image of what fashion could be. The piece she showed was made from flag bags from The Warehouse and incorporates a long dress train and a cake made from plastic Warehouse toys. Another work, illustrated here (Figure 8) is Fiona's Waste What, designed for a show called Fashioning the Future, organised by the Centre for Sustainable Fashion at the London College of Fashion in 2010.

\section{Fiona Jenkin}

To conclude the day, Fiona Jenkin spoke to her PowerPoint presentation. Fiona is the second core member of Stitch Kitchen. Fiona told the story of when she and Fiona Clements met, many years ago, discussed what they wanted to do and their ethical approach and decided to set up the Just Atelier Trust, now renamed Stitch Kitchen. Fiona showed photographs illustrating her upbringing in an alternative family marked by embracing sustainability, living thriftily, making things for themselves and encouraging the children to make, too. This background engrained her present outlook which sees 'living from the scraps' as the glass being half-full: "You can have anything, if you make it yourself.' Fiona's mother often helps Stitch Kitchen sort their fabric room, which is full of folded and colour-sorted pieces of donated fabric. Like her mother, Fiona trained in textile science and then moved into image consultancy, where she taught others how to make the most of the items in their wardrobe, possibly re-tailoring them or simply mixing and matching to create the look they wanted. Although she also worked for many years in retail, Fiona is very happy investing her energy in this textile-based social enterprise. She loves the sense of community and the vast potential for upcycling and salvaging fabrics. Fiona showed the audience a red velvet dress (figure 9) which had been hacked at the front fastening; she had designed a sash from the same fabric that covered the front elegantly. Fiona has an interest in tailoring and enjoys taking sewing classes for the Bags for Good project which she initiated and continues to run.

Kirsten Koch is a Dutch Pākehā who was born in Dunedin spending her childhood on a native tree farm in Portobello, Dunedin. Kirsten holds an MFA in Textiles, an MA in sociology and anthropology, a graduate diploma in indigenous development and a post-graduate diploma in anthropology. Kirsten's interests include the intersection between clothing/culture and identity politics. She is particularly interested in the potential clothing and adornment offer to reflect on and express the multiple aspects of our overlapping identities. She is also interested in the material reality of art and culture construction and examining the creative yet underfunded and often under-exposed realities of local creative practitioners. 
I A Gwilt, A Practical Guide to Sustainable Fashion (London and New York: Bloomsbury Publishing, 20 I 4), I 46.

2 A McRobbie, Be Creative: Making a Living in the New Culture Industries (Malden, MA: Polity Press, 20 I6).

3 G McQuilten and A White, Art as Enterprise: Social and Economic Engagement in Contemporary Art (London and New York: IB Tauris, 2016).

4 G McQuilten, "The Political Possibilities of Art and Fashion Based Social Enterprise," Continuum, 3 I:I (2017), 69-83.

5 Gwilt, A Practical Guide.

6 L Edelkoort, Anti-Fashion: A Manifesto for the Next Decade, 2nd ed. (Paris:Trend Union, 20 I5).

7 J Milburn, Slow Clothing: Finding Meaning in What we Wear (Brisbane:Textile Beat, 2017).

8 AVänskä, "How to do Humans with Fashion:Towards a Posthuman Critique of Fashion," International Journal of Fashion Studies, 5:I (2018), |5-31.

9 S Swale, "Speed,Technology, Entrophy:The Fashion System at Breaking Point," Scope:Art \& Design, I5:2 (20 I 7), I 39-45, https:// www.thescopes.org/art-and-design- I5/speed-technology-entropy-the-fashion-system-at-breaking-point/.

I0 RR Shailaj, "Post-Fashion, Hybridity, the Unconventional: Implications for the End of Fashion," Scope:Art \& Design, I5:2 (20।7), 103- I 3, https://www.thescopes.org/art-and-design- 15/post-fashion-hybridity-the-unconventional-implications-for-the-end-offashion/.

II H Clark, "SLOW + FASHION - an Oxymoron - or a Promise for the Future?," Fashion Theory, I2:4 (2008), 427-46; H Clark, and M Rottman, "Fashion Studies Takes on Politics," in The International Politics of Fashion: Being Fab in a Dangerous World, ed. A Behnke (London and New York: Routledge, 2017), 187-99.

12 Edelkoort, Anti-Fashion:A Manifesto.

13 F Clements, "Unstitched: Local Fashion Revolution Dunedin," Scope:Art \& Design, 15:2 (2017), 36-4I, https://www.thescopes. org/art-and-design-I5/unstitched-local-fashion-revolution-dunedin/.

14 Tearfund New Zealand, The 2019 Ethical Fashion Report:The Truth behind the Barcode, April 2019, https://www.tearfund.org. nz/getmedia/a3d9fc5f-54al-46cl-b85f-c004da975620/FashionReport_2019_I0-April-19_NZ.pdf.aspx (accessed 29 May 2019).

15 C Gale and J Kaur, The Textile Book (Oxford: Berg, 2002), 50-5I.

16 A Bray, "Creating A Slow Fashion Collection - A Designer-Maker's Process," Scope: Art \& Design, I5:2 (2017), 29-35, https:// www.thescopes.org/art-and-design- I 5/creating-a-slow-fashion-collection-a-designermakers-process/.

17 Jane Tolerton, "Clothing and Footwear Manufacturing: Page 2. Clothing Factories," I I March 20 I 0, Te Ara - the Encyclopedia of New Zealand, https://teara.govt.nz/en/clothing-and-footwear-manufacturing/page-2. 


\section{ETHICAL FASHION: SCALING FOR SOCIAL IMPACT - A PRESENTATION BY SAMANTHA JONES OF LITTLEYELLOW BIRD, THURSDAY 9 MAY 2019}

\section{Katie Mangai}

Everyone in fashion wants to be sustainable these days. It seems to be de rigueur for fashion students to express a desire for their work, design and business practice to enter the marketplace clearly 'not guilty' of gross human rights abuses and environmental calamity. If this feels both obvious and optimistic, it still points to a reality where few would claim total ignorance of the issues at stake for the industry, even if many struggle to know how to act in response.

The 'why' of sustainable fashion is no longer big news. We know about Rana Plaza. We know 'fast fashion' is bad for both people and planet. And knowing this is (mostly) a good thing. But if the 'Why' has become obvious, the 'How' has a complexity that continues to simmer, begging resolution, long after the ease and rage of greenwashing activity and accusation ceases to function as click-bait. The 'How' is less glamorous and less righteous, but it is where the work has to be done, and is being done, by pioneers like Samantha Jones at Little Yellow Bird.

The Little Yellow Bird business model focuses on a core B2B offer of corporate uniform products (mainly shirts and aprons) which are also sold as wardrobe staples for the general public via the Little Yellow Bird website. Sales to the public currently account for approximately 15 percent of revenue, and this side of the business is set to grow. Samantha and her small team are based in a distribution warehouse in Wellington, with manufacturing taking place in various locations in India close to where their rain-fed organic cotton is sourced. HerWellington-based core team have roles that focus mainly on management and logistics, drawing heavily on a strong and trusted advisory group for assistance as needed, from design to finance and everything in-between. Samantha visits India regularly and from the LYB blog it is clear that out of the solid foundation of face-to-face relationships, along with a commitment to reflection and continuous improvement, community engagement initiatives have grown up alongside the production work in meaningful and impactful ways.

On Thursday 9 May 2019, local ethical textile waste pioneers Stitch Kitchen hosted a presentation by Samantha in the Otago Polytechnic Hub. Samantha had reached out to Stitch Kitchen, who in turn reached out to Otago Polytechnic, and from there the event was publicised through both Stitch Kitchen and the Design School's networks. In attendance were a mix of members of the public, Stitch Kitchen community, fashion and design students and faculty, and people connected to the Audacious business development programme. (A convergence that tells you something about the appeal of Little Yellow Bird and the importance of the way they are telling their story.)

Samantha's presentation was entitled "Scaling for Social Impact," and she talked through some of the Little Yellow Bird journey from start-up to this year's Pledge Me crowdfunding campaign.

The Little Yellow Bird Pledge Me campaign invites potential investors to "invest in ethical fashion" and "become part of NZ's first community-owned ethical fashion brand." Shares are being sold in order to scale growth and impact, 
and I left the event genuinely wanting to look further into the possibility of investing in this innovative enterprise. This is a great business lesson in itself - the storytelling matters! It was compelling, real, raw and very genuine. Samantha Jones very much wants to connect with like-minded individuals and share her knowledge.

The pursuit of whole supply-chain transparency in an apparel business is clearly not an easy road at any level, but Samantha is clearly a person of some tenacity. She comes to the apparel industry with military-trained supply chain expertise, and this military unflappability is clearly in evidence in the way she has gone after the core principles of her business. A huge focus has been building long-term relationships with her Orissa-based organic rain-fed cotton growers, visiting several times a year in the early stages of the business.

Little Yellow Bird came into being within the context of a Wellington-based business incubator, not dissimilar to Dunedin's own Audacious programme. Samantha opened her presentation with a quote from Reid Hoffman (the founder of Linkedln): "If you are not embarrassed by the first version of your product, you've launched too late." Some of what is interesting about Little Yellow Bird in the ethical fashion space is the extent to which it has benefited from business and social enterprise start-up advice and support.

Innovative business models are key to the thriving and surviving of any new fashion business, with or without an ethical focus, and while the industry has some unique challenges, aspiring sustainable fashion businesses would do well not to ignore the innovations and support of the wider business community. So much of the advice Samantha shared is just good solid business advice: Know why and how you are different from your competition, know when to give up and when not to, always be innovating, apply for everything and anything, engage in shameless selfpromotion, drive engagement, don't just do what has always been done, do what is right for you and your business. Be frugal. Get good advice.

Little Yellow Bird has done all these things and it has paid off. Their niche has been uniforms for hospitality and other corporate wear. The baristas in your favourite organic fair-trade coffee shop may be wearing organic fairtrade aprons and shirts thanks to Little Yellow Bird! You or I can also make individual purchases through their online platform and, as mentioned above, these sales currently make up around I 5 percent of their business.

The Little Yellow Bird model is certainly not the only approach to addressing issues of sustainability in the New Zealand fashion landscape, but when I reflect on similarities and differences between what is happening at Little Yellow Bird and established ethical labels such as Kowtow, or with Mindful Fashion New Zealand (brainchild of Kate Sylvester and Emily Miller-Sharma of Ruby), what I see is a landscape of diverse industry professionals, each working to their own strengths, in their own niche, with significant clarity of vision regarding what is in front of them. Gosia Piatek has built Kowtow, with its minimal, feminine and utilitarian aesthetic, to consistently produce garments which are highly sophisticated demonstrations of the way aesthetics and values and style can flow together. There is a clarity to the design that echoes the transparency in their supply chains, and a lack of fussy finishes sits well with ethical efficiency in production. For established New Zealand fashion designers, Mindful Fashion New Zealand sets out to solve some very practical issues in relation to auditing existing supply chains. Having had the opportunity to hear both Kate Sylvester and Emily Miller-Sharma talk about this initiative, I was equally impressed by how grounded that project is, focusing on what they can do right now, with the industry knowledge they have, to impact the supply chains they are already involved with that affect their everyday business. All of these approaches are encouraging.

The day after the Little Yellow Bird presentation I noticed on social media that a comment had appeared under a Little Yellow Bird promotion to the effect that if they really cared about sustainability they would use only hemp, and that the pledge was the work of more money-grabbing capitalists. Supporters jumped in to defend the brand, and Little Yellow Bird themselves replied promptly with appropriate clarity (incidentally, they are actually exploring adding hemp) - but the incident made me realise that in the real world of working it all out, for some nothing will be good enough. 
Little Yellow Bird is a business that thinks every decision through for its implications for sustainability, from working out ways to reduce the plastic used in export (tying garments in cotton instead of individually in plastic wrap) to marketing strategies that are specifically designed to reach consumers where the alternative is not non-consumption, but consumption of a less sustainable product. This is a subtle but significant endeavour that demonstrates some of the tensions present when growing an environmentally and socially sustainable business. Clearly greenwashing is a thing, but we can't give up the pursuit of genuine sustainability for fear of criticism, and we can't wait around until all the problems are solved before we even begin. I am looking forward to seeing what the future holds for Samantha Jones and Little Yellow Bird.

Katie Mangai is a student of fashion design at Otago Polytechnic. She holds an MA in applied theatre and a BA in theatre studies. After many years working on product development for a community investment consultancy, her interest in social justice and innovation in business (combined with a love of beautiful clothing) has led to a specific interest in sustainable fashion. 
doi no: 10.34074/scop. 1017004

\title{
FASHION FLUID: A PANEL DISCUSSION
}

\author{
Simon Swale, in discussion with Bernadette Casey, Donna \\ Dinsdale, Emily Miller-Sharma, Murray Bevan and Sue Prescott.
}

\section{INTRODUCTION}

On Friday 15th March 2019 at the Dunedin Public Art Gallery, Otago Polytechnic School of Fashion staff hosted a fashion symposium as part of iD Fashion Week. Entitled "Fashion Fluid" in keeping with the theme of this journal, the symposium offered a range of presentations by industry professionals, academics and fashion educators. To conclude the day, five guests were invited to form a panel and discuss the future of the New Zealand fashion industry. This panel was comprised of: Bernadette Casey, co-founder and creative director of textile research and sustainable development company The Formary; Donna Dinsdale, Programme Co-ordinator of the fashion department at Toi Ohomai institute of Technology, Tauranga; Emily Miller-Sharma, General Manager of RUBY and designer of the Liam line; Murray Bevan, founder and director of PR and communications company Showroom 22; and Sue Prescott, Programme LeaderFashion at Massey University. The panel discussion was chaired by the author, Otago Polytechnic School of Design fashion lecturer Simon Swale. What follows is an edited version of that discussion. Some editing has been undertaken to add brevity and clarity to the conversation.

'Fashion Fluid' was the second fashion symposium of its kind, following on from the success of 'Metamorphosis' in 2017. 'Metamorphosis' (and the corresponding special issue of Scope: Fashion) had been initiated by Otago Polytechnic Academic Leader of Fashion Dr Margo Barton after many discussions with staff mourning the demise of the not-forprofit organisation Fashion Industry of New Zealand (FINZ). Among many roles, FINZ hosted an annual conference for the fashion/apparel industry and educators to come together, support one another and discuss the general state of sector. Since the demise of FINZ there has been no regular forum for the fashion industry and/or fashion educators to come together. With iD Fashion Week being an annual event on the fashion calendar, moves were made to maximise the opportunity of many educators and industry professionals being in one place at the same time. There seems agreement that discussions such as the one that follows provide networking opportunities and sources of rich knowledge that can be leveraged across the industry by its many stakeholders.

As the panel chair I contacted the panellists to create a framework for our discussion. I referred them to a previous fashion industry panel discussion organised by FINZ and sponsored by international shipping company DHL. Having summarized the main points that I took from that discussion, I provided these to the panellists to reflect upon and to consider as areas we may find useful to pick up on eight years after their initial discussion. Points raised in the 201 I discussion included (I) an emphasis on the speed of change within the fashion industry, and of it becoming a 24/7 environment which never stopped. This necessitated a need to be switched on all the time. (2) The increasing globalisation of fashion and New Zealand's place within that; (3) an increasing focus on exporting and the need to think of Australia as a domestic market to be a viable concern; (4) the importance of branding and the need to build emotional connections with your market. This was seen as essential in creating a point of difference. Finally, (5) the role of the media and the ability of new media to tell stories, for example, 'sneak peaks' backstage at fashion shows through the use of emergent technologies (phone cameras) and technology (such as social media). Interestingly, sustainability did not seem to feature as a major discussion topic, so this was an additional area that seemed an essential talking point. 


\section{'FASHION FLUID' PANEL DISCUSSION}

Simon Swale: I might just start the discussion with Emily; how relevant does the content of the 20 I I DHLFINZ meeting remain in 2019 ?

Emily Miller-Sharma: I think that with the power of new media, we've all become much more exaggerated in what our belief systems are, so I feel like we've gone deeper.We can seek out brands or movements that really resonate with us (unlike through a generic mass media), so when you relate that to us as a clothing company we've had to become deeper and we've had to really understand who we are as humans in the company that we are working in, and who our customers are as humans, so I'm not sure that it completely answers your question but there's something about richness and depth which I think is really important.

SS: I think that picks up on that idea of storytelling and building that emotional connection with your customers.

EMS: Absolutely, and there's always this tension because, to be honest, we (RUBY) are a company and so our job is to be a profitable company, so when we talk about being genuine, there's a tension: "so what is genuine"; there's genuine genuine, and then genuine to the brands, because they are not always two different things but there is a tension that I guess, you are always walking.

SS: It was interesting hearing Kate Sylvester talk at lunchtime, about Kate Sylvester the person and Kate Sylvester the brand; where the boundaries between the two are (or are not). That kind of fluidity, it's quite interesting to think of the way people relate to Kate and her brand.

As the operator of a PR and Communications business Murray, how do you see brands having changed their focus maybe in the last few years and what are they asking of you in your role in PR and marketing?

Murray Bevan: It's been really interesting, the last ten years... there's been this huge saturation of the New Zealand market; overseas brands coming in, local brands starting up It used to be that it was Kate, Karen, World, Zambesi, Trelise and Nom'D- now there's like 50-60 and there's ten new brands that start every year. So what clients are asking of us is of course more for less - because our population is quite small, you don't have the chance to make a lot of money so you see brands like Maggie Marilyn immediately going overseas, Wynn Hamlyn immediately going overseas. They have to really own the New Zealand market, which brands like RUBY- they're getting more of a foothold in retail and they're owning their own conversation, so they're coming direct to the consumer, they've got their own publication channels, they've got their own social media, they've got their own voice which means they don't actually have to rely on the media as much as they used to. So I suppose clients, to answer your question, it's been this crazy sort of chopping up of the industry- many, many, more moving parts. Not as many big media any more, lots of little media, micro influencers, which means you have to get one idea and split it 100 ways to make everyone happy. Then of course as an agency we have to become more creative to satiate the appetite of our designers. It's no longer just a press release and a look book and we just present to them this huge swathe of editorial at the end of the season. We don't use press releases now and look books are just kind of falling flat so we have to create stories and storytelling and exclusives and firsts.

SS: So smaller stories but a lot more of them?

MB: Well probably not smaller stories but fewer stories and deeper stories. I remember when we were launching Juliette Hogan and Kathryn Wilson. A press release sent to 90 people would get you about 50 hits, profile stories, cover pages, sponsorships. These days, I'm constantly in meetings with my staff and we're thinking up 200 new ideas a week, it feels like that anyway, and it's exhausting, it's hard.

SS: That sounds like a massive shift, and very, very quick since 2011 . 
MB: Yeah a pretty big shift. There's been massive job cuts in the media; Fairfax let go of four lifestyle writers two weeks ago so that means that we don't have the chance to proliferate these great stories through fashion and lifestyle media because it just doesn't exist.

I was supposed to give this talk on branding and marketing and PR at one of the fashion schools, and I was like, "right, guys, so here's this case study. who heard about it?" Fourth year students, the most senior students in the school, two people put their hand up. I said, "where do you get your news from?"'They were like, "we just look at the brands we like on Instagram and they just tell us what they are doing" So Viva, which gets 230,000 readers a week, is redundant to young people... don't try and target a 20 year old because they are just not reading the paper.

SS: You talk about some of the people you employ in your team and I wonder, where are they coming from? Are they coming from fashion schools, or are you getting people from business programmes, how do you recruit? I'm leading to fashion education, and whether we teaching the right stuff?

MB: We recruit from a really narrow pool of people who are obsessed with an extremely small industry, which is fashion PR, which is why we are one of the only groups of people that do what we do in this tiny country. Pretty much we go through social media and ask, would you like to come and work with us? So yeah, it's fashion students but you can take someone from any industry; our best staff member was an architecture graduate with a Masters. Her only fashion experience was that she worked retail at Moochi, but she just said, "I've always wanted to work here, I came here for a school visit when I was in seventh form and l've never forgotten about this place." She was the last interviewee I had and I was like, "it's yours." But we need good people; I can't exist or grow my business just with fashion PR in New Zealand, we have to do water, beer, cars, hotels, events, gifting, sponsorships.

SS: And I guess that's the reality of fashion today that it really transcends all parts of culture to a certain degree.

EMS: Thinking about fashion transcending culture and about fashion education. When I studied I learned that during times of the plagues, the baby doll line was really popular for women to wear because it made them appear as if they were pregnant, even if they weren't. So that for me was like, "Woah! clothing and society are intricately linked", and that for me was learning to think as a student, but then there is still a need for a well cut pair of pants. That is a skill as well and that's a different skill and I think that both are really, really important. Especially for us in our business model, we require a lot of hands on, we have internal pattern makers, we cut all our own samples, we've just employed a sample machinist and so we require that technical skill as well as the thinkers; both skills are important.

SS: Absolutely. Let us hear from a fashion educator; Donna?

Donna Dinsdale:I think that's our challenge, the integration of creative practice, of being innovative, of expecting our students to constantly have idea generation, and those technical skills, you're right in saying, are just as important. But something's got to give, and we find it quite difficult to deliver creative thinkers alongside technical expertise and so we are always discussing at Toi Ohomai the relationship between those two things and how we can manage that and it's not easy, and hence that's why we are here (at this forum), wanting to get some feedback.

EMS: One of my favourite things when I was at university was pattern making, but actually my technical skills, especially from a construction perspective but also a pattern making perspective, came when I was in a workroom because you have to sew ten of the same collars in a row to learn how to sew a collar and you need to be doing it for weeks on end and you also need to be doing it when you're been paid, and you sit there at the sewing machine and that is all you are doing for that day or that week or that month, or that six months. So I am in the process of trying to set up an industry body, and the long term vision for that would be around working in partnership with institutions to make apprenticeships a thing, because you know, our pattern maker is 55, and she has trained so many people on just like basic, basic pattern manipulation and there is something so valuable about that. 
Most of our production department have come from being interns. Our sample machinist was an intern, she was just really good at sewing, and she finished university and it was like, "you like sewing, you're really good at it, do you want to be our sample machinist", like we haven't had an in house sample machinist before but we really wanted one, and she's like, "yep l'll give that a go", and she's just kind of rolled with it.

DD: Because within an educational environment we can only deliver and teach so much. It's a bit of a bubble really- it's not the real world, but we expect our students to have outcomes so they need to know how to do those technical things on certain levels.

Sue Prescott: In education it's hard to fit in all these things and you're not going to produce an expert in every field because you are constantly bringing in new things, and nothing drops off because you've been used to this quality that you've been producing in your students and you don't want to let that go. But at the same time you're bringing in huge levels of innovative thinking and critical thinking and all kinds of other things that make our students go forward into a multidisciplinary world.... About internships, a lot of the time they do learn on the job. Often that's a non-paid internship, (which is another issue, and we probably won't even go there just now,) but it means that those internships are only available to students that can afford to do that, it's not really to be considered education at that point because some just can't afford to go and live in Auckland for four months, you know, which is a real issue to us, and I know it's something that's been looked at not just in New Zealand, in terms of the unpaid labour.

EMS: As of this year our interns are paid. We've actually just started doing an internship programme, maybe two school holidays ago, in our store, and I know this is a little off topic, but just on interns, I just love it, it's really cool, we have high school students during their holidays, they can intern in our retail stores and they're paid, so they are paid minimum wage, but it's the concept of, it's really hard as a 16 year old to get experience if you have no experience, so that's kind of the thinking.

SS: There's a lot of focus on sustainability today and so it's another aspect within fashion education, and how do we address that? - what do you think is the starting conversation we should be having with students?

SP: In education? It should be in there full stop. It can't not be in there. There are universities, like Parsons and others, where you can go and do a sustainable fashion degree, but it can underpin everything you do. Once upon a time, you might say, "oh I think I'm going to do a sustainable collection"," woah, edgy!", but now it would be an expectation with the information that's available, and the impact that we see and feel, it should just be in there- they should be thinking of systems, looking at supply chain. We take students to India and we go and study just that, we do lots of workshops for weeks in lots of different parts of India, and we do collaborations with Indian students and our students come back very wise as a person, you know, and go on to do things after that but I think it's something that should just be underpinning everything. Obviously we're a fashion department, but it's across the design school that they are looking at sustainability, it's not just in fashion.

DD: I think a lot of the students coming through now are really informed and ethically, they're really onto it and there is an expectation to step up to that and I think hearing how how sustainable practice has been put into real life situations is really important for educators.

Bernadette Casey: We're often invited to guest lecture at universities and what we are finding is that we're increasingly being asked by intermediate schools and primary schools if they can come and visit our operations because the education is starting much younger, as we can see down in the Octagon today (where school students took to the streets in as part of the international 'Strike 4 Climate Change' movement). They're far more aware.

SS: Just thinking about a systems based approach which we talked about quite a lot with Bernadette and whether there is a need to petition government to make change. There's often discussion about how we as an industry are such a small part. It's great that an individual does their bit, but do we as a body, as an industry, need to petition the government to make a greater impact? 
BC: Before I did my master's research in ethical purchasing I thought yeah, it is the individual's responsibility, and after completing my research I stepped away from that position. With the Intergovernmental Panel on Climate Change (IPCC) report saying we've got a dozen years to address this issue, we've got a really condensed timeframe and for individuals, it's virtually impossible to navigate how ethical a brand is just by reading their reports. We're seeing things, like the Fixing Fashion report from the audit and ethics committee of the House of Commons that came out just a couple of weeks ago, recommending that it's policy not individual choice that is going to make the difference and the issue around climate change is so massive that we are going to need those polices to protect society, to protect people's wages, to protect the environment etc., so I think that's where we're heading.

MB: concerning too much information- if you look to the Baptist World Aid Tear Fund report. Fashion labels get stamped with this mark, the public doesn't really care to read about why, they just nail them to the wall if it's bad and that sucks because lots of good brands get taken to task and they shouldn't be.

SP: People believe what they read and may not think "how does that accreditation process work and how many people in this company was there to put that great case forward to get an A+ rating", Because then there is this company that is a bit smaller, just as good but didn't have that personnel or resources behind them. There's no discussion about that and it's a really important factor when you are reading things like those results.

EMS: Can I add to that, thinking about scale and how you can actually affect change as an individual company, which is really limited, especially in a country like New Zealand. As New Zealand labels we are small within the clothing industry, so our ability to affect real change on our own is limited, but if we're working together it's much more powerful. We've been working with the team at Kate Sylvester and what we've really learned is the need to be sharing supplier information in order for us to know what we are working with. So it's a big project but Kate and I, we're trying to work on this larger industry thing because there is actually a genuine need for it.

BC: We've seen that kind of collaboration coming through with the Textile Reuse Programme. We've got Alsco, Barkers, Deane Apparel (who is New Zealand's largest uniform supplier), and uniform purchasers, and because they are around the table together they are starting to share that knowledge but also because it is such a massive problem not one individual company is going to be able to solve it on their own and that's why I think we've moved to a space where collaboration is becoming more natural.

EMS: And that's what we're aiming with this network. The first stage is that all of the members of the network have to, of their New Zealand supply base, give the details of their machinists, their pressers, their pleaters, their fabric agents, and then, basically a questionnaire for each of the companies to fill out, how many staff do you have, where is your premises, etc., From there, working with an independent company to assess the risk baskets around New Zealand manufacture and to set some reasonable benchmarks, which are not necessarily the same as what a CMT factory's benchmarks would be in China or in Vietnam. Usually our CMT factories would be anywhere between 3 and 15 staff, so what do we reasonably expect from an employer of three staff, to have trained their staff in terms of joining a union, what is a reasonable expectation in the New Zealand fashion industry for our local makers? That is literally what we are trying to do.

I do believe through the designers that we've been speaking with, I feel like there is a tipping point and there's a realisation that if we don't do something radical, we are all a bit stuffed. It's a sort of slow shift but it is actually shifting.

SS: That leads me to ask about new business models. Are young designers operating in a different way to traditional models?

MB: Fundamentally no; I think they've all got to have a customer, they've got to have collections. Maybe they are tightening up on their seasonality and not doing the traditional two collections a year.l think it's probably more in the branding, the marketing, the social media, the reliance on media. Marketing budgets are almost non-existent. Some labels still spend an eye-wateringly large amount on advertising a year but their customer responds to that- they 
are older and read magazines, but the young designers are way more nimble. They'll activate something overnight, they'll push it on Instagram tomorrow, it will be done by the next day and then they will move on. Others wouldn't be able to get their heads around that, their way of thinking is so engrained in the old school. But no, fundamentally the businesses have to be based on profit and loss, and not making too much stuff and not buying too much fabric and not having too many staff. One thing l've seen is that lots of those older companies made their way up from nothing; they are self-made, and a few of the new ones are probably funded, that's a new thing.

EMS: Yes, 'cos you need cash. I mean your point about profit and loss, stock management; that is literally it! Yes, absolutely businesses are changing from a marketing perspective, but fundamentally you don't want to be holding onto too much stock because then you've got no cash and you can't buy new stock. That hasn't changed.

MB: One thing we are seeing is that few of the new designers have gone into their own retail stores quickly. So you look at previous generations, there was no such thing as online, so you had to have a door that opened and jeans inside the door. So now you've got Georgia Alice, Maggie Marilyn, Wynn Hamlyn- no retail, Harman Grubisa one tiny store, and it's like a war to keep a store afloat.

SS: Is it worth it today?

MB: I don't know; can you survive online? A lot of them are doing it, the turnover is not huge but you can expand overseas, so do you then go and get an overseas agent quickly, PR, sales, push yourself in New York, become the designer du jour and all of a sudden you're on Net-a-Porter.

Maggie's gone there, Georgia's gone there, Wynn's only started to go there now, Harman Grubisa went there and they got catapulted by winning the regional Woolmark Award, the first time ever a Kiwi designer has won that.

SS: I was thinking of Courtney Pellow, who l'd never heard of, I don't know who she is, but she's a Kiwi kind of gaining momentum off one Instagram post where Kendell Jenner is wearing her clothing. To me that's "...wow". That undoubtedly garnered her a lot of visibility.

MB: I don't know how she did that but you look at a raft of different brands here who get international exposure on celebrities. When Madonna wore Karen Walker's pants at the MTV awards it sold so many thousands of units of those trousers - the public dined out on it for ages. Now, Gigi Hadid wears something on one Instagram post from a Kiwi designer and an hour later the media are going "next, what else you got"... maybe a spike in sales but then the consumer's also like, "I hate her, next".

But probably Karen, more than anyone, has been a trailblazer pushing New Zealand fashion overseas and has spent many, many years doing it and man it's a hard slog, but now she going "it's about my own media, my own stores, my own channel, my social media"- she can sell hundreds of units of a product in a weekend just with one Instagram post and the media don't even get wind of that, and then it's gone, so she's been able to stay pretty much at the head of the curve which is changing and winding and everything, super quick.

SS: Thinking back to the DHL forum which was in $201 \mathrm{I}$ - the year after Instagram launched. It's amazing how fast Instagram has become so influential.

EMS: Yesterday Instagram was down and we had some new product going into store and our marketing exec, she was in our showroom, she was taking some photos of the product to post on Instagram and she was kinda like, "I don't really know what to do"- it was a really weird thing for her.

MB: Yesterday, someone in my office said "imagine if Instagram and Google and everything was down for a year, what would we do?" I said "see that thing next to your computer, that's called a phone. You pick that up and you go and have meetings with people- it would be fine". But people forget that some of the best communication you can 
have, the most binding, the most loving, the most lasting, is actually taking someone out for a cup of coffee, or sitting down with them, across the table and saying, "I've got this story for you." And then they go, "really, me, wow... you thought about me?"You don't get that with a press release.

SS: To the educators: have you noticed a change in the students coming through and the manner of their creativity? Now that social media is so entwined with their lives, do you think it has changed their creativity, or the way they think creatively?

DD: Yeah, it has had an impact. I was thinking about the discussion around collaboration. We teach in a collaborative environment, there's a lot of open spaces, there's a lot of working across, and what we're finding is the students are demanding that those collaborations are there; thinking creatively beyond your discipline or your major to enhance what you are doing and what you produce, and that comes with social media. Now that's just a given.

SS: It's part of that connectedness with other people?

SP: It's the real world. But I think in terms of creativity, the students are very quick to pick up the phone and go onto Pinterest or something, and I'm thinking, "no, no- this idea has to be born into your brain first, just have some thoughts, don't be looking for somebody else's precedent first. They seem to be forgetting how to originate thinking, and I think that is really, really important.

DD: For us within education, those collaborations that our students have are really, really important, and this is what education needs also, you know, we should all be talking with industry, because we're all in the same gig, we're passionate about fashion.

SP: We have tried in the past, when I first came to New Zealand, there was a board that was set up between education and industry but we just couldn't fund it. It lasted about two years.

SS: I wonder, is there any real or perceived disconnect between what students are learning in their education and what they actually need in the industry.

EMS: Can I say, one of the greatest things that l've taught our team is maths- we do a lot of profit and loss training at work. It's big concepts for a lot of people when they first start learning about it but there is an aspect to it across the board, not just fashion. That's an aspect l've really noticed.

Then there's the apprenticeship model that I really truly believe is what shores up our manufacturing industry here and when I say manufacturing, I'm talking about bulk production and I'm talking about pattern making, bespoke making as well, for me those are two really big opportunities.

DD: Having the right forums to share and to get feedback is so important, because what we're delivering and the content that we hope to deliver is driven by industry; we're training the future, and so for us, we have to have that feedback, we need it.

FINZ was a great way for educators to all meet, to get industry and speakers together. So I'm really thrilled about this symposium, but I feel we need more of it. We need relevance, and we need to maintain currency with the fast pace of change.

\section{CONCLUSION}

While the above conversation highlighted the significant changes the industry has faced in the relatively short amount of time since the FINZ/DHL discussion of $201 \mathrm{I}$, it also highlighted how prescient some of those focus points were. Especially concerning the changes in fashion communication born out of technological developments, 
social media has in many ways come to dominate the fashion experience. This has, of course, exacerbated the industries incessant desire for change and for the new and which is now governed by an increasing sense of speed.'

It are these very facts that have perhaps been responsible for the rapid rise in focus for ethical fashion practices by increasing numbers of consumers. The concern for issues of sustainability have seen the conversation move from the margins, to becoming a central concern for consumers and businesses alike. In part, social media has provided a platform for consumer critique that can quickly go viral, so that today brands face an increasing expectation from consumers for transparency of their supply chains on their websites. As always, technological develops remain both a boon and a curse...

Whatever changes technology brings, it seems evident that these will only increase the prevalence of the mediated fashion experience.There is an increasing- seemingly unrelenting, demand for fashion media content and experiences outside the traditions of fashion from previous generations. This is just one area which fashion educators must remain attuned in the development of their programmes. Other areas of increasing importance are the need for graduates to be both skilful and knowledgeable in their chosen field, but also flexible, adaptable and capable of operating in increasingly diverse workforces and situations. Collaboration is nothing new to the way the fashion system operates, but there nonetheless remains a certain focus on the heroic designer model- if only in the minds of some students. It seems inevitable however that the future will become increasingly interdisciplinary and that creative practitioners will need to display competencies to work across industries rather than being grounded in any one speciality. At the same time, and as mentioned above, aspects of the industry are becoming increasingly fragmented, with a much greater number of roles required to maintain even a small start-up operation. It is both an unnerving situation and an exciting opportunity for fashion education. One where the ground feels to be constantly shifting beneath ones feet, but which also offers the potential to propel and witness change in a field which we are all so passionate about.

Along with all fashion staff at the School of Design, Otago Polytechnic, I would like to warmly thank all presenters at the 'Fashion Fluid' symposium, and particularly, the members of this panel discussion. Further thanks go also to the Research Office of Otago Polytechnic for providing funding for the 'Fashion Fluid' symposium and for supporting us to bring Bernadette and Murray to Dunedin. Transcription services for this discussion were provided by Paula Petley- thank you Paula. Thanks also to the Dunedin Public Art Gallery for providing the venue.

Simon Swale (10000-0002-5830-3034) is a Senior Lecturer in Fashion at the School of Design, Otago Polytechnic, Ke Kura Matatini ki Otago. Simon spent many years working in the local fashion industry before taking up a role at the polytechnic where he has since developed research interests in the relationship between fashion and identity, and more recently fashion and art.

I S Swale, "Speed, Technology, Entrophy:The Fashion System at Breaking Point," Scope:Art \& Design, I 5:2 (20 I7), I 39-45, https:// www.thescopes.org/art-and-design- I 5/speed-technology-entropy-the-fashion-system-at-breaking-point/. 


\section{CAN BREATHE HERE: AN EXPLORATION OF AUTO-ETHNOGRAPHY, INTUITION AND EMBODIMENT IN DESIGN PROCESS}

Katie Day

I perceive the wholeness of the world ... to live perception, to be perception itself ...

Lygia Clarke'

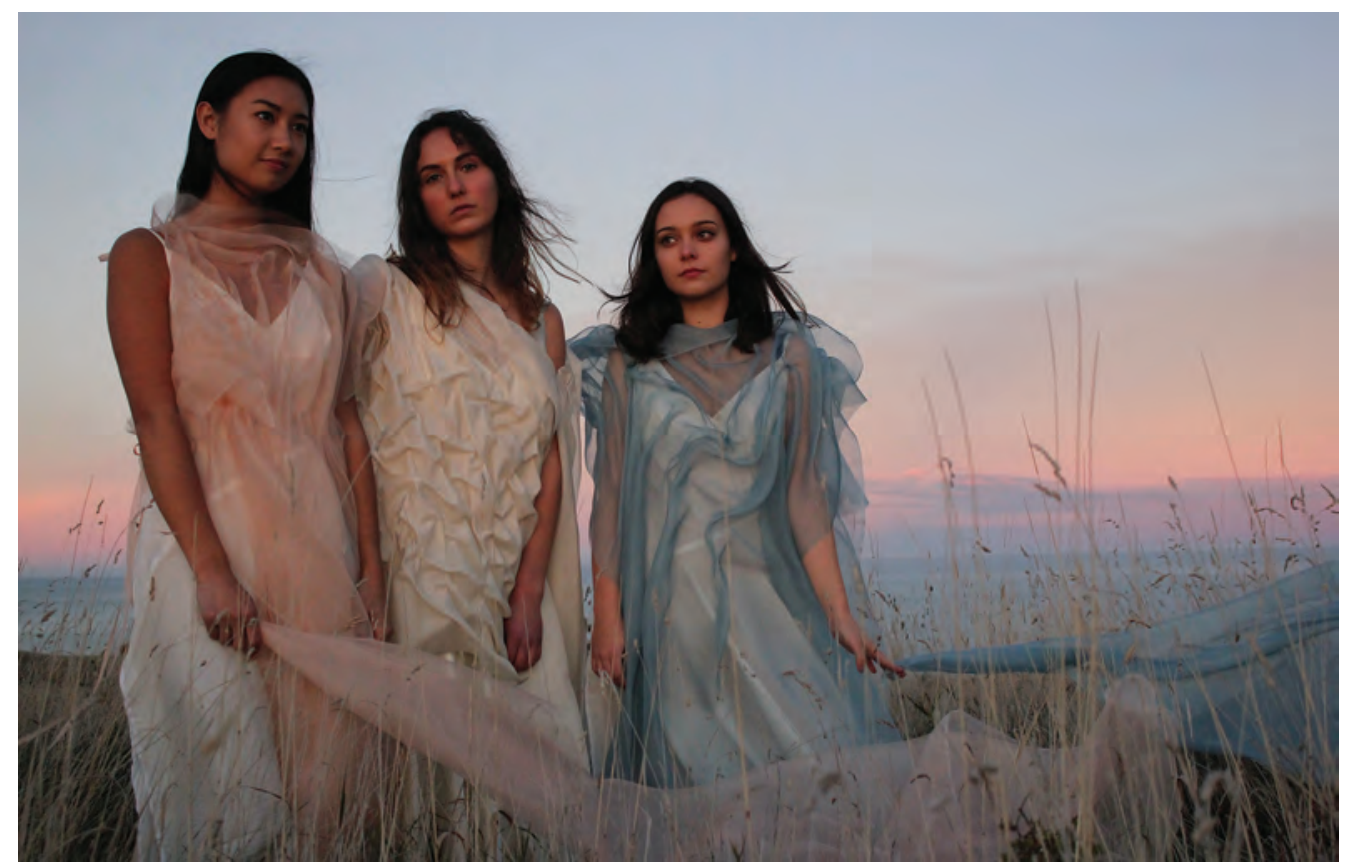

Figure I. Katie Day, I Can Breathe Here collection. 


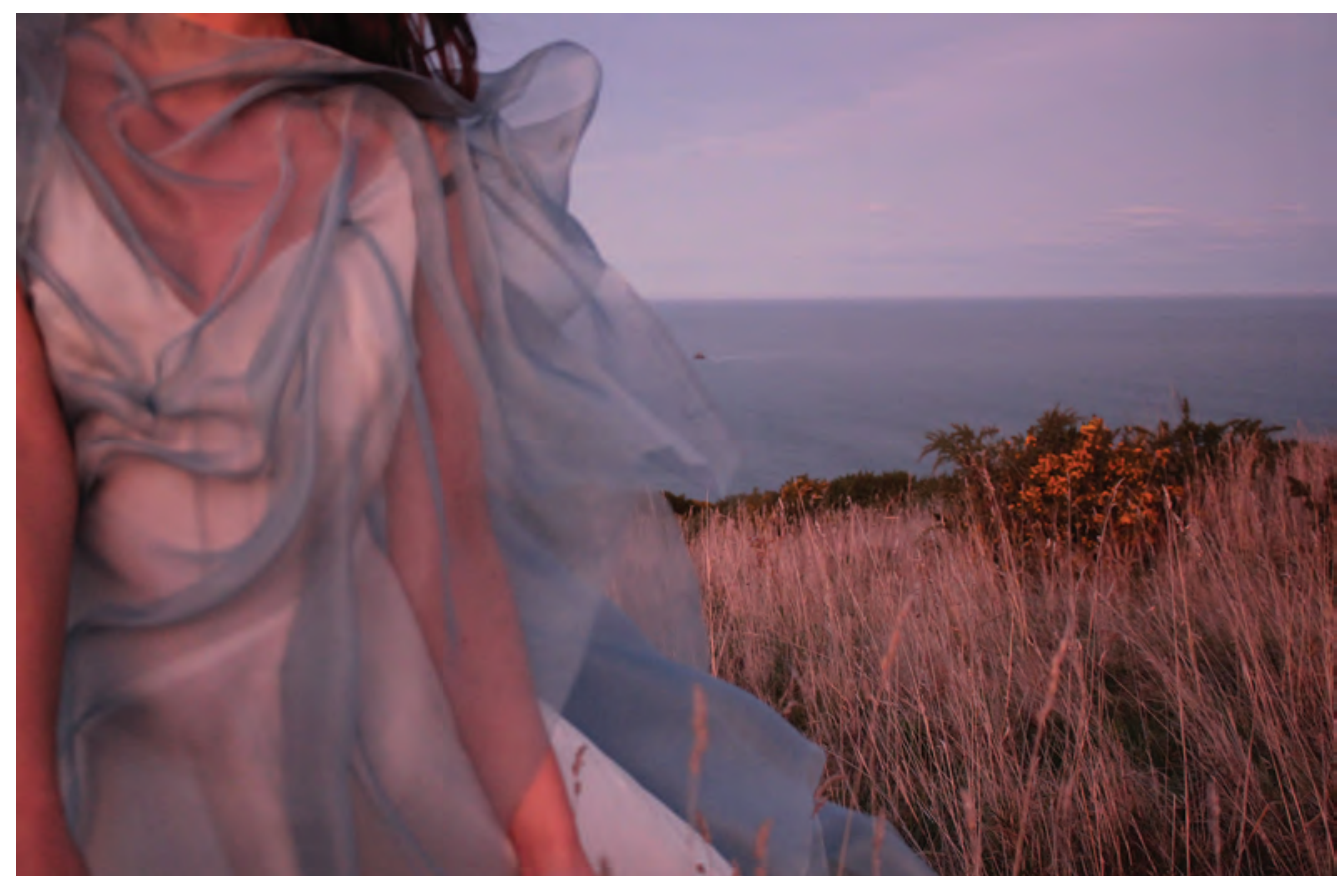

Figure 2. Katie Day, I Can Breathe Here. Example of sculpted silk and connection points.

I Can Breathe Here is a conceptual fashion collection that emerged from the rejection of my gravitation towards compartmentalisation and the wholehearted acceptance of my inherent desire for connectedness (Figure I).

I initially set out to create a collection steeped in structure and form through exploring the relationship between architecture and the body. These concepts had once offered a sense of familiarity, safety even; however, as I set off down this path, I quickly encountered internal tension, disconnection and distress. There was a separation, an expansive space between self and design. I was protecting my vulnerability, shielding true self, hiding behind structure and form. Yet the division between self and authentic created work was dangerously inhibiting the integrity of this collection. A bridge or a revelation was required to move forward. I chose both.

The revelation was that we as designers infuse ourselves into our concepts. The stories we tell draw consciously or unconsciously from personal experience - thus the concept cannot be completely separated from the designer. I could not keep a safe distance from my designs any longer. My experiences would relentlessly seep through, despite stubborn attempts to keep them protected, private. The bridge was built - rather than separating myself from my designs, why not just let go and embrace one's lived experience in the design process? An evolution in process had occurred. Rather than compartmentalising, keeping my designs clinical, safely structured and far from the soul, I would consciously choose to infuse my lived experience, values and observations into this collection.

With the theory and practice of auto-ethnography - described as "an approach to research and writing that seeks to describe and systematically analyze personal experience in order to understand cultural experience" ${ }^{2}$ - in mind, a new concept took form. Architecture and the body were still sources of inspiration, yet the process was personal now; I was connected to this collection and my sense of identity and place had weight to it. This was the fresh anchor point for my collection. I Can Breathe Here emerged as a collection exploring sense of place, belonging and connectedness, to the earth and to each other. 


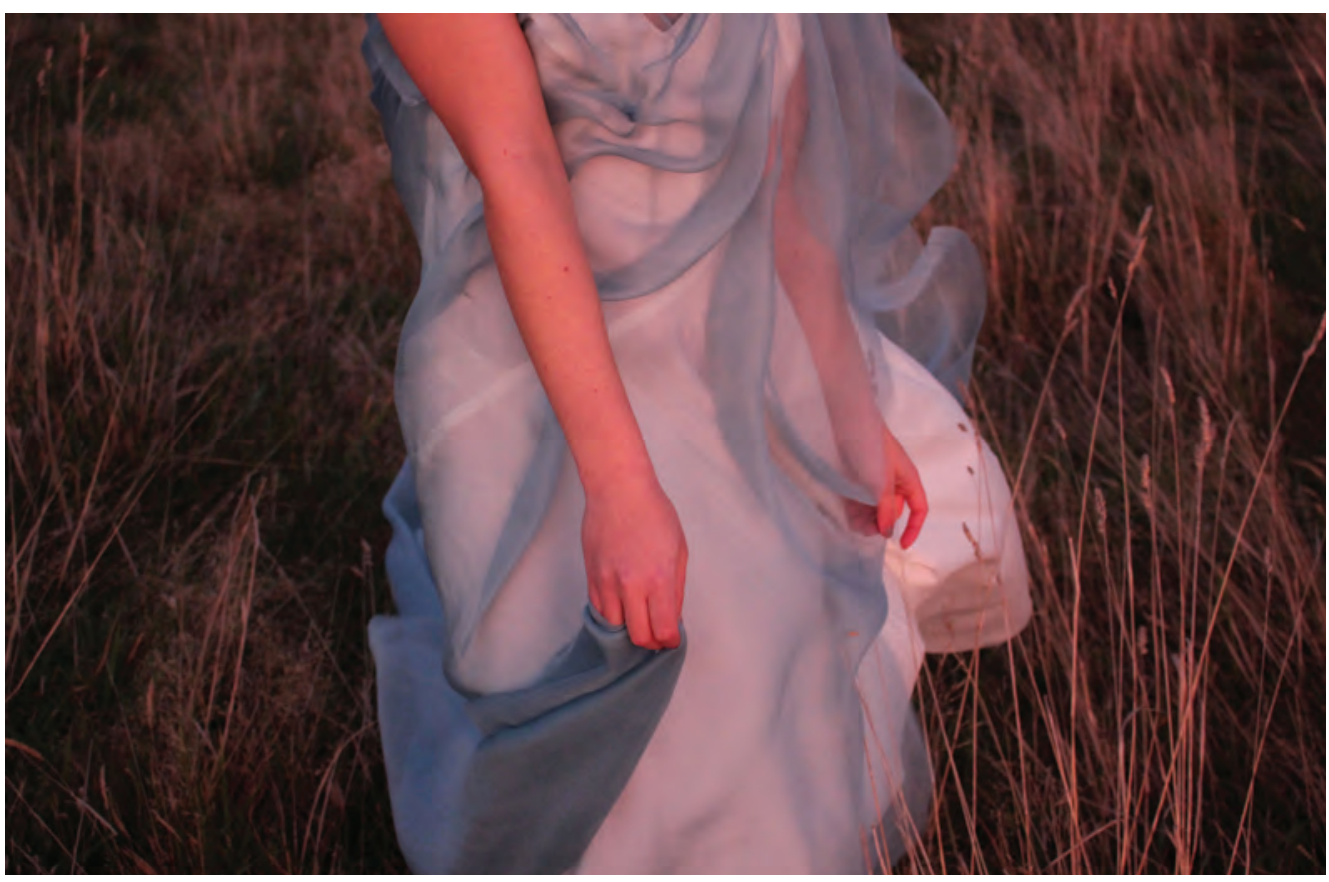

Figure 3. Katie Day, I Can Breathe Here. The body slips effortlessly through the silk.

\section{DISCOVERY}

A journey of discovery ensued as I became a student of myself and my environment. Referring to auto-ethnography, Andrea Short explains: "I believe that there is no boundary between myself as a person and myself as a designer - this method offers a great opportunity to bring these two aspects together."3 Auto-ethnography is a process of reflective observation and analysis of one's lived experience, considering time, place and culture, integrating elements of autobiography and ethnography.

I began to reflect on the land I adored and had known for a lifetime, Otepoti (Dunedin). I became mindful and heightened my awareness of all the thoughts, memories or experiences I had about the place. I ventured outside, physically exploring the land, driving from city limit to boundary line, walking as often as I could. The act of grounding was essential; I couldn't simply experience the environment with mind or memories. I needed to tangibly engage, barefoot to cool soil, hands submerged in icy waters, knees deep in tussocked hill, lungs expanded with crisp coastal air. I became connected. I immersed myself in the air, the ocean, the land and the light, and observed the narrative my thoughts would form.

I was magnetised to high places or water; naturally Otago Peninsula held my attention. I marvelled at the undulating peaks and valleys of the hills and found myself suspended in time as I stood at Taiaroa Head. Crest and trough of rhythmic waves hypnotised me as they met the break of land.

My observation of place was not reserved simply for grandeur or sacred moments, though. I captured my thoughts and feelings about this land in the mundane as well. "Autoethnographers recognize the innumerable ways personal experience influences the research process." ${ }^{\prime \prime}$ One of my journal entries reflected: "As I was driving to school today, I became aware of the hills on either side of me, a sense of peace filled my vehicle as I identified exactly how I felt. Held, but free. I was safely held within the hands of the land that surrounded me. I exhaled,'I can breathe here.' I can be."' 
My body of research was expanding as I collected thought upon thought about the air, light, breath, ground, height and the breadth of space I had encountered in Dunedin. I noted that a special term had made its way into my findings. It was "thin spaces," which could also be articulated as liminal spaces. Liminal spaces are the spaces that exist between things - a time, a season, a beginning or an end; they are the ambiguous, transitional spaces. Author Richard Rohr describes liminal spaces as places "where we are betwixt and between the familiar and the completely unknown. There alone is our old world left behind, while we are not yet sure of the new existence. That's a good space where genuine newness can begin."'5 My thin, liminal spaces were locations, often situated at points of arrival and departure around the coast, places of immense beauty, peace and minimal distraction where I felt a heightened level of connectedness to the land and to all beings. Having analysed the auto-ethnographic account I had made about my sense of place, three key words emerged: space, freedom and movement.

\title{
INTUITIVE MAKING AND EMBODIMENT
}

\author{
Maybe if I really believe in me, trust me, without any calculated plan, who knows \\ what will happen?
}

Eva Hesse ${ }^{6}$

Space. Freedom. Movement. These words became a mantra as I channelled my reflections of lived experience into fabric through an intuitive process of making. I meditated on these three words, and visualised the land as I set my hands to work on the fabric. I chose a soft, delicate, silk organza as my canvas due to its ability to represent weightlessness and capture light. I then began a process of repetitive motions, moulding and draping the silk to sculpt curves reflecting hills, rhythms reflecting water and twists depicting the wind patterns (Figure 2). I centred my thoughts on visualisation of place and meditative repetition of my mantra, disconnecting from preconceived notions of what a garment should be. The mind gave way to the hands and an embodied form of thinking led the way. "As the mind is embodied, the hand connected to the brain 'can see and feel and think' (Ufan 2004: 594), a process often described as thinking through the hands, thus defining making as a particular form of thinking."'

I draped the sculpted fabrics on the silhouette form, repeating the mantra: space, freedom, movement. I kept the connection points at the shoulders and sides minimal, creating garments that the body could slip through freely, yet still be enveloped by and connected to (Figure 3). I encountered a challenge as I attempted to communicate liminal space through the connection points in the garments, initially tacking the sculpted connection points with heavy, repetitive stitches. However, this created tension rather than ethereality. I drew from feedback I was given and explored hand-stitching options, finding a stitch that gently held the sculpted silk together, yet allowed for the in-between and gave space for the fabric to move and breathe (Figure 2). I crafted each connection point by hand, the stitching a continuous repetitive process that became an evening ritual, a practice of embodiment and a pathway out of overthought.

Natural Otago light is, at best, clear, illuminating and inspires a sense of wonder. The gradual, fading hues of dusk and dawn are particularly enchanting, often coaxing me into a dream-like state of reality. The silks' colour was chosen to reflect the natural light of dusk, the time of day I am most mesmerised by. Soft hues of salmon pink, dusty blue and crisp ivory encapsulate the remnants of fading daylight (Figure 4).

Connectedness wove itself through every aspect of this collection. Reflecting on my kinship to the land, it was crucial that I chose materials and construction techniques that had minimal impact on the Earth. I chose silk and silk-cotton, natural fibres that can biodegrade and, one day, peacefully return to the land. Unfortunately, a compromise had to be made in fabrication of the silk slip dresses. Although the dresses were primarily composed of silk, they did contain 3 percent Lycra and though this percentage is small, every fibre has a life cycle and this was not ideal. In future, all my garments will be composed of one hundred percent natural or recycled fibres. I would also like to explore natural dyes, sourced from local waste products, to reinforce the influence of place on a collection and to minimise the 


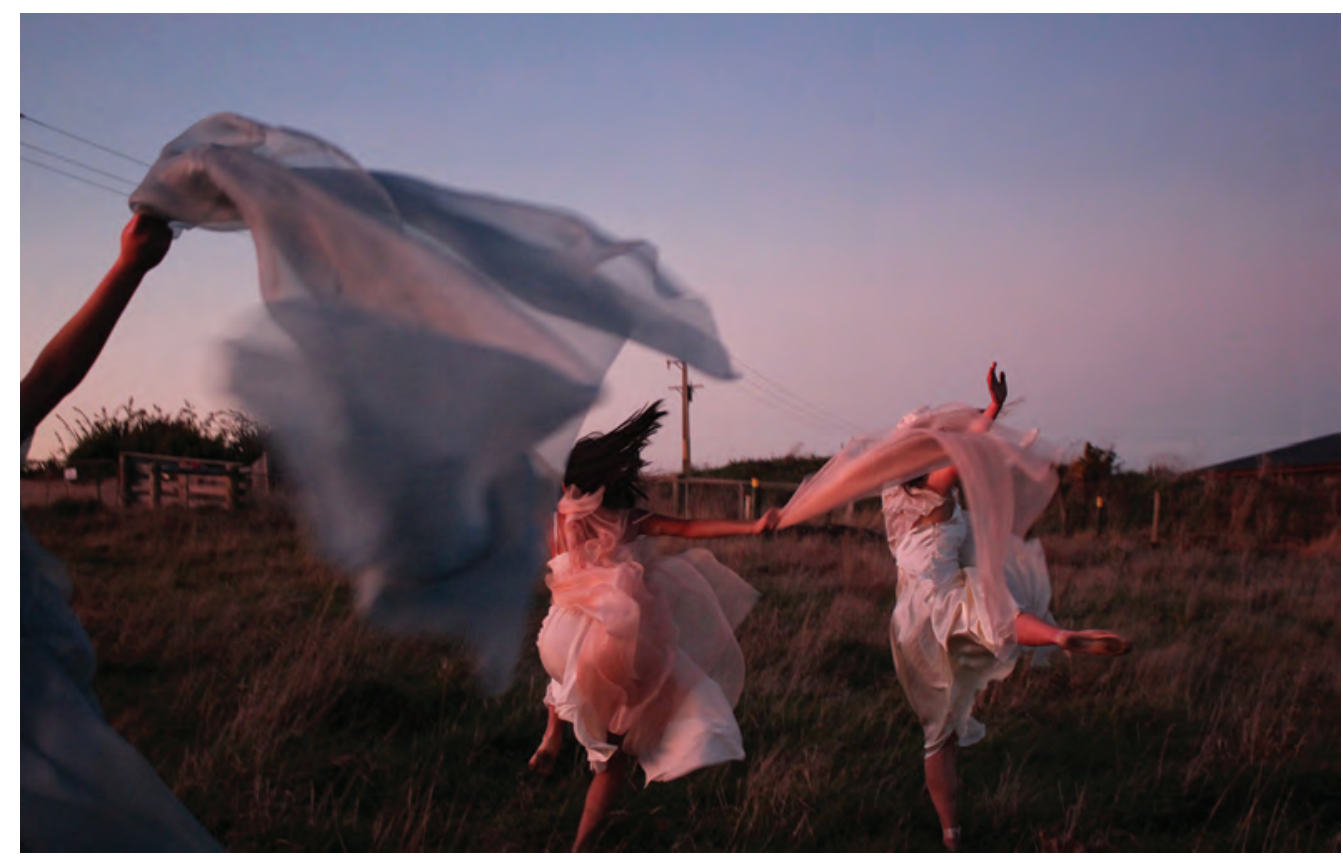

Figure 4. Katie Day, I Can Breathe Here. The soft hues of fading daylight are captured as the models embody my design values of space, freedom and movement.

impact that the fabric-colouring process has on the waterways and our environment. The outer, sculpted garments were made using zero-waste patternmaking techniques, sculpting individual, chosen lengths of silk. Form was created through the surface manipulation of the fabric, void of any cutting.

Through the use of zero-waste techniques, this collection represents an evolution of my sustainable practices. As designers, we are problem-solvers and storytellers and sustainability must be at the forefront of our minds. We are constantly learning, growing and re-evaluating our practices and each step to sustainability counts as we are all walking down the necessary path of change.

\section{CONCLUSION}

Isn't success, in the case of artists, the ability to express one's ideas to whatever public might be touched by that expression? Like many creative ideas, it is not necessarily the originality of the premise that is important or that defines the 'art' but the means and purity of its expression.

Maison Martin Margiela ${ }^{8}$

I Can Breathe Here is a great exhalation. A letting go. This collection allowed walls to fall in thought and process and provided a pathway for deepened connection between self and design. Place, belonging and connectedness, explored through auto-ethnography and expressed through an intuitive and embodied process of making, reinforced my sense of identity and presence. This collection is a personal journal given fabric form, and is a gentle reminder that vulnerability is strength, not weakness. My desire for connectedness to the earth and with each other has revealed itself with salient clarity, and our togetherness is the story I will continue to explore, unfold and expand upon throughout future collections. 
Katie Day is a final-year Bachelor of Design student majoring in fashion at Otago Polytechnic in Dunedin, New Zealand. Reflection, observation, embodiment and intuition guide her design process as she endeavours to tell stories of connectedness through exploration of vulnerability and regenerative action.

I Lygia Clarke, quoted in Stephen Horne, "Embodying Subjectivity," in Material Matters: The Art and Culture of Contemporary Textiles, eds Ingrid Bachmann and Ruth Scheuing (Toronto, ON:YYZBOOKS, 1998), 35.

2 Carolyn Ellis, Tony E Adams, and Auther P Bochner, "Autoethnography: An Overview," Historical Social Research, 36:4 (20I I), 273.

3 Andrea Short, "An Autoethnographic Reflection on Conceptual Fashion Textiles," Scope:Art \& Design, I5 (2017), 137.

4 Ellis, Adams and Bochner, "Autoethnography," 274.

5 Richard Rohr, Everything Belongs: The Gift of Contemplative Prayer (New York: Crossroad Publishing Company, 1999).

6 Cindy Nemser, "An Interview with Eva Hesse," Artforum (May 1970), 59-63, https://www.hauserwirth.com/stories/I4479interview-eva-hesse.

7 Solveigh Goett, "Materials, Memories and Metaphors," in The Handbook of Textile Culture, eds Janis Jefferies, Diana Wood Conroy and Hazel Clark (London: Bloomsbury Academic, 20I5), 127.

8 Maison Martin Margiela, quoted in Susannah Frankel, "The Birth, Death, and Re-birth of Conceptual Fashion," in Maison Martin Margiela, Maison Martin Margiela (New York: Rizzoli, 2009). 


\section{SOFT UNIVERSE}

\section{Ruby van der Zanden}

Speak to me, speak to me

With love in your words

Make for me, make for me

A soft universe

Aurora

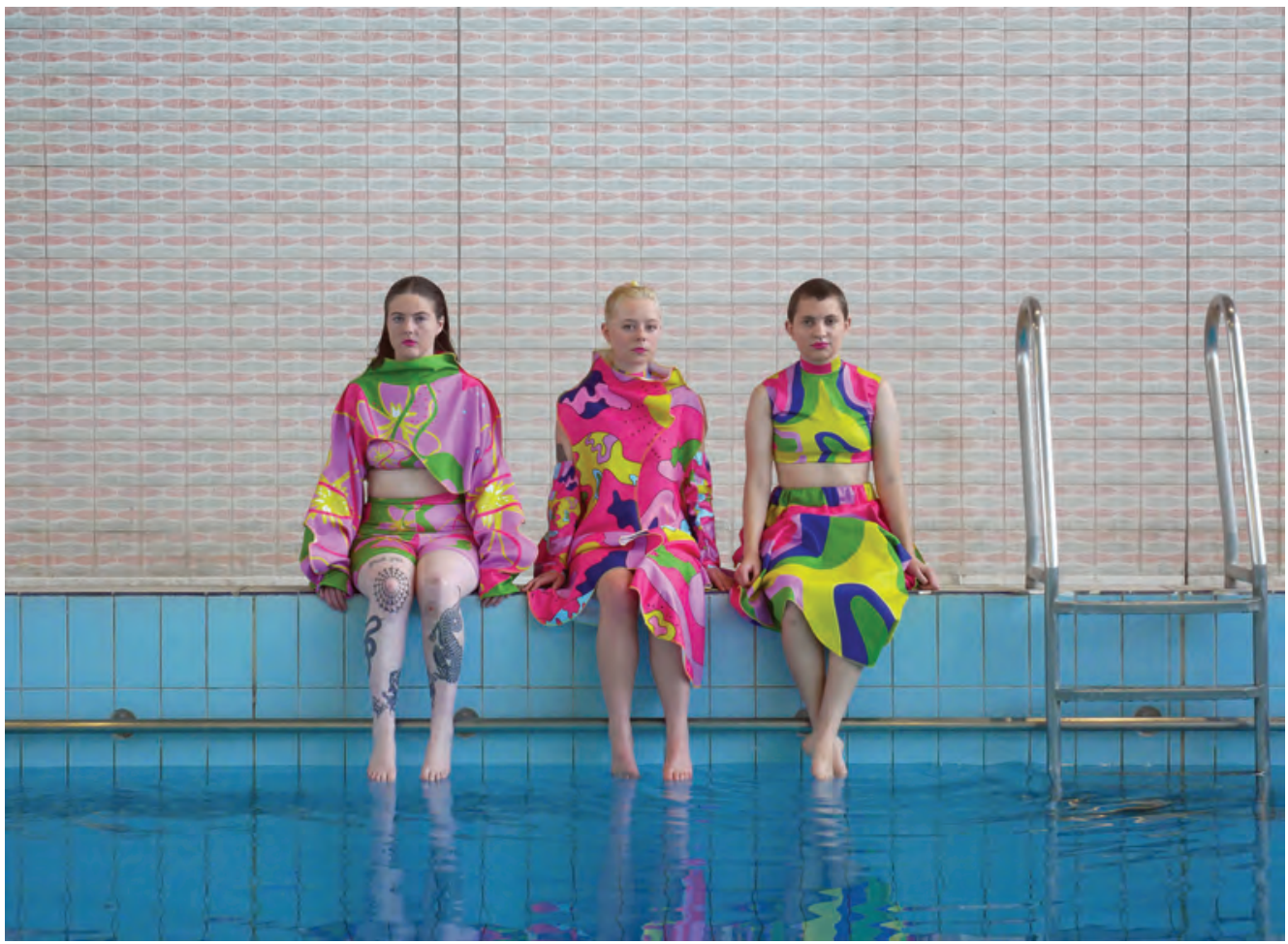

Figure I. Ruby van der Zanden, Soft Universe, conceptual swimwear collection, 2019. Models: Brittany Kingsland (left), Stella Vis (middle) and Emma Spencely (right). Photograph: Jess Thompson. 
Listening to music is huge a part of mine, and many people's everyday life. This year, it became even more important and influential than ever before. Without realising it, I began the process for this collection on 22 December when my dad unexpectedly passed away. Suddenly, a huge part of myself and my best friend had been ripped away from me, leaving me with terrifying images and memories of that night.

Although for many days afterwards I was surrounded by family and friends, I turned to sound as my distraction, a way to cope and gain distance from what was happening around me. I couldn't relax or turn off my mind naturally, and so I used sound to do so.

Music was always something that connected my dad and me, and felt very special to us. But I never imagined the importance it would soon have. I came up with the idea for this collection while planning my dad's funeral. For me, being in charge of the photos and music that were to be played was a very big deal, and I had to choose carefully the songs that meant the most. After this, I spent the next month and a half mostly in my head - always going for walks, listening to music, using it to help me sleep or simply just for comfort when I was by myself, so that I could somehow feel less lonely.

I have always felt that music had the power to send me into my own world, but after dad's death I observed this feeling increase markedly and felt that the importance of this reality needed to be heard. I decided to show it in the best way I know, through design.

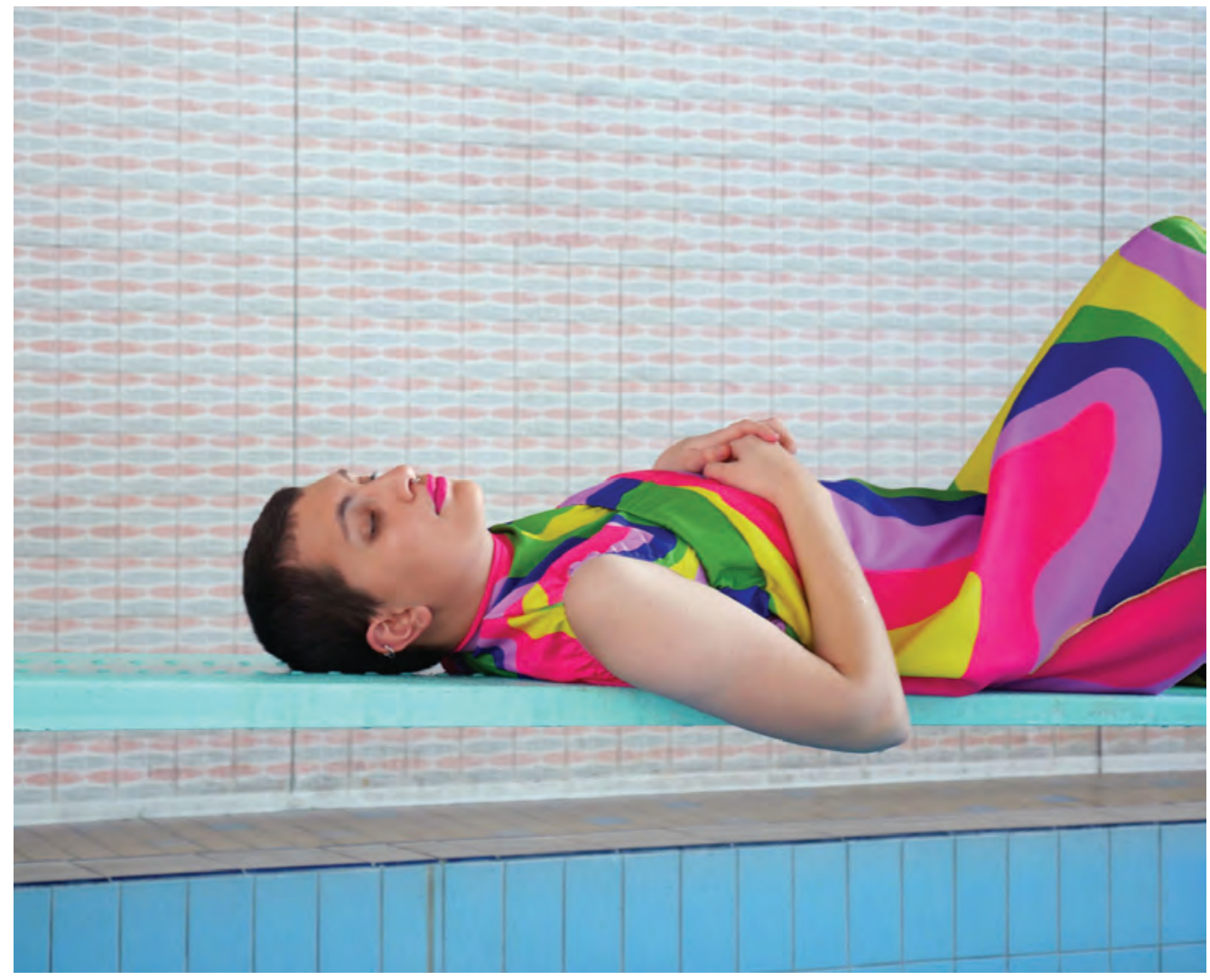

Figure 2. Ruby van der Zanden, Brain Waves outfit from the Soft Universe collection. Model: Emma Spencely. Photograph: Zak Booth. 
I embarked on a journey and a study of the self, using self-reflection and writing to explore personal experience and then connected this with my design research. I decided to allow intuition, reflection, adaptation and meditation to drive my design process through the act of listening to music. I would let myself be vulnerable and enter my Soft Universe, bringing a conceptual fashion collection out of it. The more I grow as a designer, the more I have found my identity to be closely linked with my practice. I use the act of making to design. My practice is intuitive and meditative and sits alongside the psychological phenomenon of 'flow'

Hungarian psychologist Mihaly Csikszentmihalyi describes flow as an "energised focus where identity disappears from consciousness and individual existence is temporarily suspended."' When I listen to music, I find myself feeling as if I am leaving this earth and floating away into my own Soft Universe. This state allows me to relax, meditate and intuitively assess situations as well as create my most abstract, conceptual work. When I am back in reality, I am hyper-aware of myself, my body, thoughts and surroundings. I end up with feelings of self-doubt and anxiety. Moving into other states of consciousness allows my mind to relax, be connected to my body and assess situations through my intuition.

As my design process developed, I continued to learn more and more about both the concept I was exploring and myself. The process began by creating a large playlist consisting of around 500 songs. The playlist was diverse and included a huge range of genres and artists. I find that listening to music is often a spiritual experience for me, as there are some artists and songs I feel very deeply connected to. What I have been listening to includes a lot of post-rock, dream pop and ambient music, in particular artists like Pink Floyd (whose music gives me the most connection and emotions around my dad) Hana, Grimes, Mogwai, Massive Attack and Aurora.

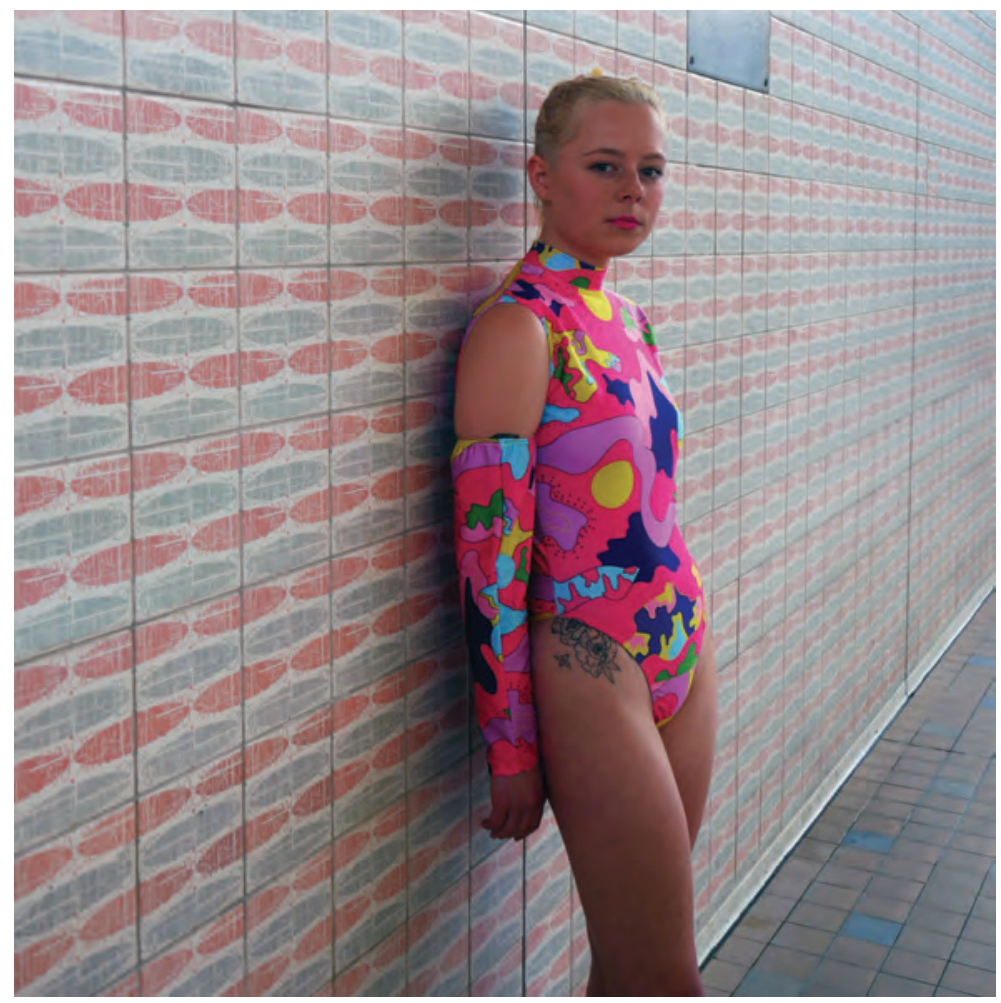

Figure 3. Ruby van der Zanden, Brain Cosmos swimsuit from the Soft Universe collection. Model: Stella Vis. Photograph: Jess Thompson. 
The title for this collection came from a song called Soft Universe by Norwegian artist Aurora. She is probably the artist I feel the most connected to on a spiritual level. I resonate very deeply with her music, especially Soft Universe, which explores her own experience of dreaming and fantasy.

In her book Everyday Music Listening, Ruth Herbert explains that "music is effective in promoting shifts in consciousness" 2 and shows how these altered states of consciousness induced by listening to music and the listener's relationship with a particular kind of music can influence this process. Herbert also says that "[a]bsorption and dissociation are manifestations of trancing" and that one can experience music-induced trancing and even transcendence of the self. As I was experiencing these shifts in consciousness by listening to music while trying to create textiles and silhouettes, I conducted further research into the precise states of consciousness that I was experiencing.

At this stage, I had been using the concept of flow and self-reflection to understand my thought process when designing intuitively while listening to music. I spent a lot of time in my room with headphones on to cancel ambient noise. Then dancing, draping, drawing and collaging. I dabbled with ideas of using a dance studio and other more public spaces for experimentation and giving myself room to move around. However, while in these spaces I felt that I was on show and either had to hide my authentic self or put on a show for others.

Being alone in my room allowed me to literally dance like no one was watching and move the way I needed to, experiencing and feeling everything as it came to me. Letting myself have this time was very therapeutic and allowed me to get used to the process of designing aided by music; it also enabled me to assess it and myself for my research. Doing this allowed me to make real headway with the project. I began to feel more comfortable and confident within myself and with letting my emotions run as they needed to. Only after taking this time to be alone with my mind and my music was I able to return to the studio and work from there.

You can cry, drinking your eyes.

Do you miss the sadness when it's gone?

And you let the river run wild,

and you let the river run wild. ${ }^{3}$

Once I returned to the studio, I began doing more reading into the shifts of my consciousness, exploring how this was happening and the states that I could feel myself entering. This in turn led to a more informed design process. I came to learn more about specific brain waves and the way that different waves lead the consciousness into altered states. I decided to focus on the three main waves that resonated most with my own experiences and the journey of leaving reality: beta, alpha and theta. Once I had a deeper understanding of these brain states, I was able to fully immerse myself in my practice and ultimately design my final textile outcomes. I am a very textile-based designer, and finalising my textiles before my silhouettes has become a defining part of my practice, as this is where most of my conceptual thinking occurs.

Beta is the brain wave that produces a state closest to reality. It usually kicks in when one is most excited. A person is on high alert and has full control of their surroundings. It is a gentle state often called "fast idle" or "musing," when we still have a full grasp of reality and our minds can rapidly process creative thought. My experience of this state issued in my Brain Flowers print. This is the outfit that represents the beginning of my journey into my consciousness. This print explores feelings of frustration, rapidly moving memories and images in my day-to-day life while listening to music, but still being mostly present in the external world. This state was the easiest to enter, yet interestingly the textile associated with it was the last one to be resolved. I think that because this state leaves us more alert than the other two I entered, I had more ideas that were fleeting and ever-changing. Although I didn't settle on this print until very late in the design process, in the end it felt right in my gut. The flowers refer to my feeling that this state is closest to nature and the real world, but also shows the blooming of ideas and creativity. 


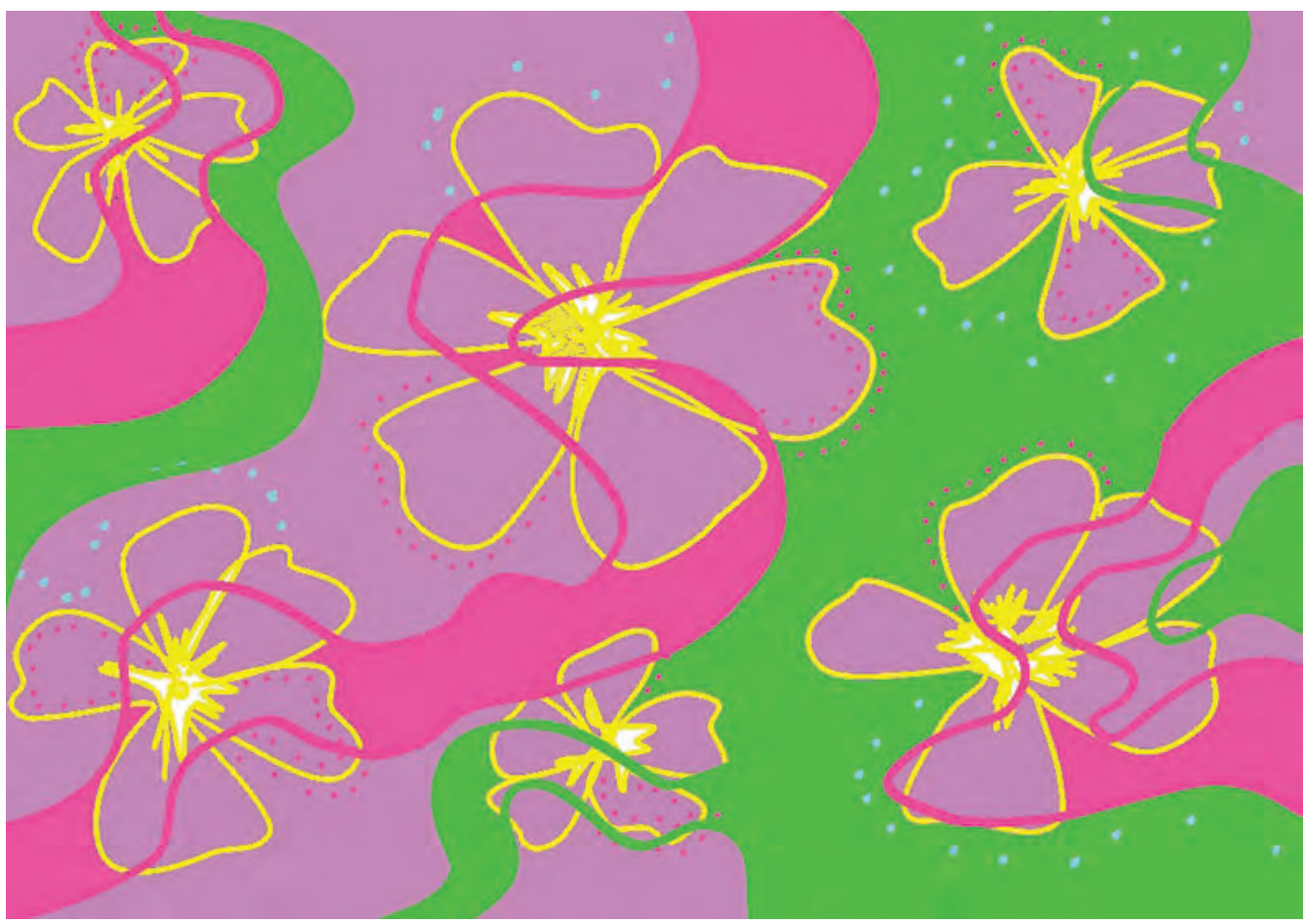

Figure 4. Ruby van der Zanden, Brain Flowers, digital print.

The second brain state is alpha. Alpha brain waves are the most present during quietly flowing thoughts, meditation and daydreaming. This is the state in which I spent the most time. One is able to be present and fully in touch with one's intuition, yet creativity is also at its most heightened potential; we are able to see the most vivid images while in the alpha state. Entering the alpha state is often used as a tool in treating anxiety and depression, as the mind is often clear of negative and unwanted thoughts, allowing more creative and positive thoughts to take their place. The alpha state is represented in my collection through my Brain Cosmos textile. This print embodies the most accurate representation of my Soft Universe; the waves, mountains, valleys, suns and moons of my mind are vivid and bright.

The third state is theta. Theta is the state of deepest relaxation - the point where you're not quite asleep, but not quite awake. This was the hardest state for me to enter, but the most rewarding. Theta is the state into which a person is put while under hypnosis. It accesses the part of our mind that lies between the conscious and the subconscious. It enables us to retain memories and emotions - they are always creative, characterised by feelings of inspiration and often deeply spiritual. Theta is the most healing state, "the first stage of the phase when we dream."4 Being in theta was extremely powerful for me. After experiencing it, I realised that my whole design process and the act of making was actually the thing that had helped me through the last five months after losing my dad more than anything else. I have a long way to go, but I have found just how healing the act of making can be and it is now a defining part of my practice and philosophy. My experience and research into the theta state informed my final digital print, Brain Waves.

I chose to represent these brain states through swimwear.When I am in these altered states of consciousness, it feels extremely real to me and my visions are so vivid that I can see them and feel them on my skin. The images start to appear on my arms and legs and chest - energy manifests on my body. I wanted to create garments that had the feeling of tattoos on the body - there is often a strong link between tattoos and one's memories and emotions. I have tattoos on my legs that are a part of me and I feel very connected to them, just like my Soft Universe. As this energy grows in my mind, it covers the skin and begins to take over as I am fully immersed and no longer a part of reality. 


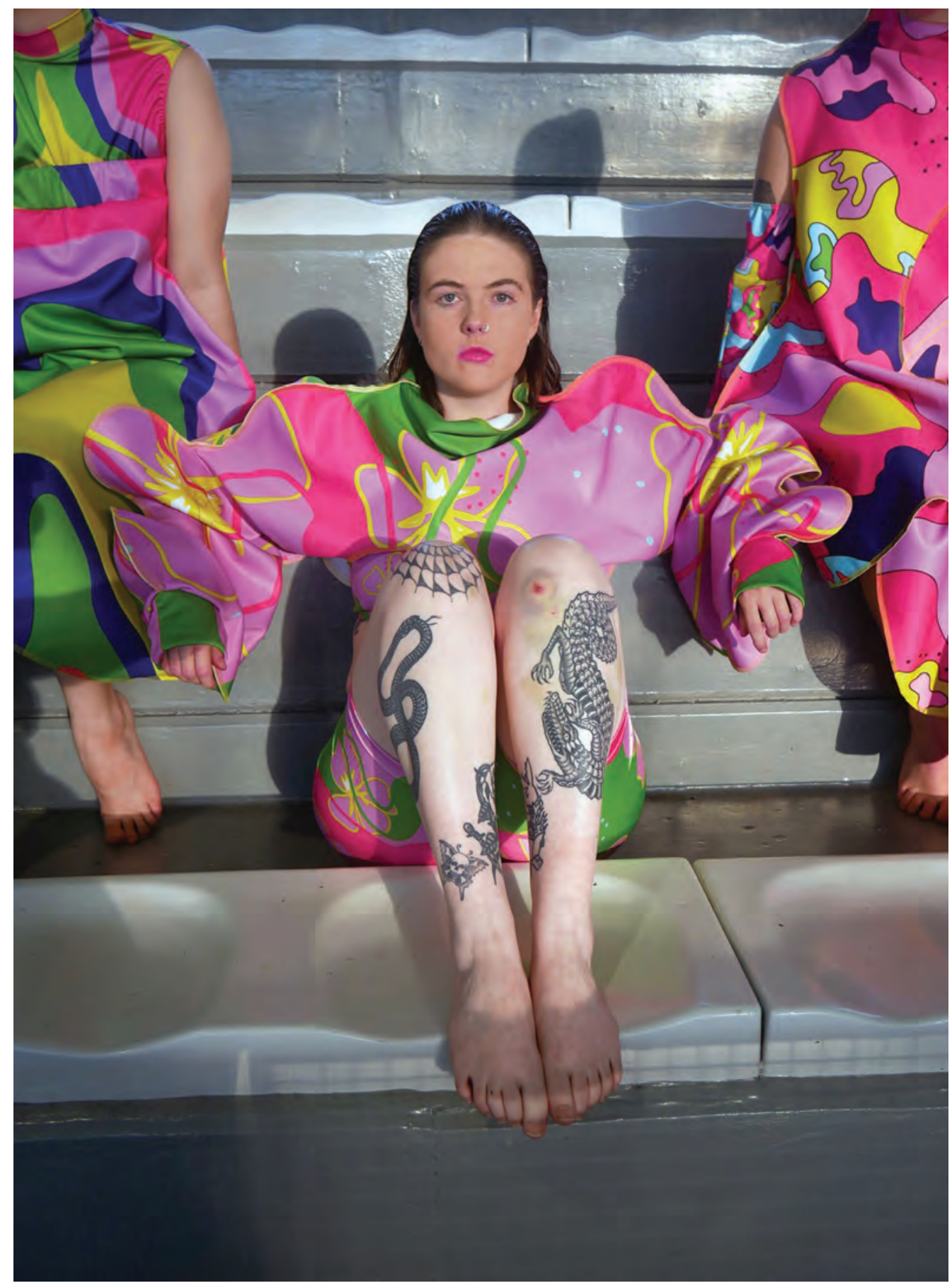

Figure 5. Ruby van der Zanden, garments from the Soft Universe collection.

Models: Emma Spenceley (left), Brittany Kingsland (middle) and Stella Vis (right). Photograph: Jess Thompson. 


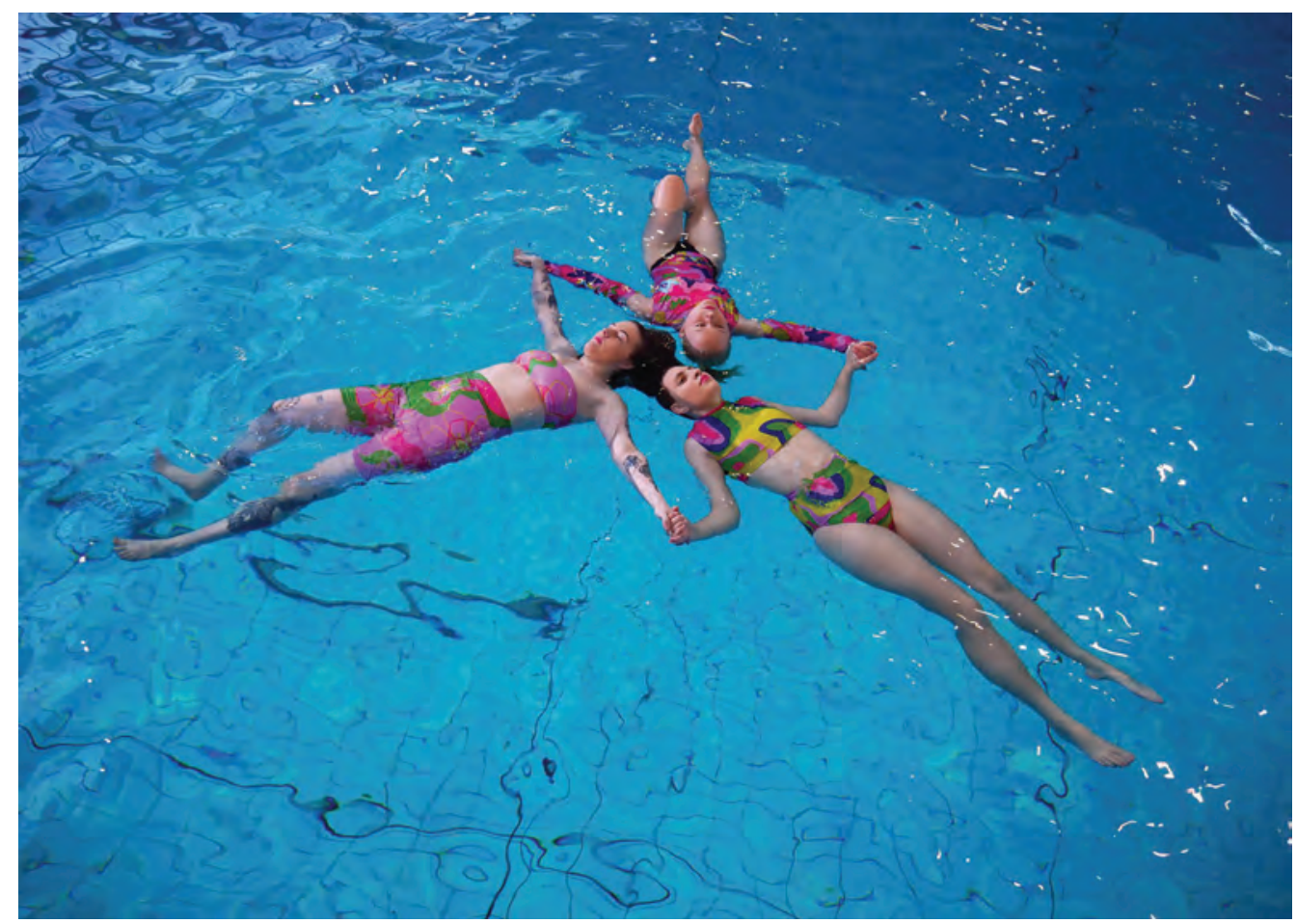

Figure 6. Ruby van der Zanden, swimwear pieces from the Soft Universe collection, 2019.

Models: Brittany Kingsland (left), Emma Spenceley (middle) and Stella Vis (right).

Photograph: Jess Thompson.

These waving, moving, swirling, fluid shapes are what I always found myself drawing during the design process. As I leave reality, everything becomes liquified and I feel like l'm floating. I wanted to create garments that represented the idea of motion and fluidity, and I decided to do this in a way that held the most personal connections for me - through tight-fitting lycra pieces. I grew up a dancer, gymnast and ice skater. Movement and expressing myself through movement has always been a huge part of my life. So instead of creating garments that moved themselves, I wanted to make pieces that the body could move in and with. These lycra separates act as fully functioning swimwear. They allow the body to be immersed, whether in or out of the water, clinging to the skin and allowing one to feel the energy that created them. It was important for the swimwear pieces especially to embody the phenomenological element, as I was seeking to show through these garments what I was feeling and allow other to experience this, too.

The outerwear pieces were developed later. I played a lot with abstract, blob-like shapes that were very similar to the digital prints. These blobs felt like manifestations of energy and emotion, and I decided to use these shapes as the base for my outer garments. I played a lot with collage, both on the form and on paper. I experimented with cutting out shapes in fabric and seeing what they would do on the body, as well as taking photographs of things I had thrown around my room, cutting them out and using these shapes on paper to create unique silhouettes. I included outerwear in the collection to communicate how real this music-induced transcendence felt for me. It was as if the energy had not only manifested on my body, but was so strong that it was growing into a more physical, powerful entity that was beyond my own self. I wanted to create big 3D pieces, but at the same time to illustrate this flat, cartoony, fantasy feeling that I was experiencing. To create this flat look, all of my seams were sewn with the wrong sides together to eliminate bulk and feel less 'real.' 


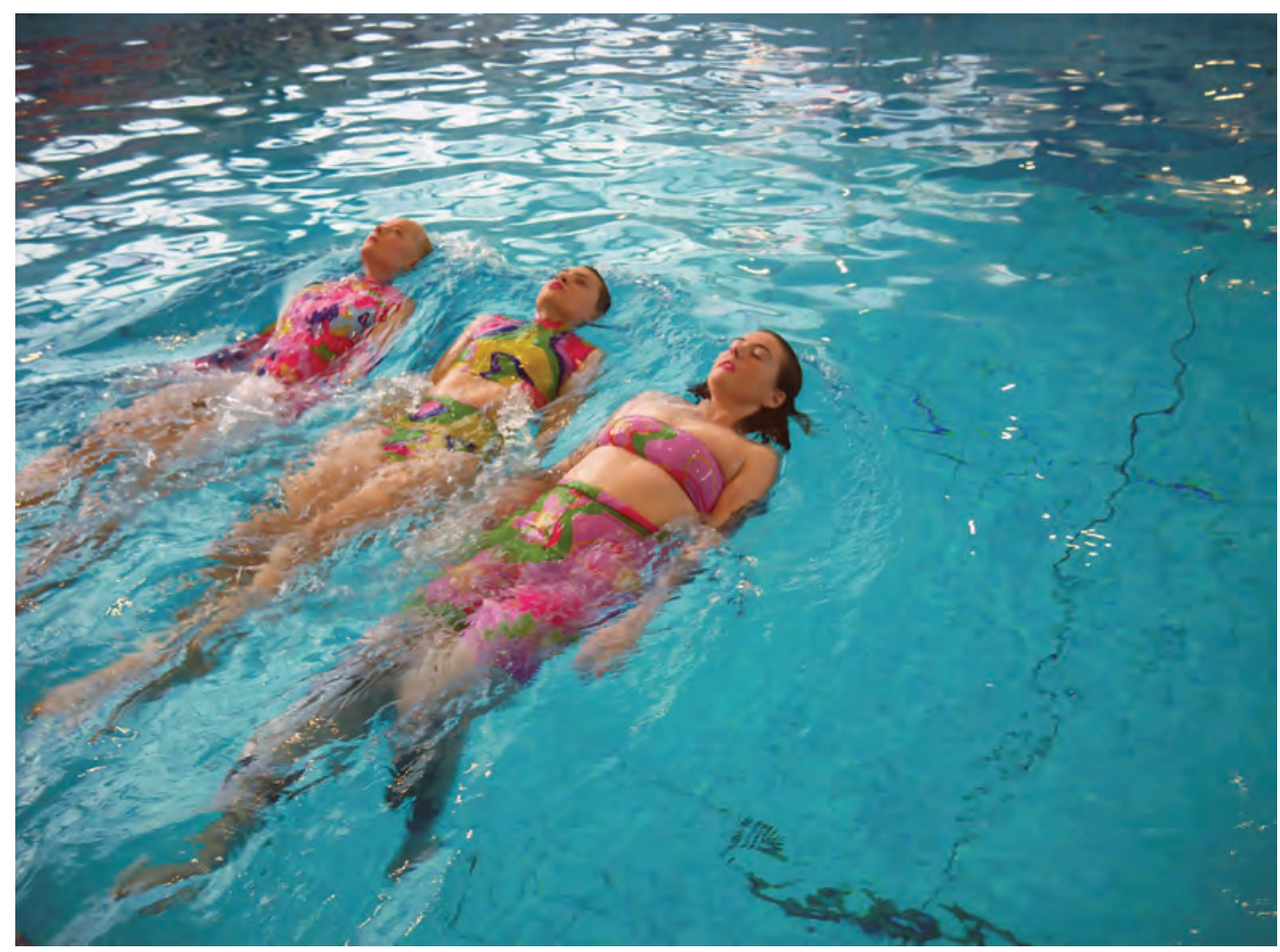

Figure 7. Action shot of swimsuits from the Soft Universe collection being worn in the pool.

Models: Stella Vis (left), Emma Spenceley (middle) and Brittany Kingsland (right). Photograph: Jess Thompson.

The process of designing this collection has been extremely special, spiritual and healing for me. I have a deeper understanding of myself now, and feel that this project and the process of making has helped my grieving process more than anything else. I have learnt many valuable things that I will be taking into FDS6. There are areas within this project that I need to work on and polish in the future. One of these is my construction. I feel that although I have improved a lot, there were still some areas that didn't quite work out. One of these was putting domes in the crutch of the Brain Cosmos swimsuit; I didn't know at the time that they wouldn't be strong enough and have a tendency to pop open. Another thing I would do is toile in my final fabric, as it was much less stretchy than the material I tested my swimsuits in, leaving me with tension issues and some cover seaming coming undone. I know now what I need to do to improve on this

I believe that my collection could easily be pared back to become commercial. The swimsuits are already fully wearable, and the outerwear pieces could be turned into proper sports jackets and tracksuit pants. Or they could be worn 'as is' for special events like the Burning Man festival, which encourages experimental dressing.

I have been exploring other designers in my community of practice, and have found that my aesthetic and practice relates well to the Danish label Helmstedt. In her collections, designer Emilie Helmstedt focuses on fantasy and utopian ideals through the use of colourful prints. ${ }^{5}$ Someone in the same mould is designer Rebecca Carrington, whom I connected with during iD Dunedin Fashion Week on many levels, but mainly around design. We have similar ways of looking inwards during our design process and bringing out what we feel through graphic, storytelling textiles. 
In the end, I have come to I feel much more connected to myself, as well as with my dad. My self-confidence has grown immensely on this journey, and the biggest reward was learning not to create a collection to please others, but to please myself. This design outcome is the most authentic representation of myself.

\section{Freedom. Confidence. Joy.}

Ruby van der Zanden says: "Freedom, confidence and joy are at the centre of my design ethos. My work is very process-based and often explores things that are currently happening in my life as I bring them to life through digital textiles and exploratory silhouettes. I aim to evoke joy and empower others through my collections."

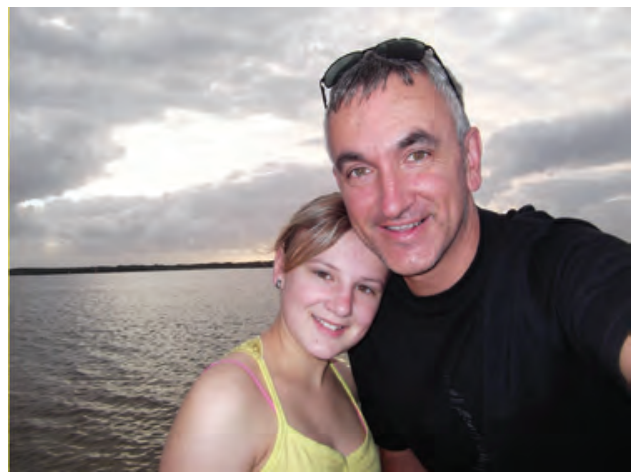

To my best friend. I love you and will always feel close to you through our music.

https://www.youtube.com/watch?v=FwbjNovSWAs

I Mihaly Cziksentmihalyi, Flow: The Psychology of Optimal Experience (New York: Harper \& Row, 1990), https://books.google. co.nz/books?hl=en\&lr=\&id=KTQXAgAAQBAJ\&oi=fnd\&pg=PR9\&dq=flow mihaly csikszentmihalyi\&ots=0swiEb0nrV\&sig= mATue4QhIC4iBNcK5KkqpBFeaZw\#v=onepage\&q=flow mihaly csikszentmihalyi\&f=false (accessed 30 May 20I9).

2 Ruth Herbert, Everyday Music Listening: Absorption, Dissociation and Trancing, Ist ed. (London: Routledge, 201।), https://www.routledge.com/Everyday-Music-Listening-Absorption-Dissociation-and-Trancing-I st-Edition/Herbert/p/ book/978I 409421252 (accessed 30 May 2019).

3 AURORA, The River, 10 May 2019, https://www.youtube.com/watch?v=P7IE-G l oC34.

4 “ThetaHealing® Theta Brain State," ThetaHealing, https://www.thetahealing.com/about-thetahealing/thetahealing-theta-state. html (accessed 30 May 2019).

5 Brooke Bobb, "Emilie Helmstedt is Writing her own Danish Fairy Tale with Whimsical Clothes," Vogueworld, 22 March 2019, https://www.vogue.com/vogueworld/article/emilie-helmstedt-copenhagen-fashion-designer (accessed 30 May 20 l9). 


\section{DOWNHILL/ASCENT:AN EXPLORATION OF CONCEPTUAL FASHION IN SKI APPAREL}

Maia Holder-Monk

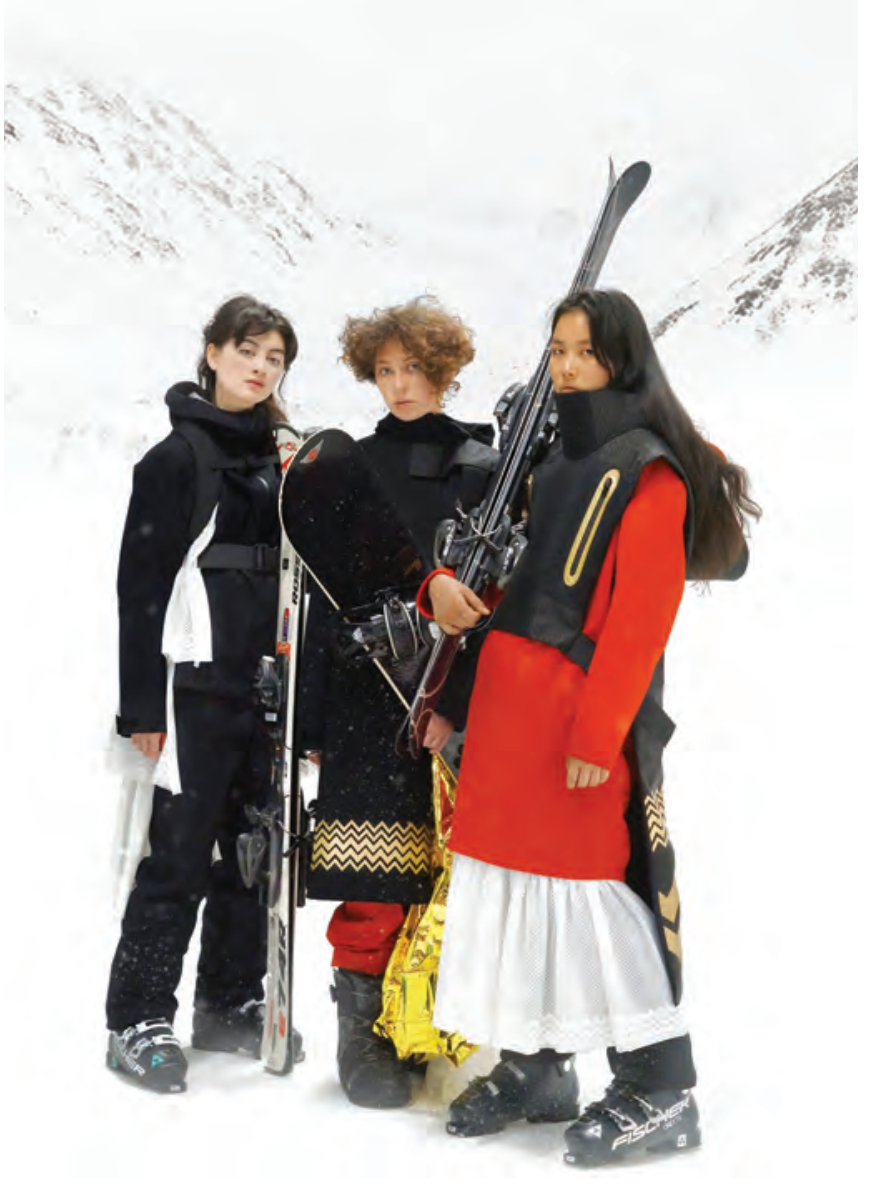

Figure I. Maia Holder-Monk, Downhill Ascent collection. Photography: Chris Motion. 


\section{MOUNTAIN/CATHEDRAL}

"And how many times have the gods listened, the stars aligned, and wonder of wonders, you found yourself standing on the edge of ecstasy with acres of untracked fluffiness just waiting for your unworthy self?"।

For me, 'the mountain' (denoting all mountains) is a sacred place of joy and reverence. Throughout my life, I have discovered that engaging with this enormity of nature through skiing holds many similarities to sacred and religious practices: the mountain as cathedral; a humbling of oneself to magnitude, power, volatility. It is a form of communion, and an honouring of the beauty and movement in both the earth and my own body.

The more I reflected on my experience, the more parallels I unearthed. Ecstasy and rapture in the wooping and hollering of swift movement, the awe and reverence of something much bigger than oneself, the echoes and interiority of the immersive mountain, the rituals of preparation in dressing.

Downhill Ascent conceives of a ceremonial skiwear. My brief placed emphasis on disregarding the many (often rigid) conventions of ski apparel and has sought to explore imaginative possibilities of what a sacred or religious experience of skiing might look like in dress. I was curious about what could happen if the structures, values and fabrications of ski apparel became the canvas for conceptual design.

Quoting Hussein Chalayan in her theoretical work on conceptual fashion, Hazel Clark explains how "he employed fashion and art as a device for 'framing something that already exists."' 2 Downhill Ascent is a collection which has taken both conceptual fashion and ski apparel as devices to frame my spiritual experience of skiing and the mountain.

Clark also defines conceptual fashion through observing how Issey Miyake, Yohji Yamamoto and Rei Kawakubo "[t] ogether and apart ... questioned the conventions of fashion." In pursuing a career in women's ski apparel design, it was immensely important for me to challenge and deconstruct the many conventions and formulas of this area of design, so I can enter my future work with a freedom of innovation and bold creativity. My desire to create something new and generative in its disruption of convention connected me to conceptual design. Thus, by applying the critical and transgressive approaches of conceptual fashion, I hope to establish a fertile and critical foundation for future work.

\section{THE RUNWAY/THE SLOPES}

Contextualising my collection with other designers and practitioners posed some challenges. The relationship between ski culture and the avant garde is, at present, fairly undeveloped. This did, however, make bridging the gap between the two a more exciting and surprising experience.

As we have seen, ski apparel is an area of design with many conventions and a generally formulaic conceptual scaffold. Within a sport context, the order of priorities is different from everyday fashion. Function comes strictly before form, and comfort, range of movement, aerodynamics and weather protection all sit above aesthetics and expression.

When collaborating with Burton and Vogue, Virgil Abloh of Off-White described their project as marrying "high fashion in its tailoring and fit [and] the element of no-fuss and utilitarianism." ${ }^{\prime 4}$ He distinguishes the practical and functional aspects of outdoor apparel as their key signifier and trait.

I found that most engagements between ski apparel and high fashion happened through these kinds of collaborations on off-season drops. Moncler's Moncler Genius series involves collaborating high fashion designers creating monthly collections which draw from the design identity and history of the brand. ${ }^{5}$ Designers including Pierpaolo Piccioli, Simone Rocha and Craig Green, whose collection "interpret[s] Moncler's high performance based history,"6 bring 
their high-fashion sensibility to outerwear materials and conventions and, in doing so, approach the avant garde through mere fusion. The stage for these collections, along with others such as Junya Watanabe Man $\times$ The North Face, ${ }^{7}$ remains as the runway, bringing outerwear into the fashion sphere. In keeping the mountain and skiing as the intended context, my practice has done the opposite.

While the way apparel is designed for gendered bodies is something I wish to explore and improve in my future work, for this project I decided to focus on challenging the priorities of ski apparel. What might happen when speed and optimal performance are no longer the primary goals?

I believe there is a space in ski apparel for play and joy, for contemplation and ceremony. The spiritual experience of skiing in which I have immersed myself, when placed as a higher intention, will result in a difference in dress.

\section{ELEVATION/HUMILITY}

Through my investigation of sacred practices, specifically sacred reading practices, ${ }^{8}$ I came to understand that a thing, place or act, becomes and remains sacred through our treatment of it. Dress plays a significant part in this, as an "active participant in human lives." "When entering a sacred space, our dress changes to reflect or respect this change of context. We may take off our shoes on entering a marae, or cover our heads on entering a mosque. Ceremonies and rituals are marked further by specifics of dress, in colour, embellishment and style.

Through Downhill Ascent, I sought to ask how it might look if we treated dressing for the sacred space of the mountain, and a sacred practice of skiing, in the same way as we do for other spaces and practices. What would a ceremonial skiwear look like?

My approach to finding an answer to this question (not the answer, but an answer) through design began with research into the visual tropes and meaningful purposes of religious dress. It was key for me to look deeper into the designs and contexts to see what defined and shaped religious dress. Like the skifield, sacred spaces and places of worship have a unique set of values and intentions for clothing that differ from fashion.

I found that the purposes, and subsequent designs, of religious dress mostly fell into two categories: Humbling and Elevating.

The 'elevating' garments were highly embellished and dense with symbolism and narrative imagery. They acted as visual stimuli to prompt pious reflection, communicate morals non-verbally, or functioned as an addition to the beauty of a holy space - beauty as an offering and a way to ascend closer to God. These garments also acted to visibly demonstrate hierarchy, status and power. ${ }^{10}$

In deep contrast to the opulence of this ceremonial wear, other religious wear, ranging from monastic garments to ihram - the Islamic dress worn on pilgrimage to Mecca so as to "appear in the holy places in the guise of a beggar" " | - works to bring the wearer closer to the earth in "community, simplicity and humility." 2 These vestments often feature dark, muted colours or monotonal ensembles, hoods and head coverings, and encourage conformity in their lack of personal identification.

\section{RITUAL/PRACTICE}

One of the tasks I set myself in conceiving a ceremonial dress for the mountain was creating a symbology for this context. In traditional religious garments, the highly decorated pieces were often embellished with a language of symbols and references in terms of colour, imagery and materials. If we understand religion as "an historically transmitted pattern of meanings embodied in symbols,"'13 then the importance of a distinct visual language is clear. 
To begin my conceptual process, I explored the imagery and language I associated with ski culture, the mountain, my own experience and apparel conventions through brainstorming sessions, often using poetic language - the wavy lines cut through the snow by skis, the layers of snow with floral life waiting beneath, eloquent descriptions of fresh snow.

One of the core concepts that underlay this project was the idea of skiing as a ritual. Journeying up, then skiing down, over and over until the day ended, only to be repeated again tomorrow. I drew this repetition of movement in a zigzag, an ascent and descent with no completion. This pattern held not only the simplified shape of mountain peaks and valleys, but also the symbolism of ritual, of sacred practice.

"Look at the zig zag of the blanket. Mountains and valleys, mountains and valleys."'4

I was connected back to a book I loved in my childhood, Esperanza Rising. In it, a grandmother teaches her granddaughter how to crochet the zigzag stitch, describing the many mountains and valleys of life. This became the link between my concept and my experience of design process.

Beginning the making and experimenting stage of this project was an immense challenge for me. My personal expectations of perfection - exceeding all my previous achievements - had grown exponentially, so the pressure of choosing the right thing to create, the right tangent to follow, was too intimidating for me to even begin.

When I came to this zigzag pattern, I saw parallels in the way I could view my design practice. There would be many mountains and valleys in my process, not just one mountain to climb and conquer. In an attitude very reflective of a capitalist, individualist societal structure, I had been imagining my design career as a ladder, where I had to keep outdoing myself, fuelled by a constant fear of descent.

Exploring ritual, and indulging in imagination and recollection of my skiing as a sacred practice, I noted how it was neither the journey nor the destination, not the ascent or the descent, which was my purpose. It was the doing again and again, the skiing, the ritual.

Partway through this project, I shifted my experience or understanding of design to this same pattern. Like the crochet zigzag, each stitch builds on the last, not upwards but rather creating a lateral web. Like skiing, it is a practice.

\section{MAKING/MATERIALS}

Following my new understanding of my design as a practice, and releasing myself from the stresses of continuous ascent, my process became a lot freer and more hands-on. I moved away from sketching and did most of my ideation on full- and half-size mannequins in drape. Working with my hands and giving myself the liberty to spend time stepped back and squinting at the scraps of fabric I had pieced together was very generative. My previous design process had often been strictly demarcated: design through sketching followed by construction and execution. For this project, the designing went on throughout and inside the making process, continuing right up until the last days of work.

While draping, I worked with both fabric and paper. I found that draping in firm paper allowed me to explore more extreme silhouettes and structures which would distinguish my garments from conventional skiwear. In flat patternmaking, I experimented with chevron lines with inserted flare and volume to create the structural train piece. For the base jackets and pants, I worked with spreading and inserting ease into articulated seams around knees, elbows and back, to both allow for movement and to create the signature ski posture and form I desired to accentuate.

Beyond bringing symbolism and visual languages to the ski field, I also wanted the silhouette, fit and features of the garments to be rooted there. Through research and analysis I found that the 'humbling' kinds of religious dress often worked phenomenologically to incite a certain mood of repentance, reverence and humility. ${ }^{15}$ Hoods and head 
coverings encourage the wearer to gently bow their head and aid concentration in prayer; long robes connect one firmly to the earth.

I also reflected on my physicality while skiing, especially the muscle memory of slightly bent knees and hunched shoulders, relaxed yet engaged, ready for movement and impact. I emulated this S-bend shape - which occurs naturally when standing in ski boots - in my articulations of base jackets and pants. The tucking of one's chin behind collars and buffs was reflected in a high foam-structured collar and a gold chevron buff, and the security of steady pressure against the collarbones was suggested in feature backpack straps.

In devising the base pieces, my intention was to create garments that were fully wearable and functional for skiing. Though I designed the outer decorative garments to also be appropriate for skiing, I took the creation of these pieces as an opportunity to learn conventional ski apparel techniques. In making a fully waterproof garment, I had to find a way of sealing the seams to prevent water leaking through needle holes. I established a connection with Elco Apparel, who specialise in seam-sealed outdoor apparel. While this added some limitations and requisites to my construction methods, through analysis of a variety of garments borrowed from industry professionals at Product Design and Earth Sea Sky, and discussion with machinists at Elco, I was able to create waterproof garments which were fully seam-sealed.

This project has required me to seek out resources and knowledge from the wider industry and community. Facing challenges in sourcing appropriate waterproof outerwear fabric, I undertook workroom visits to Kathmandu and Cactus Outdoor. Not only did this let me engage with industry professionals, but it also enabled me to create relationships of support and collaboration. The team at Cactus Outdoor offered me access to materials and fastenings from their stock. The 2-layer and 3-layer Goretex I chose gave me options for both lined and unlined garments.

Although my range of choices for fabrics and colourways created some limitations, I feel that these boundaries actually helped to keep the collection contextually accurate and grounded. My use of 'lace' was a crucial example of this. I used a light sport mesh, embellished with a chevron pattern in heat-applicated vinyl. When seen on the reverse side, this manipulation gave the impression of lace, a craft used widely for ceremonial garments (such as christening gowns and veils in marriage or mourning rites) due to its precious and narrative-rich character, while also retaining its materiality and identity as outerwear.

Quoting Martin Margiela, Susannah Frankel describes an approach to conceptual fashion which is simply "to take an existing form and to rework it." ${ }^{\prime 6}$ By utilising the materials and techniques of ski apparel in alternative and narratively referential ways, I have been reworking the form, as Margiela puts it. This is one contributing methodology to my overarching aim of challenging conventions in ski apparel.

\section{ASCEND/DESCEND}

I decided to explore the forms of religious/ceremonial dress that I had distinguished in my research, with two distinct ski-wear layers in each outfit. The base pieces - fully waterproof technical outerwear - draw on the 'humbling' side of religious vestments, visually referencing these monotonal garments as well as (explored here through a posturebased silhouette) working to ground the wearer.Worn over the top of these humble bases are the 'elevating' pieces. These garments express and embody the celebratory, opulent and sanctified aspects of religious dress through embellishment, movement and bold forms.

To follow the style of downhill movement of skiing versus snowboarding, I kept asymmetry for the snowboard look. The lace petticoat pieces add softness to the structural outerwear and will create dramatic movement when flowing behind the skier in motion. Over-sized side-release buckles feature throughout the collection, along with silicon-grip elastic, backpack straps and waterproof zips. Alongside the distinctive protective fabrics, these features tie the collection to its outdoor space. 


\section{LOOK I}

The 'elevating' garment in this look finds its inspiration in the dalmatic, a type of open-sided tunic worn for liturgy. It features foam structuring, buckle fastenings at the sides, bold gold chevrons at the back hem, and gold sealed zip pockets, which are constructed using heat-activated adhesive, making a stitchless pocket. The collar on this piece mimics the drop and curve of a hood against the upper back, dramatising this shape that appears in most ski apparel, as well as connecting it to the upright collars of ecclesiastical uniforms. On the oversized red hoodie beneath, a cutoff hood suspended by a forehead band adds another layer to this striking side view, and draws on various forms of the wimple (a feature of nuns' monastic habits). A ruffle petticoat skirt is worn between this and the articulated knee pants beneath.

\section{LOOK 2}

The snowboarder look is for someone who rides goofy, right foot downhill. Working with this feature, the train - featuring a sculptural chevron hip piece and lace ruffle over a voluminous gold emergency blanket - whips out behind the boarder as she descends the mountain. On the 'elevating' garment, more gold chevrons trim the base of a foam structured panel that falls down the front of the body. These long rectangular shapes hanging from the shoulders also reference ecclesiastical garments such as the dalmatic, stole, cope and chasuble. These pieces treat the body almost as an altar, draping flat, highly embellished offerings or artworks across it. A backpack strap appears again, holding the piece on the shoulders, and revealing the low-hemmed, articulated back jacket, which is lined and features waterproof zip pockets and a stormshield. The red pants, when worn with the oversized red hoodie of Look I, offer an Eastern monastic aesthetic, which favours bright, rich monotonal ensembles.

\section{LOOK 3}

Drawing on the lightness and grace of garments such as wedding dresses and veils, this look's 'elevating' piece hangs tiered lace ruffles from a foam-padded backpack harness. It fastens around the waist and across the chest over the articulated sleeve jacket and lined pants. This piece brings softness and elegant movement to the dark base pieces with their utilitarian function designed for mountain use. A gold chevron face mask shields the chin and nose and completes the look.

\section{PEAKS/VALLEYS}

Developing this collection has been a challenging, yet highly rewarding and generative experience. The struggle I experienced at the beginning of the project paralleled my interrogation of the motifs of ascent and descent in my experiences in skiing, and led me to challenge my own ideas of high and low. Ups and downs were flipped on their heads - in skiing, 'down' connotes exhiliration, flow, speed and ecstasy, while 'up' connotes the climb, hard work, dedication, commitment and struggle. This experience has been immensely positive for me and the future harmony of my work and wellbeing.

Through it, I have gained crucial and foundational skills and techniques in ski apparel construction, along with new relationships with industry, which will support me in my next ski apparel collection. This experience has given me both a familiarity and confidence with the materials, and also an urge to further challenge and reinvent them.

A key limitation I faced in this project were the restricted options available to me in the area of materials and fastenings. While I believe that I used these limitations in a positive way to stabilise the connection between the idea and the context, in future it will be important for me to undertake extensive sourcing research and create connections to overseas suppliers. 


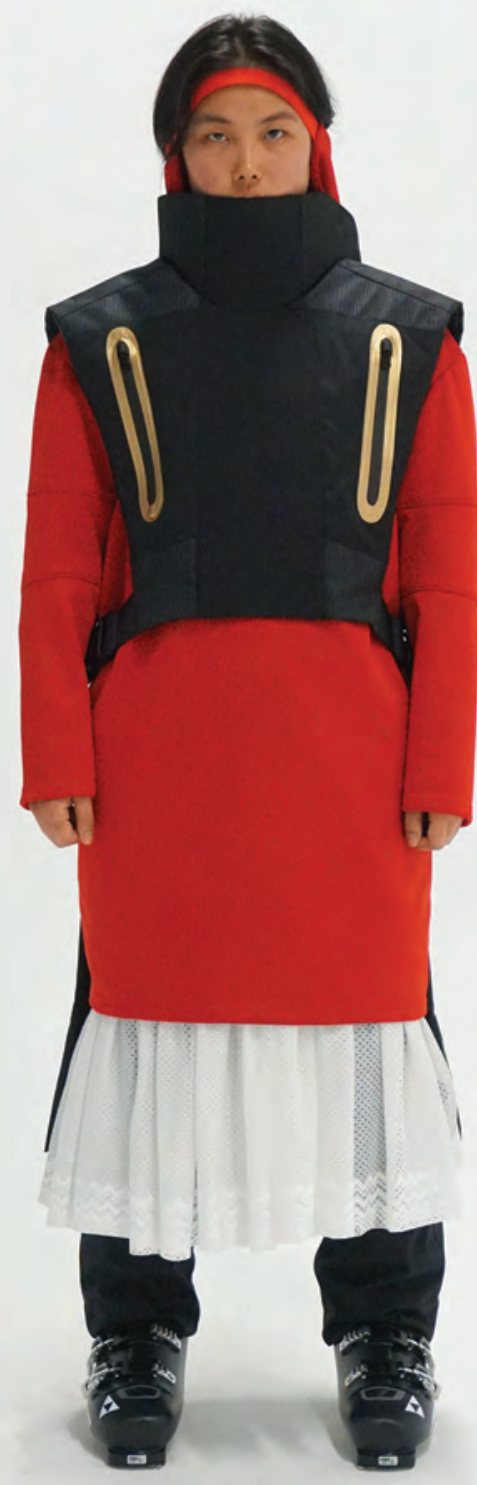

Figure 2. Maia Holder-Monk, Downhill Ascent collection, LOOK I. Photography: Chris Motion 


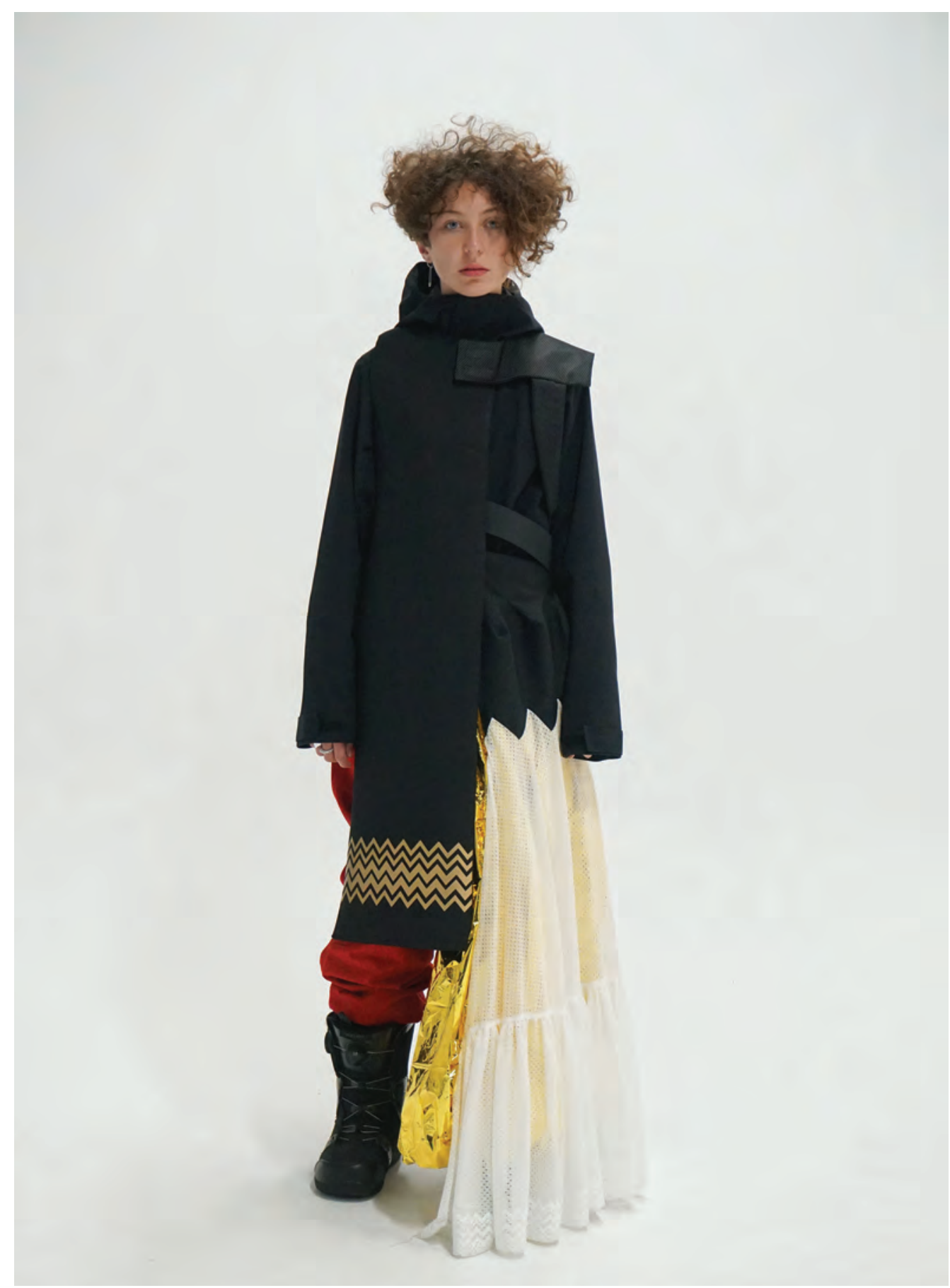

Figure 3. Maia Holder-Monk, Downhill Ascent collection, LOOK 2. Photography: Chris Motion. 


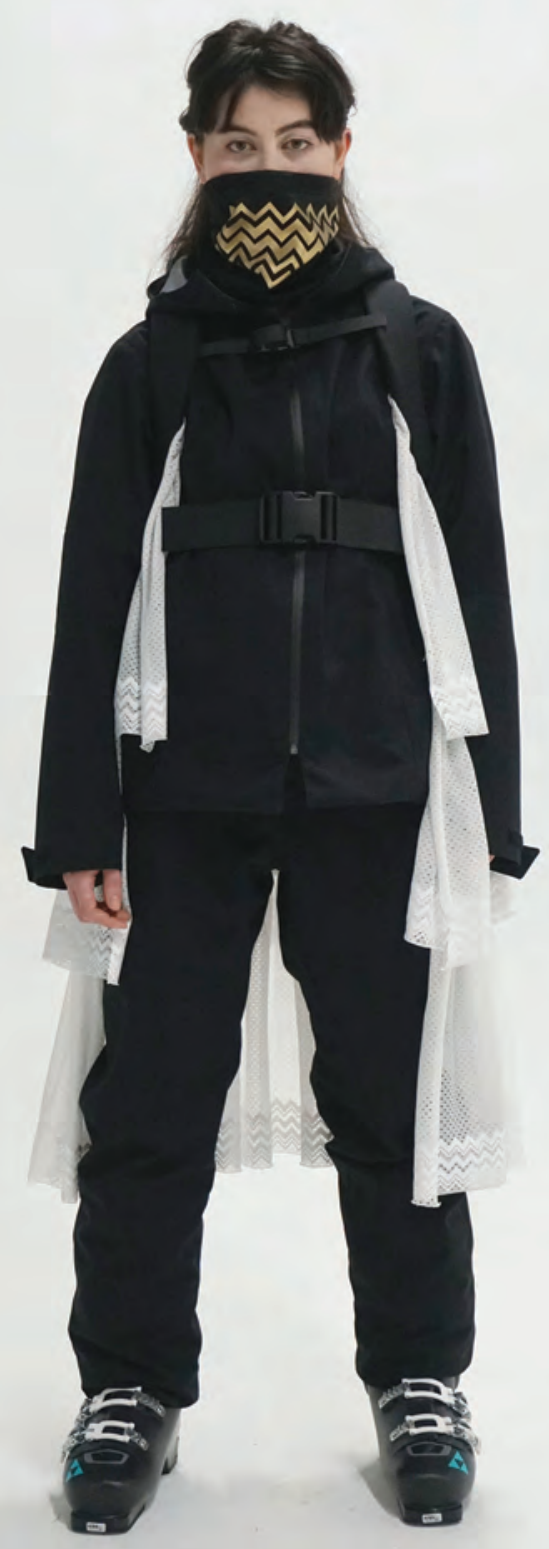

Figure 4. Maia Holder-Monk, Downhill Ascent collection, LOOK 3. Photography: Chris Motion 
The elements of phenomenological design that emerged in my research are areas that I wish to pursue further in my next work. The way that dress can shape and enhance the embodied experience of skiing is fascinating to me, and could be applied to my designing regardless of concept or idea.

Completing this collection did not resolve my curiosity over how avant garde qualities might impact outdoor apparel - it only increased it. I believe there is vast space for more exploration of these two design contexts.

Whāia e koe te iti kahurangi;: Ki te tūoho koe, me mounga teite If you are to bow your head, let it be to a lofty mountain.

\author{
Acknowledgements: \\ Tania - Elco Apparel \\ Tim - Product Design \\ Sarah and Jo - Cactus Outdoor \\ Chris - Otago Polytechnic
}

Maia Holder-Monk is completing her final year of study for a Bachelor of Design (Fashion) at Otago Polytechnic School of Design, focusing on expanding and renegotiating the conventions of women's ski apparel through conceptual design. Her work has a foundation in feminist phenomenology and aims to enable a fully embodied experience for women in motion.

I Neil Stebbins, "A Cynosure Careless," Powder, 45:I (September 2016), 38.

2 Hussein Chalayan, quoted in Hazel Clark, "Conceptual Fashion," in Fashion and Art, eds V Karaminas and A Geczy (London: Bloomsbury, 2013), 71.

3 Ibid, 68.

4 Virgil Abloh, quoted in TS Fox, "Off-White ${ }^{\text {TM }}$, Burton \& 'Vogue' Unite for Limited Edition Capsule Collection," HYPEBEAST, I 3 January 20 I8, https://hypebeast.com/20 I8/l/off-white-burton-vogue-capsule (accessed 31 May 2019).

5 Luke Leitch, "Moncler 4 Simone Rocha Fall 2019 Ready-to-Wear Fashion Show," Vogue, 23 February 2019, https://www. vogue.com/fashion-shows/fall-2019-ready-to-wear/moncler-4-simone-rocha (accessed 31 May 2019).

6 Craig Green, quoted in Ali Morris, "Craig Green's Voluminous Pieces for Moncler Resemble Flotation Devices," Dezeen, 30 August 2018, https://www.dezeen.com/2018/08/24/craig-green-launches-voluminous-moncler-genius-collection-design/ (accessed 31 May 2019).

7 Jake Silbert, "Junya Watanabe Drops SS19 The North Face and Karrimor Collab Jackets," HYPEBEAST, 21 February 2019. https://hypebeast.com/2019/2/junya-watanabe-man-the-north-face-karrimor-spring-summer-2019-jackets-drop (accessed 31 May 2019).

8 CasperTer Kuile and Vanessa Zoltan, Harry Potter and the Sacred Text, podcast audio, http://www.harrypottersacredtext.com/.

9 Lynne Hume, The Religious Life of Dress: Global Fashion and Faith (London: Bloomsbury Academic, 20 I3), 2.

10 E Michael Pye and James Dickie,"Religious Dress," Encyclopædia Britannica, I I August 20 I8, https://www.britannica.com/topic/ religious-dress (accessed 31 May 2019).

|l Ibid.

12 Hume, The Religious Life of Dress, 35.

13 Victoria S Harrison, "The Pragmatics of Defining Religion in a Multi-cultural World," International Journal for Philosophy of Religion, 59:3 (2006), | 33-52, doi: I 0. I007/s I I 153-006-696 I-z.

14 Pam Muñoz Ryan, Esperanza Rising (Waterville, ME:Thorndike Press, 2018).

15 Pye and Dickie, "Religious Dress."

16 Martin Margiela, quoted in Susannah Frankel, "The Birth, Death and Re-birth of Conceptual Fashion," in Martin Margiela, Maison Martin Margiela (New York: Rizzoli, 2009). 


\section{ORDINARY}

\section{Gràinne O'Connell}

All these old things have a moral value Charles Baudelaire
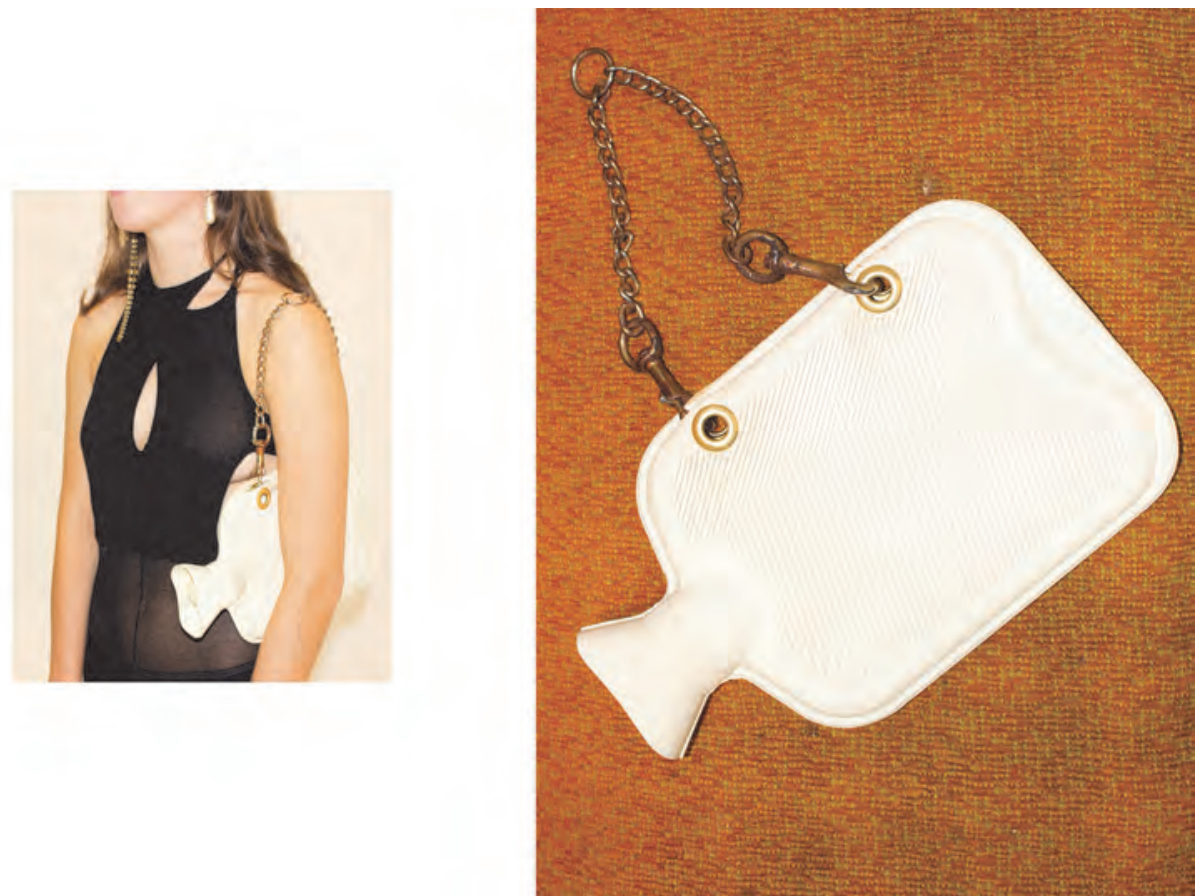

Figure I. Gràinne O'Connell, Hoisery Dress and Hot Water Bottle Bag. Model: Lola Morten. Photograph: Gràinne O'Connell. 


\section{INTRODUCTION}

Ordinary is a conceptual collection which draws its content from everyday aesthetics and found materials in my environment, and explores what we place value on and what we overlook. For me, collecting, op-shopping, remaking, is entropic work, a ritual that respects the ordinary. I have implemented this in my practice to show that from the ordinary it is possible to design and make things of beauty, purpose and value.

The word 'ordinary' originates from the Latin ordinarius, meaning customary or orderly; ordinary work can be understood as work that is in harmony with the natural environment. In this context, the term 'entropic' refers to a ritual or ordinary task in daily life.' However, in the industrialised capitalist world, entropic work is given a low status and is therefore devalued in this consumer-orientated world.

I drew on the concept of kaitiakitanga in my process as a means of establishing my position on sustainability and the values we assign to what is made, based on who makes it or how it is made. This decision developed subconsciously and grew from my childhood values of respect, curation and a deep loathing of waste that was instilled in me. Kaitiakitanga is a Māori value that translates loosely as guardianship and conservation. ${ }^{2}$ In order to describe how this concept fits with my process, it must be understood that it exists beyond just sustainability; it is interwoven with spiritual, cultural and social life. It is about only taking what is needed from the environment and respecting the natural world. It also applies to our interpersonal relations as we come to understand that the environment we live in directly impacts our quality of life.

My decision to study fashion followed from my experience of the make and design process, which I saw as a beautiful skill through which I could curate my own individual world and reject the current fashion system's frivolity, destruction and growing waste. This way of thinking has become increasingly relevant as we are being forced to operate in a world of diminishing resources in which the orthodox mantras of endless growth are being questioned. Adding more stuff to the world is no longer a justifiable way of working.

In recognising this, I made the decision to work only with the materials and found objects which then informed my work. This lead me to looking in op-shops, rubbish bins and anywhere possible to source discarded materials, analysing how best they can be utilised in ways that reflect the "redesign, rethink and recycle" mantra. By exploring my materials in this way, I was able to explore fashion and sustainability through unique pieces, giving them a new dimension of life when seen through a previously neglected perspective.

The fashion industry has often been guilty of capturing an ideological construct such as recycling and turning it into just another commodity, another item to consume. Where once op-shopping and trading used items were simply necessary to meet one's needs, they are now vehicles used to repackage another product. Although this commodification of recycling, known as 'upcycling,' tries to minimise waste and repurpose, it has given rise to a new market force. As a designer, I want to challenge what is perceived to be 'sustainable' practice, but that is usually only a tack-on or a marketing ploy rather than an ethically researched, robust practice and tool for change. Too often, 'sustainable' also means 'high cost,' and can end up exploiting young emerging designers who are genuine in their pursuit of environmental and structural change. Sustainability is still premised on making more. I would like to challenge the cycle based on what is 'in vogue,' and instead focus on the quality and longevity of pieces and multi-use garments. Mass production and profit at all costs is destroying our planet, and the fashion and clothing industries are major perpetrators.

I see possibilities for revaluing skills in making clothing (and its makers) and in finding innovative, yet simple and polished ways of re-purposing and ending waste, moving away from the present reality where nothing has value and everything is for sale. ${ }^{3}$ We need to take pride in having fewer clothes and knowing their provenance, not simply discarding the 'old' in a never-ending cycle - a cycle that operates off "the very nature of the commodity guarantees that the more we acquire the less satisfied we are."' 
With these considerations in mind, my process was mindful and meticulous, appreciating both the physical and conceptual processes that contribute to fashion as an art form, establishing new values along the way. This raised some important questions. What is waste? Why is it not wearable? How can we create new meaning from old?

\section{THE RAG-PICKER}

From an historical perspective, I learned something of the role of the rag-picker or chiffonier. These workers made a living by rummaging through the refuse of the streets to collect material for salvage and then sell it as a way of earning a living. ${ }^{5}$ This entropic work, although seeming desperate, was actually respected within its own social context. Through "collating the annals of intemperance," 6 rag-pickers were a crucial part of the natural cycle that saw resources purposefully reused and waste minimised in towns. Each piece of urban debris embodies a cultural metanarrative based on consumption with no end in sight. Through analysing this work of the past, we can perhaps see how this strategic appreciation of trash suggests a path of recycling for the future.?

Working from within this ideological framework, my process developed both methodically and organically. I became the rag-picker. While I was aware of the deconstruction-reconstruction concept, this was secondary to the process I was developing. As processes, these methods were less about aesthetics and more about appreciating the great potential of fashion to redefine itself. I was also committed (born of sheer need) not to spend money to solve this design project. Exploring the concept of no waste also meant not wasting money and it forced me to truly problem-solve.

\section{BRICOLAGE}

I chose to work with what I had and make changes that fitted with my resources. My process was as important as the final pieces. It became similar to the making of a collage, or the work of the bricoleur. The French term bricolage means to tinker - a kind of DIY. It is characterised by combining unfamiliar items to create something new, and was popular in the twentieth century at times when resources were scarce. In the creative sphere, bricolage is resourceful in its approach and allows the inquirer to draw from various aspects of their life experience and piece them together. ${ }^{9}$ Creating a body of work reflecting different perspectives and drawing on personal philosophies, the bricoleur "appropriates commodities by placing them in a symbolic ensemble," subverting or erasing their original meaning. ${ }^{10}$

Drawing on this concept, I worked to recombine and assemble, using elements of sculpture, drape and collage, which often led me in surprising design directions. When things didn't work, I re-stitched, reconstructed, unpicked, re-evaluated and found new perspectives. As I developed the range of pieces in my collection, I was able to style the objects as they developed, changing layouts, with necklaces worn on the side, bags as necklaces - changing the look with each outfit, or on its own, allowing the wearer to become the bricoleur and following the op-shop aesthetic of reinvention and reclamation.

Collating my tools, materials, themes and experiences, my inspiration remained constantly changing. It was about being intuitive with what I had and borrowing from traditional silhouettes and re-appropriating and combining elements to create puzzling, yet workable arrangements. As I collected found items, I let the materials lead me, improvising, experimenting and taking risks. This process of designing with recycled and found materials became an exercise in improvisation and anti-strategy. It was serendipitous - letting the pieces lead me and working intuitively. 


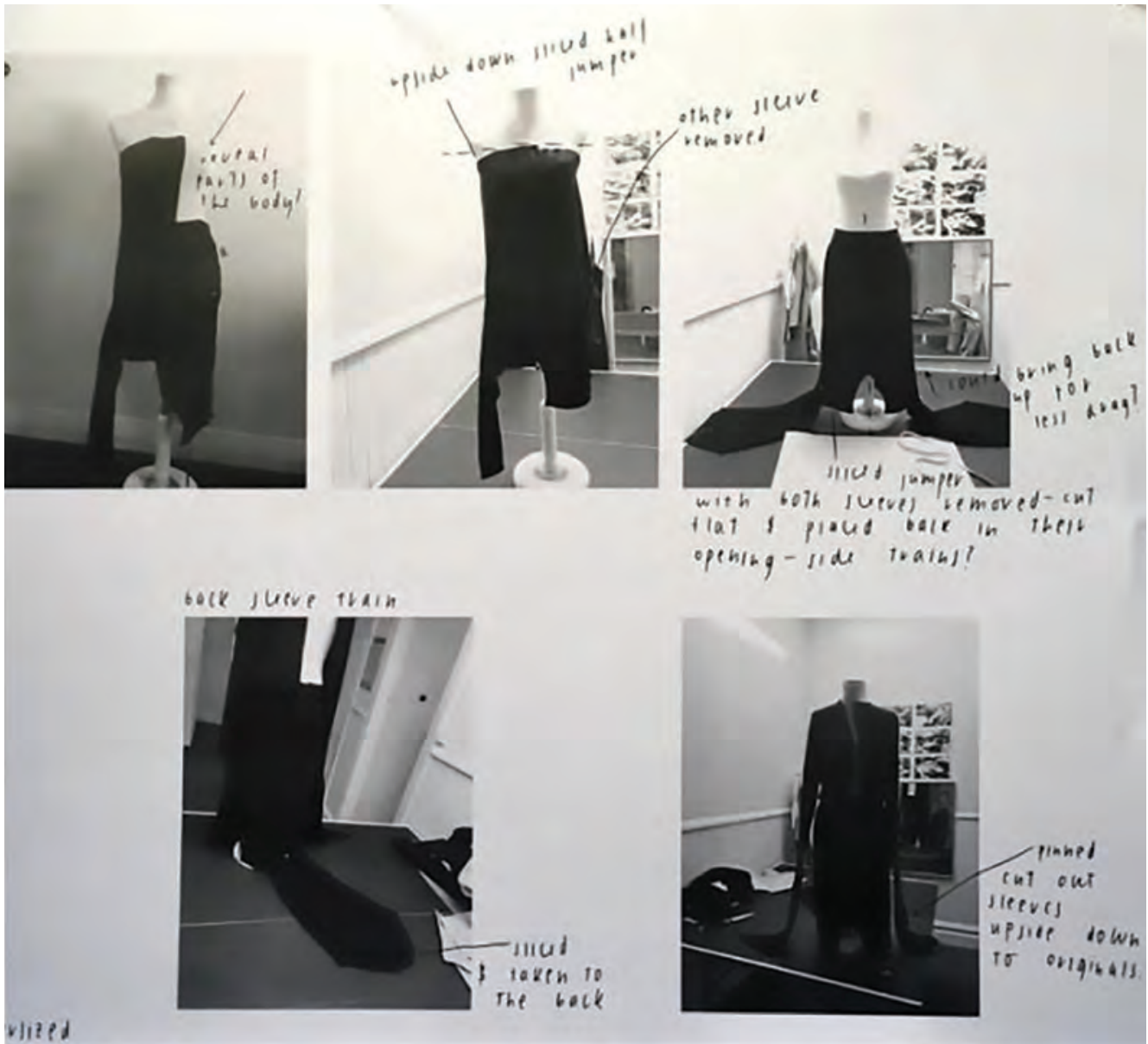

Figure 2. Gràinne O'Connell, workbook pages: 'slicing' technique.

\section{PROCESS}

My commitment not to waste materials and resources meant that all my work had only a single toile. This evolutionary approach to designing meant that I had to work thoughtfully and let go of any predetermined ideas I had about the end product. I found inspiration in Martin Margiela who, in the fashion and art world, is one of bricolage's most skilled exponents. He has made a shirt out of gloves, used broken crockery to make a waistcoat, and a sweater from army surplus socks, to name but a few of his pieces. "I was drawn to his work and his way of showing how objects can come together to create avant-garde but simultaneously wearable pieces, tricking the eye.

\section{JUMPER MERINO KNIT DRESS}

Two merino men's jumpers: St Andrews Street Opshop, \$4 each; hiking backpack: The Hospice Shop, \$4. 

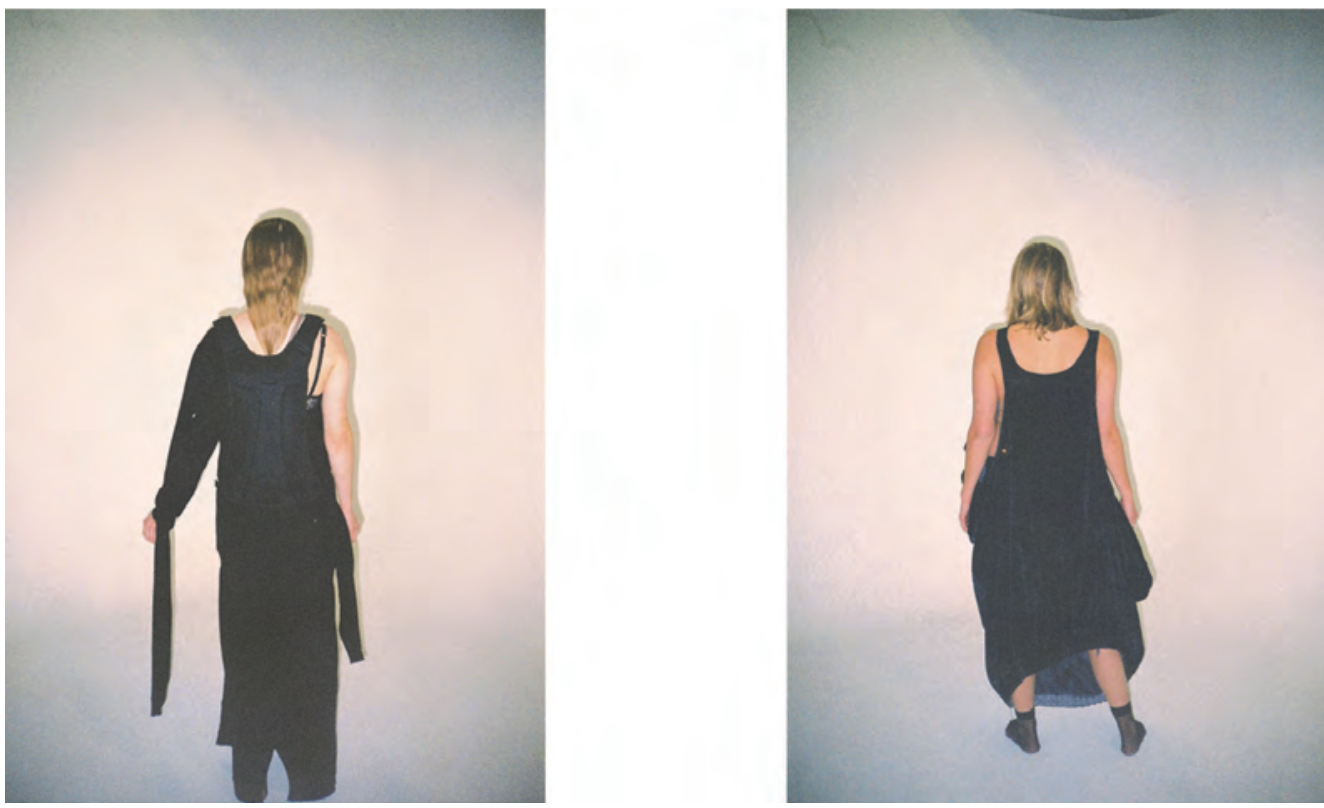

Figure 3. Gràinne O'Connell, Curtain Dress and Jumper Merino Knit Dress (back view). Photograph: Gràinne O'Connell.

The jumper dress borrowed from and re-appropriated '90s design elements to compose a visual mix. I was particularly interested in Helmut Lang's sophisticated interpretation of utilitarian wear. Utilising soft, clean detailing that was unassuming but functional in its own right, Lang was a pioneer of minimalism and deconstructivist fashion. ${ }^{12}$

The process of making the dress involved slicing in half and re-instating. By slicing the garment in this manner I was able to utilise it as a whole, with no added waste and without compromising the original. I began on the dress form with my unpicked whole pattern pieces, making iterations. The side slits were created by removing and reestablishing in the right sleeve, allowing for movement in the legs. Where the upside of the jumper met the top, I left the fabric to drop naturally, creating a soft curve. The hiking bag straps were detached and turned over to show the padded detailing of the underside, originally intended to support the wearer's back. Where holes were made, I darned over in the same cotton. Drawing attention to what might conventionally be deemed unfixable, or'removing from' the materials I used, now became a design feature of the garment.

\section{CURTAIN DRESS}

Curtains: St Andrews Street Opshop, 2 for $\$ 4$.

Green rope and spray paint: Found in family shed

Side filling: Fabric waste from garments

Curtain end: $\$ 2$

Ski gloves: $\$ 4$

Inspecting the shape, stitches, faded sun marks, hem and curtain tape of the original, I visualised the curtain as a sculpture. Once halved, the ridges of the pleating became encased in a balloon shape, tapering inwards. The velvet upholstery, heavy but malleable, was once suited for keeping out the cold. Stitching the sides together, I then cut through only one layer, utilising the curtain as a whole, allowing the weight to guide its shape. The rest came somewhat serendipitously. Because of the uneven weight distribution, the front billowed down, creating folds and textures, while the back then revealed the top, but upside down. 
Originally a pale blue, I decided I wanted to change the colour to match the rest of my pieces. I used fabric dye to try and achieve a deeper blue, but when this proved unsuitable, I spray-painted it black, working as the bricoleur to alter its original function. It can be worn both front and back and displaced to transform the silhouette even further. Following this aesthetic of accretion, ${ }^{13}$ the eyelets allow the wearer to hitch the garment up and it can be tied in any way desired. The side filling, a cushioning element, was made from remaining fabric waste and mimicked a sort of sculpture - an upholstery form.
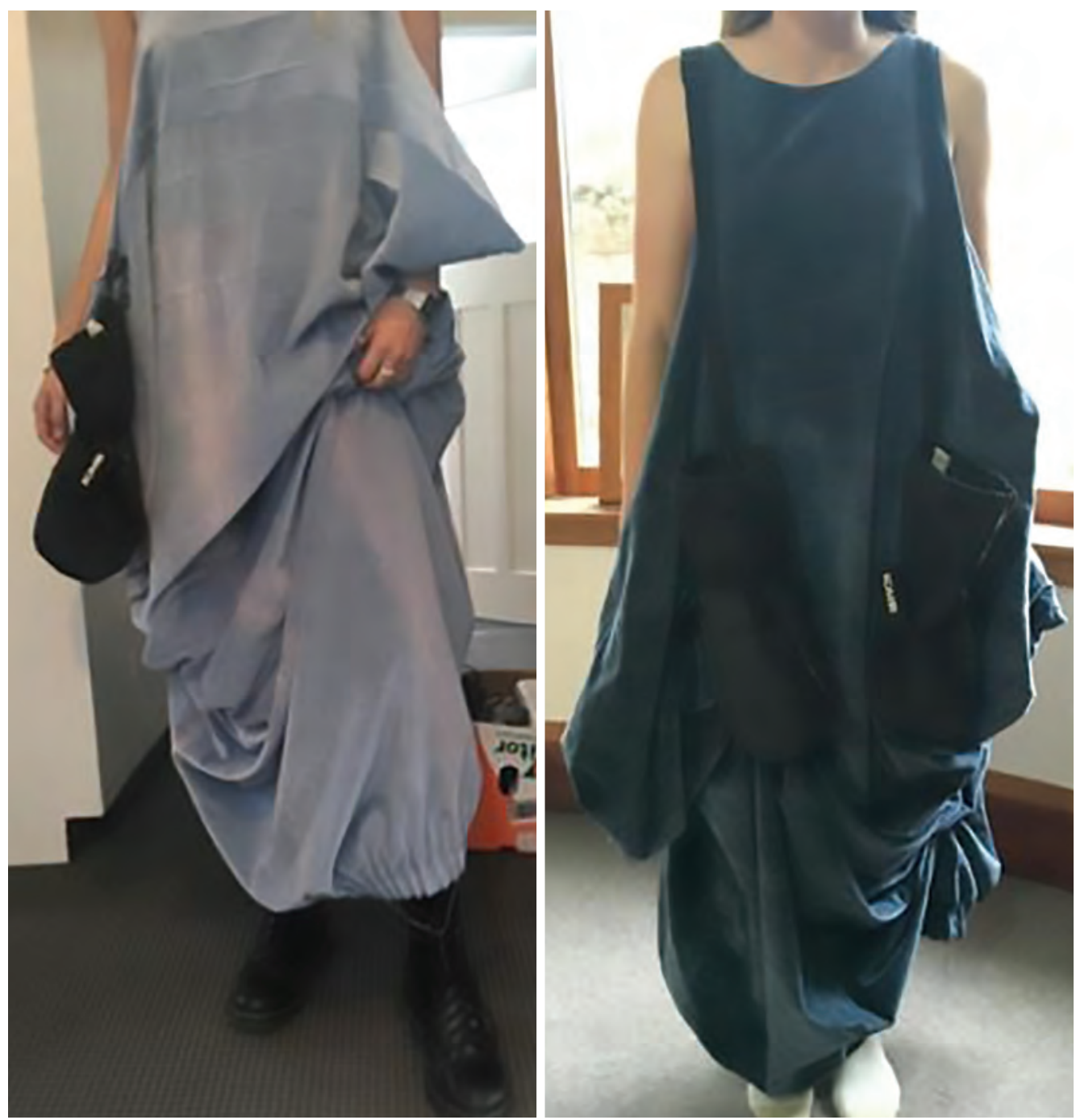

Figure 4 and 5. Gràinne O'Connell, Curtain Dress transformations.

Photograph: Gràinne O'Connell. 


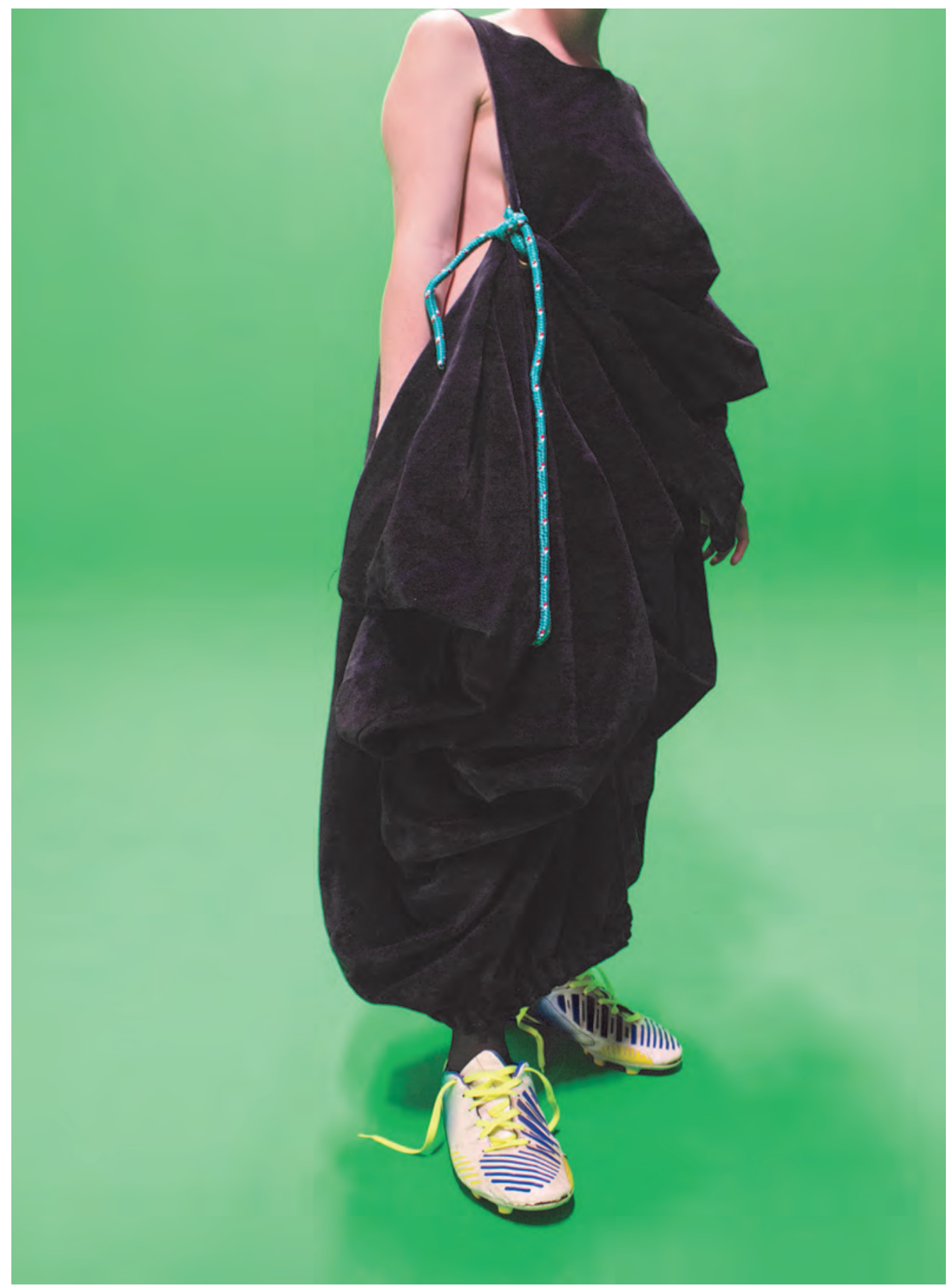

Figure 6. Gràinne O'Connell, Curtain Dress. Photograph: Gràinne O'Connell. 

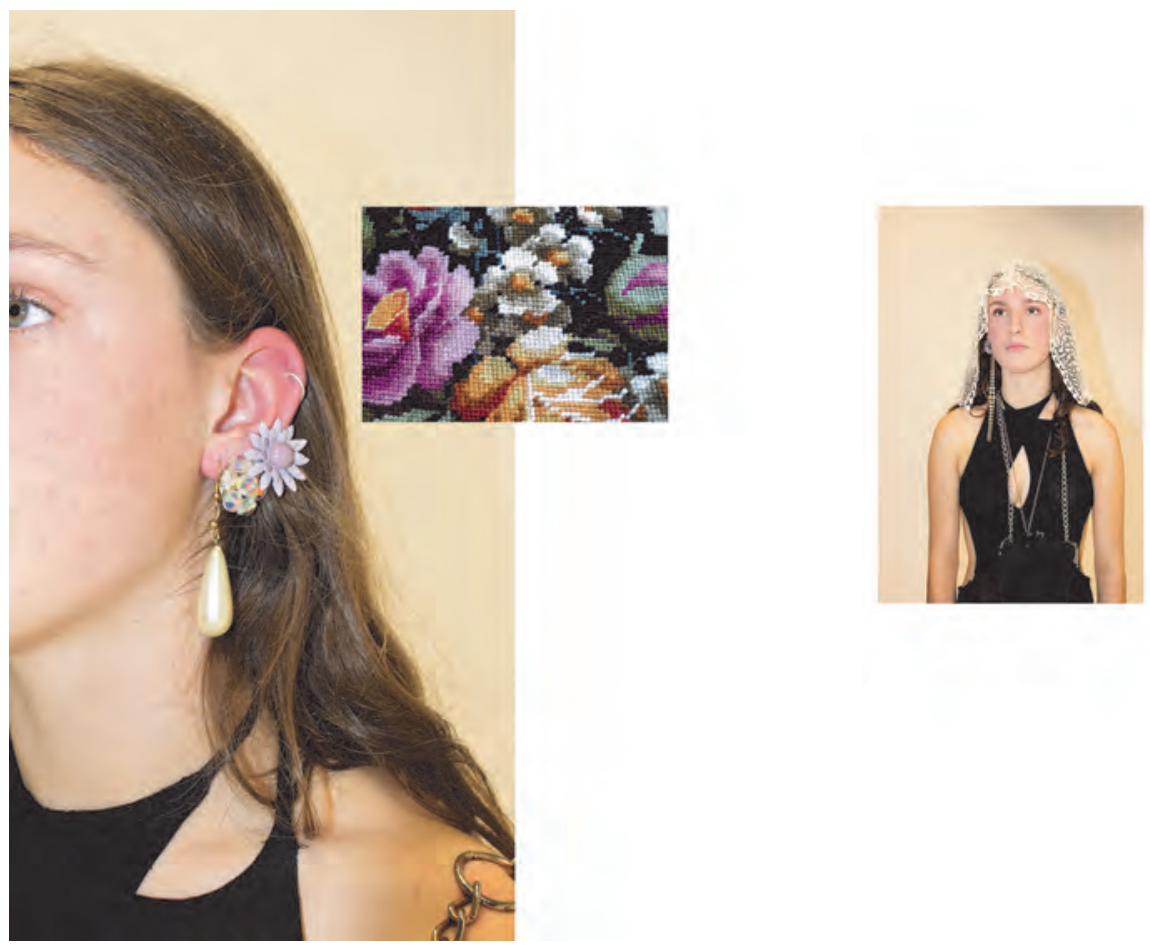

Figure 7. Gràinne O'Connell, workbook pages: Hoisery Dress (details) and Lace Curtain Bonnet. Model: Lola Morten. Photograph: Gràinne O'Connell.

\section{HOISERY DRESS}

Lace curtain: Found in family home

My own socks and tights

Shoelaces: 'Borrowed' from my boyfriend

Hot water bottle bag: The Salvation Army, \$3

Bag chain (dog collar): Found in family home

The process for the hosiery dress followed the same principle as the jumper dress. Slicing the tights in half and reconnecting them, the fit followed how the tights were originally worn, almost skin-tight, moulded to the body. The dress was worn with a lace curtain bonnet borrowed from a 1910 milkmaid design, a disorientating juxtaposition. As the silhouette continues, the curved lines of the sides, middle and back were sculpted and shaped as the stretched hosiery allowed. The stitched lines revealed in the lower layer when the fabric is stretched by the wearer showed the outline of a cross shape. The top section was then lined with another layer of the pantyhose to give added stability, and visually differentiate the top from the bottom. The shoelaces used to tie the top of the dress is a design element that furthers this aesthetic founded on manipulation and recreation. 

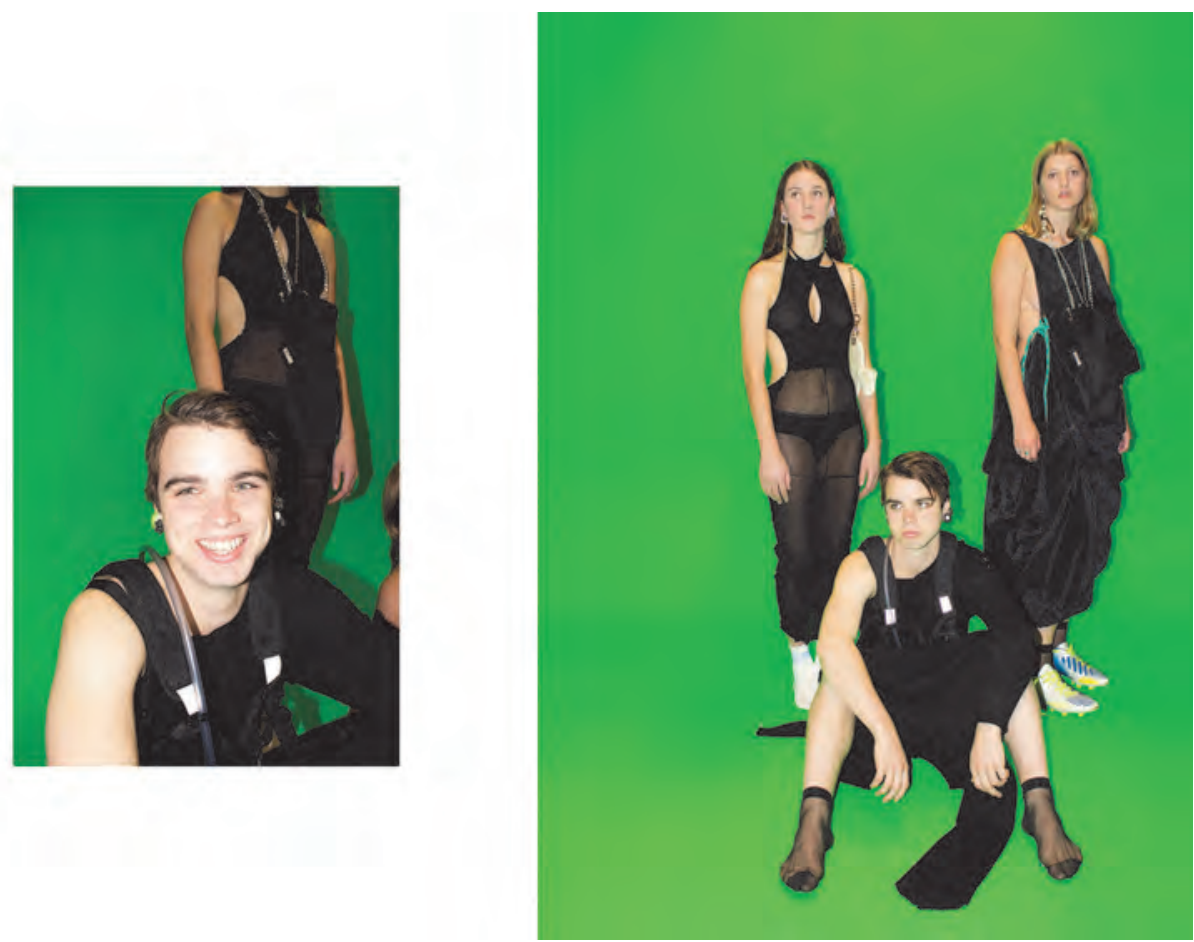

Figure 8. Gràinne O'Connell, various designs for the Ordinary collection.

Group shot. Models, left to right: Lola Morten, Albert Aitken, Emma McRobie. Photograph: Gràinne O'Connell.

\section{CONCLUSION}

My journey through this project began with childhood memories of dressing up, op-shopping, green living, makingdo and experiencing how well we lived without spending. We took pleasure in ordinary skills. My sisters and I op-shopped and swapped and loved what we wore, relishing the old as new. I wanted to explore these values and processes, believing as a designer that I can replicate regenerated fashion and make it viable through offering a real alternative to the destructive, exploitative and mass-produced meaningless clothing of today. I know that I cannot function in fashion blind to the sustainability crisis we face globally, and passionately believe that there is an alternative. While the project tested me, I trusted the journey and it led me to produce my collection on an almostzero budget, creating unique pieces with a newfound value.

I cannot escape the contribution that textile waste makes to polluting our planet. The Western 'rag trade' exploits artisan skills and then discards what is made. Reflecting on the important place of the historical rag-picker in their community, I am saddened and appalled to know that the rag-pickers of today in India, Brazil and a myriad of Third World countries pick through the filth and flotsam created by First World consumers merely to survive. ${ }^{14}$ They have no value. The waste they sift through is created by our worship of mass production and the profit-driven mentality that continues to dominate the fashion trade, regardless of the broader social and environmental costs. The future of fashion must be different. 
Gràinne O’Connell says: "Working mainly with upcycled clothing and materials, my nostalgic approach to design is honest and meticulous. Utilising content drawn from everyday aesthetics and found materials in my environment, I am interested in what we place value on and what we can overlook."

I Barbara Coloroso, Parenting Wit \& Wisdom from Barbara Coloroso (Toronto: Penguin Canada, 200 I).

2 Te Ahukaramū Charles Royal, "Kaitiakitanga - Guardianship and Conservation,"'Te Ara - the Encyclopedia of New Zealand, http://www.TeAra.govt.nz/en/kaitiakitanga-guardianship-and-conservation (accessed 31 May 2019).

3 Natalie Lozinski-Veach, “Decompositions: Inheriting Trash with Walter Benjamin and Bruno Schulz," MLN, I $33: 3$ (20 I 8), 763 92.

$4 \quad$ Ibid., 768.

5 “The Rag-Picker's Wine \& Walter Benjamin," Verweile Doch! Du Bist so Schön!, 23 February 20 I6, https://stellte.wordpress. com/2016/02/19/the-rag-pickers-wine-walter-benjamin/ (accessed I May 2019).

6 Walter Benjamin, Charles Baudelaire:A Lyric Poet in the Era of High Capitalism (London and New York:Verso Books, 1997$), 79$.

7 Lozinski-Veach, “Decompositions," 768.

8 Annamma Joy, John F Sherry Jr, Alladi Venkatesh, JeffWang and Ricky Chan, "Fast Fashion, Sustainability, and the Ethical Appeal of Luxury Brands," Fashion Theory, $16: 3$ (2012), 273-95.

9 Sharlee Ghent, "Fashion Identity and the Art of Bricolage: Studio-based Research Methods and Reflection-in-Action in Fashion Design," Scope: Art \& Design, I5:2 (2017), 50-8, https://www.thescopes.org/assets/Uploads/777dcf594I// 5.8.-Ghent. pdf.

10 Dick Hebdige, Subculture:The Meaning of Style (London: Routledge, 2012 ), 52.

I I Alison Gill, “Deconstruction Fashion:The Making of Unfinished, Decomposing and Re-assembled Clothes," Fashion Theory, 2: I (1998), 25-49.

12 Thomas Hecht, "Helmut Lang," LoveToKnow, https://fashion-history.lovetoknow.com/fashion-clothing-industry/fashiondesigners/helmut-lang (accessed I May 2019).

13 Natalie Smith and Hilary Radner, "NOM*d: Conceptual Couture in Dunedin," in NOM*d:The Art of Fashion (Dunedin: Centre for Research on National Identity, University of Otago; Gore: Eastern Southland Gallery, 20 I2).

I4 Rajanya Bose and Bhattacharya Anirban, "Why Ragpickers, Unrecognised and Unpaid, are Critical for Waste Management in India," IndiaSpend, 12 May 2017, https://archive.indiaspend.com/cover-story/why-ragpickers-unrecognised-and-unpaid-arecritical-for-waste-management-in-india-43164 (accessed I May 2019). 